\title{
WestVirginiaUniversity
}

THE RESEARCH REPOSITORY @ WVU

Graduate Theses, Dissertations, and Problem Reports

2011

\section{Molecular Phylogeny of the Oestroidea}

\author{
Baneshwar Singh \\ West Virginia University
}

Follow this and additional works at: https://researchrepository.wvu.edu/etd

\section{Recommended Citation}

Singh, Baneshwar, "Molecular Phylogeny of the Oestroidea" (2011). Graduate Theses, Dissertations, and Problem Reports. 4791.

https://researchrepository.wvu.edu/etd/4791

This Dissertation is protected by copyright and/or related rights. It has been brought to you by the The Research Repository @ WVU with permission from the rights-holder(s). You are free to use this Dissertation in any way that is permitted by the copyright and related rights legislation that applies to your use. For other uses you must obtain permission from the rights-holder(s) directly, unless additional rights are indicated by a Creative Commons license in the record and/ or on the work itself. This Dissertation has been accepted for inclusion in WVU Graduate Theses, Dissertations, and Problem Reports collection by an authorized administrator of The Research Repository @ WVU.

For more information, please contact researchrepository@mail.wvu.edu. 
Molecular Phylogeny of the Oestroidea

Baneshwar Singh

\begin{abstract}
Dissertation submitted to the Eberly College of Arts and Sciences at West Virginia University in partial fulfillment of the requirements for the degree of
\end{abstract}

Doctor of Philosophy
in
Biology

Jeffrey D. Wells, Ph.D., Chair James W. Amrine Jr., Ph.D. Stephen P. DiFazio, Ph.D. David A. Ray, Ph.D. Donna I. Ford-Werntz, Ph.D.

Department of Biology

Morgantown, WV

2011

Keywords: Molecular systematics; Molecular phylogenetics; Oestroidea; Calliphoridae; forensic entomology; Medical entomology.

Copyright 2011 Baneshwar Singh 


\section{ABSTRACT \\ Molecular Phylogeny of the Oestroidea}

\section{Baneshwar Singh}

The superfamily Oestroidea includes approximately $9 \%(\approx 14,000 \mathrm{spp}$.) of the order Diptera. Many members of the superfamily are of medical, veterinary, agricultural, and forensic importance. Although Oestroidea has been the subject of much scientific scrutiny, the exact patterns of phylogenetic relationships among the key groups of the superfamily are unresolved and controversial. For a better understanding of oestroid evolutionary hypotheses, phylogenies of Oestroidea were reconstructed at several taxonomic levels using DNA sequence data. The specific aims were to determine the phylogeny of the 1) genus Chrysomya (Chrysomyinae); 2) subfamily Chrysomyinae (Calliphoridae); 3) family Oestridae (Oestroidea); and 4) family Calliphoridae (Oestroidea). Sequence data from both mitochondrial and nuclear genes from 99 representative species were analyzed using maximum parsimony (MP), maximum likelihood (ML) and Bayesian (BA) methods. Trees obtained from the different phylogenetic methods were almost identical. The status of family Calliphoridae (the blow flies) has for years been the central systematic problem of the superfamily. These results show that Calliphoridae is polyphyletic, with the phylogenetic position of Mesembrinellinae still uncertain but clearly outside the lineage that includes other Calliphoridae and some non-calliphorids, and Polleniinae is the sister group of the family Tachinidae. Strong support for a sister group relationship between Rhiniinae and traditional calliphorid subfamilies undermines a recent proposal to give Rhiniinae family status. The Chrysomya and Chrysomyinae phylogenies were well resolved and suitable for testing a number of existing evolutionary hypotheses. The Chrysomyinae colonization of the neotropics apparently involved a single ancestral species, and the traditional chrysomyinae tribal classification should be abandoned. Tuberculate larvae evolved twice within Chrysomya, and published hypotheses about the evolution of sex determination, eye morphology, and genome size within the genus appear to be incorrect. Efforts to resolve the relationships of the Oestroid families were largely inconclusive, although the monophyly of the superfamily was strongly supported. 


\section{ACKNOWLEDGEMENTS}

It is my pleasure to thank the many people, without whom this dissertation wouldn't have been possible.

First of all, I would like to thank my advisor, Dr. Jeffrey Wells for his continuous support, guidance, and encouragement throughout my graduate study at West Virginia University, Morgantown, USA. Dr. Wells not only helped me in achieving my research goals but also taught me scientific writing, independent thinking and strong research ethics. Thanks also to Kelley for always being so nice with me and Smita.

Next, I would like to thank Drs. James Amrine, David Ray, Stephen DiFazio, Donna Ford-Werntz - quartet of my dissertation committee for providing assistance whenever I was in need. Each one of you helped me in learning different techniques that were a must for completion of this dissertation. Dr. Amrine taught me how to identify these wonderful flies, Dr. Ray taught me several phylogenetic method, I have used in this dissertation, Dr. DiFazio taught me different population genetics methods, and Dr. Ford-Werntz was helpful in improving my writing skills. I would also like to thank Dr. Jane Caldwell for her help in teaching methods during the initial period of my dissertation.

Thanks also go to T. L. Whitworth (Whitworth Pest Solutions Inc., Puyallup, WA, USA), T. Pape (Natural History Museum of Denmark, Copenhagen, Denmark), K. Rognes (University of Stavanger, Stavanger, Norway), C. Koshman (Universidade de Brasília, Brazil), A. D. Souza (Instituto Nacional de Pesquisas da Amazonia, Manaus, Brazil), J.F. Wallman (University of Wollongong, NSW, Australia), J. R. Stevens (University of Exeter, UK), T. C. Vander Linde (University of the Free State, Bloemfontein, SA) , J. Mendez ( University of Panama, Panama), H. Banziger, (Chiang Mai University, Thailand), T. T. Torres (Universidade Estadual de Campinas, Brazil), D. Otranto (University of Bari, Italy), D. Colwell (Agriculture and Agri-Food, Canada), J. E. O'Hara (Agriculture and Agri-Food, Canada), J. M. Perez (Universidad de Jaén, Spain), C. J. Picard (Texas A\&M University, College Station, USA), A. Tarone (Texas A\&M University, College Station, USA), H. Kurahashi (National Institute of Infectious Diseases, Shinjuku-ku, Tokyo, Japan), A. Snyder (West Virginia University, Morgantown, USA), R. Rio (West Virginia University, Morgantown, USA) and J. Hall (West Virginia University, Morgantown, USA) for supplying invaluable specimens and DNA samples, without which this work wouldn't have been possible. Thanks to J.K. Moulton (University of Tennessee, Knoxville, USA) for supplying unpublished CPS gene primer sequences.

Thanks to Mariam, Christine, John, Anne, Lizmery and Joshua for nice suggestions during lab meetings and for making my life easier and full of fun at WVU 
during the past few years. I would also like to thank graduate students, staff and faculty of the Department of Biology at WVU for their help and support during the past few years. Special thanks go to Marlene, Mickey, Diana, Kristy, Pat, Katrina, Wendy, Madhu, Brahma, Mohna, Shalaka, Taniya, and Hari.

I would like to thank my parents, in-laws and other family members for their love and encouragement. Most importantly, I would like to thank my uncle and aunt, Dr. Y. K. Singh and Sagyan Singh, for their love, help and support at a very confusing stage in my career. Whatever I am today is because of both of you. THANK YOU!

Last but not least, I would like to thank my wife Smita for her love and unconditional support. Thanks for cooking nice foods and for tolerating my tantrums during the last few months.

Finally, thanks to all my funding sources: 1) Sir J.N. Tata Endowment Trust, Mumbai, India, 2) Department of Biology, Eberly College of Arts and Sciences, Graduate Education \& Life of WVU, and the National Institute of Justice (Grant \# 2003RC-CX-K001 awarded to Dr. Max Houck). 


\section{Table of Contents}

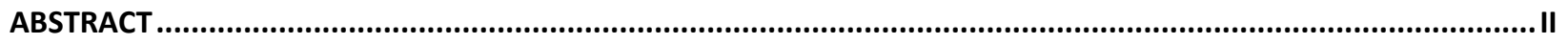

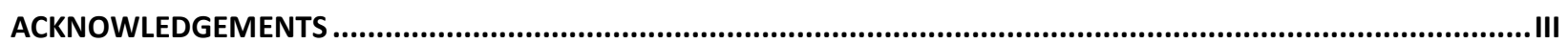

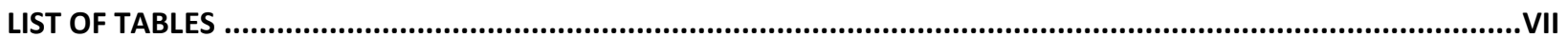

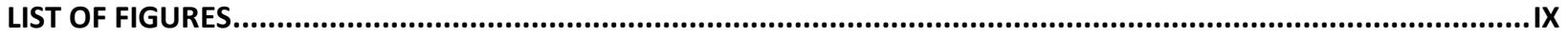

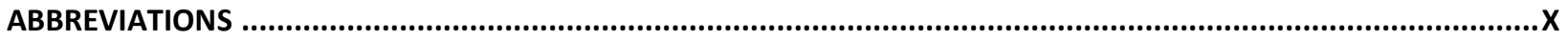

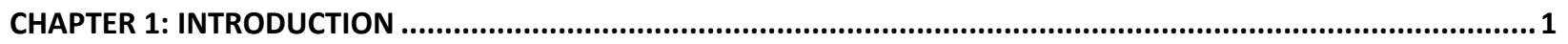

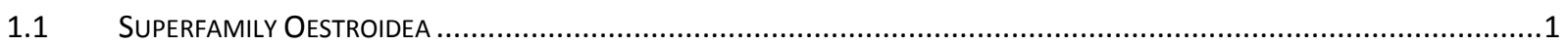

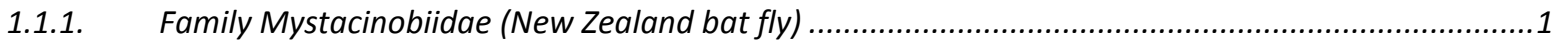

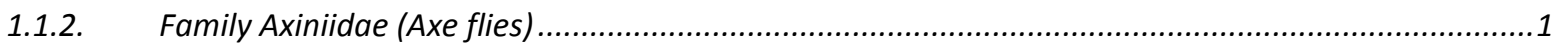

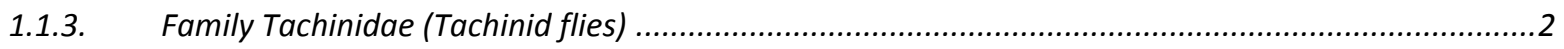

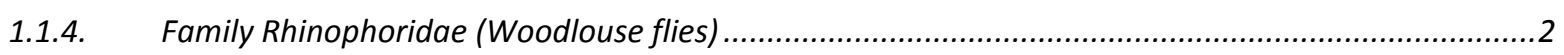

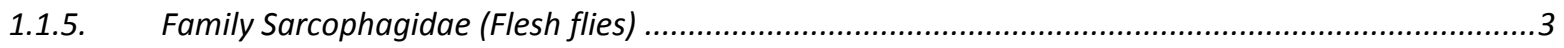

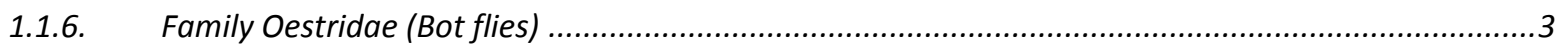

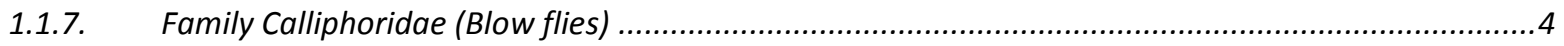

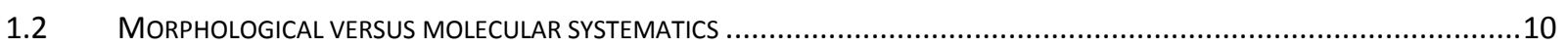

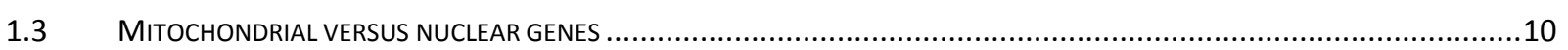

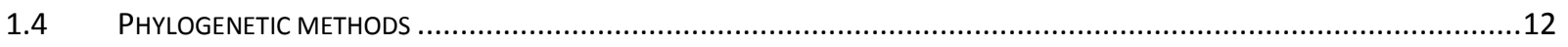

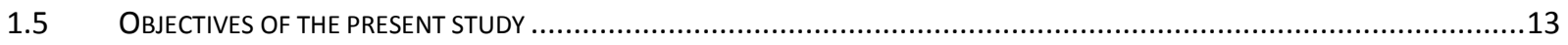

CHAPTER 2 : MOLECULAR PHYLOGENY OF THE CHRYSOMYA (CALLIPHORIDAE: CHRYSOMYINAE)..................... 15

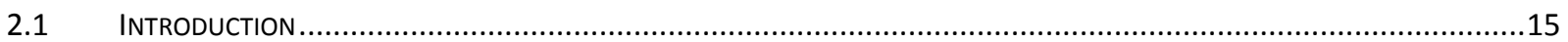

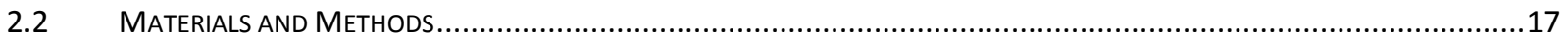

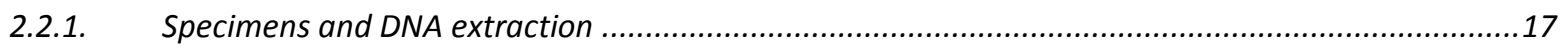

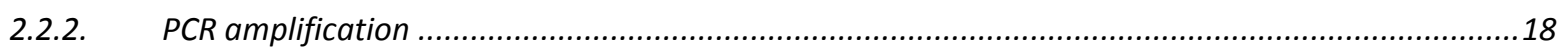

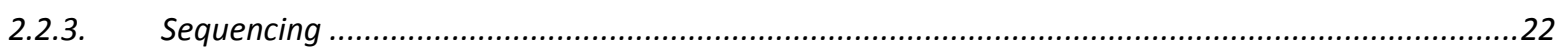

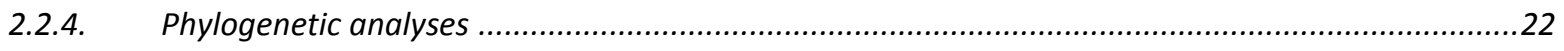

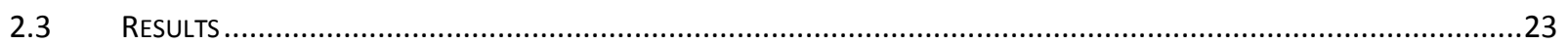

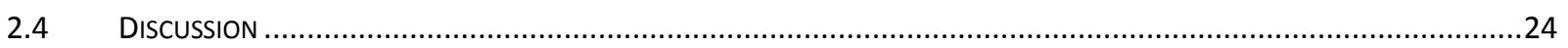

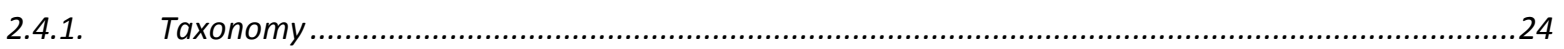

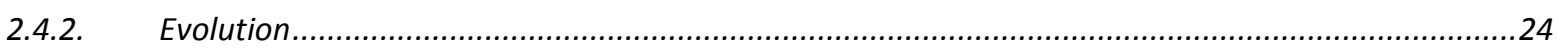

CHAPTER 3: MOLECULAR PHYLOGENY OF THE CHRYSOMYINAE (DIPTERA: CALLIPHORIDAE). ........................... 29

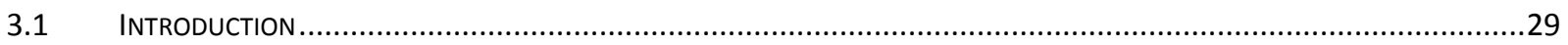

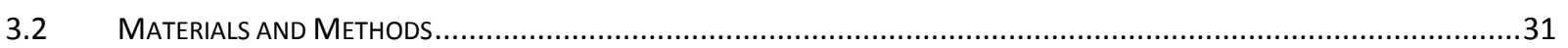

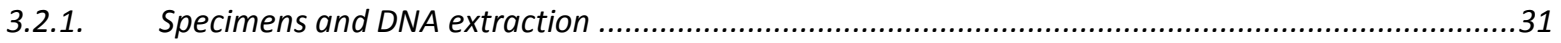

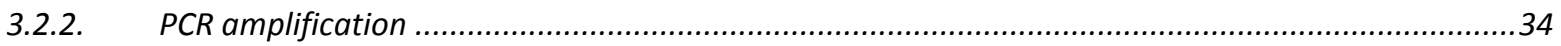

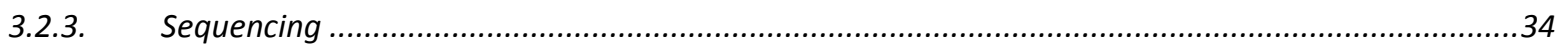

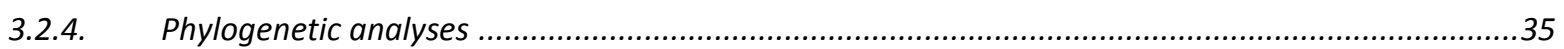

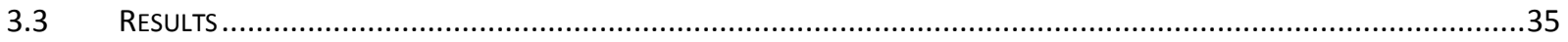

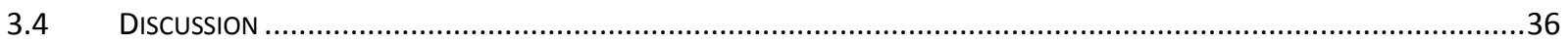

CHAPTER 4: MOLECULAR PHYLOGENY OF THE OESTRIDAE (DIPTERA: OESTROIDEA). ....................................39 


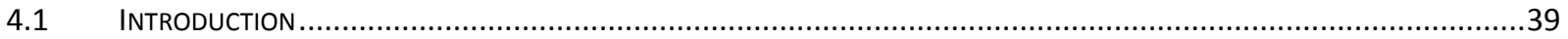

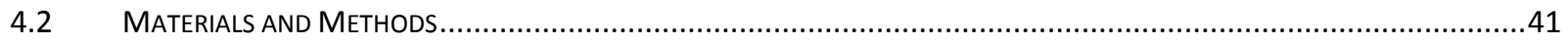

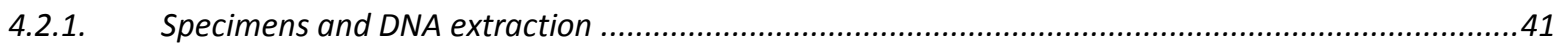

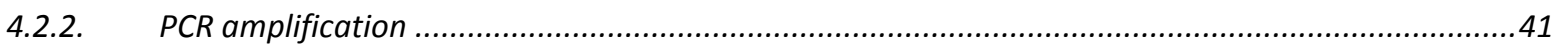

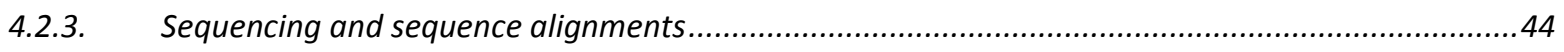

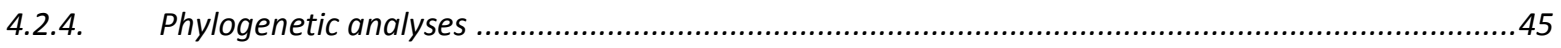

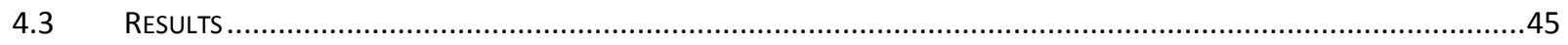

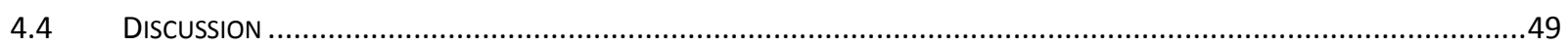

CHAPTER 5: MOLECULAR PHYLOGENY OF THE CALLIPHORIDAE (DIPTERA: OESTROIDEA)................................50

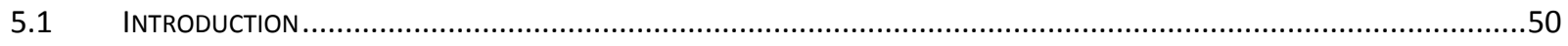

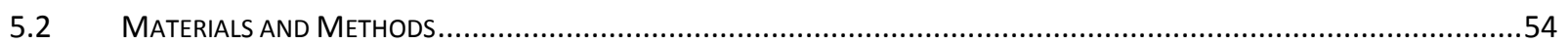

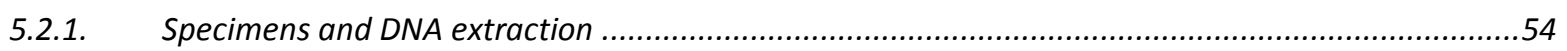

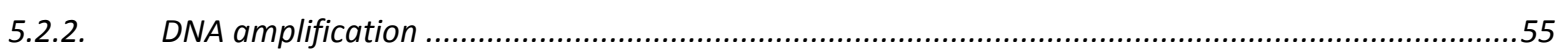

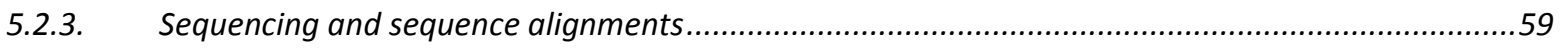

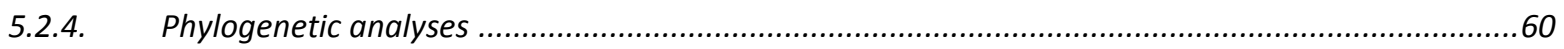

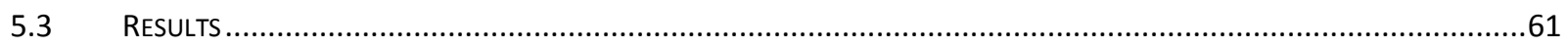

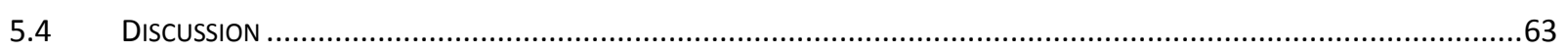

5.4.1. Relationships between oestroid families ..........................................................................63

5.4.2. Relationships within and between calliphorid subfamilies......................................................63

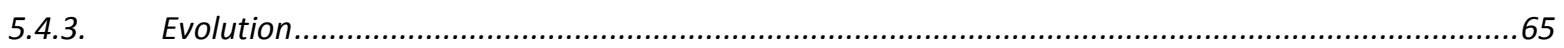

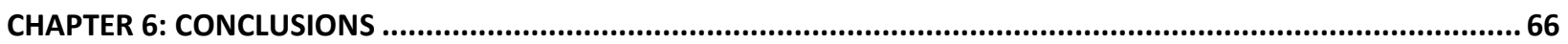

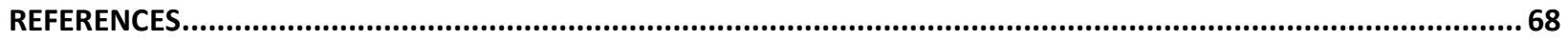

APPENDIX A: LIST OF MORPHOLOGICAL CHARACTERS THAT SUPPORT MONOPHYLY OF VARIOUS OESTROID

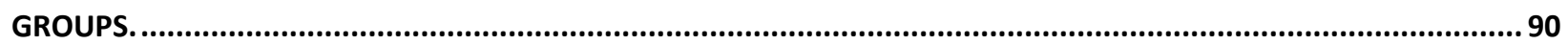

APPENDIX B: TABLES SHOWING PAIRWISE P-DISTANCE AND PAIRWISE TRANSITION-TRANSVERSION RATIO OF

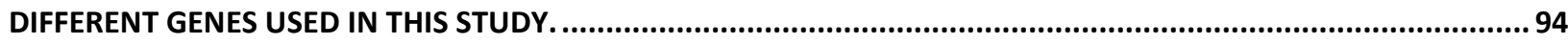




\section{LIST OF TABLES}

TABLE 2.1: SPECIMEN DETAILS, COLLECTION INFORMATION AND GENBANK ACCESSION NUMBERS. .....................19

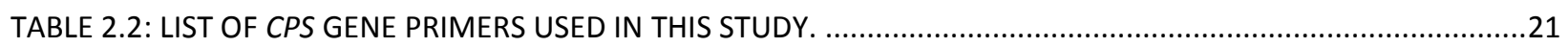

TABLE 3.1: SPECIMEN DETAILS, COLLECTION INFORMATION AND GENBANK ACCESSION NUMBERS. .......................32

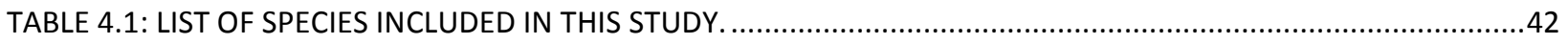

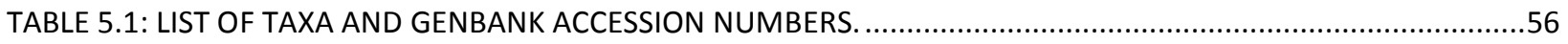

TABLE 5.2: LIST OF NEWLY DESIGNED CARBAMOYLPHOSPHATE SYNTHETASE (CPS) GENE PRIMERS. ......................59

TABLE A1: PAIRWISE P-DISTANCE OF CYTOCHROME OXIDASE SUBUNIT ONE (CO I) GENE USED IN CHRYSOMYA

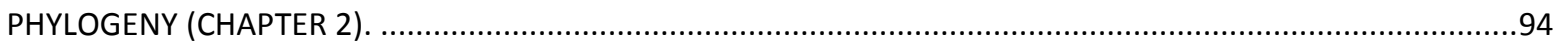

TABLE A2: PAIRWISE TRANSITION-TRANSVERSION RATIO OF CYTOCHROME OXIDASE SUBUNIT ONE (CO I) GENE

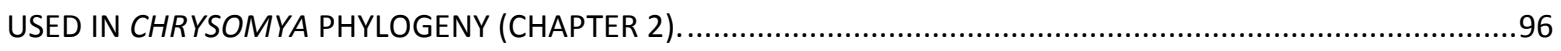

TABLE A3: PAIRWISE P-DISTANCE OF CARBAMOYLPHOSPHATE SYNTHETASE (CPS) GENE USED IN CHRYSOMYA

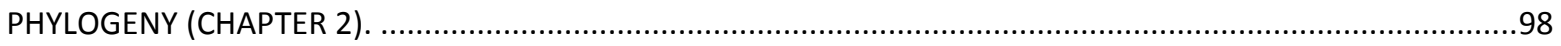

TABLE A4: PAIRWISE TRANSITION- TRANSVERSION RATIO OF CARBAMOYLPHOSPHATE SYNTHETASE (CPS) GENE

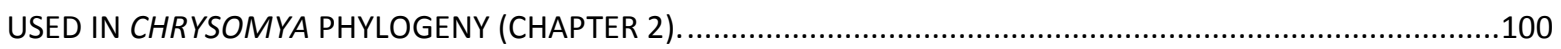

TABLE A5: PAIRWISE P-DISTANCE OF CYTOCHROME OXIDASE SUBUNIT ONE (CO I) GENE USED IN CHRYSOMYINAE

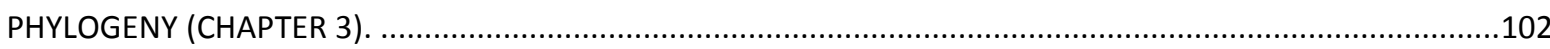

TABLE A6: PAIRWISE TRANSITION- TRANSVERSION RATIO OF CYTOCHROME OXIDASE SUBUNIT ONE (CO I) GENE

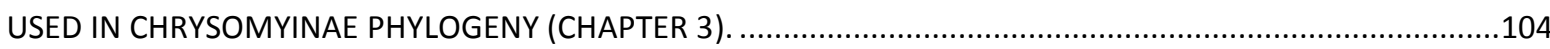

TABLE A7: PAIRWISE P-DISTANCE OF CARBAMOYLPHOSPHATE SYNTHETASE (CPS) GENE USED IN CHRYSOMYINAE

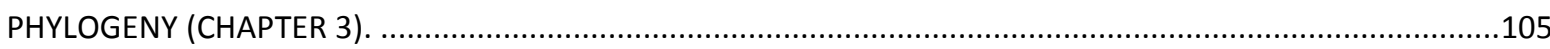

TABLE A8: PAIRWISE TRANSITION- TRANSVERSION RATIO OF CARBAMOYLPHOSPHATE SYNTHETASE (CPS) GENE

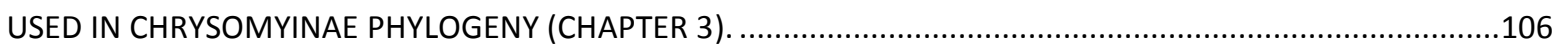

TABLE A9: PAIRWISE P-DISTANCE OF 28S RIBOSOMAL RNA (28S RRNA) GENE USED IN OESTRIDAE PHYLOGENY (CHAPTER 4)

TABLE A10: PAIRWISE TRANSITION-TRANSVERSION RATIO OF 28S RIBOSOMAL RNA (28S RRNA) GENE USED IN OESTRIDAE PHYLOGENY (CHAPTER 4).

TABLE A11: PAIRWISE P-DISTANCE OF CYTOCHROME OXIDASE SUBUNIT ONE (CO I) GENE USED IN OESTRIDAE PHYLOGENY (CHAPTER 4).

TABLE A12: PAIRWISE TRANSITION-TRANSVERSION RATIO OF CYTOCHROME OXIDASE SUBUNIT ONE (CO I) GENE USED IN OESTRIDAE PHYLOGENY (CHAPTER 4).

TABLE A13: PAIRWISE P-DISTANCE OF ELONGATION FACTOR ONE ALPHA (EF1A) GENE USED IN OESTRIDAE PHYLOGENY (CHAPTER 4).

TABLE A14: PAIRWISE TRANSITION-TRANSVERSION RATIO OF ELONGATION FACTOR ONE ALPHA (EF1A) GENE USED IN OESTRIDAE PHYLOGENY (CHAPTER 4).

TABLE A15: PAIRWISE P-DISTANCE OF 28 S RIBOSOMAL RNA (28S RRNA) GENE USED IN CALLIPHORIDAE PHYLOGENY (CHAPTER 5).

TABLE A16: PAIRWISE TRANSITION-TRANSVERSION RATIO OF 28S RIBOSOMAL RNA (28S RRNA) GENE USED IN CALLIPHORIDAE PHYLOGENY (CHAPTER 5).

TABLE A17: PAIRWISE P-DISTANCE OF CYTOCHROME OXIDASE SUBUNIT ONE (CO I) GENE USED IN CALLIPHORIDAE PHYLOGENY (CHAPTER 5).

TABLE A18: PAIRWISE TRANSITION-TRANSVERSION RATIO OF CYTOCHROME OXIDASE SUBUNIT ONE (CO I) GENE USED IN CALLIPHORIDAE PHYLOGENY (CHAPTER 5).

TABLE A19: PAIRWISE P-DISTANCE OF CARBAMOYLPHOSPHATE SYNTHETASE (CPS) GENE USED IN CALLIPHORIDAE PHYLOGENY (CHAPTER 5). 
TABLE A20: PAIRWISE TRANSITION-TRANSVERSION RATIO OF CARBAMOYLPHOSPHATE SYNTHETASE (CPS) GENE

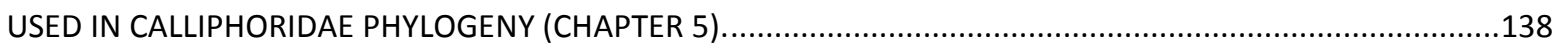

TABLE A21: PAIRWISE P-DISTANCE OF ELONGATION FACTOR ONE ALPHA (EF1A) GENE USED IN CALLIPHORIDAE

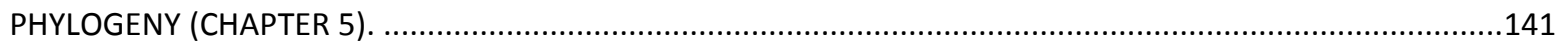

TABLE A22: PAIRWISE TRANSITION-TRANSVERSION RATIO OF ELONGATION FACTOR ONE ALPHA (EF1A) GENE USED IN CALLIPHORIDAE PHYLOGENY (CHAPTER 5). 146 


\section{LIST OF FIGURES}

FIGURE 2.1: MALE COMPOUND EYE OF CHRYSOMYA SHOWING TWO KINDS OF COMPOUND EYE. LEFT: NORMAL MALE EYE OF CH. PACIFICA; RIGHT: DERIVED MALE EYE OF CH. MEGACEPHALA. .....

FIGURE 2.2: STRICT CONSENSUS OF THE TWO MOST PARSIMONIOUS TREES OF THE CHRYSOMYA BASED ON 2386 BP OF COMBINED COI AND CPS DNA SEQUENCES. A NUMBER IN BOLD INDICATES BREMER SUPPORT AND NUMBER IN ITALICS INDICATES BOOTSTRAP SUPPORTS FOR INDIVIDUAL BRANCHES. $f=$ MONOGENIC SPP.; $\$$ $=$ AMPHOGENIC SPP.; $¥=$ SPECIES WITH UNKNOWN SEX DETERMINATION SYSTEM; * = SPECIES THAT PRODUCES HAIRY MAGGOTS; $@$ = SPECIES THAT PRODUCES SMOOTH MAGGOTS; @ = SPECIES WITH UNKNOWN LARVAL STRUCTURE; $\infty=$ SPECIES SHOWING DERIVED MALE EYE CONDITION; $C H .=$ CHRYSOMYA; PH. = PHORMIA; CO. = COCHLIOMYIA; LU. = LUCILIA; CA. = CALLIPHORA. .25

FIGURE 2.3: MAXIMUM-LIKELIHOOD TREE OF THE CHRYSOMYA BASED ON 2386 BP OF COMBINED COI AND CPS DNA SEQUENCES. NUMBER IN BOLD INDICATES POSTERIOR PROBABILITY VALUE (IN BA) AND NUMBER IN ITALICS INDICATES BOOTSTRAP SUPPORTS (IN ML ANALYSIS) FOR INDIVIDUAL BRANCHES. NODES NOT SHARED WITH MP TREE INDICATED BY “ $\neq$ ". CH. =CHRYSOMYA; CO. =COCHLIOMYIA; PH. = PHORMIA; LU. = LUCILIA; CA. = CALLIPHORA.

FIGURE 3.1: PUBLISHED HYPOTHESES OF PHYLOGENETIC RELATIONSHIPS BETWEEN PHORMIINI GENERA BASED ON MORPHOLOGICAL (A-B) AND MOLECULAR (C) DATA. (A) MODIFIED FROM PEUS, 1960, (B) MODIFIED FROM ROGNES, 1985, AND (C) MODIFIED FROM WHITWORTH ET AL., 2007.

FIGURE 3.2: BAYESIAN PHYLOGRAM OF THE CHRYSOMYINAE BASED ON 2285 BP OF COMBINED COI AND CPS DNA SEQUENCES. BRANCH SUPPORT VALUES: STANDARD FONT = BAYESIAN POSTERIOR PROBABILITY; BOLD = MAXIMUM LIKELIHOOD \% BOOTSTRAP; ITALICS = MAXIMUM PARSIMONY \% BOOTSTRAP; UNDERLINED =

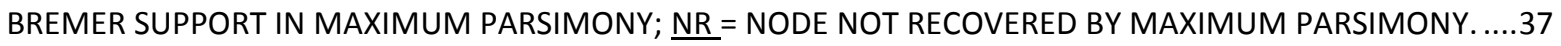

FIGURE 4.1: PUBLISHED ALTERNATE HYPOTHESES OF PHYLOGENETIC RELATIONSHIP BETWEEN DIFFERENT SUBFAMILIES OF THE OESTRIDAE. LEFT: BASED ON MORPHOLOGICAL DATA (MODIFIED FROM PAPE, 2001) AND, RIGHT: BASED ON MITOCHONDRIAL CYTOCHROME OXIDASE SUBUNIT ONE GENE (MODIFIED FROM OTRANTO ET AL., 2003).

FIGURE 4.2: BAYESIAN PHYLOGRAM OF THE OESTRIDAE BASED ON 688 BP OF COI DNA SEQUENCES. BRANCH SUPPORT VALUES: STANDARD FONT = BAYESIAN POSTERIOR PROBABILITIES; BOLD = MAXIMUM LIKELIHOOD

$\%$ BOOTSTRAP; ITALICS= MAXIMUM PARSIMONY \% BOOTSTRAP.

FIGURE 4.3: BAYESIAN PHYLOGRAM OF THE OESTRIDAE BASED ON 716 BP OF $28 S$ RRNA GENE SEQUENCES. BRANCH SUPPORT VALUES: STANDARD FONT = BAYESIAN POSTERIOR PROBABILITIES; BOLD = MAXIMUM LIKELIHOOD \% BOOTSTRAP; ITALICS= MAXIMUM PARSIMONY \% BOOTSTRAP.

FIGURE 4.4: BAYESIAN PHYLOGRAM OF THE OESTRIDAE BASED ON 550 BP OF EF1A GENE SEQUENCES. BRANCH SUPPORT VALUES: STANDARD FONT = BAYESIAN POSTERIOR PROBABILITIES; BOLD = MAXIMUM LIKELIHOOD \% BOOTSTRAP; ITALICS= MAXIMUM PARSIMONY \% BOOTSTRAP.

FIGURE 5.1: PHYLOGENETIC TREE, SHOWING RELATIONSHIPS BETWEEN DIFFERENT FAMILIES OF THE OESTROIDEA (FROM MCALPINE, 1989).

FIGURE 5.2: PUBLISHED HYPOTHESES OF PHYLOGENETIC RELATIONSHIP BETWEEN DIFFERENT GROUPS OF OESTROID FLIES BASED ON MORPHOLOGICAL DATA. (A) MODIFIED FROM PAPE (1992; FIG. 8); (B) MODIFIED FROM ROGNES (1997; FIG. 3).

FIGURE 5.3: BAYESIAN PHYLOGRAM OF THE OESTROIDEA BASED ON 5189 BP OF COMBINED COI, CPS, 28S RRNA, AND EF1A DNA SEQUENCES. BRANCH SUPPORT VALUES: STANDARD FONT = BAYESIAN POSTERIOR PROBABILITY; BOLD = MAXIMUM LIKELIHOOD \% BOOTSTRAP; ITALICS = MAXIMUM PARSIMONY \% BOOTSTRAP. 


\section{ABBREVIATIONS}

\begin{tabular}{|c|c|}
\hline BA & Bayesian method \\
\hline bp & Base pair \\
\hline $\mathrm{BP}$ & Bootstrap percentage \\
\hline BS & Bremer support \\
\hline CAD & $\begin{array}{l}\text { Carbamoylphosphate synthetase, aspartate transcarbamylase, and } \\
\text { dihydroorotase }\end{array}$ \\
\hline $\mathrm{COI}$ & Cytochrome oxidase subunit one \\
\hline COII & Cytochrome oxidase subunit two \\
\hline CPS & Carbamoylphosphate Synthetase \\
\hline Cyt. b & Cytochrome b \\
\hline DDC & Dopa-decarboxylase \\
\hline DNA & Deoxyribonucleic acid \\
\hline EDTA & Ethylenediaminetetraacetic acid \\
\hline$E F-1 \alpha$ & Elongation factor one alpha \\
\hline G & Gamma \\
\hline GTR & General time reversible \\
\hline I & Invariable site \\
\hline LBA & Long branch attraction \\
\hline ML & Maximum likelihood \\
\hline MP & Maximum parsimony \\
\hline MPT & Most parsimonious tree \\
\hline mtDNA & Mitochondrial DNA \\
\hline $\mathrm{NaCl}$ & Sodium chloride \\
\hline $\mathrm{NNI}$ & Nearest neighbor interchange \\
\hline PAUP & Phylogenetic analysis using parsimony \\
\hline PCR & Polymerase chain reaction \\
\hline PEPCK & Phosphoenolpyruvate carboxykinase \\
\hline PP & Posterior probability \\
\hline RNA & Ribonucleic acid \\
\hline rRNA & Ribosomal RNA \\
\hline SDS & Sodium dodecyl sulphate \\
\hline TBR & Tree-bisection-reconnection \\
\hline TE & Tris-EDTA \\
\hline
\end{tabular}




\section{CHAPTER 1: Introduction}

\subsection{Superfamily Oestroidea}

Oestroidea is a superfamily of calyptrate flies, which are characterized mainly by a vertical row of bristles on the meron (McAlpine, 1989). More than 14,000 species of the Oestroidea are known from all zoogeographical regions (Kutty et al., 2010). Rognes (1997) considered the families, Mystacinobiidae (New Zealand bat fly), Axiniidae (Axe flies), Tachinidae (Tachinid flies), Rhinophoridae (Woodlouse flies), Sarcophagidae (Flesh flies), Oestridae (Bot flies), and Calliphoridae (Blow flies), to be in the Oestroidea.

\subsubsection{Family Mystacinobiidae (New Zealand bat fly)}

Mystacinobiidae is a highly distinct family, as flies in this family are wingless, haltere-less, physogastric, communal and guano feeders (Holloway, 1976). This family is represented by a single species Mystacinobia zelandica, which is endemic to New Zealand and shows a phoretic relationship with the New Zealand short tailed bat, Mystacina tuberculata. A female lays eggs in two batches and then dies. Mystacinobia eggs are characterized by the presence of respiratory horns and chorionic denticles. Although respiratory horns on eggs are present in other dipteran families (such as Sepsidae and Drosophilidae), Mystacinobia eggs differ from them, in not being hydrophobic (Holloway, 1976). Finally, Mystacinobia is distinguished from other Diptera in that it pupates inside an empty bat-fly puparium (Holloway, 1976).

\subsubsection{Family Axiniidae (Axe flies)}

Axiniids are very small size $(2.5-6.0 \mathrm{~mm})$ flies of Australia and New Guinea (Colless, 1994). There are only four genera and 15 species. Most of the information we know about this family is from adult males. Although no immature specimen has been reported, limited information obtained from female genitalia, indicates that the larvae may be parasitic (Colless, 1994). More than 8 synapomorphic characters (appendix 1) support monophyly of the group (Colless, 1994). As some characters (such as 3 separate spermathecal ducts) of axiniids are similar to family Tachinidae, Crosskey 
(1977) suggested axiniids be placed within Tachinidae, but as they lack characters typical of tachinids (such as a strong subscutellum, and bristled thoracic surfaces) Colless (1994) raised this group to the family level within Oestroidea. Phylogenetic analysis based on morphological data suggests axiniids are either the sister group of all other oestroids except Mystacinobia (Colless, 1994; Rognes, 1997) or a member of family Rhinophoridae (Pape \& Arnaud, 2001). Intrafamiliar relationships are still not well known (Colless, 1994).

\subsubsection{Family Tachinidae (Tachinid flies)}

Tachinids are small to large flies $(2-20 \mathrm{~mm})$, often extensively bristled, which can be easily identified by the presence of a strongly developed subscutellum. Worldwide, 10,000 species of tachinids are known, which makes it the second largest family of Diptera after Tipulidae (Belshaw, 1993; Irwin et al., 2003). The majority of tachinids are ovolarviparous (Wood, 1987c). All tachinid larvae are endoparasitic on arthropods (mainly insects), which make this family very important from a pest management point of view (Efil \& Kara, 2004; O'Hara, 2008). Although the monophyly of the family is well supported based on the characters listed in appendix 2 (Wood, 1987c; Pape, 1992; Rognes, 1997), classification within the family has been revised several times (Townsend, 1934-1942; Crosskey, 1980; Herting, 1984). Most recently, O'Hara (2008) divided this family into four subfamilies: Phasiinae, Dexiinae, Exoristinae and Tachininae. Phasiinae and Dexiinae are less speciose subfamilies whereas Exoristinae and Tachininae are more speciose. The monophyly of Dexiinae is well supported, as they possess a characteristic hinge connection between basiphallus and distiphallus of the aedeagus, but monophyly of other tachinid subfamilies is still unclear (O'Hara, 2008).

\subsubsection{Family Rhinophoridae (Woodlouse flies)}

Rhinophoridae is a comparatively small family, with only 150 described species, with maximum diversity in the Mediterranean region and in Africa (Herting, 1961; Crosskey, 1977; Kutty et al., 2010). They are oviparous and the larvae are endoparasites of woodlice (Crustacea: Isopoda) (Thompson, 1934). They are the only Diptera that parasitize Crustacea (Crosskey, 1977). They appear morphologically 
similar to tachinid flies but differ as they have a weakly developed postscutellum and narrow calypteres (Wood, 1987b). Monophyly of the Rhinophoridae is supported (excluding Angioneura, Melanomya, and Morinia) based on the synapomorphies listed in appendix 3 , but its exact relationship with other members of the Oestroidea remains unclear (Crosskey, 1977; Pape, 1986).

\subsubsection{Family Sarcophagidae (Flesh flies)}

Sarcophagids are robust flies varying in size from 2.5 to $18 \mathrm{~mm}$. Mostly they appear dull gray in color. All sarcophagids are either ovoviviparous (larvae emerges immediately after deposition of eggs that are in advanced stage of embryonic development) or larviparous (larvae hatches inside female body before deposition (Shewell, 1987; Meier et al., 1999). Many sarcophagid larvae mature on carrion and hence play an important role as a forensic indicator species for the estimation of a postmortem interval (PMI) (Wells et al., 2001; Pape et al., 2007). Approximately 2600 species of sarcophagids are known from all over the world that belong to three subfamilies: Sarcophaginae, Miltogramminae and Paramacronychiinae (Pape et al., 2007). Sarcophaginae includes mainly New World flesh flies whereas Miltogramminae includes mainly Old World flesh flies (Pape et al., 2007). Paramacronychiinae is a very small subfamily, which is restricted to the Holarctic region (Pape et al., 2007). Many characters (appendix 4) support monophyly of the Sarcophagidae (Pape, 1992). Even recent molecular analysis supported monophyly of the Sarcophagidae (Kutty et al., 2010).

\subsubsection{Family Oestridae (Bot flies)}

Oestridae (bot flies) is very well studied family because of their importance in the area of medical and veterinary entomology (Papavero, 1977; Pape, 2001). About 150 species of Oestridae are widely distributed in Africa and central Asia and have a limited distribution in North America (Wood, 1987a; Kutty et al., 2010). They are medium to large (9-25 $\mathrm{mm})$, heavy bodied flies with reduced mouthparts and a pilose bristleless body. Adults do not feed, but rather survive on fat reserves (Wood, 1987a). Although the meron does bear a patch of setae, the characteristic row of bristles is lacking, as present in other families of the Oestroidea. All bot fly larvae are obligate parasites of 
mammals, including humans, with a high level of host specificity (Wood, 1987a; Catts, 1982). Most species are oviparous with the exception of members of the subfamily Oestrinae, which are larviparous (Catts, 1964; Anderson, 1975). Larvae develop within the host, and upon reaching maturity they leave the host to pupate in the soil.

Oestridae consists of four subfamilies: Cuterebrinae, Gasterophilinae, Hypodermatinae and Oestrinae (Wood, 1987a). Although extensive morphological data (appendix 5) and the mitochondrial cytochrome oxidase subunit one gene support monophyly of the Oestridae (Pape, 1992; 2001; Otranto et al., 2003), $16 \mathrm{~S}$ and $18 \mathrm{~S}$ ribosomal RNA genes suggest non-monophyly of the Oestridae (Nirmala et al., 2001). Also, subfamiliy relationships differ when inferred from morphological (Pape, 2001) compared to molecular analysis (Otranto et al., 2003).

Cuterebrinae is exclusively American (Guimarães, 1967), and its larvae are mainly subcutaneous parasites of rodents and lagomorphs. Third larval instars of Cuterebrinae are unique among all oestrids because they are entirely encrusted with small-flattened plate-like spines. Gasterophilinae are distributed worldwide with no species endemic to the Americas. However, some Gasterophilus spp. were introduced to the Americas along with horses. Gasterophilinae larvae are gut parasites of horses, zebras, rhinos and elephants. Sometimes they puncture the stomach wall or obstruct the stomach, which may lead to death. The Hypodermatinae has a worldwide

distribution with the highest diversity seen in Central Asia (Zumpt, 1965). Three species belonging to the genus Hypoderma are known from North America, to which they were introduced along with cattle. Like Cuterebrinae, Hypodermatinae larvae are subcutaneous parasites, but they lack the small plate like spines on the integument. Hypodermatinae larvae enter the skin through enzymatic dissolution of the tissue, supposedly caused by salivary secretions (Wolfe, 1959). Members of the Oestrinae are distributed worldwide but most species are in Asia and Africa. Their larvae parasitize the host respiratory passages.

\subsubsection{Family Calliphoridae (Blow flies)}

The Calliphoridae include a diverse group of flies varying in size from $2.5 \mathrm{~mm}$ to $19 \mathrm{~mm}$ and also varying in color (e.g. metallic blue, green or purple to non-metallic 
black, gray, brown or yellow) (Rognes, 1998). Approximately 1450 species of calliphorid flies (including 400 species of Rhiniinae) are known from all continents except Antarctica (Verves, 2005; Kutty et al., 2010). Adult blow flies are known to frequent flowers, feces, carrion and wounds for nutrition. They also serve as vectors of disease, where they transport bacteria, viruses, protozoans and helminths (Greenberg, 1971). Although most blow flies are oviparous, some are either multilarviparous (e.g. Onesia, Bellardia, Eggisops, etc.) or unilarviparous (Helicoboscinae, Mesembrinellinae, Ameniinae and Phumosiinae). Since the majority of blow fly larvae are carrion breeders, they play an important role both as an indicator species in forensic entomology and as prominent decomposers (Schumann, 1965). Some larvae are endoparasitic (Pollenia, Bellardia, etc.) whereas a few show blood-sucking habits (e.g. Auchmeromyia, Protocalliphora etc.) (Rognes, 1998). Historically, the family Calliphoridae has been divided into different numbers of subfamilies by different authors (Lehrer, 1970; Hennig, 1973; Pont, 1980; Kurahashi, 1989), but Ameniinae, Auchmeromyiinae, Bengaliinae, Phumosiinae, Mesembrinellinae, Helicoboscinae, Toxotarsinae, Calliphorinae, Luciliinae, Melanomyinae, Polleniinae, Rhiniinae, Chrysomyinae, Aphyssurinae, and Prosthetosomatinae have been recognized by most recent authors (Pape, 1992; Norris, 1999; Rognes, 1991; 1997; Kutty et al., 2010). Monophyly of Calliphoridae is uncertain. Some believe it is monophyletic (Lehrer, 1970; Pape, 1992; Stevens, 2003) while others believe in its non-monophyly (Rognes, 1997; Kutty et al., 2010). Morphological data supports the monophyly of each subfamily (See appendix 6), but the placement of some subfamilies is unclear (Rognes, 1991; 1997). The sister group relationships Chrysomyinae + Toxotarsinae and Auchmeromyiinae + Bengaliinae are well supported, whereas the positions of Rhiniinae, Bengaliinae, Mesembrinellinae, Helicoboscinae, and Polleniinae are uncertain (Pape, 1992; Rognes, 1997).

\subsubsection{Subfamily Ameniinae}

Members of subfamily Ameniinae are medium to large $(5 \mathrm{~mm}$ to $20 \mathrm{~mm})$ sized metallic green flies that are distributed in Oriental and Australasian regions (Crosskey, 1965). Appendix 6.1 lists the characters that support monophyly of the group. Members of this subfamily have characteristic white spots on the thorax and abdomen. Because of its large size, metallic coloration, comparatively developed subscutellum and strong 
facial carina, this group superficially resembles tribe Rutiliini of family Tachinidae, but other characters, such as presence of a tuft of long black hairs on the anterior lappet of metathoracic spiracle, in-utero larval development (Macrolarviparity) and larvae parasitic on living mollusks excludes any possibility of its inclusion in the Tachinidae (Crosskey, 1965). Molluscan parasitism among oestroid flies is present in both Calliphoridae and Sarcophagidae, but because of resemblance of male genitalia and morphology (large metallic in color) with calliphorid flies, it was included in the Calliphoridae (Crosskey, 1965).

\subsubsection{Subfamily Auchmeromyiinae}

Auchmeromyiinae are yellow to brown Afrotropical and Oriental flies that are either obligate parasites of mammals or associated with ants and termites (Zumpt, 1965). Pape (1992) put members of subfamily Auchmeromyiinae within the subfamily Bengaliinae because of the shared character of elongated anal veins. However, Rognes (1991) created the new subfamily Auchmeromyiinae, because the aedeagus is very distinct from the members of the subfamily Bengaliinae. Appendix 6.2 lists the characters that support monophyly of the group.

\subsubsection{Subfamily Bengaliinae}

Bengaliinae are also yellow to brown Afrotropical and Oriental flies, with large mouthparts (Senior-White et al., 1940). Most bengaline larvae are primarily predators of ants, termites and wasp larvae and pupae (Pont, 1980; Kurahashi, 1989). Some members (such as Verticia fasciventris) are parasitoids of termites (Tsang et al., 2008). Appendix 6.3 lists the characters that support monophyly of the group.

\subsubsection{Subfamily Phumosiinae}

Phumosiinae are metallic green to blue Afrotropical, Oriental and Australian flies that are distinguished by the characters listed in appendix 6.4. Rognes (1997) included a single genus Phumosia in this subfamily, but it has been suggested that the genus Euphumosia, which is non-metallic, be included within the Phumosiinae (Kurahashi, 1987; Rognes, 1991). The breeding habit of Euphumosia is still unknown (Ferrar, 1978). 


\subsubsection{Subfamily Mesembrinellinae}

Mesembrinellinae are exclusively Neotropical flies, which can be characterized by the features listed in appendix 6.5. Guimarães (1977) erected the family Mesembrinellidae for this group based on the presence of a very large reniform metathoracic spiracle with single operculum, but most other authors consider this group as a subfamily of the Calliphoridae based on similarity of male genitalia and other morphological characters (Shannon, 1923; Hall, 1948; James, 1970; Hennig, 1973; Rognes, 1991; Pape, 1992).

\subsubsection{Subfamily Helicoboscinae}

Helicoboscinae are Western Palaearctic and Western Himalayan flies with only two genera and four species (Rognes, 1993). Characters listed in appendix 6.6 support it as a monophyletic group (Rognes, 1991; Rognes, 1993). Verves (1986) and Shewell (1991) listed Eurychaeta in Sarcophagidae, but Rognes (1986) erected the subfamily Helicoboscinae within Calliphoridae for Eurychaeta. Based on morphological data, Pape (1992) supported its position within Calliphoridae.

\subsubsection{Subfamily Toxotarsinae}

Toxotarsinae is a Neotropical group of flies characterized by the autapomorphies listed in appendix 6.7. Some members are sarcophagid-like, but they differ from them in many aspects, such as presence of a telescopic ovipositor and large paralobes in the aedeagus (Dear, 1979). External characters that support its exclusion from Sarcophagidae include setulose stem vein and presence of two notopleural setae (Dear, 1979).

\subsubsection{Subfamily Calliphorinae}

Calliphorinae is a comparatively large subfamily, which is worldwide in distribution (Rognes, 1991). Rognes (1991) suggested synapomorphies (see appendix 6.8) for the monophyly of the Calliphorinae in a restricted sense. The suggested autapomorphy of setae on the lower calypter is also present in a few other blow fly genera (e.g. Pachychoeromyia, Chrysomya etc.) (Dear, 1985; Rognes, 1991). Tricycleopsis spp. also have a few setae on the lower calypter, and may be members of 
Calliphorinae, but some authors consider it a member of Melanomyinae (Kurahashi, 1970; Rognes, 1991). Most members of subfamily Calliphorinae are oviparous, but there are some larviparous species belonging to genera Bellardia, Onesia, Polleniopsis and Tainanina (Onesia group of Kurahashi, 1972) and some subgenera of Calliphora (Kurahashi, 1989).

\subsubsection{Subfamily Luciliinae}

Subfamily Luciliinae, also known as the greenbottle flies, have worldwide distribution (Rognes, 1991). Characters that support monophyly of this group are listed in appendix 6.9 (Rognes, 1991; 1997). It includes the following genera: Dyscritomyia, Hypopygiopsis, Hemipyrellia and Lucilia. All members are oviparous (Rognes, 1991).

\subsubsection{Subfamily Melanomyinae}

Melanomyinae are Palaearctic, Nearctic and Oriental flies. Diagnostic characters are listed in appendix 6.10 (Kurahashi, 1970; Shewell, 1987; Rognes, 1991). The biology of the members of this subfamily is not well known, but limited information indicates that larvae of these flies are parasitic on snails (Rognes, 1991). Rognes (1991) tentatively included Angioneura, Eggisops, Glutoxys, Melanomya, Melinda, Opsodexia, Paradichosia, Pseudopsodexia and Tricycleopsis under this subfamily; however Melinda, Paradichosia, Eggisops, and Angioneura are traditionally considered as a part of Calliphorinae (Kurahashi, 1970; Schumann, 1986; Shewell, 1987).

\subsubsection{Subfamily Polleniinae}

Polleniinae contains Holarctic, Oriental and Australian non-metallic flies that can be characterized by comparatively strong facial carina, unarmed acrophallus of aedeagus and many other characters as listed in appendix 6.11(Rognes, 1997). Polleniinae includes: Dexopollenia, Melanodexia, Morinia, Nesodexia, Pollenia, Xanthotryxus and Wilhelmina, but the inclusion of many genera remains tentative, as information about them is limited (Rognes, 1991). Placement of Nesodexia in Polleniinae is still not well supported as its aedeagus has an armed acrophallus (Rognes, 1991). 


\subsubsection{Subfamily Rhiniinae}

Subfamily Rhiniinae is mostly Afrotropical, Oriental and Australian flies that can be characterized by the features listed in appendix 6.12. Most members are oviparous (Rognes, 1991; Peris, 1952) and larvae are predators of ants, termites, and wasps (Dear, 1977; Kurahashi, 1989).

\subsubsection{Subfamily Chrysomyinae}

The subfamily Chrysomyinae is distributed in all zoogeographical regions except Antarctic. Characters that support monophyly of the subfamily are listed in appendix 6.13 (Rognes, 1991). Most members of the subfamily are saprophagous but Protocalliphora and Trypocalliphora are bloodsucking parasites of nestling birds, and Chrysomya bezziana and Cochliomyia hominivorax feed on living mammals (Rognes, 1991; Dear, 1985). Most genera under the subfamily Chrysomyinae are probably monophyletic with well-defined autapomorphies (Dear, 1985; Whitworth, 2006). Trypocalliphora, Phormia, Phormiata, Chloroprocta, and Chrysopyrellia are monotypic genera whereas Protocalliphora with 28 species and Chrysomya with 36 species are the most diverse genera of the subfamily Chrysomyinae (Dear, 1985; Whitworth et al., 2007; Boyes \& Shewell, 1975; Wells \& Kurahashi, 1996; Ullerich \& Schottke, 2006).

\subsubsection{Aphyssurinae}

Aphyssurinae is newly added subfamily of the Calliphoridae, which is distributed only in Australia. These fly are very small in size $(5 \mathrm{~mm})$ and are larviparous. Life history is not well-known, but there is an indication that they may be associated with ants (Norris, 1999). Aphyssurinae is represented by single genus Aphyssura Hardy and 28 species (Norris, 1999).

\subsubsection{Prosthetosomatinae}

Prosthetosomatinae are known only from the larval stage and are distributed in Neotropical and Afro-tropical regions (Pont, 1980). These larvae infest nest-mounds of termites (Pont, 1980). Pont (1980) transferred this subfamily from family Muscidae to family Calliphoridae based on similarities in morphological structures and larval habits. 


\subsection{Morphological versus molecular systematics}

Both morphological and molecular systematic approaches have been used for inferring phylogeny at different systematic levels of the Oestroidea (Pape, 1992; Rognes, 1997; Pape, 2001; Otranto et al., 2003, McDonagh, 2009; Kutty et al., 2010). Both methods complement each other and both have some advantages and disadvantages. Molecular data are good because large numbers of molecular characters are available for phylogenetic analysis, whereas in morphological data we have limited number of characters for inferring phylogeny of a particular group. For phylogenetic reconstructions, useful characters must demonstrate heritable variation as seen in most molecular characters, whereas some morphological characters may show non-heritable variation. There are also some disadvantages to using molecular data. The first is the problem of Long Branch Attraction (LBA), which is an erroneous grouping of rapidly evolving non-sister taxa, as a sister taxa, because of interpretation of homoplasies as a synapomorphies (Bergsten, 2005). Morphological characters are less commonly affected by LBA than are molecular characters (Grant \& Kluge, 2003), as molecular characters (DNA sequence data) have only four possible character states, whereas morphological characters may have more possible character states (Jenner, 2004). The second is the cost. It is much cheaper to do morphological systematic analysis than to do molecular systematic studies. The third is the specimen availability. Many species of Oestroidea are rare in collection and are available only in museums. For these species only morphological systematic analysis is possible. There are some oestroid taxa (such as Adipterites, Cretaphormia) that are known only from fossils (Rognes, 1991). Phylogenetic analysis of these taxa with existing oestroid taxa is only possible by morphological systematic analysis.

\subsection{Mitochondrial versus nuclear genes}

Mitochondrial and nuclear genes have been extensively used in phylogenetic studies of different groups of flies (Wells \& Sperling, 1999; Moulton \& Wiegmann, 2004 Kutty et al., 2008; 2010; McDonagh, 2009). Mitochondrial genes have many advantages over nuclear genes such as easy amplification from a variety of taxa (because universal primers are available for many mitochondrial genes), easy direct PCR product sequencing (as it is haploid), its usefulness in the study of closely related taxa 
(because, mitochondrial genes frequently evolve at a faster rates than nuclear genes in animals) (Moritz et al., 1987; Lin \& Danforth, 2004). This faster rate of evolution helps in resolving species level and genus level phylogeny, but it may not be as good for deeper divergences. However, in one case a whole mitochondrial genome analysis helped resolve a phylogeny of the Diptera (Cameron et al., 2007). Species-level polyphyly due to incomplete lineage sorting is less of concern for mitochondrial genes than for nuclear genes, because effective population size $(\mathrm{Ne})$ of mitochondrial genes is theoretically one-fourth that of nuclear genes (Heckman et al., 2007).

Mitochondrial gene based phylogeny can be affected by horizontal gene transfer, introgression and presence of pseudogenes (Funk \& Omland, 2003). In some insect groups among-site rate variations are more heterogeneous in mitochondrial genes than in nuclear genes, which suggests more homoplasious nature of data obtained from mitochondrial genes than from nuclear genes (Lin \& Danforth, 2004). Also in general, mitochondrial genes show a more biased base composition than nuclear genes (Lin \& Danforth, 2004). Commonly used mitochondrial genes in insect systematics are cytochrome oxidase subunit one (COI), cytochrome oxidase subunit two (COII), cytochrome b (Cyt. b), 12S ribosomal RNA, and 16S ribosomal RNA (Wells \& Sperling, 1999; Kutty et al., 2008; 2010). Most nuclear protein coding genes are present in single copy and nuclear ribosomal genes are present in multiple copies. Nuclear ribosomal genes (18S, 5.8S and 28S) demonstrate diverse rate of genetic evolution, which make these genes better markers for elucidating phylogenetic relationships between recent as well as old divergences (Larson, 1991; Stevens \& Wall, 2001). Universal primers are abundant and hence it is easy to amplify and sequence ribosomal genes but it is difficult to align these sequences (Hickson et al., 2000). Single copy nuclear genes are difficult to amplify but easier to align as these genes are protein coding genes. Single copy nuclear genes commonly used for insect systematics are Elongation factor one alpha ( EF-1a) (Cho et al., 1995), Phosphoenolpyruvate Carboxykinase (PEPCK) (Leys et al., 2002), Dopa-decarboxylase (DDC) (Fang et al., 2000), Wingless (Brady, 2003), White (Baker et al., 2001), Opsin (Kawakita et al., 2004), Hunchback (Baker \& DeSalle, 1997), Period (Regier et al., 1998), Carbamoylphosphate Synthetase (CPS) (Moulton \& Wiegmann, 2004), Enolase (Farrell et al., 2001) and Arginine Kinase (Kawakita et al., 
2004). Danforth et al. (2005) suggested use of nuclear ribosomal genes along with nuclear protein coding genes for better resolution at deeper nodes. As incongruence of gene and species trees are not uncommon (Cummings, 1994), use of various independent loci gives more accurate evolutionary history of a group of organisms (Rubinoff \& Holland, 2005). Combined analysis of mitochondrial and nuclear genes gives better support, stability, and resolution than separate analysis of any of them (Baker \& DeSalle, 1997).

\subsection{Phylogenetic methods}

Several methods are available for phylogenetic analysis of morphological and molecular data but maximum parsimony (MP), maximum likelihood (ML) and Bayesian methods (BA) are more commonly used methods as these methods are character based, use optimality criteria for tree selection and are truly cladistic in nature. MP is a simple non-parametric statistical method that assumes that evolution is rare and the best tree is that which has the least total length. ML is a parametric statistical method that assumes independent evolution of nucleotide sites. ML estimates the probability of obtaining the observed sequence (data) given a tree (hypothesis) under the chosen evolutionary model. The tree that gives highest likelihood is the best. BA is the most recently developed parametric statistical method of phylogenetic inference that is based on Bayes theorem of posterior probability, which uses a Monte Carlo Markov Chain to sample a tree from a posterior probability distribution. BA estimates the probability of obtaining a tree given the data (sequence alignment) and model.

Although all these methods have different optimality criteria, under most sets of realistic conditions they perform similarly and often result in congruent tree topology (Reed et al., 2002). No method is perfect and each one has some advantages and disadvantages (Swofford \& Olsen, 1990; Archibald et al., 2003). For morphological data, MP method is the only option because no stochastic model for non-molecular data is available. MP method is more sensitive to LBA, than model based ML and BA methods (Felsenstein, 1978). BA provides clade support in terms of frequency of occurrence of a particular clade among all trees sampled and hence it is less time consuming than ML with bootstrap analysis. Although BA has advantages in terms of speed and reliability it 
requires information on prior distribution of data, which is sometimes not easy to provide.

\subsection{Objectives of the present study}

With more than 14,000 described species ( $\approx 9 \%$ of all known Diptera), Oestroidea is one of the most important superfamilies of Diptera. Some members, such as, flesh flies, blow flies, and tachinid flies, are commonly encountered in day to day life, while others such as New Zealand bat fly are rare but very unusual in terms of morphology and behavior. Many members of the superfamily are agricultural and veterinary pests and some cause myiasis (Zumpt, 1951; Pape, 2001; O'Hara, 2008). Some members are widely used in forensic entomology as an indicator species for estimation of time since death (Goff \& Odum, 1987).

Although the superfamily Oestroidea has been the subject of much scientific scrutiny, the exact patterns of phylogenetic relationships among the key groups of the superfamily remain the subject of continuing revision (McAlpine, 1989; Pape, 1992; Rognes, 1997; McDonagh, 2009; Kutty et al., 2008; 2010). Except Calliphoridae, the monophyly of each oestroid family is well-supported (Rognes, 1997). Extensive morphological cladistic analysis of the Oestroidea by Pape (1992) and Rognes (1997), disagrees on monophyly of the Calliphoridae and also on interfamilial relationships within Oestroidea. It is difficult to understand evolution and phylogeny of the Calliphoridae without understanding the evolution and phylogeny of the Oestroidea and vice versa (McAlpine, 1989; Rognes, 1997). Uncertain systematic positions of Mystacinobia and the Rhinophoridae along with uncertain monophyly of the Calliphoridae are major unresolved oestroid systematic questions (McAlpine, 1989; Pape, 1992; Rognes, 1997; Kutty et al., 2010). Even within Oestroidea, there are many taxonomic groups (families, subfamilies and genera) that require separate detailed systematic study, but these studies are constrained because of difficulty in collection of these flies (Rognes, 1997; Pape, 2001; Otranto et al., 2003; Nirmala et al., 2001; Kutty et al., 2010).

The main objective of this dissertation was to infer the evolution and phylogeny of the Oestroidea with an emphasis on the family Calliphoridae using DNA sequence data. 
This will involve the consideration of systematic questions of Oestridae, Calliphoridae, Chrysomyinae and Chrysomya. I chose Oestridae, Calliphoridae, Chrysomyinae and Chrysomya for detailed systematic studies, because they have many unresolved systematic questions that need an answer and, also, because I had better taxon sampling from these groups.

Therefore, the objectives of this dissertation are to determine 1.) intrageneric relationships of the genus Chrysomya, 2.) intergeneric relationships of the subfamily Chrysomyinae, 3.) intrafamilial relationships of the family Oestridae, and 4.) intrafamilial relationships of the family Calliphoridae, using both mitochondrial and nuclear genes.

Each chapter was written as a publishable manuscript, which addresses the above mentioned objectives separately. Although I tried to avoid unnecessary repetition between different chapters, there are still some repetitive sections because each chapter must be independent of the other. Although this dissertation is my original work, at many places, I have used "We" instead of "I" to give credit to people who have contributed significantly during different stages of this study and are co-authors on the manuscripts. 


\title{
CHAPTER 2 : Molecular Phylogeny of the Chrysomya (Calliphoridae: Chrysomyinae).
}

\author{
Singh, B., Kurahashi, H. \& Wells, J. D. (2010) Molecular phylogeny of the blowfly genus \\ Chrysomya. Medical and Veterinary Entomology, DOI: 10.1111/j.1365- \\ 2915.2010.00914.X
}

\subsection{Introduction}

Chrysomya Robineau-Desvoidy is a genus of blow fly native to the Old World tropics and subtropics. Like other familiar calliphorids, most Chrysomya spp. breed in carrion and putrefied wounds (Fuller, 1934; Norris, 1965). Ch. bezziana Villeneuve larvae feed on healthy warm-blooded vertebrates and are serious medical and veterinary pests (Zumpt, 1951; 1965). With about 36 species (Boyes \& Shewell, 1975; Wells \& Kurahashi, 1996; Ullerich \& Schottke, 2006), the genus is not unusually large for the Calliphoridae. However, compared to other blow fly genera, the Chrysomya are notably diverse in morphology and habits, and some of their unique features may have contributed to the ability of several species to spectacularly succeed in invading new geographic regions.

Several authors have proposed hypotheses about evolutionary trends within Chrysomya. Ullerich \& Schottke (2006) quantified genome size from nine species of Chrysomya. Based on karyotype and distribution of species-specific inversions, they concluded that genome size increased over evolutionary time.

The larvae of several species have prominent spiny tubercles not found in other calliphorids (Kitching, 1976; Kitching \& Voeten, 1977; Erzinclioglu, 1987; Sukontason et al., 2003; 2005), and are sometimes referred to as "hairy maggots". All tuberculate species with known natural history are also facultative predators on other maggots (Froggatt, 1918 (as cited in Fuller, 1934); Fuller, 1934; Senior-White et al., 1940; Ullyett, 1950). Hairy maggots are dorso-ventrally flattened, and in one species we have observed, Ch. rufifacies (Macquart), will curl and present the spines rather like a hedgehog when disturbed. Therefore, we suspect that the tubercles serve to reduce cannibalism. The ability to both scavenge carrion and eat one's competitors make these Chrysomya powerful ecological competitors for the carrion resource, and the introduction of both hairy and smooth Chrysomya to new regions appears to have reduced populations of native calliphorids (Hanski, 1977; Guimarães et al., 1979; 
Baumgartner \& Greenberg, 1984; Wells \& Greenberg, 1992a). Lunt (2002), after considering a limited number of Chrysomya species suggested cuticular tubercules evolved twice in Chrysomya.

Some Chrysomya adult males show a normal compound eye, where ommatidium size decreases gradually from top to bottom, while others show a form of male compound eye, not seen in other blow flies, but not too rare in lower Diptera. This involves a sharply demarcated pattern of enlarged upper and small lower ommatidia (Fig. 2.1) (Kurahashi, 1982; Wells et al., 1994). Kurahashi (1982) theorized that this derived eye evolved in Ch. megacephala in response to the development of anthropogenic habitats. Ch. megacephala is a hugely successful urban pest that has invaded all of the world's warm regions (Wells, 1991). The possible association between the derived eye and synanthropy has not been so well studied in other Chrysomya spp., but what is known does not contradict that pattern (Wells et al., 1994).

\section{Normal male eye}

\section{Derived male eye}

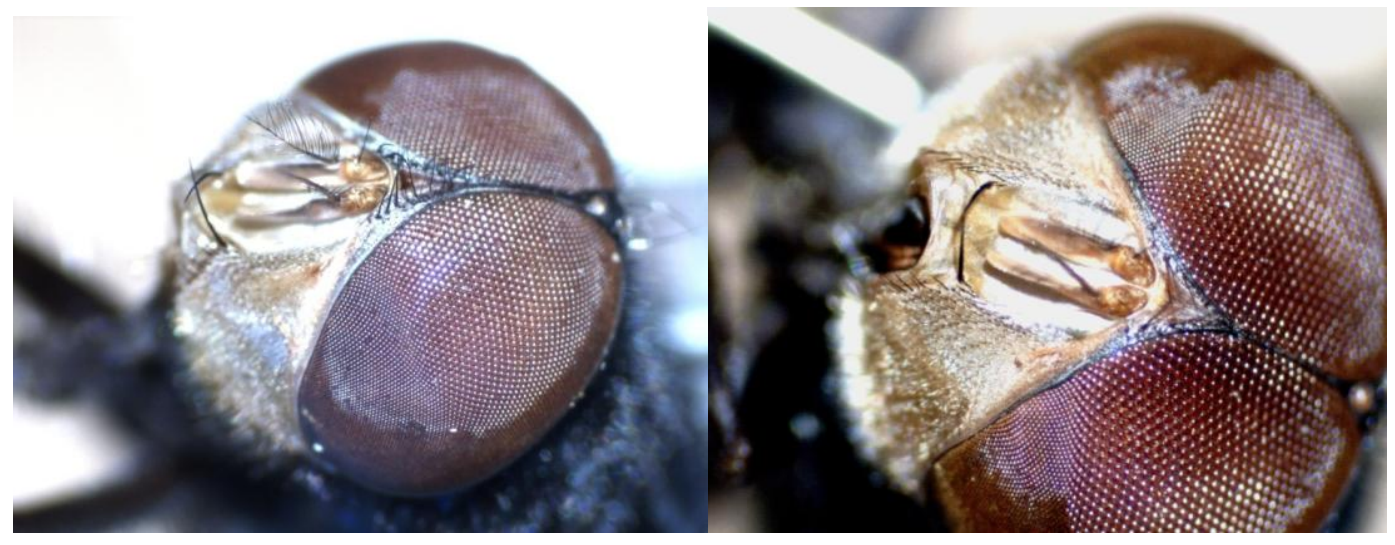

FIGURE 2.1: Male compound eye of Chrysomya showing two kinds of compound eye. Left: normal male eye of Ch. pacifica; Right: derived male eye of Ch. megacephala.

Perhaps most striking is that some Chrysomya have a unique mode of sex determination. In the so-called monogenic Ch. rufifacies and Ch. albiceps Wiedemann, sex is determined by the mother's genotype, i.e. a female produces offspring of a single sex (Ullerich, 1958; 1963; Ullerich \& Schottke, 2006). Ullerich (1976) suggested monogeny evolved from amphogeny because monogenic species had what he believed was a derived karyotype. Alternatively, Puchalla (1994) argued that amphogeny evolved 
from monogeny in Chrysomya, as he observed a homosequencial band pattern in monogenic Ch. rufifacies and the outgroup Lucilia cuprina (Wiedemann). Such evolutionary scenarios have been difficult to evaluate, because there is no robust phylogeny that can be used to infer such things as the number of times a character has evolved or whether a condition is primitive or derived within the genus (Wiens et al., 2006).

Similarly, taxonomic divisions within Chrysomya have not been shown to be true clades. Proposed subgenera are Microcalliphora (Townsend) [Ch. varipes (Macquart), Ch. flavifrons Aldrich], Eucompsomyia (Malloch) [Ch. semimetallica (Malloch), Ch. latifrons (Malloch), Ch. sabroskyi (Theowald)], Achoetandrus (Bezzi) or villeneuvi group of Kurahashi \& Magpayo (1987) [Ch. albiceps, Ch. rufifacies, Ch. yayukae Kurahashi et Magpayo, Ch. villeneuvi Patton, Ch. sulcifrons James, and Ch. schoenigi Kurahashi et Magpayo] and Ceylonomyia (Fan) [Ch. nigripes Aubertin]. Kurahashi \& Magpayo (1987) recognized, the megacephala group, including Ch. defixa (Walker), Ch. megacephala Fabricius, Ch. pinguis (Walker), Ch. saffranea Bigot, and Ch. thanomthini Kurahashi et Tumrasvin.

Kurahashi (1982) produced a morphological phenogram of the megacephala group. More recently, DNA sequence data mostly generated for identifying forensic evidence (Wells \& Sperling, 2001; Harvey et al., 2003; Wallman et al., 2005; Wells \& Williams, 2007; Nelson et al., 2007; Nelson et al., 2008; Harvey et al., 2008) were used to produce phylogenies of Chrysomya and other calliphorids. However, these data were insufficient for testing evolutionary hypothesis of Chrysomya, as they included few Chrysomya species, and the fast-evolving mitochondrial genes used didn't resolve deeper nodes.

The main purpose of this study was to develop a robust phylogeny of the Chrysomya.

\subsection{Materials and Methods}

\subsubsection{Specimens and DNA extraction}

A total of 27 blowfly specimens were included in this study (See Table 2.1 for collection details). 22 specimens represented the ingroup genus Chrysomya and five served as outgroups. All the specimens except Cochliomyia hominivorax (Coquerel) 
(see below) were preserved live in 95\% ethanol. For DNA extraction approximately 20 $\mathrm{mg}$ of thoracic muscles of the selected taxa were cut into smaller pieces and then mixed with $500 \mu \mathrm{l}$ of lysis buffer containing Tris-Cl $(\mathrm{pH}=9.0) 100 \mathrm{mM}, \mathrm{NaCl}=100 \mathrm{mM}$, EDTA $(\mathrm{pH}=8.0)=50 \mathrm{mM}$ and Sucrose $=200 \mathrm{mM}, 50 \mu \mathrm{l}$ of $10 \%$ SDS and $20 \mu \mathrm{l}$ of 20 $\mathrm{mg} / \mathrm{ml}$ proteinase K. After overnight incubation at $55^{\circ} \mathrm{C}$, DNA purification was done using a phenol:chloroform:isoamyl alcohol (25:24:1) method as described in Moulton and Weigmann (2004). DNA was washed in 70\% ethanol and precipitated in equal volume of $100 \%$ iso-propanol. Pelleted DNA was dried in a vacuum centrifuge at room temperature for about 20 minutes. The dried pellet was re-suspended in $100 \mu \mathrm{l}$ of TE buffer (Tris-Cl $10 \mathrm{mM}$ and $1 \mathrm{mM}$ EDTA). DNA quantification was done using a NanoDrop ${ }^{\mathrm{TM}} 1000$ spectrophotometer (Thermo Scientific, Waltham, MA).

Approximately, 4000 to $6000 \mathrm{ng}$ of DNA was obtained from each specimen and was stored at $-20^{\circ} \mathrm{C}$. T. T. Torres (Universidade Estadual de Campinas, Brazil) supplied DNA for Co. hominivorax. Voucher specimens were deposited to West Virginia University Entomological collections, and voucher identification numbers from the same were submitted to GenBank (See Table 2.1 for voucher ID).

\subsubsection{PCR amplification}

\subsubsection{Carbamoylphosphate synthetase (CPS)}

CPS is an enzymatic element in the fused carbamoylphosphate synthetase, aspartate transcarbamylase, and dihydroorotase (CAD) protein involved in pyrimidine biosynthesis. An $850 \mathrm{bp}$ fragment of CPS was amplified from 26 of the study taxa using primers listed in Table 2.2. Published degenerate CPS primers 787F and 1098R and Schizophora specific degenerate primers Shiz 3' and Shiz 5' (sequences were supplied by Dr. J. K. Moulton (The University of Tennessee, Knoxville,TN) worked for some blow fly taxa. The resulting sequences were edited and aligned using Sequence Navigator (Applied Biosystems, Foster city, CA) and used to design Chrysomya specific primers (Table 2.2), using primer 3 software (Steve \& Helen, 2000). All primers were purchased from either Integrated DNA Technologies, Inc. (Coralville, IA) or Operon Biotechnologies, Inc. (Huntsville, AL). 
TABLE 2.1: Specimen details, collection information and GenBank accession numbers.

\begin{tabular}{|c|c|c|c|c|c|c|c|}
\hline \multirow{2}{*}{$\begin{array}{l}\text { Sr. } \\
\#\end{array}$} & \multirow[t]{2}{*}{ Species name } & \multirow[t]{2}{*}{ Location } & \multirow[t]{2}{*}{ Date } & \multirow[t]{2}{*}{ Collected by } & \multirow[t]{2}{*}{ Voucher number } & \multicolumn{2}{|c|}{ Accession number } \\
\hline & & & & & & CPS & COI \\
\hline 1 & $\begin{array}{l}\text { Chrysomya albiceps } \\
\text { Wiedemann, } 1819\end{array}$ & $\begin{array}{l}\text { Bloemfontein, South } \\
\text { Africa }\end{array}$ & $15 / \mathrm{V} / 1997$ & $\begin{array}{l}\text { T.C. Vander } \\
\text { Linde }\end{array}$ & WVU2009-017-1 & FJ169339 & AF083657 \\
\hline 2 & $\begin{array}{l}\text { Chrysomya cabrearai } \\
\text { Kurahashi et } \\
\text { Salazar,1977 }\end{array}$ & $\begin{array}{l}\text { SERAM Manusela } \\
\text { National Park, } \\
\text { Indonesia }\end{array}$ & $27 / / X / 1996$ & H. Kurahashi & WVU2009-017-2 & FJ169349 & FJ195378 \\
\hline 3 & $\begin{array}{l}\text { Chrysomya chani } \\
\text { Kurahashi, } 1979\end{array}$ & $\begin{array}{l}\text { Lam Dong } \\
\text { Prov.,Vietnam }\end{array}$ & 05/XI/2000 & H. Kurahashi & WVU2009-017-30 & FJ169348 & FJ195377 \\
\hline 4 & $\begin{array}{l}\text { Chrysomya putoria } \\
\text { (Weidemann, 1830) }\end{array}$ & $\begin{array}{l}\text { Near Chilibre, } \\
\text { Panama }\end{array}$ & 03/IX/1995 & J. Mendez & WVU2009-017-3 & FJ169353 & FJ195384 \\
\hline 5 & $\begin{array}{l}\text { Chrysomya defixa } \\
\text { (Walker,1856) }\end{array}$ & $\begin{array}{l}\text { Chumphon, South } \\
\text { Thailand }\end{array}$ & $30 / 1 / 2004$ & H. Banziger & WVU2009-017-4 & FJ169358 & FJ195375 \\
\hline 6 & $\begin{array}{l}\text { Chrysomya greenbergi } \\
\text { Wells et } \\
\text { Kurahashi,1996 }\end{array}$ & $\begin{array}{l}\text { Mt. Nokilalaki, } \\
\text { Sulawesi, Indonesia }\end{array}$ & $31 / \mathrm{VIII} / 1996$ & H. Kurahashi & WVU2009-017-5 & FJ169354 & FJ195385 \\
\hline 7 & $\begin{array}{l}\text { Chrysomya incisuralis } \\
\text { (Macquart, 1851) }\end{array}$ & $\begin{array}{l}\text { Kuranda, QId, } \\
\text { Australia }\end{array}$ & $24 / \mathrm{VI} / 2002$ & J.F. Wallman & WVU2009-017-6 & FJ169337 & FJ195373 \\
\hline 8 & $\begin{array}{l}\text { Chrysomya latifrons } \\
\text { (Malloch,1927) }\end{array}$ & $\begin{array}{l}\text { Mt. Kiera, New } \\
\text { South Wales, } \\
\text { Australia }\end{array}$ & $--/ I I / 2005$ & J.F. Wallman & WVU2009-017-7 & FJ169338 & FJ195374 \\
\hline 9 & $\begin{array}{l}\text { Chrysomya marginalis } \\
\text { (Weidemann, 1830) }\end{array}$ & $\begin{array}{l}\text { Bloemfontein, South } \\
\text { Africa }\end{array}$ & $15 / \mathrm{V} / 1997$ & $\begin{array}{l}\text { T.C. Vander } \\
\text { Linde }\end{array}$ & WVU2009-017-8 & FJ169347 & FJ195380 \\
\hline 10 & $\begin{array}{l}\text { Chrysomya } \\
\text { megacephala Fabricius, } \\
1794\end{array}$ & Guam & $31 / \mathrm{IV} / 2002$ & P. Erwin & WVU2009-017-9 & FJ169350 & AF092761 ${ }^{g}$ \\
\hline 11 & $\begin{array}{l}\text { Chrysomya nigripes } \\
\text { Aubertin,1932 }\end{array}$ & $\begin{array}{l}\text { Toili, Sulawesi, } \\
\text { Indonesia }\end{array}$ & $3-11 / I X / 1996$ & H. Kurahashi & WVU2009-017-10 & FJ169346 & FJ195379 \\
\hline 12 & $\begin{array}{l}\text { Chrysomya norrisi } \\
\text { James, } 1971\end{array}$ & $\begin{array}{l}\text { Wau, Papua New } \\
\text { Guinea }\end{array}$ & 19/IV/1995 & J. D. Wells & $\mathrm{N} / \mathrm{A}$ & FJ169344 & $\mathrm{AF}^{295552^{\mathrm{g}}}$ \\
\hline 13 & $\begin{array}{l}\text { Chrysomya pacifica } \\
\text { Kurahashi, } 1991\end{array}$ & $\begin{array}{l}\text { Laboratory colony } \\
\text { originated from New } \\
\text { Britain, Papua New } \\
\text { Guinea }\end{array}$ & $27 / \mathrm{V} / 1995$ & H. Kurahashi & WVU2009-017-11 & FJ169355 & FJ195383 \\
\hline
\end{tabular}




\begin{tabular}{|c|c|c|c|c|c|c|c|}
\hline 14 & $\begin{array}{l}\text { Chrysomya flavifrons } \\
\text { Aldrich, } 1925\end{array}$ & $\begin{array}{l}\text { Kuranda, Qld, } \\
\text { Australia }\end{array}$ & NA & NA & ABTC78506 & NA & AY842615 \\
\hline 15 & $\begin{array}{l}\text { Chrysomya pinguis } \\
\text { (Walker,1858) }\end{array}$ & Sarangkot, Nepal & $29 / V / 2007$ & J.D. Wells & WVU2009-017-12 & FJ169357 & FJ195381 \\
\hline 16 & $\begin{array}{l}\text { Chrysomya rufifacies } \\
\text { (Macquart, 1843) }\end{array}$ & $\begin{array}{l}\text { Montgomery, AL, } \\
\text { USA }\end{array}$ & 05/X/2005 & J.D. Wells & WVU2009-017-13 & FJ169341 & $\mathrm{AF}^{2} 83658^{\mathrm{g}}$ \\
\hline 17 & $\begin{array}{l}\text { Chrysomya } \\
\text { semimetallica (Malloch, } \\
\text { 1927) }\end{array}$ & $\begin{array}{l}\text { Near Hoskins, New } \\
\text { Britain, Papua New } \\
\text { Guinea }\end{array}$ & 25/IV/1995 & J. D. Wells & $\mathrm{N} / \mathrm{A}$ & FJ169345 & $\mathrm{AF}^{295562^{g}}$ \\
\hline 18 & $\begin{array}{l}\text { Chrysomya thanomthini } \\
\text { Kurahashi et } \\
\text { Tumrasvin, } 1977\end{array}$ & $\begin{array}{l}\text { Lao Cai, Sapa, } \\
\text { Vietnam }\end{array}$ & 02/X/1995 & H. Kurahashi & WVU2009-017-14 & FJ169356 & FJ195386 \\
\hline 19 & $\begin{array}{l}\text { Chrysomya varipes } \\
\text { (Macquart, 1851) }\end{array}$ & Adelaide, Australia & 03/X/1997 & J.D. Wells & WVU2009-017-15 & FJ169343 & $\mathrm{AF}^{295556^{\mathrm{g}}}$ \\
\hline 20 & $\begin{array}{l}\text { Chrysomya villeneuvi } \\
\text { Patton, } 1922\end{array}$ & $\begin{array}{l}\text { Lam Dong Prov., } \\
\text { Vietnam }\end{array}$ & $05 / \mathrm{XI} / 2000$ & H. Kurahashi & WVU2009-017-31 & FJ169342 & FJ195382 \\
\hline 21 & $\begin{array}{l}\text { Chrysomya yayukae } \\
\text { Kurahashi et Magpayo, } \\
1987\end{array}$ & $\begin{array}{l}\text { Toili, Sulawesi, } \\
\text { Indonesia }\end{array}$ & 3-11/IX/1996 & H. Kurahashi & WVU2009-017-16 & FJ169340 & FJ195376 \\
\hline 22 & $\begin{array}{l}\text { Chrysomya bezziana } \\
\text { Villeneuve, } 1914\end{array}$ & $\begin{array}{l}\text { Institute Haiwan, } \\
\text { Malaysia }\end{array}$ & $09 / \mathrm{XI} / 2001$ & J. Stevens & WVU2009-017-17 & FJ169351 & $\mathrm{AF}^{295548^{9}}$ \\
\hline 23 & $\begin{array}{l}\text { Phormia regina } \\
\text { (Meigen, 1826) }\end{array}$ & $\begin{array}{l}\text { Laboratory colony } \\
\text { originated from } \\
\text { Pullman, WA, USA }\end{array}$ & $29 / V / 2008$ & C.J. Picard & WVU2009-017-18 & FJ169331 & AF295550 ${ }^{9}$ \\
\hline 24 & $\begin{array}{l}\text { Cochliomyia macellaria } \\
\text { (Fabricius, } 1775 \text { ) }\end{array}$ & $\begin{array}{l}\text { Laboratory colony } \\
\text { originated from } \\
\text { Morgantown, WV, } \\
\text { USA }\end{array}$ & 14/IX/2006 & B. Singh & WVU2009-017-19 & FJ169333 & AF295555 ${ }^{9}$ \\
\hline 25 & $\begin{array}{l}\text { Cochliomyia } \\
\text { hominivorax (Coquerel, } \\
\text { 1858) }\end{array}$ & Brazil & NA & T.T. Torres & $\mathrm{N} / \mathrm{A}$ & FJ169334 & AF260826 ${ }^{9}$ \\
\hline 26 & $\begin{array}{l}\text { Lucilia sericata } \\
\text { (Meigen, 1826) }\end{array}$ & $\begin{array}{l}\text { Morgantown, WV, } \\
\text { USA }\end{array}$ & 13/V/2005 & J.D. Wells & WVU2009-017-20 & FJ169332 & AJ417717 ${ }^{9}$ \\
\hline 27 & $\begin{array}{l}\text { Calliphora vomitoria } \\
\text { (Linnaeus, 1758) }\end{array}$ & $\begin{array}{l}\text { Morgantown, WV, } \\
\text { USA }\end{array}$ & 14/VIII/2005 & J. Hall & WVU2009-017-21 & FJ169335 & EU418569 ${ }^{g}$ \\
\hline
\end{tabular}


TABLE 2.2: List of CPS gene primers used in this study.

\begin{tabular}{|l|l|l|l|}
\hline $\begin{array}{l}\text { Sr. } \\
\#\end{array}$ & $\begin{array}{l}\text { Name of } \\
\text { primer }\end{array}$ & Nucleotide Sequence (5' to $\mathbf{3}^{\prime}$ ) & Reference \\
\hline 1 & $787 \mathrm{~F}$ & GGDGTNACNACNGCNTGYTTYGARCC & Moulton and Wiegmann, 2004 \\
\hline 2 & $1098 \mathrm{R}$ & TTNGGNAGYTGNCCNCCCAT & Moulton and Wiegmann, 2004 \\
\hline 3 & Shiz $3^{\prime}$ & TTKGCAATNAKYTGCATGTTRAA & $\begin{array}{l}\text { Moulton JK (Personal } \\
\text { communication) }\end{array}$ \\
\hline 4 & Shiz 5' & CANGTGGCYGGAGAA TGG CC & $\begin{array}{l}\text { Moulton JK (Personal } \\
\text { communication) }\end{array}$ \\
\hline 5 & CALCAD192F & AACCCACCGATAAGAGACCA & Designed for this study \\
\hline 6 & CALCAD1180R & TTCCTTGGCTTCCGTTAAGA & Designed for this study \\
\hline 7 & CH109F & TCCGTCAATGGTTTTGATCC & Designed for this study \\
\hline 8 & CH431F & TGGGCATTATTCCGTTTGTT & Designed for this study \\
\hline 9 & CH634F & TTGAGAAATCTGGGCAAACC & Designed for this study \\
\hline 10 & CH584R & ATGCGGTAAACACCTGAACC & Designed for this study \\
\hline 11 & CH653R & GGTTTGCCCAGATTTCTCAA & Designed for this study \\
\hline 12 & CH856R & CCAAAACCTTGGCTTGTTGT & Designed for this study \\
\hline 13 & CH878R & TCAATGGATTCGGGAGAAGT & Designed for this study \\
\hline 14 & CH1044R & CATAGCAGCACCCGACAATA & Designed for this study \\
\hline
\end{tabular}

Other PCR reagents were purchased from Promega Corp. (Madison, WI). Each $25 \mu \mathrm{l} \mathrm{PCR}$ reaction was prepared with $12.5 \mu \mathrm{l}$ of $2 \mathrm{X}$ Promega Master Mix (Catalog \# M7505), $2 \mu \mathrm{l}$ of each primer ( $5 \mathrm{pmol} / \mu \mathrm{l}), 1-3 \mu \mathrm{l}$ of template (10-30ng) and enough water to complete the total $25 \mu \mathrm{l}$ volume. Amplification was done using the touchdown PCR program of Moulton and Wiegmann (2004) using a GeneAmp® PCR System 9700 (Applied Biosystems, Foster City, CA).

\subsubsection{Cytochrome oxidase subunit one (COI) gene}

A $1536 \mathrm{bp}$ fragment of the widely studied COI gene was amplified using the primers and thermal cycler program described by Wells \& Sperling (1999). Table 2.1 lists those species that were sequenced for this study and those for which published COI sequence data were available. The PCR reaction mix was prepared as given above for CPS. 


\subsubsection{Sequencing}

PCR product was cleaned either by using a QIAquick PCR purification kit (Qiagen Inc., Valencia, CA) or by using ExoSAP-IT® (USB Corporation, Cleveland, Ohio) as per manufacturer's instructions. Direct sequencing of one or both strands of the cleaned PCR product involved the same primers used for its amplification. Cycle sequencing was performed on a GeneAmp® PCR System 9700 (Applied Biosystems, Foster City, CA) with the Big Dye ${ }^{\mathrm{TM}}$ Terminator v3.1 Cycle Sequencing Kit (Applied Biosystems, Foster city, CA). Each cycle sequencing reaction was prepared with 0.7 to $1.2 \mu \mathrm{l}$ of cleaned PCR product, $1 \mu \mathrm{l}$ of $5 \mathrm{X}$ sequencing buffer, $1 \mu \mathrm{l}$ of primer $(2.5 \mathrm{pmol} / \mu \mathrm{l}), 0.5 \mu \mathrm{l}$ of BigDye ${ }^{\mathrm{TM}}$ and enough water to complete the total $5 \mu \mathrm{l}$ volume. Cycling conditions included initial denaturation at $96^{\circ} \mathrm{C}$ for 1 minutes followed by 30 cycles of $96^{\circ} \mathrm{C}$ for 10 seconds, $50^{\circ} \mathrm{C}$ for 5 seconds, and $60^{\circ} \mathrm{C}$ for 4 minutes, followed by a $4^{\circ} \mathrm{C}$ hold. Cycle sequencing product was cleaned either by using spin columns filled with Sephadex G-50 beads (Sigma-Aldrich, Milwaukee, WI) or by ethanol precipitation. For the ethanol precipitation method, $25 \mu \mathrm{l}$ of a mixture containing $120 \mu \mathrm{l}$ $3 \mathrm{M}$ Sodium acetate $(\mathrm{pH}=5.2)$ in $3 \mathrm{ml}$ of absolute alcohol, was added to each well containing $5 \mu \mathrm{l}$ sequencing product and then centrifuged at $4000 \mathrm{rpm}$ for 20 minutes. The supernatant was removed by inverting the plate. The pellet was washed with $100 \mu \mathrm{l}$ of $70 \%$ ethanol and centrifuged at $4000 \mathrm{rpm}$ for 12 minutes. The supernatant was again removed, initially by inverting the plate and then by wrapping the plate in several layers of kimwipe followed by inverted centrifugation at $700 \mathrm{rpm}$ for 1 minute. All centrifugation steps were performed at $4^{\circ} \mathrm{C}$ in a Thermo Scientific Sorvall@ Legend RT centrifuge. Plates with purified cycle sequencing products were air-dried at room temperature for 15 minutes. $10 \mu \mathrm{l}$ of Hi-Di formamide was added into each well and sequencing products were then separated on an Applied Biosystems 3130xl genetic analyzer (Foster City, CA). Sequence files were edited and aligned using Sequence Navigator (Applied Biosystems, Foster City, CA). All new CPS and COI DNA sequences were submitted to the GenBank database (See Table 2.1 for accession numbers).

\subsubsection{Phylogenetic analyses}

Phylogenetic analyses were performed on separate and combined CPS and COI sequences, a total of 2386 aligned bases. More than one tree-building method was 
used to test if phylogenetic results were robust to different analytical assumptions. Maximum parsimony (MP) and maximum likelihood (ML) analyses were performed in PAUP 4.0b10 (Swofford, 2002), and Bayesian analysis (BA) was performed using Mr.Bayes v.3.0b4 (Huelsenbeck \& Ronquist, 2001). Outgroup taxa included other chrysomyine blow flies (Co. macellaria (Fabricius), Co. hominivorax, Phormia regina (Meigen)) and representatives of the calliphorid subfamilies Luciliinae ( Lu. sericata (Meigen)) and Calliphorinae (Calliphora vomitoria (Linnaeus)). Branch support for MP and $\mathrm{ML}$ analysis was assessed with bootstrapping (BP) and also by Bremer support (BS) for MP analysis. For BA, branch support was assessed as posterior probabilities (PP). MP analysis included 1000 bootstrap replicates of equally weighted heuristic searches using addseq=random nreps=10 swap=nni hold=1 commands in the PAUP block. Other branch swapping options gave the same tree topology. BS (Bremer, 1994) values were calculated for the most parsimonious tree using TreeRot.v3 (Sorenson \& Franzosa, 2007) and PAUP4.0b10 (Swofford, 2002). A best-fit model was selected for ML analysis using Modeltest 2 (Posada \& Crandall, 1998) and for BA using MrModelTest 2.2 (Nylander, 2004). ML was performed with GTR $+1+r$ model for 100 bootstrap replications using $M L$ optimality criteria. BA was performed using general time reversible model with invariable site and discrete gamma distribution (GTR+I+r) for 1.5 million generations, sampling every 100 generations. After observing the likelihood plot, burn-in value was set as 12000 and posterior probabilities were calculated from the remaining trees by means of a majority rule consensus tree.

\subsection{Results}

MP bootstrap majority rule consensus trees obtained from separate analyses of the COI and CPS genes lacked resolution at deeper nodes (not shown). A combined analysis of both genes yielded strong support for a monophyletic Chrysomya, and three lineages within Chrysomya we designated clades I-III (Figs. 2.2 \& 2.3). The ML and Bayesian trees based on combined data were identical. This tree differed from the MP tree at a few nodes (as indicated by " $\neq$ " in Fig. 2.3), but these nodes in the MP tree were weakly supported by bootstrap and Bremer support values (Fig. 2.2 and Fig. 2.3). 


\subsection{Discussion}

\subsubsection{Taxonomy}

Microcalliphora (Ch. varipes + Ch. flavifrons) was monophyletic. Ch. semimetallica and Ch. latifrons, the two species of Eucompsomyia examined here (Malloch, 1927; Bezzi, 1927), formed the basal clade I. Achoetandrus i.e. the villeneuvi group of Kurahashi \& Magpayo (Bezzi, 1927; Lehrer, 1970; Kurahashi \& Magpayo, 1987) was also monophyletic (Figs. 2.2 \& 2.3), as was Kurahashi's megacephala species group. However, we did not recover Kurahashi's defixa and megacephala subgroups of the megacephala group (Kurahashi, 1982). Relationships between the subgenera Achoetandrus, Microcalliphora and Ceylonomyia were not resolved in the MP tree, but the BA and ML trees supported a sister group relationship between Achoetandrus and Microcalliphora + Ch. norrisi James + Ceylonomyia. BA and ML trees also supported a sister group relationship between Ceylonomyia and Microcalliphora + Ch. norrisi. Both the BA and ML trees (Fig. 2.3) support Ch. pacifica Kurahashi and Ch. megacephala, as sister species, as proposed earlier (Kurahashi, 1982; Kurahashi, 1991), but the MP tree showed a slightly different topology (Fig. 2.2).

The close relationship between Ch. putoria (Weidemann) and Ch. marginalis (Weidemann) was in agreement with Ullerich \& Schottke (2006), who based their conclusions on karyotype patterns. We observed strong branch support for the species pairs: Ch. semimetallica - Ch. latifrons; Ch. varipes - Ch. flavifrons and Ch. rufifacies Ch. albiceps, close relationships that had been supported by previous authors. (Wells \& Sperling, 2001; Harvey et al., 2003; Wallman et al., 2005; Nelson et al., 2007; Wells \& Williams, 2007; Harvey et al., 2008).

\subsubsection{Evolution}

The most parsimonious explanation is that a tuberculate Chrysomya larva evolved independently in Ch. varipes and in the villeneuvi group (Fig. 2.2), as proposed by Lunt (2002). The apical positions of the monogenic Ch. rufifacies and Ch. albiceps (Fig. 2.2), with all other species for which the reproductive system is known being amphogenic, strongly indicate that monogeny is derived rather than the suggested ancestral state in Chrysomya (Puchalla, 1994; Ullerich \& Schottke, 2006). 


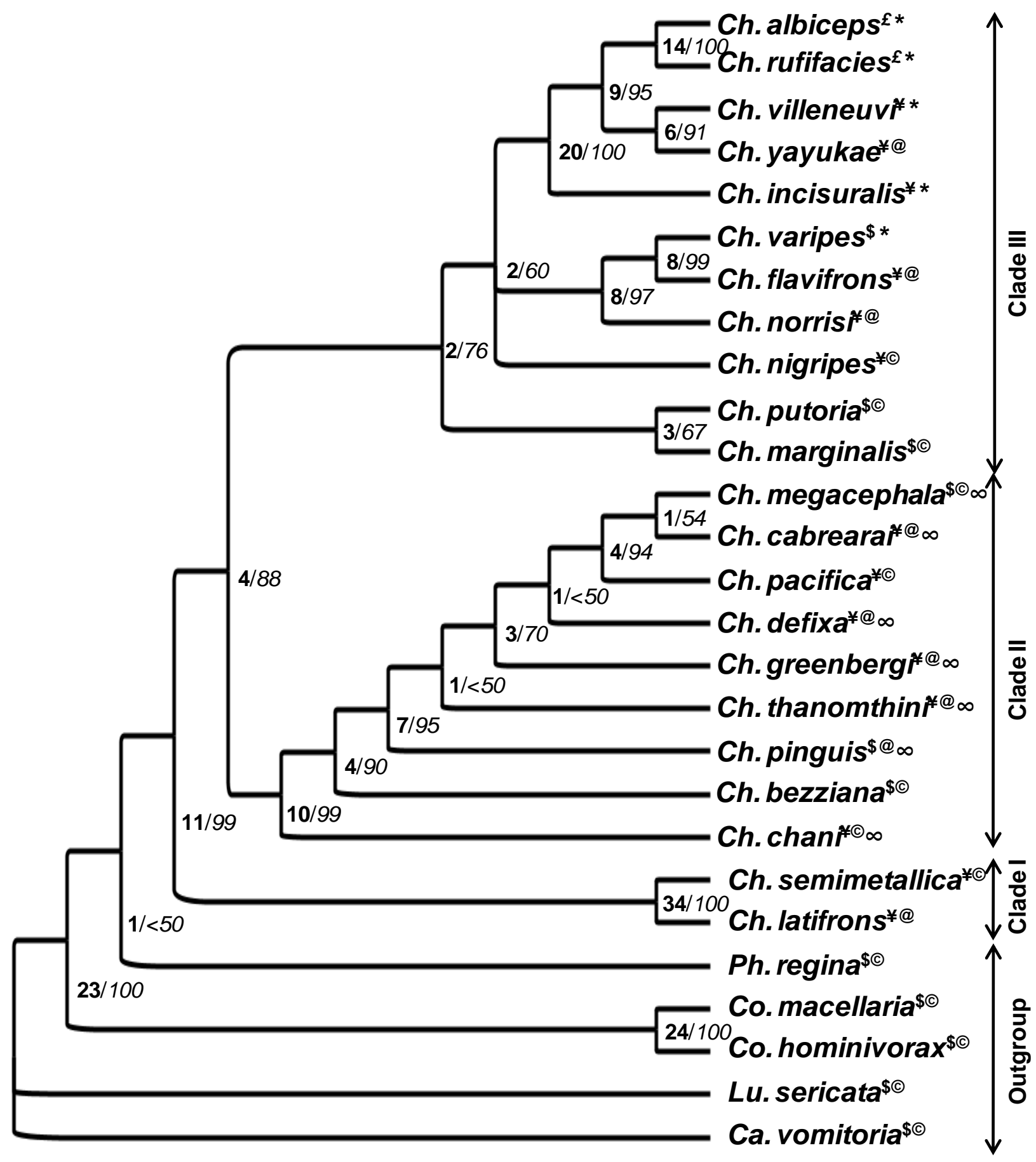

FIGURE 2.2: Strict consensus of the two most parsimonious trees of the Chrysomya based on 2386 bp of combined COI and CPS DNA sequences. A number in bold indicates Bremer support and number in italics indicates bootstrap supports for individual branches. $£=$ Monogenic spp.; $\$=$ Amphogenic spp.; $¥$ $=$ Species with unknown sex determination system; ${ }^{*}=$ Species that produces hairy maggots; $@$ @ = Species that produces smooth maggots; @ = Species with unknown larval structure; $\infty=$ Species showing derived male eye condition; Ch. = Chrysomya; Ph. = Phormia; Co. = Cochliomyia; Lu. = Lucilia; Ca. $=$ Calliphora. 


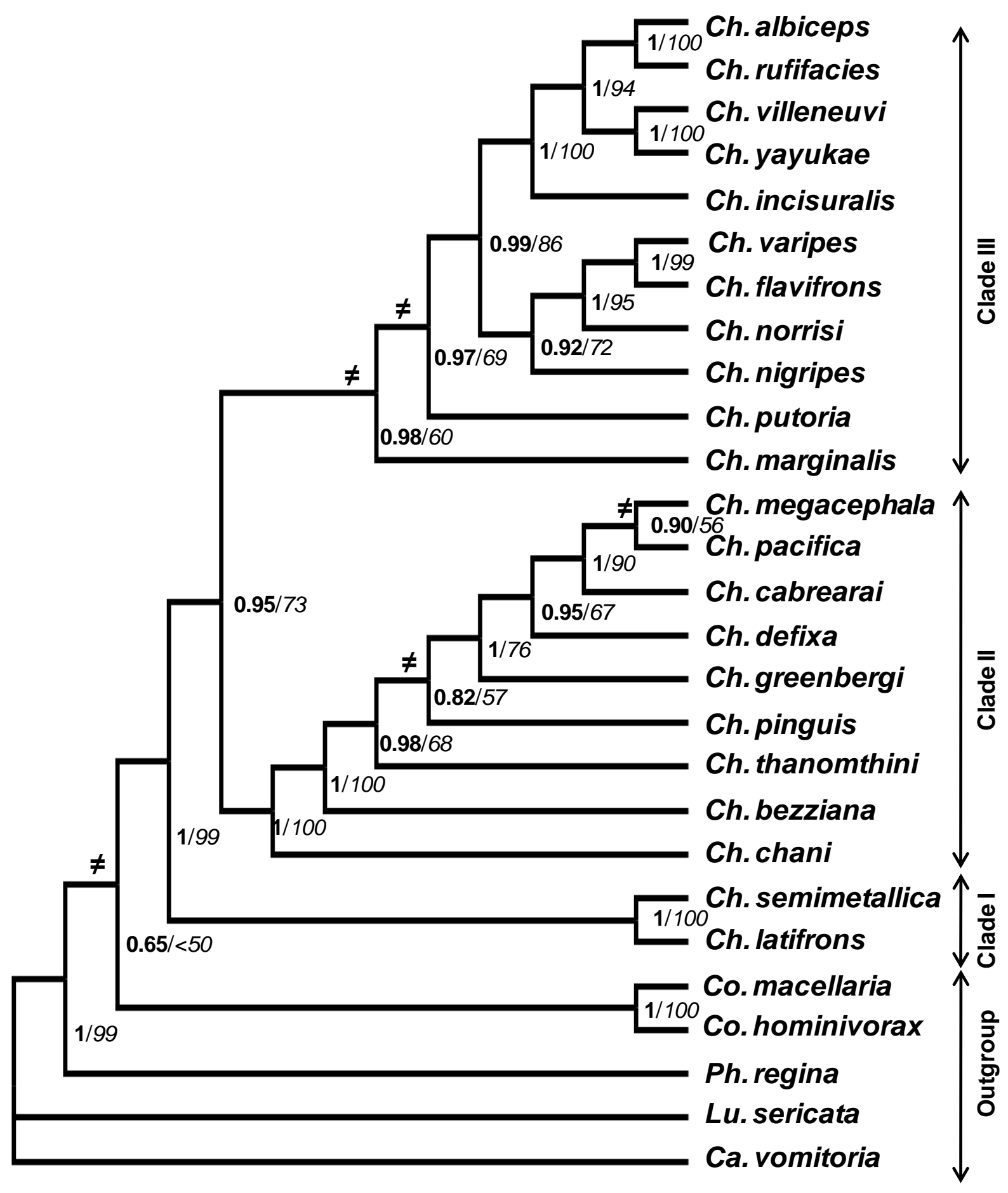

FIGURE 2.3: Maximum-likelihood tree of the Chrysomya based on $2386 \mathrm{bp}$ of combined COI and CPS DNA sequences. Number in bold indicates posterior probability value (in BA) and number in italics indicates bootstrap supports (in ML analysis) for individual branches. Nodes not shared with MP tree indicated by "f”. Ch. = Chrysomya; Co. = Cochliomyia; Ph. = Phormia; Lu. = Lucilia; Ca. = Calliphora . 
Our result contradicts the Kurahashi (1982) theory about the evolution of derived eye condition in Ch. megacephala. He proposed that the derived eye in $\mathrm{Ch}$. megacephala evolved in response to the development of anthropogenic landscapes and hence derived eye is apomorphic in Ch. Megacephala. In contrast, our result suggests derived eye as a plesiomorphic character state in megacephala group, and the loss of derived eye in Ch. pacifica may be because of its movement towards dense forest.

Similarly, the hypothesis of Ullerich \& Schottke (2006), that the average 2C DNA content in Chrysomya spp. increased over evolutionary time (see table 1 in Ullerich \& Schottke (2006) for DNA content values), appears to be incorrect. Species with lower DNA content (Ch. varipes 1.04 pg; Ch. rufifacies 1.14 pg; Ch. albiceps 1.44 pg; Ch. megacephala $1.70 \mathrm{pg}$ ), occupy apical positions, whereas species with higher DNA content (Ch. marginalis 1.63 pg; Ch. putoria 1.81pg; Ch. pinguis 2.31pg) are basal. Genome size has significant effects on phenotypic traits (Petrov, 2001). For example, Gregory \& Johnston (2008) observed a positive correlation between genome size and the developmental time for different species of Drosophila at a constant temperature. Because blow fly development rate is of forensic importance (Smith, 1986), the discovery of a similar pattern for Chrysomya might make it possible to estimate development rate with a simple measurement of genome size. Developmental data are available for many species of Chrysomya: Ch. marginalis (Lunt, 2002); Ch. putoria, Ch. chloropyga (Wiedemann) (Lunt, 2002; Richards et al., 2009); Ch. albiceps (Marchenko, 2001; Grassberger et al., 2003; Richards et al., 2008); Ch. rufifacies (O'Flynn, 1983; Byrd \& Butler, 1997); Ch. megacephala (O’Flynn, 1983; Wells \& Kurahashi, 1994; Jenson \& Miller, 2001; Richards \& Villet, 2009), Ch. bezziana (Spradbery, 1992), Ch. varipes (O'Flynn, 1983) and Ch. nigripes Aubertin (O'Flynn, 1983; Jenson \& Miller, 2001). Although, variation between published studies in experimental conditions make meaningful comparisons difficult, data available for the single temperature of $25^{\circ} \mathrm{C}: \mathrm{Ch}$. putoria $1.81 \mathrm{pg}, 11.28 \pm 0.23$ days from egg hatching to adult emergence; Ch. marginalis 1.63 pg, 12.1 days (Lunt, 2002; Ullerich \& Schottke,2006); Ch. albiceps 1.44 pg, 12.2 \pm 0.84 days (Grassberger et al., 2003; Richards et al., 2008; Ullerich \& Schottke, 2006); Ch. rufifacies: 1.14 pg, 11.54 days (Byrd \& Butler,1997; Ullerich \& Schottke, 
2006), doesn't suggest to us any obvious correlation between developmental time and genome size in Chrysomya. 


\section{CHAPTER 3: Molecular phylogeny of the Chrysomyinae (Diptera: Calliphoridae).}

Singh, B. \& Wells, J. D. (2011) Chrysomyinae (Diptera: Calliphoridae) is monophyletic: A molecular systematic analysis. Systematic Entomology, DOI: 10.1111/j. 13653113.2011.00568.x

\subsection{Introduction}

The Calliphoridae subfamily Chrysomyinae is split traditionally into two tribes: the Phormiini (Phormia Robineau-Desvoidy, Protophormia Townsend, Protocalliphora Hough, Trypocalliphora Peus, Phormiata Grunin) and the Chrysomyini (Chrysomya Robineau-Desvoidy; Chrysopyrellia Seguy; Cochliomyia Townsend; Compsomyiops Townsend; Hemilucilia Brauer; Paralucilia Brauer \& Bergenstamm and Chloroprocta Wulp) (Hall, 1948; Dear, 1985; Rognes, 1991). Phormiini are distributed in the temperate Holarctic zone, whereas Chrysomyini occur in tropical and subtropical regions. Except Chrysomya and Chrysopyrellia, all Chrysomyini are Neotropical. Most chrysomyines breed in carrion (Fuller, 1934; Norris, 1965), but Protocalliphora and Trypocalliphora larvae are obligate bloodsucking parasites of nestling birds, and Chrysomya bezziana Villeneuve and Cochliomyia hominivorax (Coquerel) larvae attack a variety of live mammals (Zumpt, 1951; Dear, 1985; Rognes, 1991). Consequently, many Chrysomyinae are of interest to medical/veterinary entomologists, forensic investigators and ecologists (Kamal, 1958; Norris, 1965; Wells \& Greenberg, 1992b;

Byrd \& Butler, 1997; O' Brien et al., 2001; Baudry et al., 2003; Ng et el., 2003; Gomez et al., 2003). Some Chrysomya have both unusual tuberculate larvae (Erzinclioglu, 1987; Sukontason et al., 2003) and a unique mechanism of sex-determination (Ullerich, 1958).

There are unresolved systematic issues concerning these flies. Morphologically, the monophyly of Chrysomyinae is well supported (Rognes, 1991). The authors of a recent large-scale molecular systematic analysis concluded otherwise, in finding Bengaliinae nested within Chrysomyinae (Kutty et al., 2010). However, the Kutty et al. (2010) analysis concerned broader questions of calyptrate fly systematics, and few Chrysomyinae were examined. Relationships between various genera of the subfamily remain unclear (Rognes, 1991). The commonly accepted tribal classification reflects the influential legacy of Hall (1948), who accepted Phormiini and Chrysomyini. However Hall was considering only the American fauna, and Dear (1985) noted that previously 
proposed diagnostic characters could not assign every chrysomyine species reliably to one of those two tribes, and that this could only be done using additional morphological characters and distribution data. In particular, Dear (1985) singled out Phormia regina (Meigen) as a "non-conformist phormiine". Furthermore, Rognes (1985) found that consideration of aedeagus morphology made it difficult to place Phormia with the other Phormiini. Rognes (1991) abandoned Hall's (1948) tribal classification, because characters that supposedly indicate monophyly of each tribe either were unreliable or plesiomorphic at the tribal level. A phylogeny based on mitochondrial DNA did not support monophyly of either tribe (Wells \& Sperling, 2001).
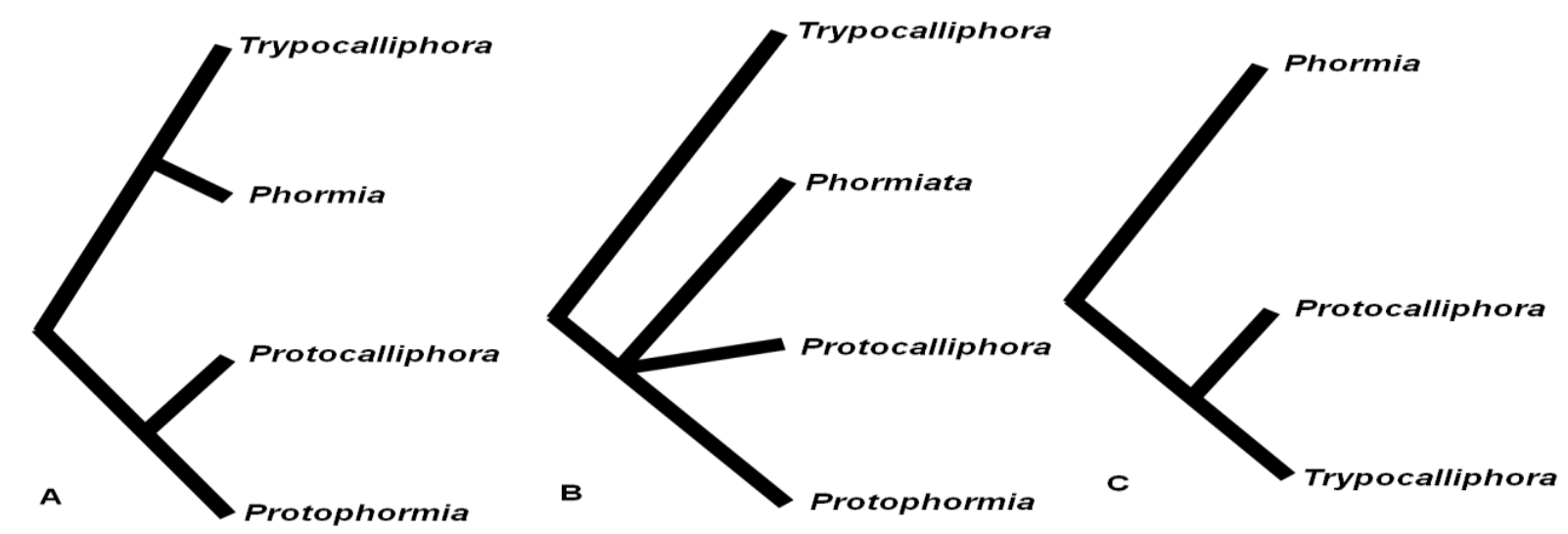

FIGURE 3.1: Published hypotheses of phylogenetic relationships between Phormiini genera based on morphological (A-B) and molecular (C) data. (A) modified from Peus, 1960, (B) modified from Rognes, 1985, and (C) modified from Whitworth et al., 2007.

Various hypotheses have been proposed concerning the taxonomy and relationships of the bird-parasitic chrysomyine genera (Fig. 3.1). Peus (1960) erected the monotypic genus Trypocalliphora for all blow fly larvae that cause subcutaneous myiasis in nestlings and divided Phormiini into: 1.) Phormia + Trypocalliphora and 2.) Protophormia (including Boreellus) + Protocalliphora (Fig. 3.1-A). Trypocalliphora was accepted as a valid genus because of its distinct aedeagal structure by Rognes (1985), and he suggested synapomorphies for the monophyly of group Trypocalliphora + 
(Protocalliphora + Protophormia (including Boreellus) + Phormiata) (Fig. 3.1-B). Several authors (Zumpt, 1965; Sabrosky, 1967; Sabrosky et al., 1989) included Trypocalliphora in Protocalliphora. However, in an examination of Trypocalliphora specimens used by Sabrosky et al. (1989), Whitworth (2003) did not find the reported prothoracic fringe, reportedly characteristic of Protocalliphora. Based on adult morphology, Rognes (1991) concluded that Trypocalliphora + Protocalliphora is monophyletic. However he did not advocate synonymizing the generic names given that the two are rather distinct in form and larval habit. Sabrosky et al. (1989) argued that differences in the larval habits of Protocalliphora and Trypocalliphora, although generally true, are not fixed. Feeding Trypocalliphora have been found in the nest material, and some Protocalliphora have been found embedded in host tissue. Molecular systematic analysis based on a limited number of genera found that Trypocalliphora + Protocalliphora was a monophyletic group (Fig. 3.1-C) and Trypocalliphora braueri (Hendel) did not fall within Protocalliphora (Whitworth et al., 2007).

Resolution of all of the above taxonomic issues would be aided by a robust phylogeny of the Chrysomyinae. In this dissertation we propose one based on the nuclear carbamoylphosphate synthetase (CPS) and mitochondrial cytochrome oxidase subunit one (COI) genes.

\subsection{Materials and Methods}

\subsubsection{Specimens and DNA extraction}

A total of 17 exemplar species belonging to 10 genera of Chrysomyinae were included in this study. We were unable to obtain the rare monotypic chrysomyine genera Chrysopyrellia and Phormiata. As outgroups, we included four species belonging to the calliphorid subfamilies Bengaliinae (Verticia orientalis Malloch), Toxotarsinae (Sarconesia versicolor Bigot), Luciliinae (Lucilia sericata (Meigen)) and Calliphorinae (Calliphora vomitoria (Linnaeus)). All specimens, except Protocalliphora occidentalis Whitworth and Protocalliphora sialia Shannon and Dobroscky, were identified morphologically by the collector (Table 3.1). Protocalliphora occidentalis and Protocalliphora sialia were identified by Dr. T. L. Whitworth (Whitworth Pest Solutions Inc., USA). 
TABLE 3.1: Specimen details, collection information and GenBank accession numbers.

\begin{tabular}{|c|c|c|c|c|c|c|c|}
\hline \multirow{2}{*}{$\begin{array}{l}\text { Sr. } \\
\text { \# }\end{array}$} & \multirow[t]{2}{*}{ Species name } & \multirow[t]{2}{*}{ Location } & \multirow[t]{2}{*}{ Date } & \multirow[t]{2}{*}{ Voucher \# } & \multirow[t]{2}{*}{ Collected by } & \multicolumn{2}{|c|}{ Accession number } \\
\hline & & & & & & CPS & $\mathrm{COI}$ \\
\hline 1 & $\begin{array}{l}\text { Chrysomya putoria } \\
\text { (Weidemann, 1830) }\end{array}$ & $\begin{array}{l}\text { Near Chilibre, } \\
\text { Panama }\end{array}$ & 03/IX/1995 & WVU2009-017-3 & J. Mendez & FJ169353 ${ }^{g}$ & FJ195384 $^{g}$ \\
\hline 2 & $\begin{array}{l}\text { Chrysomya } \\
\text { megacephala } \\
\text { Fabricius, } 1794\end{array}$ & Guam & $31 / I V / 2002$ & WVU2009-017-9 & P. Erwin & FJ169350 & AF092761 ${ }^{\circ}$ \\
\hline 3 & $\begin{array}{l}\text { Chrysomya rufifacies } \\
\text { (Macquart, 1843) }\end{array}$ & $\begin{array}{l}\text { Montgomery, AL, } \\
\text { USA }\end{array}$ & $05 / X / 2005$ & WVU2009-017-13 & J.D. Wells & FJ169341 ${ }^{g}$ & AF083658 ${ }^{9}$ \\
\hline 4 & $\begin{array}{l}\text { Chrysomya bezziana } \\
\text { Villeneuve, } 1914\end{array}$ & $\begin{array}{l}\text { Institute Haiwan, } \\
\text { Malaysia }\end{array}$ & $09 / \mathrm{XI} / 2001$ & WVU2009-017-17 & J. Stevens & FJ1693519 & AF295548 $^{9}$ \\
\hline 5 & $\begin{array}{l}\text { Cochliomyia } \\
\text { macellaria } \\
\text { (Fabricius,1775) }\end{array}$ & $\begin{array}{l}\text { Laboratory colony } \\
\text { originated from } \\
\text { Morgantown, WV, } \\
\text { USA }\end{array}$ & $14 / I X / 2006$ & WVU2009-017-19 & B. Singh & FJ169333 $^{g}$ & AF295555 \\
\hline 6 & $\begin{array}{l}\text { Cochliomyia } \\
\text { hominivorax } \\
\text { (Coquerel, 1858) }\end{array}$ & Brazil & $\mathrm{N} / \mathrm{A}$ & $\mathrm{N} / \mathrm{A}$ & T.T. Torres & FJ169334 & AF260826 ${ }^{9}$ \\
\hline 7 & $\begin{array}{l}\text { Compsomyiops } \\
\text { callipes Bigot, } 1877\end{array}$ & $\begin{array}{l}\text { CA, Contra Costa } \\
\text { CO Martinez. }\end{array}$ & $30 / \mathrm{VI} / 1999$ & WVU2009-017-22 & S. D. Wicks & HM639979 & AF295549 \\
\hline 8 & $\begin{array}{l}\text { Compsomyiops } \\
\text { fulvicrura Robineau- } \\
\text { Desvoidy, } 1830\end{array}$ & $\mathrm{~N} / \mathrm{A}$ & $\mathrm{N} / \mathrm{A}$ & RMBR\#102682 & $\mathrm{N} / \mathrm{A}$ & FJ025571 & $\mathrm{FJ}^{2} 25607^{9}$ \\
\hline 9 & $\begin{array}{l}\text { Chloroprocta idioidea } \\
\text { Robineau-Desvoidy, } \\
1830\end{array}$ & Brasilia, DF, Brazil & 17/VIII/2009 & WVU2009-017-23 & C. Kosmann & HM639980 & HM639976 \\
\hline 10 & $\begin{array}{l}\text { Hemilucilia } \\
\text { segmentaria } \\
\text { (Fabricius,1805) }\end{array}$ & Campinas, Brazil & 18/V/1998 & WVU2009-017-24 & $\begin{array}{l}\text { Lucilia } \\
\text { Carvalho }\end{array}$ & $\mathrm{N} / \mathrm{A}$ & HM639977 \\
\hline 11 & $\begin{array}{l}\text { Paralucilia paraensis } \\
\text { (Mello, 1969) }\end{array}$ & Manaus, AM, Brazil & $12 / X / 2008$ & WVU2009-017-25 & $\begin{array}{l}\text { Alex De } \\
\text { Souza }\end{array}$ & $\mathrm{N} / \mathrm{A}$ & HM639978 \\
\hline 12 & $\begin{array}{l}\text { Phormia regina } \\
\text { (Meigen, 1826) }\end{array}$ & $\begin{array}{l}\text { Laboratory colony } \\
\text { originated from } \\
\text { Pullman, WA, USA }\end{array}$ & $29 / \mathrm{V} / 2008$ & WVU2009-017-18 & C. J. Picard & FJ169331 ${ }^{g}$ & AF295550 ${ }^{\circ}$ \\
\hline
\end{tabular}




\begin{tabular}{|c|c|c|c|c|c|c|c|}
\hline 13 & $\begin{array}{l}\text { Protophormia } \\
\text { terraenovae } \\
\text { Robineau-Desvoidy, } \\
1830 \\
\end{array}$ & $\begin{array}{l}\text { Mandore Co. CA, } \\
\text { USA }\end{array}$ & $3 / \mathrm{VI} / 2002$ & WVU2009-017-26 & J.D. Wells & HM639981 & $\mathrm{AF}^{295553^{9}}$ \\
\hline 14 & $\begin{array}{l}\text { Protophormia atriceps } \\
\text { Zetterstedt, } 1845\end{array}$ & Sognefjell, Norway & $\mathrm{N} / \mathrm{A}$ & $\mathrm{N} / \mathrm{A}$ & $\mathrm{N} / \mathrm{A}$ & $\mathrm{N} / \mathrm{A}$ & $\begin{array}{l}\text { AF295560 } \\
\text { AF295561 }\end{array}$ \\
\hline 15 & $\begin{array}{l}\text { Trypocalliphora } \\
\text { braueri (Hendel, } \\
\text { 1901) }\end{array}$ & Wheeling, WV, USA & $\begin{array}{l}\text { Summer, } \\
2004\end{array}$ & WVU2009-017-27 & $\begin{array}{l}\text { T. L. } \\
\text { Whitworth }\end{array}$ & HM639982 & HM639974 \\
\hline 16 & $\begin{array}{l}\text { Protocalliphora sialia } \\
\text { Shannon and } \\
\text { Dobroscky, } 1924\end{array}$ & $\begin{array}{l}\text { Near Saskatoon, } \\
\text { SK, Canada }\end{array}$ & 10/VII/2004 & WVU2009-017-28 & $\begin{array}{l}\text { Marie-line } \\
\text { Gentes }\end{array}$ & HM639983 & AF295559 ${ }^{9}$ \\
\hline 17 & $\begin{array}{l}\text { Protocalliphora } \\
\text { occidentalis } \\
\text { Whitworth, } 2003\end{array}$ & $\begin{array}{l}\text { Near Prince George, } \\
\text { BC, Canada. }\end{array}$ & $\begin{array}{l}\text { Summer, } \\
2004\end{array}$ & WVU2009-017-29 & $\begin{array}{l}\text { Russ } \\
\text { Dawson }\end{array}$ & HM639984 & HM639975 \\
\hline 18 & $\begin{array}{l}\text { Verticia orientalis } \\
\text { Malloch, } 1927\end{array}$ & Selangor, Malaysia & $\begin{array}{l}20 / I I- \\
20 / I I I / 1997\end{array}$ & WVU2009-017-32 & B. Viklund & HQ248106 & HQ248105 \\
\hline 19 & $\begin{array}{l}\text { Lucilia sericata } \\
\text { (Meigen, 1826) }\end{array}$ & $\begin{array}{l}\text { Morgantown, WV, } \\
\text { USA }\end{array}$ & $13 / V / 2005$ & WVU2009-017-20 & J.D. Wells & FJ169332 & AJ417717 ${ }^{9}$ \\
\hline 20 & $\begin{array}{l}\text { Sarconesia versicolor } \\
\text { Bigot, } 1857\end{array}$ & $\mathrm{~N} / \mathrm{A}$ & $\mathrm{N} / \mathrm{A}$ & RMBR \# 103610 & $\mathrm{~N} / \mathrm{A}$ & GQ409291 ${ }^{g}$ & GQ4093199 \\
\hline 21 & $\begin{array}{l}\text { Calliphora vomitoria } \\
\text { (Linnaeus, 1758) }\end{array}$ & $\begin{array}{l}\text { Morgantown, WV, } \\
\text { USA }\end{array}$ & 14/VIII/2005 & WVU2009-017-21 & J. Hall & FJ169335 & GQ223336 ${ }^{g}$ \\
\hline
\end{tabular}


All specimens except Paralucilia paraensis (Mello) were preserved live in 95\% ethanol. Paralucilia paraensis was preserved in $70 \%$ ethanol. DNA was extracted from thoracic tissues (with the exception of $P$. paraensis, see below) using an organic extraction method as described in Singh et al. (2010). DNA extraction from Paralucilia paraensis was done from crushed head tissue using a Qiagen DNeasy blood and tissue Kit (Qiagen, Valencia, CA) as per the manufacturer's protocol. A NanoDrop ${ }^{\mathrm{TM}} 1000$ spectrophotometer (Thermo Scientific, Waltham, MA) was used for DNA quantification. Voucher specimens from each individual were deposited in West Virginia University's Entomological Collection (See Table 3.1 for voucher ID).

\subsubsection{PCR amplification}

PCR amplification was carried out for $850 \mathrm{bp}$ of the nuclear carbamoylphosphate synthetase (CPS) gene and 1435 bp of the mitochondrial cytochrome oxidase subunit one (COI) gene. CPS was amplified using primers listed in Singh et al. (2010) using the PCR program described in Moulton \& Wiegmann (2004). For COI gene amplification, we followed the protocols in Wells \& Sperling (1999). All primers were purchased from either Integrated DNA Technologies, Inc. (Coralville, IA) or Operon Biotechnologies, Inc. (Huntsville, AL). Other PCR reagents were purchased from Promega Corp. (Madison, WI). PCR reactions for both CPS and COI genes were prepared for $25 \mu \mathrm{l}$ final volume using PCR reagents following Singh et al. (2010). All PCR amplifications were carriedout in a GeneAmp® PCR System 9700 (Applied Biosystems, Foster City, CA).

\subsubsection{Sequencing}

The amplified products were cleaned by using ExOSAP-IT® (USB Corporation, Cleveland, Ohio) as per manufacturer's instructions. Direct sequencing was performed on the purified product with the same primers used for PCR and using a Big Dye ${ }^{\mathrm{TM}}$ Terminator v3.1 Cycle Sequencing Kit (Applied Biosystems, Foster City, CA). The sequencing protocol was as described in Singh et al. (2010). The sequencing product was separated on an Applied Biosystems 3130xl genetic analyzer (Foster City, CA). Sequence files were edited and aligned using Sequence Navigator (Applied Biosystems, Foster City, CA). COI gene sequence of Lucilia sericata (AJ417717; Stevens et al., 2002) and CPS gene sequence of Epalpus signifier (Walker) (AY280680; 
Moulton \& Wiegmann, 2004) were used as a reference sequences for alignment. All sequences were indel free and simple to align manually. New CPS and COI DNA sequences were submitted to the GenBank database (See Table 3.1 for accession numbers).

\subsubsection{Phylogenetic analyses}

A total of $2285 \mathrm{bp}$ of concatenated data from both genes was used for phylogenetic analysis by maximum parsimony (MP), maximum likelihood (ML) and Bayesian methods (BA). Different phylogenetic methods were used to test robustness of the tree obtained under each set of assumptions. MP analysis was performed for 1000 bootstrap replications using an equally weighted heuristic search and treebisection-reconnection (TBR) branch swapping options in PAUP 4.0b10 (Swofford, 2002). Bremer support (Bremer, 1994) was calculated as branch support for the most parsimonious tree using TreeRot.v3 (Sorenson \& Franzosa, 2007) and PAUP4.0b10 (Swofford, 2002). ML analysis was performed for 1000 bootstrap replications using the equally weighted heuristic search option in PAUP4.0b10 (Swofford, 2002). A general time reversible model with variable sites and discrete gamma distribution $(G T R+1+r)$ was selected as a best-fit model for $M L$ and $B A$ analysis. Best-fit model for $M L$ and $B A$ analysis was selected using the Akaike Information Criterion (AIC) in Modeltest 3.7 (Posada \& Crandall, 1998) and in MrModelTest 2.3 (Nylander, 2004) respectively. BA was performed for two concurrent sets of six independent chains (5 heated and one cold) for 1.5 million generations sampling every 100 generations using the default parameters in Mr. Bayes v.3.1.2 (Huelsenbeck \& Ronquist, 2001). After observing the likelihood plot, out of 15001 trees, 12000 trees were discarded as the burnin, and remaining trees (3001) were used for generation of the $50 \%$ majority rule consensus tree. Posterior probabilities were calculated as branch support from all trees that remained after setting burnin. All trees were edited using software MrEnt v.2.2 (Zuccon \& Zuccon, 2010).

\subsection{Results}

We were unable to amplify CPS for Paralucilia paraensis and Hemilucilia segmentaria (Fabricius). ML, BA and MP analyses resulted in almost identical trees, but some nodes in the MP tree were unresolved (Fig. 3.2). All analyses produced a 
monophyletic Chrysomyinae and a paraphyletic Chrysomyini. Interestingly, the Neotropical genera Chloroprocta + Hemilucilia + Paralucilia + Compsomyiops + Cochliomyia were strongly supported as a monophyletic group in all analyses, suggesting a single ancestral colonization of the New World tropics. Protocalliphora + Trypocalliphora + Phormia + Protophormia + Chrysomya was also monophyletic in all analyses. Monophyly of Phormiini was supported by BA/ML but this was not resolved by MP. Similarly, sister groups Chloroprocta + Hemilucilia and Cochliomyia + Compsomyiops were supported in BA and ML, but these were not resolved in MP. In all analyses Protocalliphora + Trypocalliphora was clearly a monophyletic group, and all genera for which we examined $>1$ species were monophyletic (Fig. 3.2).

\subsection{Discussion}

Given these results and Rognes' (1991) morphological analysis, we conclude that the evidence currently favours chrysomyine monophyly. This conflicts with Kutty et al. (2010), who found that Bengaliinae was the sister group of Chrysomyinae excluding Protocalliphora. Differences in experimental design between Kutty et al. (2010) and this study make it difficult to explain the different topology: they used more genes, including short sections of COI and CPS for many taxa, but only five chrysomyine species and, from the standpoint of Chrysomyinae, many more outgroups. However, concerning what was only a small portion of Kutty et al.'s phylogeny, we have confidence in our more complete taxon sample. Because we included only one species each from outgroup subfamilies Bengaliinae, Toxotarsinae, Calliphorinae, and Lucilinae, this was not a strong test of broader aspects of calliphorid systematics (Rognes, 1997), but our results do agree with Kutty et al. (2010) in that Toxotarsinae is more closely related to Calliphorinae than to Chrysomyinae, as was sometimes indicated by morphology (Pape, 1992; Rognes, 1997). A close relationship between Toxotarsinae and Calliphorinae was suggested also by Greenberg \& Szyska (1984) based on larval morphology and developmental rate.

The subfamily Chrysomyinae includes two major lineages that do not correspond to the traditional tribal classification. Instead chrysomyine evolutionary history reflects geographic distribution: Neotropical and Holarctic/Paleotropical (and perhaps originally Old World). 


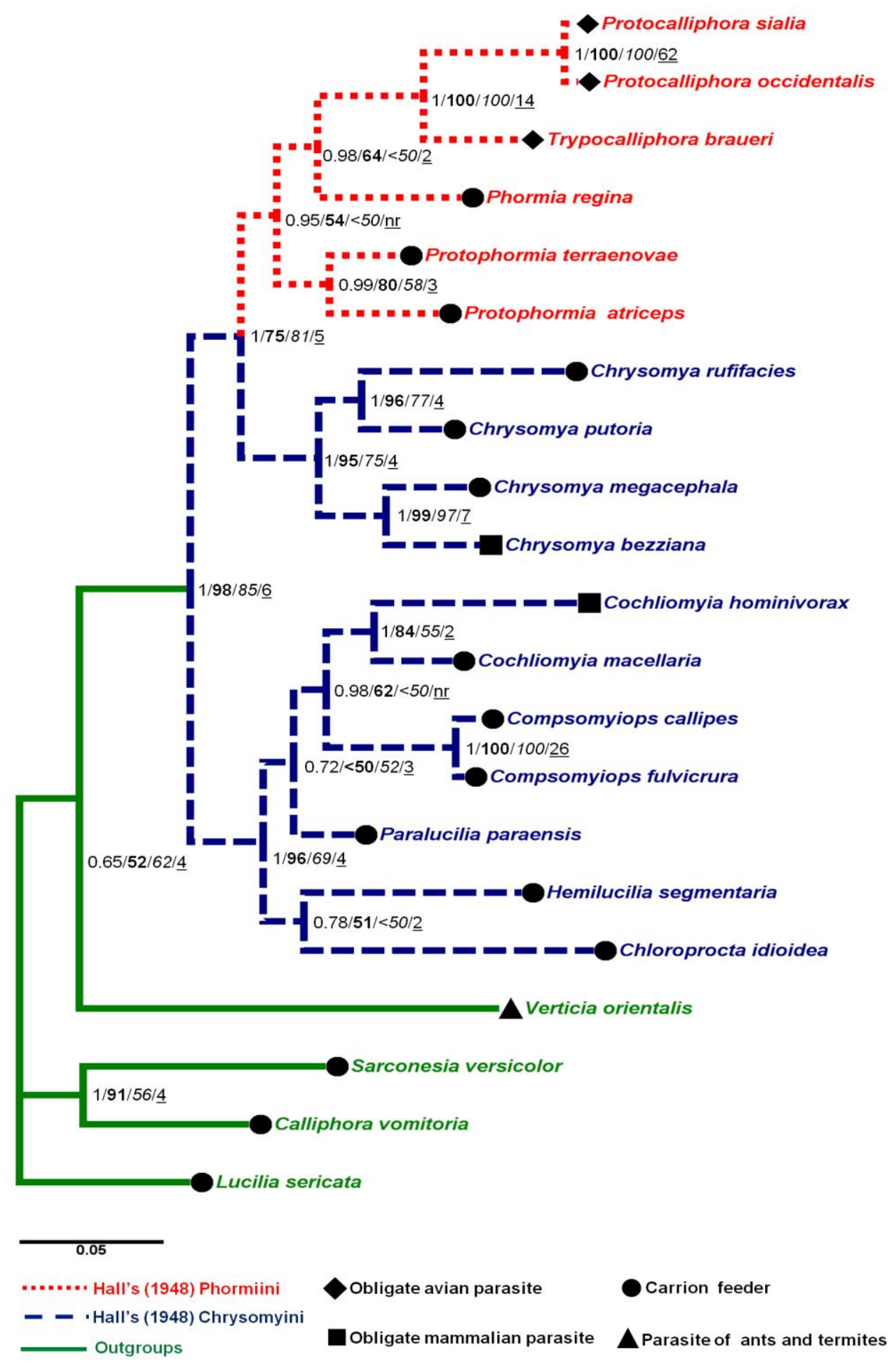

FIGURE 3.2: Bayesian phylogram of the Chrysomyinae based on $2285 \mathrm{bp}$ of combined COI and CPS DNA sequences. Branch support values: Standard font $=$ Bayesian posterior probability; Bold = maximum likelihood \% bootstrap; Italics = maximum parsimony \% bootstrap; Underlined = Bremer support in maximum parsimony; $\underline{\mathrm{nr}}=$ node not recovered by maximum parsimony. 
If our phylogenetic conclusions are correct, then a taxonomic subdivision of the Chrysomyinae would require tribal names for each of these two major lineages.

However, we believe that a better policy would be to drop the use of chrysomyine tribes altogether (see also Rognes 1991), because a revised system (Article 23, 24 \& 29.4, ICZN, 1999) would involve a new and confusing definition for at least one taxonomic name familiar to many non-systematists who are interested in these flies. Both Phormiini (Phorminae of Shannon, 1923; Sabrosky, 1999) and Chrysomyini (Shannon, 1923; Sabrosky, 1999) have equal priority for Protocalliphora + Trypocalliphora + Phormia + Protophormia + Chrysomya. Either Cochliomyiini (Lehrer, 1970) or Hemiluciliini (Lehrer, 1970) would designate the Neotropical lineage.

Although Phormia regina has been difficult to objectively group with other traditional Phormiini based on anatomy (Dear, 1985; Rognes 1985), the association was unambiguous in our analyses.

The most parsimonious explanation is that bird parasitism (in Protocalliphora and Trypocalliphora) evolved once within the Chrysomyinae. Whether these two bird blow fly lineages are distinct enough to be separate genera is unclear from the molecular data in that the branches are of similar length. Therefore, this would instead depend on judgement of the importance of differences between Protocalliphora and Trypocalliphora in morphology and larval habits (Rognes, 1991). 


\title{
CHAPTER 4: Molecular Phylogeny of the Oestridae (Diptera: Oestroidea).
}

\author{
Singh, B., Otranto, D. \& Wells, J. D. (In preparation) Is Oestridae (Diptera: Oestroidea) a \\ natural assemblage?
}

\subsection{Introduction}

Oestridae is a small ( $\approx 150$ species) but well known family of the Oestroidea. All oestrid larvae cause obligate myiasis of mammals including humans, with high level of host specificity (Catts, 1982; Wood, 1987a). Obligate myiasis by these flies results in huge economical loss to the livestock industry both in developed and developing countries (Otranto et al., 2003). These flies are mainly distributed in Africa and central Asia but have a limited distribution in North America (Catts, 1982; Wood, 1987a).

Most recent author, recognize four subfamilies (Cuterebrinae, Gasterophilinae, Hypodermatinae, and Oestrinae) within the Oestridae (Wood, 1987a; Pape, 1992; 2001; Otranto et al., 2003). Cuterebrinae larvae are mainly subcutaneous parasites of rodents and lagomorphs, whereas Gasterophilinae larvae are gut parasites of horses, zebras, rhinos and elephants. Like Cuterebrinae, Hypodermatinae larvae also penetrate the skin, but they lack the small plate-like spines on the integument, characteristic of the Cuterebrinae. Oestrinae larvae parasitize the host respiratory passages. Most species are oviparous with the exception of the members of the subfamily Oestrinae, which are larviparous (Catts, 1964; Anderson, 1975; Papavero, 1977; Anderson \& Nilssen, 1990). Larvae develop within the host for several weeks, and, upon reaching maturity, they leave the host to pupate in the soil (Otranto et al., 2003).

Although Oestridae is one of the most investigated families of Diptera, only a few studies were dedicated for the systematics of these flies (Zumpt, 1957; Papavero, 1977; Sabrosky, 1986; Pape, 1992; 2001; Otranto et al., 2003; Kutty, 2008; Kutty et al., 2010; Pollock, 2010). These studies raised many systematic questions, which are still unanswered.

The first and the most important question is whether Oestridae is monophyletic. It seemed that the morphological evidence for monophyly was overwhelming (Pape, 1992; Pape, 2001) but recent comparative anatomical study suggested that Glossinidae 
+ Hippoboscidae is nested withn Oestridae, and that this entire lineage belongs to the Acalyptratae (Pollock, 2010). However, molecular systematic analyses strongly support placement of Glossinidae, Hippoboscidae and Oestridae within Calyptratae (Nirmala et al., 2001; Peterson et al., 2007; Kutty, 2008; Kutty et al., 2010; Wiegmann et al., 2011) although they differ on monophyly of the Oestridae. Nirmala et al. (2001) observed Oestrinae + (Gasterophilinae + Hypodermatinae) more closely related to either Muscidae or Tachinidae than to Cuterebrinae, in combined 16S rRNA and 18S rRNA genes analysis. Kutty (2008) included only one oestrid, Cuterebra baeri Shannon\& Greene in a molecular systematic analysis of Calyptratae. Although it fell within Oestroidea, she excluded other members of the Oestridae from her analysis, because they showed affinity with members of the superfamily Hippoboscoidea and had leafstability value below the threshold set at 75 .

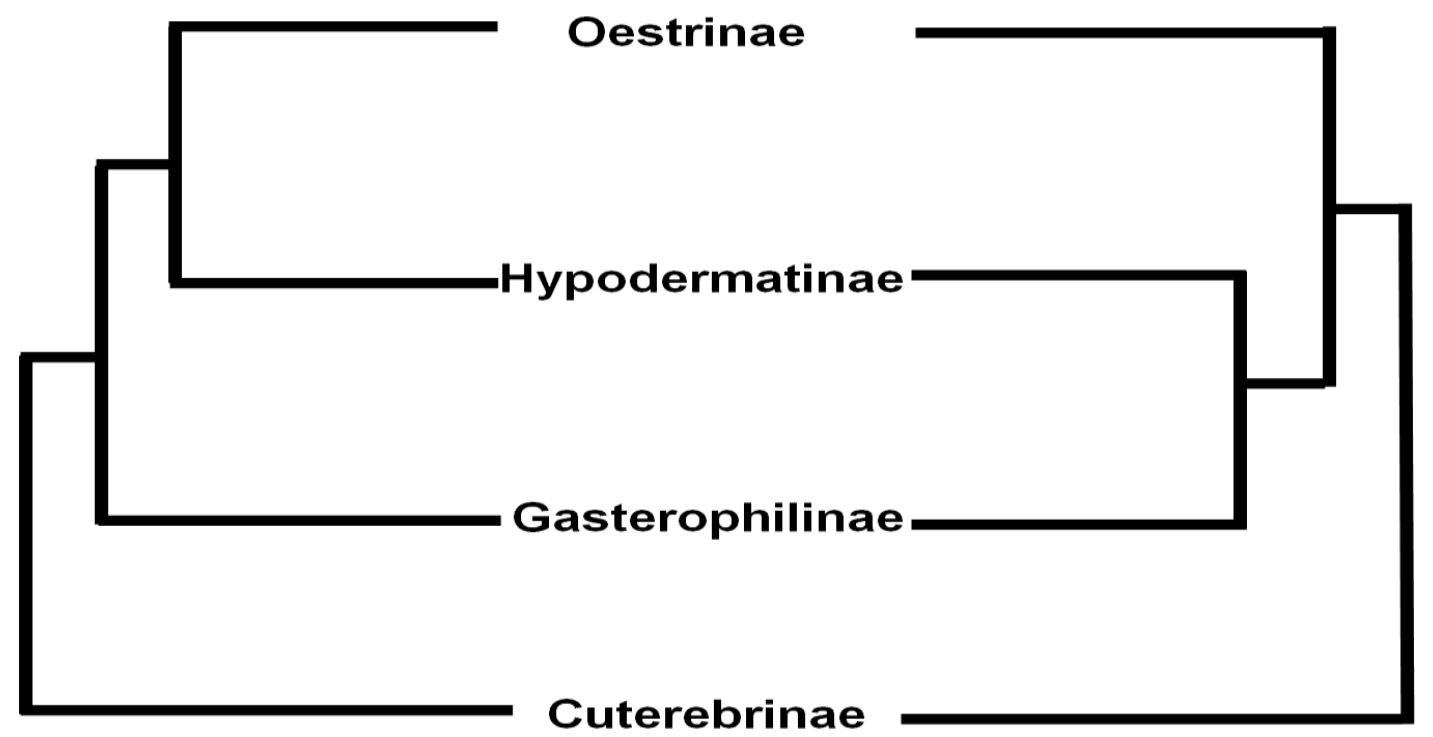

FIGURE 4.1: Published alternate hypotheses of phylogenetic relationship between different subfamilies of the Oestridae. Left: based on morphological data (modified from Pape, 2001) and, right: based on mitochondrial cytochrome oxidase subunit one gene (modified from Otranto et al., 2003).

Otranto et al. (2003) observed monophyletic Oestridae based on 688 bp of mitochondrial cytochrome oxidase subunit one (COI) gene but it was not a robust test for the monophyly of the Oestridae because all species that caused non-monophyly of the Oestridae in Nirmala et al. (2001) were not included as outgroups in their analysis. 
Even if one accepts oestrid monophyly, there are conflicting hypotheses of the subfamily relationships (Pape, 1992; 2001; Nirmala et al., 2001; Otranto et al., 2003). Morphological analysis suggests Hypodermatinae + Oestrinae as a sister group of Gasterophilinae (Pape, 1992; 2001), whereas molecular analysis suggests Hypodermatinae + Gasterophilinae as a sister group of Oestrinae (Nirmala et al., 2001; Otranto et al., 2003) (Fig. 4.1).

Resolution of all of the above taxonomic issues requires extensive molecular systematic analysis based on both mitochondrial and nuclear genes. Here we proposed one based on mitochondrial cytochrome oxidase subunit one $(C O I)$ and nuclear $28 \mathrm{~S}$ ribosomal RNA (28S $r R N A)$ and Elongation factor one alpha (EF1a) genes.

\subsection{Materials and Methods}

\subsubsection{Specimens and DNA extraction}

A total of 20 ingroup taxa and 8 outgroup taxa were included in this study. Extracted DNA from all ingroup taxa, except Cuterebra fontinella Clark, Cuterebra spp. and Hypoderma lineatum De Villers, were supplied by the second author. DNA was extracted from a teneral adult of the Cuterebra spp. using Qiagen DNeasy blood and tissue Kit (Qiagen, Valencia, CA) as per the manufacturer's protocol. Species of Glossinidae, Muscidae, Tachinidae, Rhinophoridae, Mystacinobiidae, Sarcophagidae and Calliphoridae were included as outgroups (See Table 4.1) (Nirmala et al., 2001; Pape, 2001; Kutty, 2008).

\subsubsection{PCR amplification}

PCR amplifications were carried out for $688 \mathrm{bp}$ of the mitochondrial cytochrome oxidase subunit one (COI) gene, 550 bp of elongation factor one alpha (EF1a) gene and for approximately 750 - 800 bp of D1-D2 region of the 28S rRNA gene. COI, Ef1 $\alpha$, and $28 S$ rRNA genes were amplified by using primers and protocol as described in Wells \& Sperling (1999), McDonagh (2009), and Stevens \& Wall (2001) respectively. EF1a genes of Hypoderma tarandi Brauer and Hypoderma bovis (Linnaeus) were amplified by using newly designed Hypoderma Latreille specific EF1a primers (hn19f : 5'- AAC TCG CCC AAC TGA CAA AC -3' and hn503r: 5'- CAG CGT CAC CAG ATT TCA AG3'). 
TABLE 4.1: List of species included in this study.

\begin{tabular}{|c|c|c|c|c|c|c|}
\hline \multirow{2}{*}{$\begin{array}{l}\text { Sr. } \\
\#\end{array}$} & \multirow[t]{2}{*}{ Species name } & \multirow[t]{2}{*}{ Family } & \multirow[t]{2}{*}{ Subfamily } & \multicolumn{3}{|c|}{ GenBank accession numbers } \\
\hline & & & & COI & 28S rRNA & EF1a \\
\hline \multicolumn{7}{|c|}{ Hippoboscoidea } \\
\hline 1 & Glossina morsitans Westwood, 1851 & Glossinidae & Glossininae & JF439541 ${ }^{a}$ & JF439566 ${ }^{a}$ & JF439518 ${ }^{a}$ \\
\hline \multicolumn{7}{|c|}{ Muscoidea } \\
\hline 2 & Musca domestica Linnaeus, 1758 & Muscidae & Muscinae & AF104622 ${ }^{a}$ & AJ551427 ${ }^{a}$ & DQ567113 ${ }^{\mathrm{a}}$ \\
\hline \multicolumn{7}{|c|}{ Oestroidea } \\
\hline 3 & Mystacinobia zelandica Holloway, 1976 & Mystacinobiidae & NA & JF439542 ${ }^{a}$ & JF439567 ${ }^{a}$ & NA \\
\hline 4 & Epalpus signifer (Walker,1849) & Tachinidae & Tachininae & JF439543 ${ }^{a}$ & $\mathrm{JF}^{2} 39566^{\mathrm{a}}$ & JF439519 ${ }^{a}$ \\
\hline 5 & Rhinophora lepida (Linnaeus, 1824) & Rhinophoridae & NA & JF439546 ${ }^{a}$ & JF439571 ${ }^{a}$ & JF439522 ${ }^{a}$ \\
\hline 6 & Sarcophaga crassipalpis Macquart, 1839 & Sarcophagidae & Sarcophaginae & JF439547 ${ }^{a}$ & JF439567 ${ }^{a}$ & JF439523 ${ }^{a}$ \\
\hline 7 & Calliphora vomitoria (Linnaeus, 1758) & Calliphoridae & Calliphorinae & $\mathrm{GQ223336}^{\mathrm{a}}$ & AJ300133 ${ }^{a}$ & JF439527 ${ }^{a}$ \\
\hline 8 & Chrysomya rufifacies (Macquart, 1843) & Calliphoridae & Chrysomyinae & AF083658 ${ }^{a}$ & AJ551436 ${ }^{a}$ & JF439532 ${ }^{a}$ \\
\hline 9 & Hypoderma bovis (Linnaeus, 1758) & Oestridae & Hypodermatinae & AF497761 ${ }^{a}$ & New & New \\
\hline 10 & Hypoderma lineatum (De Villers, 1789) & Oestridae & Hypodermatinae & $\mathrm{AF}^{2} 97762^{\mathrm{a}}$ & $\mathrm{JF}^{2} 18830^{\mathrm{a}}$ & $\mathrm{JF}^{2} 39526^{\mathrm{a}}$ \\
\hline 11 & Hypoderma tarandi (Linnaeus, 1758) & Oestridae & Hypodermatinae & AF497764 ${ }^{\mathrm{a}}$ & New & New \\
\hline 12 & Hypoderma actaeon Brauer, 1858 & Oestridae & Hypodermatinae & AF497765 ${ }^{a}$ & NA & NA \\
\hline 13 & Hypoderma diana Brauer, 1858 & Oestridae & Hypodermatinae & $\mathrm{AF} 497763^{\mathrm{a}}$ & NA & NA \\
\hline 14 & Przhevalskiana silenus Brauer, 1858 & Oestridae & Hypodermatinae & AF497766 ${ }^{a}$ & New & New \\
\hline 15 & Oestrus ovis (Linné 1761) & Oestridae & Oestrinae & $\mathrm{AF} 497767^{\mathrm{a}}$ & AJ551428 ${ }^{a}$ & New \\
\hline 16 & $\begin{array}{l}\text { Rhinoestrus phacochoeri Rodhain \& } \\
\text { Bequaert, } 1915\end{array}$ & Oestridae & Oestrinae & AF497772 ${ }^{a}$ & New & New \\
\hline 17 & Rhinoestrus usbekistanicus (Gan, 1947) & Oestridae & Oestrinae & AF497771 ${ }^{a}$ & NA & NA \\
\hline 18 & Cephenemyia trompe (Modeer, 1786) & Oestridae & Oestrinae & $\mathrm{AF}^{2} 47769^{\mathrm{a}}$ & New & New \\
\hline 19 & Cephenemyia stimulator (Clark, 1815) & Oestridae & Oestrinae & AF497768 ${ }^{a}$ & New & NA \\
\hline 20 & Cephenemyia ulrichii Brauer, 1862 & Oestridae & Oestrinae & AF497770 ${ }^{a}$ & New & NA \\
\hline 21 & Gasterophilus intestinalis (de Geer, 1776) & Oestridae & Gasterophilinae & $\mathrm{AF} 497773^{\mathrm{a}}$ & AJ551429 ${ }^{a}$ & NA \\
\hline 22 & Gasterophilus pecorum (Fabricius, 1794 ) & Oestridae & Gasterophilinae & AF497776 ${ }^{a}$ & New & New \\
\hline 23 & $\begin{array}{l}\text { Gasterophilus haemorrhoidalis (Linnaeus, } \\
1758 \text { ) }\end{array}$ & Oestridae & Gasterophilinae & AF497774 ${ }^{a}$ & NA & NA \\
\hline 24 & Gasterophilus nasalis (Linnaeus, 1758) & Oestridae & Gasterophilinae & AF497775 ${ }^{\mathrm{a}}$ & NA & NA \\
\hline
\end{tabular}




\begin{tabular}{|c|c|c|c|c|c|c|}
\hline 25 & Cuterebra fontinella Clark, 1827 & Oestridae & Cuterebrinae & JF439549 ${ }^{a}$ & JF439574 ${ }^{\mathrm{a}}$ & $\mathrm{JF} 439525^{\mathrm{a}}$ \\
\hline 26 & Cuterebra baeri Shannon\& Greene, 1926 & Oestridae & Cuterebrinae & AF497777 ${ }^{a}$ & New & $\mathrm{GQ409458}^{\mathrm{a}}$ \\
\hline 27 & Cuterebra jellisoni Curran, 1942 & Oestridae & Cuterebrinae & AF497778 ${ }^{a}$ & NA & NA \\
\hline 28 & Cuterebra spp. & Oestridae & Cuterebrinae & New & New & New \\
\hline
\end{tabular}

a = DNA sequences downloaded from GenBank.

$N A=$ Not available. 
These primers were designed from $E F 1 \alpha$ sequence of $H$. lineatum using default options in the program Primer3 (Steve \& Helen, 2000). All primers were purchased from either Integrated DNA Technologies, Inc. (Coralville, IA) or Operon Biotechnologies, Inc. (Huntsville, AL). PCR amplifications were carried out in 25 ul total volume containing 12.5 ul of 2X Promega Master Mix (Catalogue \# M7505, Promega Corp., Madison, WI), $2 \mathrm{ul}$ (10 pmol) of each primer (Integrated DNA Technologies, Inc. Coralville, IA), 1-3 ul $(\approx 10-30 \mathrm{ng}$ ) of template DNA and remaining water. PCR amplifications were also performed in smaller total volume $(10 \mu \mathrm{l}-15 \mu \mathrm{l})$ for some precious taxa with less concentrated template DNA. All other reaction components were in the same proportions. GeneAmp® PCR System 9700 (Applied Biosystems, Foster City, CA) was used for all PCR amplifications.

\subsubsection{Sequencing and sequence alignments}

The amplified products were cleaned by using ExOSAP-IT® (USB Corporation, Cleveland, Ohio) as per manufacturer's instructions. Direct sequencing was performed on the purified product with the same primers used for PCR and using a Big Dye ${ }^{\mathrm{TM}}$ Terminator v3.1 Cycle Sequencing Kit (Applied Biosystems, Foster City, CA). The sequencing protocol was as described in Singh et al. (2010). The sequencing product was separated on an Applied Biosystems 3130xl genetic analyzer (Foster City, CA). Sequence files were edited in Sequence Navigator (Applied Biosystems, Foster City, $\mathrm{CA}$ ). COI and EF1a genes were aligned manually in Sequence Navigator (Applied Biosystems, Foster City, CA) using COI gene sequence of Lucilia sericata (Meigen) (AJ417717; Stevens et al., 2002) and EF1a gene sequence of Chrysomya rufifacies (Macquart) (JF439532; unpublished) respectively. All COI and EF1a gene sequences were easy to align and indel free. Alignment of all 28S rRNA gene sequences was carried out using the program Muscle (Edgar, 2004) as implemented in MEGA 5 (Tamura et al., in press) using default parameters. After multiple sequence alignment, ambiguous hypervariable regions of $28 S$ rRNA gene were excluded from the alignment and only $716 \mathrm{bp}$ of $28 \mathrm{~S}$ rRNA gene was used for further phylogenetic analysis. All newly generated DNA sequences are indicated as a new in Table 4.1. 


\subsubsection{Phylogenetic analyses}

Phylogenetic analyses were carried out using maximum parsimony (MP), maximum likelihood (ML) and Bayesian methods (BA). Different phylogenetic methods were used to test robustness of the tree obtained under each set of assumptions. MP analysis was performed for 1000 bootstrap replications using an equally weighted heuristic search and tree-bisection-reconnection (TBR) branch swapping options in PAUP 4.0b10 (Swofford, 2002). ML analysis was performed for 100 (COI gene) and 1000 (Ef1 $\alpha$ and $28 S$ rRNA genes) bootstrap replications using the equally weighted heuristic search option in PAUP4.0b10 (Swofford, 2002). Best-fit models (SYM+G for EF1 $1 \alpha, G T R+I+G$ for $C O I$ and TVM+l+G for 28S rRNA gene) for ML analysis were selected using Akaike Information Criterion (AIC) in Modeltest 3.7 (Posada \& Crandall, 1998). Similarly, best-fit models (SYM+G for $E F 1 \alpha, G T R+I+G$ for $C O I$ and $28 S$ rRNA genes) for BA were selected using AIC in MrModeltest 2.3 (Nylander, 2004). BA was performed for two concurrent sets of six independent chains ( 5 heated and one cold) for 1.5 million generations ( $E F 1 \alpha \& 28 S$ rRNA genes) and for 3 million generation ( $C O I$ gene), sampling every 100 generations using the default parameters in Mr. Bayes v.3.1.2 (Huelsenbeck \& Ronquist, 2001). After observing the likelihood plot, $80 \%$ of the trees were discarded as the burnin, and the remaining $20 \%$ of the trees from each run were used for generation of the $50 \%$ majority rule consensus tree. Posterior probabilities were calculated as branch support from all trees that remained after setting burnin. All trees were edited using software MrEnt v.2.2 (Zuccon \& Zuccon, 2010). Although nodes with Bayesian posterior probability (PP) $\geq 0.65$ are shown on the trees (Figs. 4.2- 4.4), only nodes having PP $\geq 0.95$ were deemed significant (Huelsenbeck \& Ronquist, 2001). Phylogenetic analyses of concatenated data were not performed, because for many species nuclear genes-overlap was low (Table 4.1).

\subsection{Results}

These analyses failed to resolve the question of Oestridae monophyly

(Figs. 4.2, 4.3, 4.4). In general there was strong support for the monophyly of the subfamilies, although this was less clear for Oestrinae on the 28S rRNA tree (Figs. 4.3, 4.4), and only one gasterophiline EF1a sequence was included. 


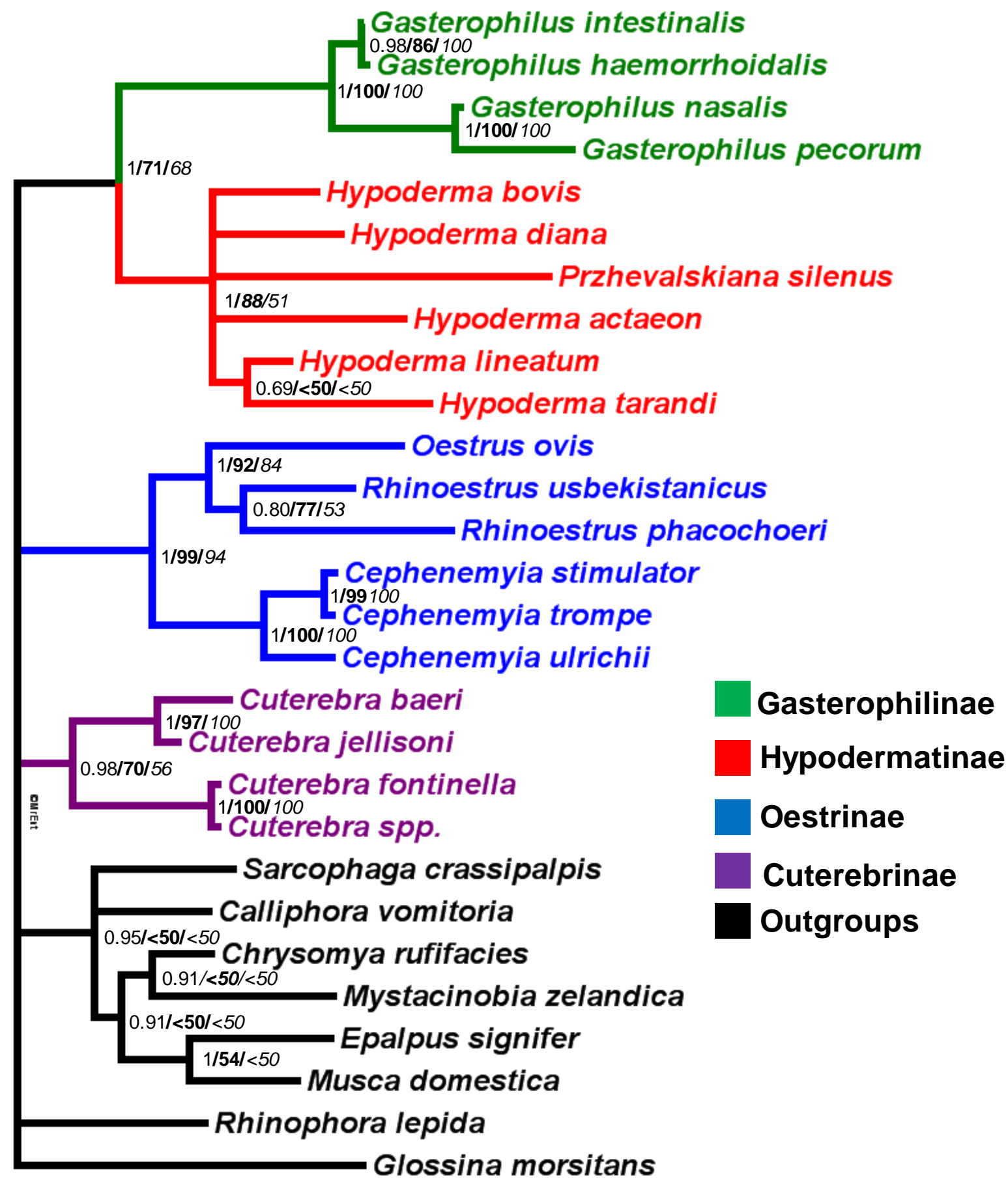

0.10

Figure 4.2: Bayesian phylogram of the Oestridae based on 688 bp of COI DNA sequences. Branch support values: Standard font = Bayesian posterior probabilities; Bold = maximum likelihood \% bootstrap; Italics= maximum parsimony \% bootstrap. 


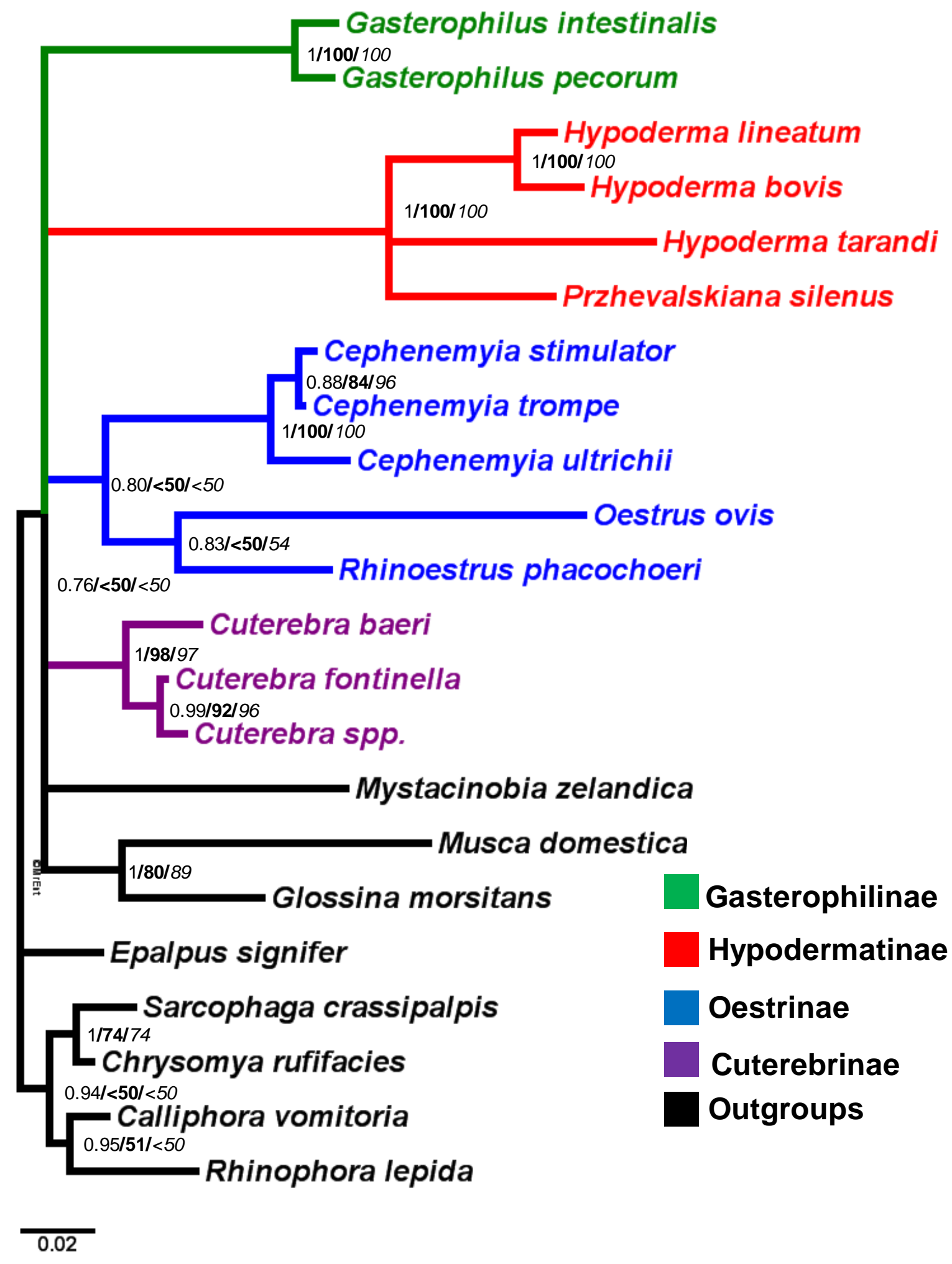

Figure 4.3: Bayesian phylogram of the Oestridae based on 716 bp of $28 S$ rRNA gene sequences. Branch support values: Standard font $=$ Bayesian posterior probabilities; Bold = maximum likelihood \% bootstrap; Italics $=$ maximum parsimony $\%$ bootstrap. 


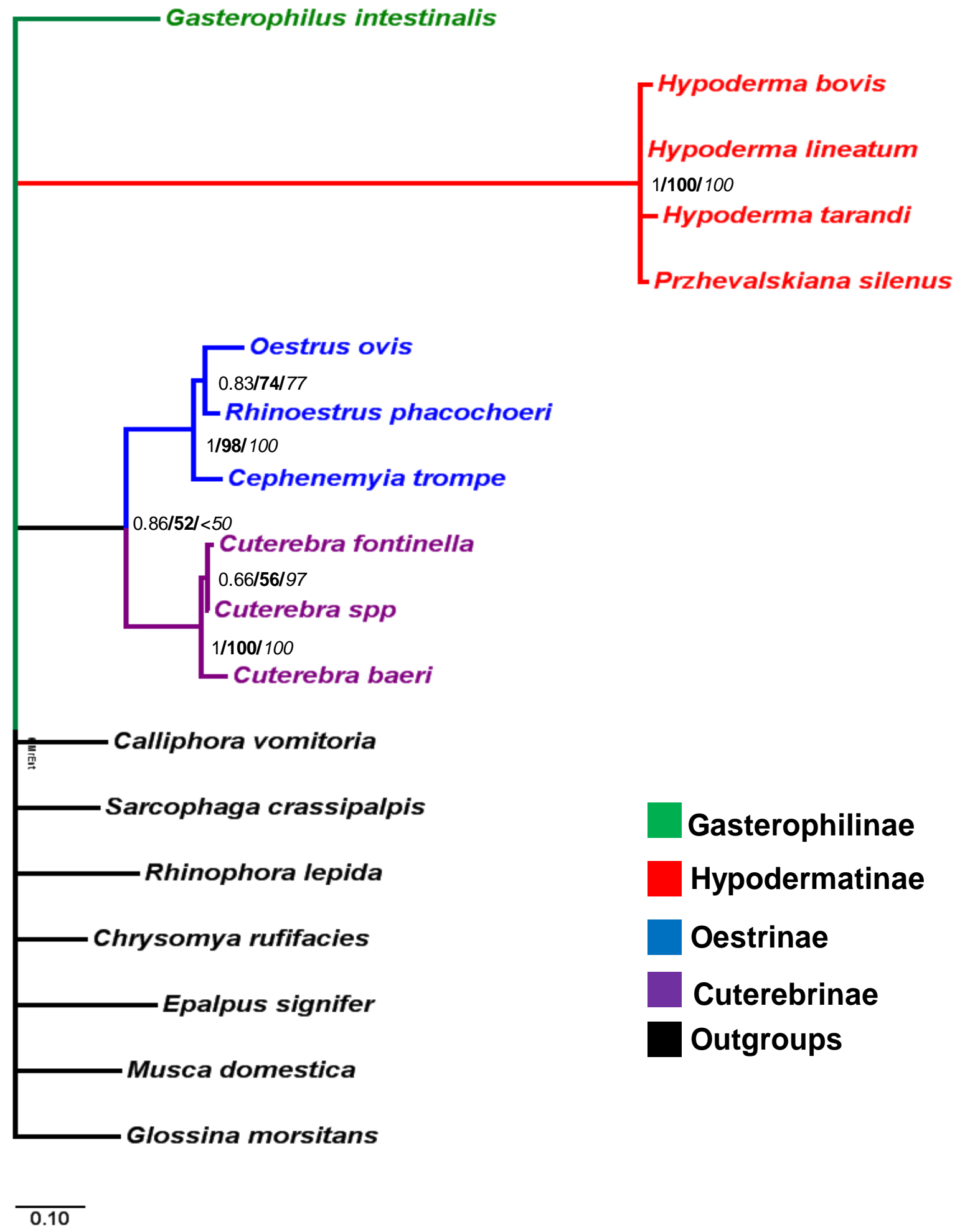

Figure 4.4: Bayesian phylogram of the Oestridae based on 550 bp of EF1a gene sequences. Branch support values: Standard font $=$ Bayesian posterior probabilities; Bold = maximum likelihood \% bootstrap; Italics= maximum parsimony \% bootstrap. 
As reported by Otranto et al. (2003), the COI gene supported a Gasterophilinae + Hypodermatinae lineage, but there was no other resolution of subfamilily relationships (Fig. 4.2). All genera for which we had more than one species were monophyletic with the exception of Hypoderma. Monophyly of Oestrus Linnaeus + Rhinoestrus Brauer was well-supported by $\mathrm{COI}$ (Fig. 4.2) but support was weak in nuclear gene analyses (Figs. $4.3,4.4)$.

\subsection{Discussion}

There are several potential reasons why we didn't find good resolution at deeper nodes. First, it may be because of lack of sufficient phylogenetic signal, as these groups have diverged in a very short span of time (Wiegmann et al., 2011). Second, because these lineages evolved at a much higher rate, they may have accumulated many homoplasious characters, which in turn is affecting resolution at deeper nodes (Hypsa, 2006). Third, because of high sequence heterogeneity among taxa, many PCR reactions failed and hence available data may not be sufficient for resolution at deeper nodes (Otranto et al., 2003). Molecular systematic analysis with much larger data sets from different mitochondrial and nuclear genes may resolve deeper nodes of oestrid phylogeny, but it will be better strategy to explore alternate methods other than primary sequences such as mobile elements, micro-RNA, gene rearrangements etc. The wellsupported sister group relationship between Glossinidae and Muscidae in $28 S$ rRNA gene analysis (Fig. 4.3) undermines hypotheses of a close relationship between Oestridae and Glossinidae (Kutty, 2008; Pollock, 2010). The unusually long-branch observed for Hypodermatinae in Ef1a gene analysis, suggests to us that Hypodermatinae is most probably the fastest evolving lineage of the Oestridae. 


\section{CHAPTER 5: Molecular Phylogeny of the Calliphoridae (Diptera: Oestroidea).}

Singh, B., Pape, T. \& Wells, J. D. (In preparation) Rhiniidae is a subfamily of Calliphoridae (Diptera: Oestroidea): Evidence from one mitochondrial and three nuclear genes.

\subsection{Introduction}

The Calliphoridae (blow flies) are a diverse group of flies of forensic, medical and veterinary importance. Approximately 1450 species of Calliphoridae (including 400 species of Rhiniinae) are known from all continents except Antarctica (Verves, 2005, Kutty et al., 2010). Adult calliphorids are known to frequent flowers, feces, carrion and wounds for nutrition. They also serve as vectors of disease, where they transport bacteria, viruses, protozoans and helminths (Greenberg, 1971). Most blow flies are oviparous but some are unilarviparous (Helicoboscinae, Mesembrinellinae, Ameniinae and Phumosiinae) or multilarviparous (e.g. Onesia Robineau-Desvoidy, Bellardia Robineau-Desvoidy, Eggisops Rondani etc.). The majority of blow fly larvae are carrion breeders and hence play an important role both as an indicator species in forensic entomology and as prominent decomposers (Schumann, 1965; Smith, 1986). Some blow fly larvae cause obligate myiasis to vertebrates (e.g. Chrysomya bezziana Villeneuve, Cochliomyia hominivorax (Coquerel), Protocalliphora Hough, Trypocalliphora Peus, Auchmeromyia Brauer \& Bergenstamm) whereas a few other are endoparasitic on invertebrates (e.g. Pollenia Robineau-Desvoidy, Onesia etc.) (Rognes, 1998; Stevens, 2003).

A variety of calliphorid subfamilies have been recognized (Lehrer, 1970; Hennig, 1973; Pont, 1980; Kurahashi, 1989), but most recent authors use Ameniinae, Auchmeromyiinae, Bengaliinae, Phumosiinae, Mesembrinellinae, Helicoboscinae, Toxotarsinae, Calliphorinae, Lucilinae, Melanomyinae, Polleniinae, Rhiniinae, Chrysomyinae, Aphyssurinae, and Prosthetosomatinae (Pape, 1992; Rognes, 1991; 1997; Norris, 1999; Kutty et al., 2010). The monophyly of each subfamily is well supported based on morphological characters, but the placement of Mesembrinellinae, Rhiniinae, Toxotarsinae, Bengaliinae, Helicoboscinae, Calliphorinae and Polleniinae are uncertain (Pape, 1992; Rognes, 1991; 1997; Kutty et al., 2010). Recent molecular 
systematic analysis suggested non-monophyly of Calliphorinae (Kutty et al., 2010; Singh \& Wells, 2011).

Most importantly, the monophyly of Calliphoridae itself has long been in serious doubt (Griffith, 1982; McAlpine, 1989; Pape, 1992; Rognes, 1997; Kutty et al., 2010). Because calliphorids are essentially the oestroid species that could not be assigned to another family, the phylogenetic status of the Calliphoridae is the central systematics problem for the entire superfamily (McAlpine, 1989; Rognes, 1997). Oestroidea includes the Mystacinobiidae (New Zealand bat flies), Axiniidae (axe flies), Rhinophoridae (woodlouse flies), Tachinidae (tachinid flies), Sarcophagidae (flesh flies), Oestridae (bot flies), and Calliphoridae (blow flies) (Rognes, 1997). Recent molecular systematic analysis suggested that the unclassified McAlpine's fly is a member of the Oestroidea (Kutty et al., 2010). Morphological analysis supports the monophyly of the noncalliphorid oestroid families (Pape, 1992; Rognes, 1997). Monophyly of Calliphoridae is uncertain as some taxonomists believe that Calliphoridae is a monophyletic assemblage (Fig. 5.1) (Lehrer, 1970; McAlpine, 1989; Pape, 1992; Stevens, 2003), while others believe otherwise in absence of satisfactory autapomorphic characters for the whole group (Griffiths, 1982; Rognes, 1997; Pape \& Arnaud, 2001; Kutty et al., 2010).

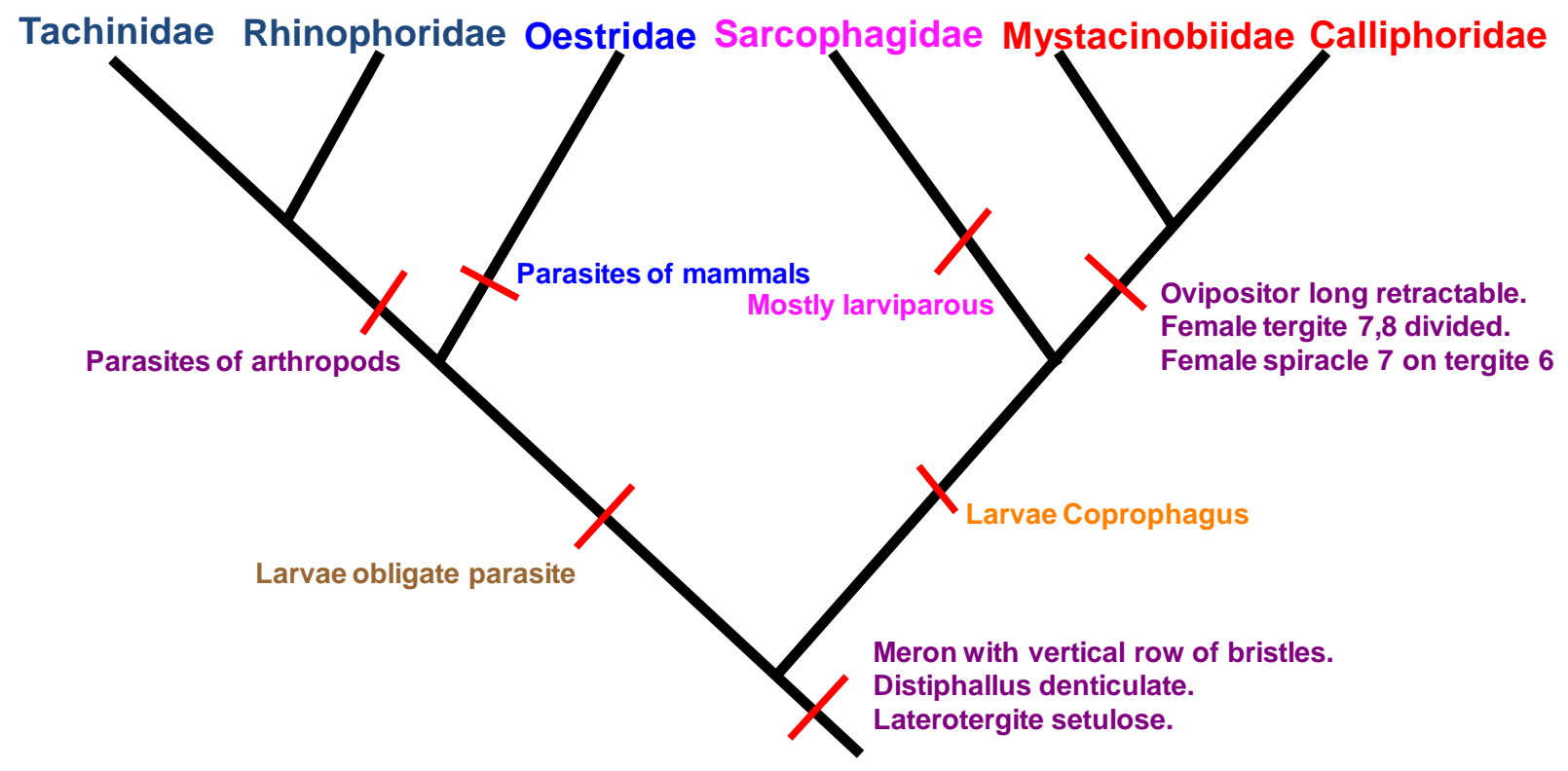

FIGURE 5.1: Phylogenetic tree, showing relationships between different families of the Oestroidea (From McAlpine, 1989). 


\section{Oestroid taxa of uncertain phylogenetic position:}

\section{Rhiniinae}

Rhiniinae have been placed within a monophyletic Calliphoridae (Pape, 1992) or as a sister group to Sarcophagidae + Tachinidae (Rognes, 1997). The latter hypothesis inspired recent authors to raise its rank from subfamily to family (Evenhuis et al., 2008). Recent molecular systematic analysis also supported a family level upgrade of Rhiniinae as a sister group of Calliphoridae + Tachinidae + Oestridae + Rhinophoridae (Kutty et al., 2010).

\section{The more obscure calliphorid subfamilies}

Toxotarsinae was grouped with Chrysomyinae based on morphology (Pape, 1992; Rognes, 1997), and with Calliphorinae + Melanomyinae based on DNA sequences (Kutty et al., 2010; Singh \& Wells, 2011). Similarly, the phylogenetic positions of Bengaliinae, Helicoboscinae, Calliphorinae, Polleniinae, and Mesembrinellinae differ in the two most extensive morphological analyses of the Oestroidea (Fig. 5.2) (Pape, 1992; Rognes, 1997). In recent molecular systematic analysis Bengaliinae was nested within Chrysomyinae, Helicoboscinae was sister group of Rhinophoridae, Calliphorinae (including Melanomyinae) was sister group of Toxotarsinae, and the systematic position of Polleniinae and Mesembrinellinae were unstable (Kutty et al., 2010).

\section{Rhinophoridae}

Some authors consider Rhinophoridae a subfamily of the Calliphoridae (Herting, 1957; Bedding, 1973; Kutty et al., 2008) while others consider it a separate family (Brues et al., 1954; Rohdendorf, 1967; Hennig, 1973; Crosskey, 1977; Tschorsnig, 1985; Pape, 1986, 1992; McAlpine, 1989; Rognes, 1997; Kutty et al., 2010). As a subfamily, it generates nomenclatural difficulty because the name predates Calliphoridae, which might then have to be changed to Rhinophoridae as per International Code of Zoological Nomenclature (ICZN) guidelines. Even as a separate family, its relationship with other oestroid families remains unclear. Rohdendorf (1967) 
favored monophyly of Rhinophoridae + Sarcophagidae; Tschorsnig (1985) favored monophyly of Rhinophoridae + Calliphoridae; McAlpine (1989) favored monophyly of

Rhinophoridae + Tachinidae; Pape (1992) considered it a sister group of Calliphoridae + Oestridae; Rognes (1997) thought it was either a sister group of Calliphoridae + Oestridae or of all other Oestroidea except Mystacinobia and Axiniidae, and Pape \& Arnaud (2001) placed Rhinophoridae (including Axiniidae) as a sister group of Rhiniinae.

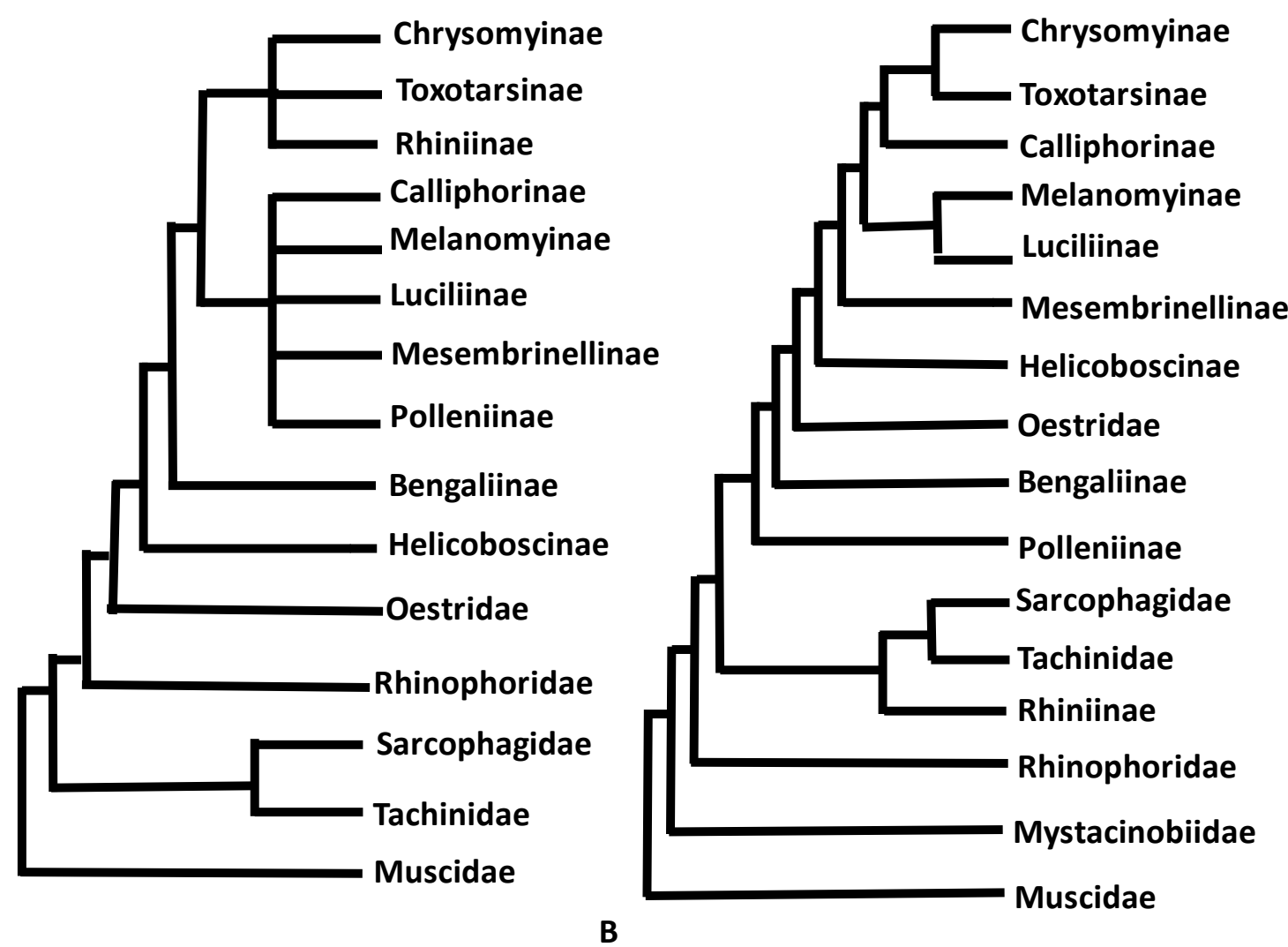

FIGURE 5.2: Published hypotheses of phylogenetic relationship between different groups of oestroid flies based on morphological data. (A) modified from Pape (1992; fig. 8); (B) modified from Rognes (1997; fig. $3)$.

\section{Mystacinobia Holloway}

These flies are so specialized that a particularly wide range of systematic hypotheses have been proposed. Maa (1971) placed them in the superfamily Hippoboscoidea based on superficial resemblance to bat ectoparasites. Holloway 
(1976) placed Mystacinobia in superfamily Ephydroidea (as Drosophiloidea) based on various head, thorax and leg features. As these body parts are highly modified in Mystacinobia for phoresy, Griffiths (1982) didn't consider these characteristics reliable and proposed its inclusion within Oestroidea based on various abdominal characters.

Although, inclusion of Mystacinobia within Oestroidea is now well-supported both by morphology and DNA based cladistic analyses (Rognes, 1997; Kutty et al., 2010), its relationship with other oestroid taxa is still uncertain. Griffiths (1982) placed Mystacinobia in the Calliphoridae based on the structure and number of spermathecal ducts, as did Gleeson et al. (2000) in a limited study using a 511 bp 165 ribosomal RNA gene. Kurahashi (1989) placed it without explanation in a separate subfamily Mystacinobiinae within Calliphoridae. The large number of autapomorphies in almost all life stages led recent authors to accept a separate family Mystacinobiidae (McAlpine, 1989; Rognes, 1997). Extensive morphological cladistic analysis supports Mystacinobia as the most basal oestroid (Rognes, 1997), whereas extensive molecular systematics analysis support it a sister-group of Sarcophagidae (Kutty et al., 2010).

\section{McAlpine's fly}

McAlpine's fly is an unusual and undescribed calyptrate fly that was named after its collector Dr. D. K. McAlpine (Ferrar, 1979). Adult females are unilarviparous and feed on dung (Ferrar, 1979). Ferrar (1979) placed it in superfamily Muscoidea based on its affinity with family Anthomyiidae but he also observed that its male genitalia was very similar to calliphorids. Recent molecular systematic analysis favored its inclusion within Oestroidea, as a sister group of Mystacinobia (Kutty et al., 2010).

The purpose of this study is to generate a robust phylogeny of the Calliphoridae including all of the problematic taxa mentioned above.

\subsection{Materials and Methods}

\subsubsection{Specimens and DNA extraction}

A total of 51 representative species from all six families of the Oestroidea were included in this study. We followed Pape's (1992) suggestion for selection of outgroups, using five representative species from three calyptrate (Glossinidae, Faniidae, and Muscidae) and one acalyptrate (Drosophilidae) families (Table 5.1). DNA was extracted 
from thoracic tissues (except Oestrus ovis Linnaeus, Hypoderma lineatum De Villers, and Mystacinobia zelandica Holloway) (see below) of $95 \%$ ethanol preserved specimens by organic extraction method as described in Singh et al. (2010). For O. ovis and $H$. lineatum, DNA was extracted from internal tissues of third and second larval instars respectively. DNA from $M$. zelandica was extracted from leg tissue. For some specimens, DNA extraction was also carried out by using a Qiagen DNeasy blood and tissue Kit (Qiagen, Valencia, CA) as per the manufacturer's protocol. Extracted DNA was quantified using NanoDrop ${ }^{\mathrm{TM}} 1000$ spectrophotometer (Thermo Scientific, Waltham, MA). Voucher specimens from each individual along with collection details were deposited in West Virginia University's Entomological Collection (See Table 5.1 for voucher ID).

\subsubsection{DNA amplification}

A total of 64 new sequences were generated from one mitochondrial (Cytochrome oxidase subunit one (CO I) ) and three nuclear (carbamoy/phosphate synthetase (CPS), Elongation factor one alpha (EF1a), and 28S ribosomal RNA (28S rRNA)) genes (See Table 5.1 for accession numbers with *). $1435 \mathrm{bp}$ of the COI gene was amplified using primers and protocol as mentioned in Wells \& Sperling (1999). 850 bp of CPS gene was amplified using the primers and PCR protocol of Moulton \& Wiegmann (2004) and Singh et al. (2010). Additional CPS gene primers were designed with the help of primer 3 software (Steve \& Helen, 2000) for those taxa that didn't amplify using published CPS gene primers (Table 5.2). 1240 bp of EF1a gene were amplified using primers and PCR protocol as described in McDonagh (2009). Approximately $2200 \mathrm{bp}$ of $28 \mathrm{~S} r R N A$ gene were amplified using primers and protocol as mentioned in Stevens \& Wall (2001). All primers were purchased from either Integrated DNA Technologies, Inc. (Coralville, IA) or Operon Biotechnologies, Inc. (Huntsville, AL). Other PCR reagents were purchased from Promega Corp. (Madison, WI). 
TABLE 5.1: List of taxa and GenBank accession numbers.

\begin{tabular}{|c|c|c|c|c|c|c|c|}
\hline \multirow{2}{*}{$\begin{array}{l}\text { Sr. } \\
\#\end{array}$} & \multirow{2}{*}{ Species name } & \multirow{2}{*}{ Subfamily } & \multirow{2}{*}{$\begin{array}{l}\text { Voucher } \\
\text { number }\end{array}$} & \multicolumn{4}{|c|}{ GenBank accession numbers } \\
\hline & & & & COI & CPS & $28 S$ & Ef1a \\
\hline \multicolumn{8}{|c|}{ Ephidroidea: Drosophilidae } \\
\hline 1 & \begin{tabular}{|l} 
Drosophila melanogaster Meigen, \\
1830
\end{tabular} & Drosophilinae & $\mathrm{N} / \mathrm{A}$ & NC_001709 & NM206765 & EF531127 & NM165850 \\
\hline \multicolumn{8}{|c|}{ Hippoboscoidea: Glossinidae } \\
\hline 2 & Glossina morsitans Westwood, 1851 & Glossininae & WVU2011-018-1 & JF439541* & EF531178 & JF439566* & JF439518* \\
\hline \multicolumn{8}{|c|}{ Muscoidea: Fanniidae } \\
\hline 3 & Fannia canicularis (Linnaeus, 1761) & Fanniinae & RMBR\#102705 & DQ657037 & EF531184 & DQ656961 & $\mathrm{N} / \mathrm{A}$ \\
\hline \multicolumn{8}{|c|}{ Muscoidea: Muscidae } \\
\hline 4 & Musca domestica Linnaeus, 1758 & Muscinae & & AY526196 & AY280689 & AJ551427 & DQ657113 \\
\hline 5 & $\begin{array}{l}\text { Hydrotaea cyrtoneurina (Zetterstedt, } \\
1845 \text { ) }\end{array}$ & Azeliinae & RMBR\# 102715 & FJ025622 & FJ025578 & FJ025526 & FJ025678 \\
\hline \multicolumn{8}{|c|}{ Oestroidea: Mystacinobiidae } \\
\hline 6 & \begin{tabular}{|l} 
Mystacinobia zelandica Holloway, \\
1976
\end{tabular} & $\mathrm{~N} / \mathrm{A}$ & WVU2011-018-2 & JF439542* & $N / A$ & $\mathrm{JF} 439567^{*}$ & $\mathrm{~N} / \mathrm{A}$ \\
\hline \multicolumn{8}{|c|}{ Oestroidea: Tachinidae } \\
\hline 7 & Epalpus signifer (Walker,1849) & Tachininae & WVU2011-018-3 & JF439543* & AY280680 & JF439568* & JF439519* \\
\hline 8 & Gymnocheta viridis (Fallén, 1810) & Tachininae & RMBR\#103759 & GQ409327 & GQ409296 & GQ409240 & GQ409463 \\
\hline 9 & Cyrtophleba nitida Curran, 1930 & Dexiinae & WVU2011-018-4 & JF439544* & JF439554* & JF439569* & JF439520* \\
\hline 10 & Nemorilla floralis (Fallén, 1810) & Exoristinae & WVU2011-018-5 & JF439545* & JF439555* & JF439570* & JF439521* \\
\hline 11 & Gymnosoma nitens Meigen, 1824 & Phasiinae & RMBR\#103754 & GQ409326 & GQ409295 & GQ409239 & GQ409462 \\
\hline 12 & Phania funesta (Meigen, 1824) & Phasiinae & RMBR\#103756 & GQ409349 & GQ409306 & GQ409260 & GQ409477 \\
\hline \multicolumn{8}{|c|}{ Oestroidea: Rhinophoridae } \\
\hline 13 & Rhinophora lepida (Linnaeus, 1824) & & WVU2011-018-6 & JF439546* & JF439556* & JF439571* & JF439522* \\
\hline 14 & Stevenia hertingi Kugler, 1978 & & RMBR\#103671 & GQ409374 & GQ409311 & GQ409282 & GQ409493 \\
\hline 15 & $\begin{array}{l}\text { Stevenia atramentaria (Meigen, } \\
\text { 1824) }\end{array}$ & & RMBR\#103670 & GQ409373 & $\mathrm{N} / \mathrm{A}$ & GQ409281 & GQ409492 \\
\hline \multicolumn{8}{|c|}{ Oestroidea: Sarcophagidae } \\
\hline 16 & $\begin{array}{l}\text { Sarcophaga crassipalpis Macquart, } \\
1839\end{array}$ & Sarcophaginae & WVU2011-018-7 & JF439547* & JF439557* & JF439572* & JF439523* \\
\hline
\end{tabular}




\begin{tabular}{|c|c|c|c|c|c|c|c|}
\hline 17 & Notochaeta sp. Aldrich, 1916 & Sarcophaginae & RMBR\#103715 & GQ409339 & GQ409301 & GQ409252 & GQ409473 \\
\hline 18 & Metopia campestris (Fallén, 1810) & Miltogramminae & WVU2011-018-8 & JF439548* & JF439558* & JF439573* & JF439524* \\
\hline 19 & $\begin{array}{l}\text { Sarcophila meridionalis Verves, } \\
1982\end{array}$ & $\begin{array}{l}\text { Paramacronychii } \\
\text { nae }\end{array}$ & RMBR\#103689 & GQ409368 & $\mathrm{N} / \mathrm{A}$ & GQ409277 & GQ409489 \\
\hline \multicolumn{8}{|c|}{ Oestroidea: Oestridae } \\
\hline 20 & Cuterebra fontinella Clark, 1827 & Cuterebrinae & WVU2011-018-9 & JF439549* & JF439559* & JF439574* & JF439525* \\
\hline 21 & $\begin{array}{l}\text { Cuterebra baeri Shannon \& Greene, } \\
1926\end{array}$ & Cuterebrinae & RMBR\#103661 & GQ409320 & GQ409294 & $\mathrm{N} / \mathrm{A}$ & GQ409458 \\
\hline 22 & $\begin{array}{l}\text { Hypoderma lineatum De Villers, } \\
1789\end{array}$ & Hypodermatinae & $\begin{array}{l}\text { WVU2011-018- } \\
10\end{array}$ & AF295558 & JF439560* & JF718830* & JF439526* \\
\hline 23 & Oestrus ovis Linnaeus, 1758 & Oestrinae & $\begin{array}{l}\text { WVU2011-018- } \\
11\end{array}$ & AF497767 & $\mathrm{N} / \mathrm{A}$ & AJ551428 & JF439540* \\
\hline \multicolumn{8}{|c|}{ Oestroidea: Calliphoridae } \\
\hline 24 & $\begin{array}{l}\text { Cynomya cadaverina Robineau- } \\
\text { Desvoidy, } 1830\end{array}$ & Calliphorinae & $\begin{array}{l}\text { WVU2011-018- } \\
12\end{array}$ & AF259505 & JF439561* & AJ300135 & FR719230 \\
\hline 25 & $\begin{array}{l}\text { Calliphora vomitoria (Linnaeus, } \\
\text { 1758) }\end{array}$ & Calliphorinae & $\begin{array}{l}\text { WVU2009-017- } \\
21\end{array}$ & GQ223336 & FJ169335 & AJ300133 & JF439527* \\
\hline 26 & Onesia tibialis Macquart, 1846 & Calliphorinae & $\mathrm{N} / \mathrm{A}$ & AY842605 & $\mathrm{N} / \mathrm{A}$ & FR719319 & FR719263 \\
\hline 27 & $\begin{array}{l}\text { Bellardia vulgaris (Robineau- } \\
\text { Desvoidy, 1830) }\end{array}$ & Calliphorinae & RMBR\#103605 & GQ409316 & GQ409290 & GQ409231 & GQ409452 \\
\hline 28 & Lucilia sericata (Meigen, 1826) & Luciliinae & $\begin{array}{l}\text { WVU2009-017- } \\
20\end{array}$ & AJ417717 & FJ169332 & AJ300140 & JF439528* \\
\hline 29 & $\begin{array}{l}\text { Hypopygiopsis infumata (Bigot, } \\
\text { 1877) }\end{array}$ & Luciliinae & $\begin{array}{l}\text { WVU2011-018- } \\
13\end{array}$ & JF439550* & JF439562* & JF439575* & JF439529* \\
\hline 30 & $\begin{array}{l}\text { Hemipyrellia fernandica (Macquart, } \\
\text { 1855) }\end{array}$ & Luciliinae & $\mathrm{N} / \mathrm{A}$ & FR719160 & $\mathrm{N} / \mathrm{A}$ & FR719291 & FR719235 \\
\hline 31 & $\begin{array}{l}\text { Dyscritomyia robusta (Grimshaw, } \\
\text { 1901) }\end{array}$ & Luciliinae & $\mathrm{N} / \mathrm{A}$ & AY074899 & $\mathrm{N} / \mathrm{A}$ & FR719289 & FR719233 \\
\hline 32 & Phormia regina (Meigen, 1826) & Chrysomyinae & $\begin{array}{l}\text { WVU2009-017- } \\
18\end{array}$ & AF295550 & FJ169331 & JF713458* & JF439530* \\
\hline 33 & $\begin{array}{l}\text { Protophormia terraenovae } \\
\text { Robineau-Desvoidy, } 1830\end{array}$ & Chrysomyinae & $\begin{array}{l}\text { WVU2009-017- } \\
26\end{array}$ & AF295553 & HM639981 & AJ300142 & JF439531* \\
\hline 34 & $\begin{array}{l}\text { Chrysomya rufifacies (Macquart, } \\
1843 \text { ) }\end{array}$ & Chrysomyinae & $\begin{array}{l}\text { WVU2009-017- } \\
13\end{array}$ & AF083658 & FJ169341 & AJ551436 & JF439532* \\
\hline 35 & $\begin{array}{l}\text { Chrysomya megacephala Fabricius, } \\
1794\end{array}$ & Chrysomyinae & WVU2009-017-9 & AF092761 & FJ169350 & JF439576* & JF439533* \\
\hline 36 & $\begin{array}{l}\text { Cochliomyia macellaria } \\
\text { (Fabricius, } 1775)\end{array}$ & Chrysomyinae & $\begin{array}{l}\text { WVU2009-017- } \\
19\end{array}$ & AF295555 & FJ169333 & AJ551438 & JF439534* \\
\hline
\end{tabular}




\begin{tabular}{|c|c|c|c|c|c|c|c|}
\hline 37 & $\begin{array}{l}\text { Cochliomyia hominivorax } \\
\text { (Coquerel, 1858) }\end{array}$ & Chrysomyinae & $\mathrm{N} / \mathrm{A}$ & AF260826 & FJ169334 & AJ551437 & FM867797 \\
\hline 38 & $\begin{array}{l}\text { Compsomyiops fulvicrura } \\
\text { Robineau-Desvoidy, } 1830\end{array}$ & Chrysomyinae & RMBR\#102680 & FJ025607 & FJ025571 & FJ025504 & FJ025667 \\
\hline 39 & $\begin{array}{l}\text { Protocalliphora sialia Shannon \& } \\
\text { Dobroscky, } 1924\end{array}$ & Chrysomyinae & $\begin{array}{l}\text { WVU2009-017- } \\
28\end{array}$ & AF295559 & HM639983 & AJ558190 & JF439535* \\
\hline 40 & $\begin{array}{l}\text { Pollenia sp. Robineau-Desvoidy, } \\
1830\end{array}$ & Polleniinae & $\begin{array}{l}\text { WVU2011-018- } \\
14\end{array}$ & JF439551* & JF439563* & AJ558192 & JF439536* \\
\hline 41 & Pollenia amentaria (Scopoli, 1763) & Polleniinae & RMBR\#103622 & GQ409350 & $\mathrm{N} / \mathrm{A}$ & GQ409262 & GQ409478 \\
\hline 42 & Verticia orientalis Malloch, 1927 & Bengaliinae & $\begin{array}{l}\text { WVU2009-017- } \\
32\end{array}$ & HQ248105 & HQ248106 & JF439577* & JF439537* \\
\hline 43 & Bengalia peuhi Villeneuve, 1914 & Bengaliinae & RMBR\#102672 & FJ025601 & FJ025566 & FJ025501 & N/A \\
\hline 44 & Bengalia depressa Walker, 1857 & Bengaliinae & $\mathrm{N} / \mathrm{A}$ & FR719154 & $\mathrm{N} / \mathrm{A}$ & FR719270 & FR719214 \\
\hline 45 & $\begin{array}{l}\text { Auchmeromyia luteola (Fabricius, } \\
\text { 1805) }\end{array}$ & Auchmeromyiinae & $\mathrm{N} / \mathrm{A}$ & FR719153 & $\mathrm{N} / \mathrm{A}$ & FR719269 & FR719213 \\
\hline 46 & $\begin{array}{l}\text { Cordylobia anthropophaga } \\
\text { (Blanchard \& Berenger-Feraud, } \\
\text { 1872) }\end{array}$ & Auchmeromyiinae & $\mathrm{N} / \mathrm{A}$ & FR719158 & $\mathrm{N} / \mathrm{A}$ & FR719285 & FR719229 \\
\hline 47 & $\begin{array}{l}\text { Melinda viridicyanea Robineau- } \\
\text { Desvoidy, } 1830\end{array}$ & Melanomyinae & RMBR\#103618 & GQ409335 & GQ409299 & GQ409248 & GQ409469 \\
\hline 48 & Mesembrinella sp. Giglio-Tos & Mesembrinellinae & $\begin{array}{l}\text { WVU2011-018- } \\
15\end{array}$ & JF439552* & JF439564* & JF439578* & JF439538* \\
\hline 49 & $\begin{array}{l}\text { Eumesembrinella quadrilineata } \\
\text { Fabricius, } 1805\end{array}$ & Mesembrinellinae & RMBR\#103619 & GQ409336 & $\mathrm{N} / \mathrm{A}$ & GQ409249 & GQ409470 \\
\hline 50 & Sarconesia versicolor Bigot, 1857 & Toxotarsinae & RMBR\#103610 & GQ409319 & GQ409291 & $\mathrm{N} / \mathrm{A}$ & GQ409456 \\
\hline 51 & $\begin{array}{l}\text { Sarconesia chlorogaster } \\
\text { (Wiedemann, 1830) }\end{array}$ & Toxotarsinae & RMBR\#103609 & GQ409359 & GQ409310 & $\mathrm{N} / \mathrm{A}$ & GQ409482 \\
\hline 52 & Isomyia gomezmenori (Peris, 1951) & Rhiniinae & $\begin{array}{l}\text { WVU2011-018- } \\
16\end{array}$ & JF439553* & JF439565* & JF439579* & JF439539* \\
\hline 53 & Rhyncomya nigripes (Séguy, 1933) & Rhiniinae & RMBR\#103626 & GQ409356 & GQ409308 & GQ409268 & GQ409481 \\
\hline 54 & $\begin{array}{l}\text { Metallea erinacea Fang \& Fan, } \\
1984\end{array}$ & Rhiniinae & RMBR\#103625 & GQ409337 & GQ409300 & $\mathrm{N} / \mathrm{A}$ & GQ409471 \\
\hline 55 & $\begin{array}{l}\text { Eurychaeta palpalis (Robineau- } \\
\text { Desvoidy, 1830) }\end{array}$ & Helicoboscinae & RMBR\#102703 & FJ025612 & FJ025575 & FJ025512 & FJ025672 \\
\hline 56 & McAlpine's fly & & RMBR\#104423 & GQ409334 & $\mathrm{N} / \mathrm{A}$ & GQ409247 & GQ409468 \\
\hline
\end{tabular}


TABLE 5.2: List of newly designed carbamoylphosphate synthetase (CPS) gene primers.

\begin{tabular}{|l|l|l|}
\hline Sr. \# & Name of Primer & Nucleotide sequence $\mathbf{( 5}^{\prime}$ - $\mathbf{3}^{\prime} \mathbf{)}$ \\
\hline 1 & Calcad207F & GAC CAT TTG TTT TGG CTG CT \\
\hline 2 & Calcad908R & AAT CAA TGG ATT GGG GAG AA \\
\hline 3 & Calcad627F & AGT TCG ATT GGT GTG CTG TG \\
\hline 4 & Calcad1011R & CAG AAA GCT ATG GCC GAT TC \\
\hline 5 & Oescad300F & AAC CCA CCG ATA AGA GAC CA \\
\hline 6 & Oescad594F & TCG ATA CTG TGG CTG GTG AA \\
\hline 7 & Oescad770F & TTG AGA AAT CTG GGC AAA CC \\
\hline 8 & Oescad1287R & TCC TTG GCT TCC GTT AAG AA \\
\hline 9 & CadT2207F & AGT GTG GGC GAG GTA ATG TC \\
\hline 10 & CadT2370F & CTG CCT TGA AAG CCA ACT TC \\
\hline 11 & CadT3156R & CAG AAA GCT ATG GCC GAC TC \\
\hline
\end{tabular}

Most PCR reactions consisted of $25 \mathrm{ul}$ total volume containing $12.5 \mathrm{ul}$ of $2 \mathrm{X}$ Promega Master Mix (Catalogue \# M7505), 2 ul (10 pmol) of each primers, 1-3 ul (10 $30 \mathrm{ng})$ of template DNA and remaining water. A smaller volume (10-15 $\mu \mathrm{l})$ was used for some taxa with precious template DNA. All reaction components were in the same proportion. All DNA amplifications were carried-out in a GeneAmp® PCR System 9700 (Applied Biosystems, Foster City, CA).

\subsubsection{Sequencing and sequence alignments}

The amplified products were cleaned by using ExOSAP-IT® (USB Corporation, Cleveland, Ohio) as per manufacturer's instructions. Direct sequencing was performed on the purified product with the same primers used for PCR and using a Big Dye ${ }^{\mathrm{TM}}$ Terminator v3.1 Cycle Sequencing Kit (Applied Biosystems, Foster City, CA). The sequencing protocol was as described in Singh et al. (2010). The sequencing product was separated on an Applied Biosystems 3130xl genetic analyzer (Foster City, CA). Sequence files were edited using Sequence Navigator (Applied Biosystems, Foster city, $\mathrm{CA}$ ). Many overlapping regions of these gene sequences were also obtained from the GenBank database (Table 5.1). Protein coding COI, CPS, and EF1 $\alpha$ genes were aligned manually in Sequence Navigator (Applied Biosystems, Foster City, CA) using sequences of Lucilia sericata (AJ417717; Stevens et al., 2002), Epalpus signifier 
(Walker) (AY280680; Moulton \& Wiegmann 2004), and Chrysomya rufifacies (Macquart) (JF439532; this study), as a reference sequence respectively. All newly sequenced protein coding genes were indel free. For the alignment of $28 s$ rRNA genes, a conservative approach was applied. Initially, different overlapping fragments of $28 S$ rRNA gene sequence from each species were edited and aligned manually in Sequence Navigator (Applied Biosystems, Foster City, CA). Because a high degree of length heterogeneity among different taxa often creates problems in multiple sequence alignments (De Rijk et al., 1995; Gillespie, 2005), we performed multiple sequence alignments (MSA) in two steps. Initially, MSA was performed in Muscle v3.8.31 (Edgar, 2004) using default parameters, for most of the species with comparatively complete $28 S$ rRNA gene sequences. After multiple sequence alignment (MSA), ambiguous hypervariable regions of $28 S \mathrm{~S} R N A$ gene were excluded from the alignment using MEGA 5 (Tamura et al., in press) and only $1664 \mathrm{bp}$ of $28 S$ rRNA gene was used for further phylogenetic analysis. Some species with comparatively smaller $28 S \mathrm{rRNA}$ gene sequence lengths were aligned separately by Muscle (Edgar, 2004) as implemented in MEGA 5 (Tamura et al., in press) using already cropped 1664 bp sequences of closely related taxa as a reference sequence. Final MSA of the 28S rRNA gene was checked by eye for sequence homology. Aligned and nexus files for all genes are available on request from the first author.

\subsubsection{Phylogenetic analyses}

Phylogenetic analyses were carried out on 5189 characters from 56 taxa using maximum parsimony (MP), maximum likelihood (ML) and Bayesian methods (BA). For all analyses, indels were coded as missing data and not as a fifth character, because indel coding generally has negligible effects on tree topology (Kutty et al., 2008; 2010). MP analysis was performed in PAUP v.4b10 (Swofford, 2002), for 1000 bootstrap replications using an equally-weighted heuristic search and tree-bisection-reconnection (TBR) branch swapping options. ML analysis was carried out for 100 bootstrap replications in Garli v.1 (Zwickl, 2006) with default options. Best fit model $(G T R+l+G)$ for ML analysis was determined in Modeltest v.3.7 (Posada \& Crandall, 1998) based in Akaike Information Criterion (AIC). Similarly, best fit model $(G T R+I+G)$ for BA was determined in MrModeltest (Nylander, 2004) based on AIC. BA was performed for two 
concurrent sets of six independent chains ( 5 heated and one cold) for 3.5 million generations sampling every 100 generations using the default parameters in Mr. Bayes v.3.1.2 (Huelsenbeck \& Ronquist, 2001). After 3.5 million generations, standard deviation of the split frequencies was 0.007 , much lower than the generally recommended level of 0.01 . After observing the likelihood plot, out of 35001 trees from each run, 28000 trees were discarded as the burnin, and the remaining trees (7001) were used for generation of the $50 \%$ majority rule consensus tree. Posterior probabilities were calculated as branch support from all trees that remained after setting burnin. Although nodes with Bayesian posterior probability (PP) $\geq 0.65$ are shown on the tree (Fig. 5.3), only nodes having PP $\geq 0.95$ were deemed significant (Huelsenbeck \& Ronquist, 2001). All trees were edited using software MrEnt v.2.2 (Zuccon \& Zuccon, 2010).

\subsection{Results}

Out of 5189 characters, 1423 were parsimony informative. MP, ML, and BA analyses produced almost identical trees, but the Bayesian tree (Fig. 5.3) was more resolved at deeper nodes ( $P P \geq 0.95)$. Oestroidea was monophyletic, as were Rhinophoridae and Tachinidae in BA and ML, but not in MP (Fig. 5.3). The other families were not recovered and consequently there was little resolution of oestroid family relationships. However, there was strong evidence against calliphorid monophyly in that 1) Messembrinellinae fell outside of a well-supported Calliphoridae (excluding Mesembrinellinae) + Rhinophoridae + Tachinidae clade, and 2) Polleniinae was the sister-group of Tachinidae (Fig. 5.3). Chrysomyinae was found to be closely allied to the mostly social insect predator/parasite taxa Auchmeromyiinae, Bengaliinae, and Rhiniinae rather than to the other familiar blow flies. Luciliinae + (Calliphorinae/Toxotarsinae/Melanomyinae) was strongly supported. All calliphorid subfamilies (except Calliphorinae and Bengaliinae) and genera for which we had more than one species were monophyletic (Fig. 5.3). 


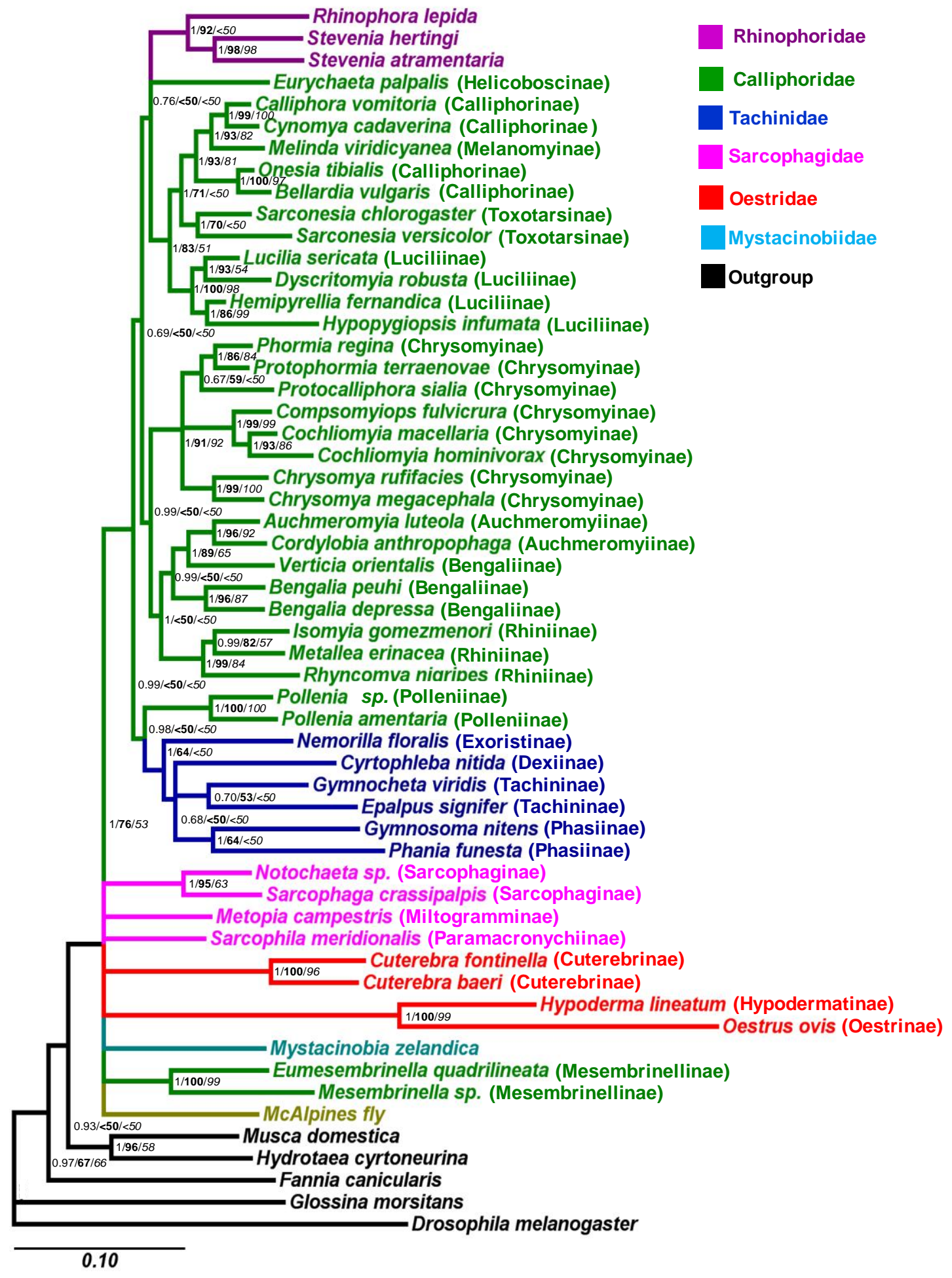

FIGURE 5.3: Bayesian phylogram of the Oestroidea based on 5189 bp of combined COI, CPS, $28 S$ $r R N A$, and EF1a DNA sequences. Branch support values: Standard font = Bayesian posterior probability; Bold $=$ maximum likelihood $\%$ bootstrap; Italics = maximum parsimony $\%$ bootstrap. 


\subsection{Discussion}

\subsubsection{Relationships between oestroid families}

We confirmed the earlier conclusion of oestroid monophyly (Pape, 1992; Rognes, 1997; Kutty et al., 2008; 2010). Our well-supported Calliphoridae (excluding Mesembrinellinae) + Rhinophoridae + Tachinidae is in agreement with Wiegmann et al. (2011) but at odds with the hypothesis that Tachinidae is the sister group of Sarcophagidae (Pape, 1992; Rognes, 1997; Tachi \& Shima, 2010), and also suggests to us that Rhinophoridae is either closely related to Calliphoridae (Tschorsnig, 1985; Rognes, 1986; 1991; Kutty et al., 2008) or Tachinidae (Wood, 1987c; McAlpine, 1989) and not to Sarcophagidae (Rohdendorf, 1967). Morphologically, Rhinophoridae looks intermediate between typical calliphorids and typical tachinids (Pape, 1986).

The systematic position of Mystacinobia Holloway within Oestroidea is not wellresolved in our analysis but it is certainly not a member of Calliphoridae as sometimes suggested (Griffith, 1982; Gleeson et al., 2000; Kurahashi, 1989). Although, we didn't recover the Mystacinobia + McAlpine's fly reported by Kutty et al. (2010), our results do agree with them in that McAlpine's fly is a member of the Oestroidea.

Relationships between oestroid families were mostly unresolved as was observed in previous studies (Kutty et al., 2010; Wiegmann et al., 2011). It may be that these groups evolved recently in a very short span of time and hence lack enough character accumulation for any phylogentic resolution (Wiegmann et al., 2011). These results add to a growing body of work supporting rhinophorid monophyly (Pape, 1992; Pape \& Arnaud, 2001; Kutty et al. 2010). They are in conflict with the Rhiniinae + (Sarcophagidae + Tachinidae) clade proposed by Rognes (1997) and they undermine the recent elevation of Rhiniinae to family rank (Evenhuis et al., 2008; Kutty et al., 2010, see next section).

\subsubsection{Relationships within and between calliphorid subfamilies}

Our result favors the earlier DNA analysis of Kutty et al. (2010) in that Melanomyinae is nested within Calliphorinae, and this combined lineage is sister to Toxotarsinae. This is an unsurprising result for Melanomyinae, the species of which have often been classified as Calliphorinae (Kurahashi, 1970; Schumann, 1986; 
Shewell, 1987). But a sister-group relationship between Calliphorinae and Toxotarsinae rejects morphology based well-supported groups such as Chrysomyinae + Toxotarsinae (Rognes, 1997) or Chrysomyinae + Rhiniinae + Toxotarsinae (Pape, 1992). Monophyly of Calliphorinae + Toxotarsinae was also advocated by Greenberg \& Szyska (1984) based on larval morphology and developmental rate and by Singh \& Wells (2011) based on molecular data.

A monophyletic Lucilinae is in agreement with previously proposed hypotheses (Rognes, 1991; Wallman et al., 2005; McDonagh, 2009; Kutty et al., 2010). Within Luciliinae monophyly of Lucilia + Dyscritomyia favours the hypothesis proposed by Wells et al. (2002).

Strong support for monophyly of Chrysomyinae in our analysis is in agreement with morphological (Rognes, 1991; 1997) and recent molecular systematic analyses (McDonagh, 2009; Singh \& Wells, 2011) but differ with Kutty et al.'s (2010) extensive molecular systematic analysis of the Calyptratae. Within Chrysomyinae, monophyly of Phormia + Protophormia and Cochliomyia + Compsomyiops are well supported, as was observed in previous molecular systematic analysis (McDonagh, 2009; Singh \& Wells, 2011). However, we didn't observe support for the sister-group relationship between traditional tribe Phormiini and Chrysomya as was suggested in recent molecular systematic analysis of these flies (Singh \& Wells, 2011). This may be because we included only a few members of Chrysomyinae in our analysis.

Morphologically, Bengaliinae and Auchmeromyiinae have always been considered as a natural assemblage (Pape, 1992; Rognes, 1997) and here we support it based on molecular data. Similarly, strong support for the monophyly of Auchmeromyia + Cordylobia is in agreement with Stevens (2003), who proposed its monophyly based on $28 S$ rRNA gene. Paraphyly of Bengaliinae with respect to Auchmeromyiinae suggest to us that Auchmeromyiinae may be a member of subfamily Bengaliinae as was proposed by Pape (1992) based on shared elongated anal veins. Members of both subfamilies are similar in color (yellow to brown) and have the same geographical distribution (Afrotropical and Oriental). 
Verves (1986) and Shewell (1991) placed Eurychaeta within Sarcophagidae, while Rognes (1986) and Pape (1992) thought it was within or the sister-group, respectively, of Calliphoridae. Although systematic position of Helicoboscinae is not well-resolved in our analysis, it is certainly not a member of Sarcophagidae (Fig. 5.3).

Mesembrinellinae has similarly been difficult to place because these flies show so many unique characters (Shannon, 1923; Hall, 1948; James, 1970; Hennig, 1973; Rognes, 1991; Pape, 1992). We found that it is not a subfamily of Calliphoridae and is therefore probably worthy of the family status proposed by Guimarães (1977). Pape (1986) argued that family status of Mesembrinellinae implied an adjustment to commonly understood morphological character polarity, that would in turn make Mesembrinellidae the sister group of all other oestroid flies. Although systematic position of the Mesembrinellinae within Oestroidea is not well-resolved in our analysis, it is certainly not a member of Calliphoridae (Pape, 1986; 1992; Rognes, 1997) or Rhinophoridae or Tachinidae (Kutty et al., 2010) (Fig. 5.3).

\subsubsection{Evolution}

A majority of calliphorid larvae are carrion breeders, but several members of this family also cause myiasis in vertebrate and invertebrate hosts (Stevens, 2003). This result in combination with Singh \& Wells (2011) suggests to us that obligate parasitism of warm-blooded animals by calliphorid larvae evolved at least four times independently and hematophagy evolved independently in Protocalliphora and in Auchmeromyia (Stevens, 2003; McDonagh, 2009). Strong support for the sister group relationship between Polleniinae and Tachinidae suggest that earthworm parasitism among calliphorid flies evolved independently in Polleniinae and in Onesia-group of Calliphorinae. Similarly, our results suggest at least two independent evolutions of snail parasitism (Helicoboscinae and Melanomyinae) in Calliphoridae. Interestingly, all calliphorid subfamilies that cause parasitism to ants and termites (Bengaliinae, Auchmeromyiinae and Rhiniinae) (Senior-White et al., 1940; Zumpt, 1965; Dear, 1977; Pont, 1980; Kurahashi, 1989) emerged as a monophyletic group in our analysis (Fig. 5.3), which suggests to us that ant and termite parasitic behavior evolved once in the Calliphoridae. 


\section{CHAPTER 6: Conclusions}

With total 94 representative ingroup taxa, this work is the most extensive molecular systematic analysis performed so far for the Oestroidea, an important clade in the dipteran tree of life. Earlier studies were conducted on systematics of Oestroidea based on both morphological and molecular data, but morphological systematic analyses differed considerably with each other and molecular systematic analyses lacked support for many deeper nodes. This was mainly due to limited taxon sampling from the calliphorid grade, the most important group for better understanding of the Oestroidea phylogeny, and/or lack of overlapping gene regions for many important taxa. Our results included more than one representative species from all major subfamilies of the Calliphoridae.

In addition to being the most extensive molecular systematic analysis of the Oestroidea, this study also developed several new single copy protein coding nuclear gene primers and demonstrated usefulness of these primers in solving systematic questions of the Oestroidea. Although it is difficult to amplify single copy protein coding nuclear genes (especially if DNA quality is not good), these have advantages over mitochondrial genes in being better in resolving deeper nodes (a major problem in Oestroidea systematics) and over ribosomal genes because of its easy alignments.

With respect to Oestroidea systematics, this study reconfirmed: 1) monophyly of the Oestroidea, Tachinidae, and Rhinophoridae, 2) non-monophyly of the Calliphoridae, 3) placement of Mystacinobia and McAlpine's fly within Oestroidea, 4) monophyly of all oestrid subfamilies, 5) Melanomyinae as a part of the Calliphorinae and 6) Toxotarsinae as a sister group of Calliphorinae. These results supplemented existing knowledge of the Oestroidea systematics by suggesting: 1) Rhiniidae is more closely related to traditional calliphorid subfamilies than to either Sarcophagidae or Tachinidae, 2) Auchmeromyiinae is a part of the Bengaliinae, 3) Chrysomyinae and Chrysomya is monophyletic, 4) Chrysomyini is paraphyletic, 5) Polleniinae is a sister group of Tachinidae, and 6) Mesembrinellinae most probably merits family rank within Oestroidea.

Well-supported phylogenies obtained from this study also helped in testing several evolutionary hypotheses, including: 1) single origin of bird parasitism, ant and 
termite parasitism, and two independent origins of hematophagy, earthworm parasitism and snail parasitism in the calliphorid grade, 2) two independent origins of tuberculate larvae in Chrysomya, 3) a decrease in genome size over evolutionary time in Chrysomya and 4) recent origin of monogeny compared to amphogeny in Chrysomya. These studies also suggest to us that all Neotropical chrysomyine genera share a common ancestral lineage.

Results from this study will help in filling several existing knowledge gaps in the Diptera tree of life, which will provide a framework for further comparative studies on these economically and socially important groups of flies. For example, genome size is positively correlated with developmental time at constant temperature in Drosophila. If we find a similar pattern for Chrysomya, then it will be much easier to estimate development rate with a simple measurement of genome size, which in turn will help in estimation of post-mortem interval (PMI) in forensic investigations, because these flies are of forensic importance. These results will also help in better understanding of how traits have evolved with time and with respect to environmental conditions. For example, the Chrysomya tree suggested that loss of male eye dimorphism in Chrysomya pacifica was because of its movement towards dense forest and not otherwise.

Although we were able to resolve many systematic questions of the Oestroidea, there are many that need further attention. Mainly, the systematic position of Mystacinobia, McAlpine's fly, Rhinophoridae, Mesembrinellinae, Sarcophagidae, and Oestridae within Oestroidea remained uncertain. Relationships between some calliphorid subfamilies were weakly-supported. Monophyly of the Oestridae is still unsupported by DNA analysis. As these lineages diverged in a short span of time, they may not have accumulated sufficient characters for well-resolved oestroid phylogeny. More extensive taxon (which will not be an easy task, considering many groups are rare in collections) and data sampling may help in better resolution of the oestroid deeper nodes, but we think alternate approaches such as use of mobile elements, microRNA's, gene rearrangement etc. may be a better strategy, as these methods are less prone to homoplasy. 


\section{References}

Anderson, J.R. (1975) The behavior of nose bot flies (Cephenemyia apicata and C. jellisoni) when attacking black-tailed deer (Odocoileus hemionus columbianus) and the resulting reaction of the deer. Canadian Journal of Zoology, 53, 977-992.

Anderson, J.R. \& Nilssen, A.C. (1990) The method by which Cephenemyia trompe (Modeer) larvae invade reindeer (Ragnifer tarandus). Ragnifer, special issue no. 3, 291-297.

Archibald, J.K., Mort, M.E., \& Crawford, D.J. (2003) Bayesian inference of phylogeny: a non technical primer. Taxon, 52, 187-191.

Baker, R.H. \& DeSalle, R. (1997) Multiple sources of character information and the phylogeny of Hawaiian drosophilids. Systematic Biology, 46, 654-673.

Baker, R.H., Wilkinson, G.S., \& DeSalle, R. (2001) Phylogenetic utility of different types of data used to infer evolutionary relationships among stalk-eyed flies (Diopsidae). Systematic Biology, 50, 87-105.

Baudry, E., Bartos, J., Emerson, K., Whitworth, T. \& Werren, J.H. (2003) Wolbachia and genetic variability in the birdnest blowfly Protocalliphora sialia. Molecular Ecology, 12, 1843-1854.

Baumgartner, D.L. \& Greenberg, B. (1984) The genus Chrysomya (Diptera: Calliphoridae) in the New World. Journal of Medical Entomology, 21, 105-113.

Bedding, R.A. (1973) The immature stages of Rhinophorinae (Diptera: Calliphoridae) that parasitize British woodlice. Transactions of the Royal Entomological Society of London, 125, 27-44.

Belshaw, R. (1993) Tachinid flies (Diptera: Tachinidae). Handbooks for the identification of British Insects. Royal Entomological Society of London, 10, part 4a(I), pp. 170.

Bergsten, J. (2005) A review of long-branch attraction. Cladistics, 21, 163-193. 
Bezzi, M. (1927) Some Calliphoridae (Diptera) from the South Pacific islands and Australia. Bulletin of Entomological Research, 17, 231-247.

Boyes, J.W. \& Shewell, G.E. (1975) Cytotaxonomy of the Calliphoridae (Diptera). Genetica, 45, 435-488.

Brady, S.G. (2003) Evolution of the army ant syndrome: the origin and long-term evolutionary stasis of a complex of behavioral and reproductive adaptations. Proceedings of the National Academy of Sciences of the United States of America, 100, 6575-6579.

Bremer, K. (1994) Branch support and tree stability. Cladistics, 10, 295-304.

Brues, C.T., Melander, A.L., \& Carpenter, F.M. (1954) Classification of insects. Key to the living and extinct families of insects and to the living families of other terrestrial arthropods. Bulletin of the Museum of Comparative Zoology Harvard, 108, 1-917.

Byrd, H.H. \& Butler, J.F. (1997) Effects of temperature on Chrysomya rufifacies (Diptera: Calliphoridae) development. Journal of Medical Entomology, 34, 353358.

Cameron, S.L., Lambkin, C.L., Barker, S.C., \& Whiting, M.F. (2007) A mitochondrial genome phylogeny of Diptera: whole genome sequence data accurately resolves relationships over broad timescales with high precision. Systematic Entomology, 32, 40-59.

Catts, E.P. (1964) Field behavior of adult Cephenemyia (Diptera: Oestridae). Canadian Entomologist, 96, 579-585.

Catts, E.P. (1982) Biology of New World bot flies: Cuterebridae. Annual Review of Entomology, 27, 313-338.

Cho, S., Mitchell, A., Regier, J.C., Mitter, C., Poole, R.W., Friedlander, T.P. \& Zhao, S. (1995) A highly conserved nuclear gene for low level phylogenetics: Elongation 
factor-1 alpha recovers morphology-based tree for heliothine moths. Molecular Biology and Evolution, 12, 650-656.

Colless, D.H. (1994) A new family of muscoid Diptera from Australasia, with sixteen new species in four new genera (Diptera: Axiniidae). Invertebrate Taxonomy, 8, 471534.

Crosskey, R.W. (1965) A systematic revision of the Ameniinae (Diptera: Calliphoridae). Bulletin of the British Museum (Natural History) (Entomology), 16, 33-140.

Crosskey, R.W. (1977) A review of Rhinophoridae (Diptera) and a revision of the Afrotropical species. Bulletin of the British Museum (Natural History) (Entomology), 36, 1-66.

Crosskey, R.W. (1980) Family Tachinidae. Catalogue of the Diptera of the Afrotropical region, (ed. by Crosskey, R.W.), pp. 822-882, British Museum of Natural History, London.

Cummings, M.P. (1994) Transmission patterns of eukaryotic transposable elements: Arguments for and against horizontal transfer. Trends in Ecology \& Evolution, $\mathbf{9}$, 141-145.

Danforth, B.N., Lin, C.P. \& Fang, J. (2005) How do insect nuclear ribosomal genes compare to protein coding genes in phylogenetic utility and nucleotide substitution patterns? Systematic Entomology, 30, 549-562.

Dear, J.P. (1977) A revision of Australian Rhiniinae (Diptera: Calliphoridae). Australian Journal of Zoology, 25, 779-826.

Dear, J.P. (1979) A revision of the Toxotarsinae (Diptera: Calliphoridae). Papéis Avulsos de Zoologia (São Paulo), 32, 145-182.

Dear, J.P. (1985) A revision of the New World Chrysomyini (Diptera: Calliphoridae). Revista Brasileira de Zoologia, 3, 109-169. 
De Rijk, P., Peer, Y.V., Broeck, V. \& De Watchter, R. (1995) Evolution according to large ribosomal subunit RNA. Journal of Molecular Evolution, 41, 366-375.

Edgar, R.C. (2004) MUSCLE: multiple sequence alignment with high accuracy and high throughput. Nucleic Acid Research, 32, 1792-1797.

Efil, L. \& Kara, K. (2004) Tachinid parasitoids (Diptera: Tachinidae) of Spodoptera exigua in cotton fields in Diyarbakir, Turkey. Phytoparasitica, 32, 363-366.

Erzinclioglu, Y.Z. (1987) The larvae of some blowflies of medical and veterinary importance. Medical and Veterinary Entomology, 1, 121-125.

Evenhuis, N.L., Pape, T., Pont, A.C. \& Thompson, F.C. (eds.) (2008). Biosystematic Database of world Diptera, Version 10.5., Available at http://www.diptera.org/biosys.htm, [accessed on March 12, 2009].

Fan, C.T. (1965) Key to the common synanthropic flies in China. Academy of Sciences, Peking. pp. $X V+300$.

Fang, Q.Q., Mitchell, A., Regier, J.C., Mitter, C., Friedlander, T.P. \& Poole, R.W. (2000) Phylogenetic utility of the nuclear gene dopa decarboxylase in noctuoid moths (Insecta: Lepidoptera: Noctuoidea). Molecular Phylogenetics and Evolution, 15, 473-486.

Farrell, B.D., Sequeira, A.S., O’Meara, B.C., Normark, B.B., Chung, J.H. \& Jordal, B.H. (2001) The evolution of agriculture in beetles (Curculionidae: Scolytinae and Platypodinae). Evolution, 55, 2011-2027.

Felsenstein, J. (1978) Cases in which parsimony or compatibility methods will be positively misleading. Systematic Zoology, 27, 401- 410.

Ferrar, P. (1978) Macrolarviparous reproduction in Euphumosia (Diptera:Calliphoridae). Journal of the Australian Entomological Society, 17, 13-17. 
Ferrar, P. (1979) The immature stages of dung-breeding muscoid flies in Australia, with notes on the species, and keys to larvae and puparia. Australian Journal of Zoology Supplementary Series No. 73, 1-106.

Froggatt, J.L. (1918) An economic study of Nasonia brevicornis, a hymenopterous parasite of muscid Diptera. Bulletin of Entomological Research, 9, 257-262.

Fuller, M.E. (1934) The insect inhabitants of carrion: A study in animal ecology. Commonwealth of Australia, Council for Scientific and Industrial Research, Bulletin, 82, 4-63.

Funk, D.J. \& Omland, K.E. (2003). Species level paraphyly and polyphyly: frequency, causes, and consequences, with insight from animal mitochondrial DNA. Annual Review of Ecology, Evolution, and Systematics, 34, 397-423.

Gillespie, J.J. (2005) Structure based methods for the phylogenetic analysis of ribosomal RNA molecules. Ph.D. Dissertation, Texas A \& M University, College Station, Texas, USA.

Gleeson, D.M., Howitt, R.L.J. \& Newcomb, R.D. (2000) The phylogenetic position of the New Zealand bat fly Mystacinobia zealandica (Mystacinobiidae: Oestroidea) inferred from mitochondrial $16 \mathrm{~S}$ ribosomal DNA sequence data. Journal of the Royal Society of New Zealand, 30, 155-168.

Goff, M.L. \& Odum, C.B. (1987) Forensic entomology in the Hawaiian Islands: Three case studies. The American Journal of Forensic Medicine and Pathology, 8, 4550.

Gomez, R.S., Perdigão, P.F., Pimenta, F.J.G.S. \& Rios Leite, A.C. (2003) Oral myiasis by screwworm Cochliomyia hominivorax. British Journal of Oral and Maxillofacial Surgery, 41, 115-116.

Grant, T. \& Kluge, A.G. (2003) Data exploration in phylogenetic inference: scientific, heuristic, (or) neither. Cladistics, 19, 379-418. 
Grassberger, M., Friedrich, E. \& Reiter, C. (2003) The blow fly Chrysomya albiceps (Wiedemann) as a new forensic indicator in Central Europe. International Journal of Legal Medicine, 117, 75-81.

Greenberg, B. (1971) Flies and Disease, Vol. 1. Princeton, NJ, Princeton University Press.

Greenberg, B. \& Szyska, M.L. (1984) Immature stages and biology of fifteen species of Peruvian Calliphoridae (Diptera). Annals of Entomological Society of America, 77, 488-517.

Gregory, T.R. and Johnston, J.S. (2008) Genome size diversity in the family Drosophilidae. Heredity, 101, 228-238.

Griffiths, G.C.D. (1982) On the systematic position of Mystacinobia (Diptera: Calliphoridae). Memoirs of the Entomological Society of Washington, 10, 70-77.

Guimarães, J.H. (1967) Family Cuterebridae. A Catalogue of the Diptera of the Americas South of United States. (ed. by N. Papavero), pp. 1-11, Departmento de Zoologia, Secretaria da Agricultura, Sao Paulo.

Guimarães, J.H. (1977) A systematic revision of the Mesembrinellidae, stat. nov. (Diptera: Cyclorrhapha). Arquivos de Zoologia, Sao Paulo, 29, 1-109.

Guimarães, J., do Prado, A. \& Buralli, G. (1979) Dispersal and distribution of three newly introduced species of Chrysomya in Brazil (Diptera: Calliphoridae). Revista Brasileira de Entomologia, 23, 245-255.

Hall, D.G. (1948) The Blowflies of North America. Entomological Society of America, Vol. 4, pp. 477, Thomas Say Foundation, Washington D.C.

Hanski, I. (1977) Biogeography and ecology of carrion flies in the Canary Islands. Annales Entomololici Fennici, 43, 101-107. 
Harvey, M.L., Mansell, M.W., Villet, M.H. \& Dadour, I.R. (2003) Molecular identification of some forensically important blowflies of southern Africa and Australia. Medical and Veterinary Entomology, 17, 363-369.

Harvey, M.L., Gaudieri, S., Villet, M.H. \& Dadour, I.R. (2008) A global study of forensically significant calliphorids: Implications for identification. Forensic Science International, 177, 66-76.

Heckman, K. L., Mariani, C. L., Rasoloarison, R. \& Yoder, A. D. (2007) Multiple nuclear loci reveal patterns of incomplete lineage sorting and complex species history within western mouse lemurs (Microcebus). Molecular Phylogenetics and Evolution, 43, 353-367.

Hennig, W. (1973) Diptera (Zweiflugler). Handbuch der Zoologie, 4, 2/31 (ed. by J. G. Helmcke, D. Starck, \& H. Wermuth), pp. 337, Walter de Gruyter, Berlin- New York.

Herting, B. (1957) Das weibliche Postabdomen der calyptraten Fliegen (Diptera) und sein Merkmalswert fur die Systematik der Gruppe. Zeitschrift fur Morphologie und Okologie der Tiere, 45, 429-461.

Herting, B. (1961) Rhinophoridae. Die Fliegen der Palaearktischen Region. (ed. by E. Lindner), pp. 1-36, Schweizerbart, Stuttgart.

Herting, B. (1984) Catalogue of the Palearctic Tachinidae (Diptera). Stuttgarter Beitraege zur Naturkunde Serie A (Biologie), 369, 1-228.

Hickson, R.E., Simon, C., \& Perrey, S.W. (2000) The performance of several multiplesequence alignment programs in relation to secondary-structure features for an rRNA sequence. Molecular Biology and Evolution, 17, 530-539.

Holloway, B.A. (1976) A new bat-fly family from New Zealand (Diptera: Mystacinobiidae). New Zealand Journal of Zoology, 3, 279-301. 
Huelsenbeck, J.P. \& Ronquist, F. (2001) MrBAYES. Bayesian Inference of phylogeny. Bioinformatics, 17, 754-755.

Hypsa, V. (2006) Parasite histories and novel phylogenetic tools: Alternate approaches to inferring parasite evolution from molecular markers. International Journal of Parasitology, 36, 141-155.

ICZN (1999) International Code of Zoological Nomenclature (by the International Commission on Zoological Nomenclature). Fourth Edition, pp. 124, The Natural History Museum, London.

Irwin, M.E., Schlinger, E.I. \& Thompson, F.C. (2003). Diptera, True flies. The Natural History of Medagascar. (ed. by S.M. Goodnan \& J.P. Benstead), pp. 692-702, University of Chicago Press, Chicago and London.

James, M. (1970) Family Calliphoridae. A catalog of the Diptera of the Americas South of the United States. (ed. by N. Papavero), Museu de Zoologia, Universidade de Sao Paulo.

Jenner, R.A. (2004) Accepting partnership by submission? Morphological phylogenetics in a molecular millennium. Systematic Biology, 53, 333-342.

Jenson, L.M. \& Miller, R.H. (2001) Estimating filth fly (Diptera: Calliphoridae) development in carrion in Guam. Micronesica, 34, 11-25.

Kamal, A.S. (1958) Comparative study of thirteen species of sarcosaprophagous Calliphoridae and Sarcophagidae (Diptera) I. Bionomics. Annals of the Entomological Society of America, 51, 261-271.

Kawakita, A., Sota, T., Ito, M., Ascher, J.S., Tanaka, H., Kato, M., \& Roubik, D.W. (2004) Phylogeny, historical biogeography, and character evolution in bumble bees (Bombus: Apidae) based on simultaneous analysis of three nuclear gene sequences. Molecular Phylogenetics and Evolution, 31, 799-804. 
Kitching, R.L. (1976) The immature stages of the Old-World screw-worm fly, Chrysomya bezziana Villeneuve, with comparative notes on other Australasian species of Chrysomya. Bulletin of Entomological Research, 66, 195-203.

Kitching, R.L. \& Voeten, R. (1977) The larvae of Chrysomya incisuralis (Macquart) and Chrysomya semimetallica (Malloch) (Diptera: Calliphoridae). Journal of the Australian Entomological Society, 16, 185-190.

Kurahashi, H. (1970) Tribe Calliphorini from Australian and Oriental regions, I. Melindagroup (Diptera: Calliphoridae). Pacific Insects, 13, 141-204.

Kurahashi, H. (1972) Tribe Calliphorini from Australian and Oriental Regions, IV. Onesia group: genus Polleniopsis (Diptera: Calliphoridae). Pacific Insects, 14, 709-724.

Kurahashi, H. (1982) Probable origin of a synanthropic fly Chrysomya megacephala, in New Guinea (Diptera: Calliphoridae). Monographiae Biologicae, 42, 689-698.

Kurahashi, H. (1987) The Blow flies of New Guinea, Bismarck Archepelago and Bougainville Island (Diptera: Calliphoridae). Occasional Publications. The Entomological Society of Japan, 1, 1-99.

Kurahashi, H. (1989) Family Calliphoridae. Catalog of the Diptera of the Australasian and Oceanian Regions, (ed. by N.L. Evenhuis), pp. 702-718, Bishop Museum Serial Publication 86, Honolulu.

Kurahashi, H. (1991) Blow flies from Samoa with description of new species of Chrysomya (Diptera: Calliphoridae). Japanese Journal of Entomology, 59, 627636

Kurahashi, H. \& Magpayo, F.R. (1987) Two new species of the genus Chrysomya from Wallacea (Diptera: Calliphoridae). Kontyu, 55, 71-79.

Kutty, S.N. (2008) Building the tree of life: reconstructing the evolution of a recent and megadiverse branch (Calyptratae: Diptera). Ph.D. dissertation, National University of Singapore, Singapore. 
Kutty, S.N., Pape, T., Pont, A., Weigmann, B.M. \& Meier, R. (2008) The Muscoidea (Diptera: Calyptratae) are paraphyletic: Evidence from four mitochondrial and four nuclear genes. Molecular Phylogenetics and Evolution, 49, 639-652.

Kutty, S.N., Pape, T., Weigmann, B.M. \& Meier, R. (2010) Molecular phylogeny of the Calyptratae (Diptera: Cyclorrhapha) with an emphasis on the superfamily Oestroidea and the position of Mystacinobiidae and McAlpine's fly. Systematic Entomology, 35, 614-635.

Larson, A. (1991) Evolutionary analysis of length-variable sequences: divergent domains of ribosomal RNA. Phylogenetic Analysis of DNA Sequences, (ed. by M.M. Miyamoto \& J. Cracraft), pp. 221-248, Oxford University Press, New York.

Lehrer, A.Z. (1970) Considerations phylogenetiques et taxonomiques sur la famille Calliphoridae (Diptera). Annotationes Zoologicae et Botanicae, 61, 1-51.

Leys, R., Cooper, S.J.B. \& Schwarz, M.P. (2002) Molecular phylogeny and historical biogeography of the large carpenter bees, genus Xylocopa (Hymenoptera: Apidae). Biological Journal of the Linnean Society, 77, 249-266.

Lin, C.P. \& Danforth, B.N. (2004) How do insect nuclear and mitochondrial gene substitution patterns differ? Insights from Bayesian analyses of combined data sets. Molecular Phylogenetics and Evolution, 30, 686-702.

Lunt, N. (2002) Applied studies of some Southern African blowflies (Diptera: Calliphoridae) of forensic importance. Masters thesis, Rhodes University, Grahamstown, South Africa.

Maa, T.C. (1971) Studies in batflies (Diptera: Streblidae, Nycteribiidae) Part I. Pacific Insects Monographs, 28, 1-247.

Malloch, J.R. (1927) Notes on Australian Diptera XI. Proceedings of the Linnean Society of New South Wales, 52, 299-235. 
Marchenko, M.I. (2001) Medicolegal evidence of cadaver entomofauna for the determination of the time of death. Forensic Science International, 120, 89-109.

McAlpine, J.F. (1989) Phylogeny and classification of the Muscomorpha. Manual of Nearctic Diptera, Monograph No. 32, Vol. 3 (ed. by J.F. McAlpine \& D.M. Wood), pp. 1397-1518, Research Branch, Agriculture Canada.

McDonagh, L.M. (2009) Assessing patterns of genetic and antigenic diversity in Calliphoridae. Ph.D. dissertation, The University of Exetor, UK.

Meier, R., Kotrba, M. \& Ferrar, P. (1999) Ovoviviparity and viviparity in Diptera. Biological Reviews of the Cambridge Philosophical Society, 74, 199-258.

Moritz, C., Dowling, T.E. \& Brown, W.M. (1987) Evolution of animal mitochondrial DNA: Relevance for population biology and systematics. Annual Review of Ecology, Evolution, and Systematics, 18, 269-292.

Moulton, J.K. \& Wiegmann, B.M. (2004) Evolution and phylogenetic utility of CAD (rudimentary) among Mesozoic-aged Eremoneuran Diptera (Insecta). Molecular Phylogenetics and Evolution, 31, 363-378.

Nelson, L.A., Wallman, J.F. \& Dowton, M. (2007) Using COI barcode to identify forensically and medically important blowflies. Medical and Veterinary Entomology, 21, 44-52.

Nelson, L.A., Wallman, J.F. \& Dowton, M. (2008) Identification of forensically important Chrysomya (Diptera: Calliphoridae) species using the second ribosomal internal transcribed spacer (ITS2). Forensic Science International, 177, 238-247.

Ng, K.H.L., Yip, K.T., Choi, C.H., Yeung, K.H., Auyeung, T.W., Tsang, A.C.C., Chow, L. \& Que, T. L. (2003) A case of oral myiasis due to Chrysomya bezziana. Hong Kong Medical Journal, 9, 454-456.

Nirmala, X., Hypsa, V. \& Zurovec, M. (2001) Molecular phylogeny of Calyptratae (Diptera: Brachycera): the evolution of $18 \mathrm{~S}$ and $16 \mathrm{~S}$ ribosomal DNAs in higher 
dipterans and their use in phylogenetic inference. Insect Molecular Biology, 10, 475-485.

Norris, K.R. (1965) The bionomics of blow flies. Annual Review of Entomology, 10, 4768.

Norris, K.R. (1999) Establishment of a subfamily Aphyssurinae for the Australian genus Aphyssura Hardy (Diptera : Calliphoridae), with a review of known forms and descriptions of new species. Invertebrate Taxonomy, 13, 511-628.

Nylander, J.A. (2004) MrModeltest v2.2 Program distributed by the author. Evolutionary Biology Centre, Uppsala University, Sweden.

O'Brien, E.L., Morrison, B.L. \& Johnson, L.S. (2001) Assessing the effect of haematophagous ectoparasites on the health of nestling birds: haematocrit vs haemoglobin levels in House Wrens parasitized by blow fly larvae. Journal of Avian Biology, 32, 73-76

O'Flynn, M.A. (1983) The succession and rate of development of blow flies in carrion in Southern Queensland and the application of these data to forensic entomology. Journal of Australian Entomological, 22, 137-148.

O'Hara, J.E. (2008) Tachinidae flies (Diptera: Tachinidae). Encyclopedia of Entomology, (ed. by J.L. Capinera), pp. 3675-3886, $2^{\text {nd }}$ edition, Springer, Netherlands, Dordrecht.

Otranto, D., Traversa, D., Guida, B., Tarsitano, E., Fiorente, P., \& Stevens, J.R. (2003). Molecular Characterization of the mitochondrial Cytochrome Oxidase I gene of Oestridae species causing obligate myiasis. Medical and Veterinary Entomology, 17, 307-315.

Papavero, N. (1977) The world Oestridae (Diptera), mammals, and continental drift. Series Entomologica, 14, 1-240. 
Pape, T. (1986) A phylogenetic analysis of the woodlouse-flies (Diptera:

Rhinophoridae). Tijdschrift voor Entomologie, 129, 15-34.

Pape, T. (1992) Phylogeny of the Tachinidae family group (Diptera: Calyptratae). Tijdschrift voor entomologie, 135, 43-86.

Pape, T. (2001) Phylogeny of Oestridae (Insecta: Diptera). Systematic Entomology, 26, 133-171.

Pape, T. \& Arnaud, P.H. (2001) Bezzimyia - a genus of native New World Rhinophoridae (Insecta, Diptera). Zoologica Scripta, 30, 257-297.

Pape, T., Dahlem, G., Mello Patiu, C.A. de. \& Giroux, M. (2007) The World of Flesh flies (Diptera: Sarcophagidae).

http://www.zmuc.dk/entoweb/sarcoweb/sarcweb/Sarc web.htm

Peris, S.V. (1952) La subfamilia Rhiniinae (Diptera: Calliphoridae). Anales de la Estacion Experimental de Aula Dei, 3, 1-224.

Petrov, D.A. (2001) Evolution of genome size: new approaches to an old problem. TRENDS in Genetics, 17, 23-28.

Peus, F. (1960) Zur Kenntnis der ornithoparasitischen Phormiinen (Diptera: Calliphoridae). Deutsche Entomologische Zeitschrift, 7, 193-235.

Pollock, J. N. (2010) Bot flies (Insecta: Oestridae, part) and Glossinidae-Hippoboscidae derive from basal Ephydroidea, not Calyptratae. Journal of Natural History, 44, 1929-1952.

Pont, A.C. (1980) Calliphoridae. Catalog of the Diptera of the Afrotropical Region, (ed. by R.W. Crosskey), pp. 779-800, British Museum (Natural History), London.

Posada, D. \& Crandall, K.A. (1998) MODELTEST: testing the model of DNA substitution. Bioinformatics, 14, 817-818. 
Puchalla, S. (1994) Polytene chromosomes of monogenic and amphogenic Chrysomya species (Calliphoridae:Diptera): analysis of banding patterns and in situ hybridization with Drosophila sex determining gene sequences. Chromosoma, 103, 16-20.

Reed, D.L., Carpenter, K.E., \& deGravelle, M.J. (2002) Molecular systematics of the jacks (Perciformes: Carangidae) based on mitochondrial cytochrome $b$ sequences using parsimony, likelihood and Bayesian approaches. Molecular Phylogenetics and Evolution, 23, 513-524.

Regier, J.C., Fang, Q.Q., Mitter, C., Peigler, R.S., Friedlander, T.P. \& Solis, M.A. (1998) Evolution and phylogenetic utility of the period gene in Lepidoptera. Molecular Biology and Evolution, 15, 1172-1182.

Richards, C.S., Crous, K.L. \& Villet, M.H. (2009) Models of development for blowfly sister species Chrysomya chloropyga and Chrysomya putoria. Medical and Veterinary Entomology, 23, 56-61.

Richards, C.S., Paterson, I.D. \& Villet, M.H. (2008) Estimating the age of immature Chrysomya albiceps (Diptera: Calliphoridae), correcting for temperature and geographical latitude. International Journal of Legal Medicine, 122, 271-279.

Richards, C.S. \& Villet, M.H. (2009) Data quality in thermal summation development models for forensically important blowflies. Medical and Veterinary Entomology, 23, 269-276.

Rognes, K. (1985) Revision of the bird-parasitic blow fly genus Trypocalliphora Peus, 1960 (Diptera: Calliphoridae). Entomologica Scandinavia, 15, 371-382.

Rognes, K. (1986) The systematic position of the genus Helicobosca Bezzi with a discussion of the monophyly of the calyptrate families Calliphoridae, Rhinophoridae, Sarcophagidae, Tachinidae (Diptera). Entomologica Scandinavia, 17, 75-92. 
Rognes, K. (1991) Blowflies (Diptera: Calliphoridae) of Fennoscandia and Denmark. Fauna Entomologica Scandinavia, 24, 1-272.

Rognes, K. (1993) A new genus of Helicoboscinae from the Himalayas (Diptera: Calliphoridae), with emended genus and subfamily concepts. Entomologica Scandinavia, 23, 391-404.

Rognes, K. (1997) The Calliphoridae (blowflies) (Diptera: Oestroidea) are not a monophyletic group. Cladistics, 13, 27-66.

Rognes, K. (1998) Family Calliphoridae. Manual of Palaearctic Diptera, vol. 3 (ed. by L. Papp \& B. Darvas), pp. 617-648, Science Herald, Budapest.

Rohdendorf, B.B. (1967) The directions of historical development of Sarcophagidae (Diptera). Trudy Paleontologicheskogo Instituta Akademii Nauk SSSR. Proceedings of the Palaeontological Journal of the Academy of Science, USSR, 116, 1-92.

Rubinoff, D. \& Holland, B.S. (2005) Between two extremes: mitochondrial DNA is neither the panacea nor the nemesis of phylogenetic and taxonomic inference. Systematic Biology, 54, 952-961.

Sabrosky, C.W. (1967) Corrections to a catalog of the Diptera of America north of Mexico. Bulletin of the Entomological Society of America, 13, 115-125.

Sabrosky, C.W. (1986) North American species of Cuterebra, the rabbit and rodent bot flies ( Diptera: Cuterebridae), Thomas Say Foundation Monogaph, 11, 1-240.

Sabrosky, C.W., Bennett, G.F. \& Whitworth, T.L. (1989) Bird blowflies (Protocalliphora) in North America (Diptera: Calliphoridae), with notes on Palearctic species. Smithsonian Institute Press, Washington D.C., pp. 312.

Sabrosky, C.W. (1999) Family group names in Diptera- An annotated catalogue. The International Journal of the North American Dipterists' Society, 10, 3-327. 
Schumann, H. (1965) Die Schmeissfliegengattung Calliphora. Merckblatter ueber angewandte Parasitenkunde, 11, 1-14.

Schumann, H. (1986) Family Calliphoridae. Catalog of the Palaearctic Diptera Calliphoridae-Sarcophagidae, Vol. 12 (ed. by A. Soos \& L. Papp), pp. 11-58.

Senior-White, R., Aubertin, D. \& Smart, J. (1940) Diptera: Vol. VI. Family Calliphoridae. Fauna of British India, London.

Shannon, R.C. (1923) Genera of Nearctic Calliphoridae, blowflies, with revision of the Calliphorini. Insecutor Inscitiae Menstruus, 11, 101-118.

Shewell, G.E. (1987) Sarcophagidae. Manual of Nearctic Diptera, Vol. 2 (ed. by J.F. McAlpine), Monograph No. 28, pp. 1159-1186, Research Branch, Agriculture Canada.

Shewell, G.E. (1991) Book Review (of Rognes: Blowflies (Diptera: Calliphoridae) of Fennoscandia and Denmark) Entomologica Scandinavia, 22, 364.

Singh, B., Kurahashi, H. \& Wells, J.D. (2010) Molecular phylogeny of the blowfly genus Chrysomya. Medical and Veterinary Entomology, DOI: 10.1111/j.13652915.2010.00914.x.

Singh, B. \& Wells, J.D. (2011) Chrysomyinae (Diptera: Calliphoridae) is monophyletic: a molecular systematic analysis. Systematic Entomology, DOI: 10.1111/j.13653113.2011.00568.x

Smith, K.G.V. (1986) A Manual of Forensic Entomology. London, Ithaca, British Museum of Natural History, Cornell University Press.

Sorenson, M.D. \& Franzosa, E.A. (2007) TreeRot Version 3. Boston University, Boston, MA.

Sota, T. \& Vogler, A.P. (2001) Incongruence of mitochondrial nuclear gene trees in the carabid beetles Ohomopterus. Systematic Biology, 50, 39-59. 
Spradbery, J. P. (1992) Studies on the prepupal and puparial stages of the Old-World Screw-worm Fly, Chrysomya bezziana Villeneuve (Diptera: Calliphoridae). CSIRO Division of Entomology, Canberra, Australia, Technical paper, 29, 1-24.

Steve, R. \& Helen, J.S. (2000) Primer3 on the WWW for general users and for biologist programmers. Bioinformatics Methods and Protocols: Methods in Molecular Biology (ed. by Krawetz S. \& Misener S.), pp. 365-386, Humana Press, Totowa, NJ.

Stevens, J. \& Wall, R. (2001) Genetic relationship between blowflies (Calliphoridae) of forensic importance. Forensic Science International, 120, 116-123.

Stevens, J.R., Wall, R. \& Wells, J.D. (2002) Paraphyly in Hawaiian hybrid blowfly populations and the evolutionary history of anthropophilic species. Insect Molecular Biology, 11, 141-148.

Stevens, J.R. (2003) The evolution of Myiasis in blowflies (Calliphoridae). International Journal for Parasitology, 33, 1105-1113.

Sukontason, K., Sukontason, K.L., Piangjai, S., Chaiwong, T., Boonchu, N. \& Kurahashi, H. (2003) Hairy maggots of Chrysomya villeneuvi (Diptera: Calliphoridae), a fly species of forensic importance. Journal of Medical Entomology, 40, 983-984.

Sukontason, K., Sukontason, K.L., Piangjai, S., Narongchai, P., Samai, W., Boonchu, N., Sripakdee, D., Ngern-klun, R. \& Siriwattanarungsee, S. (2005) Morphology of second and third instars of Chrysomya villeneuvi Patton (Diptera: Calliphoridae), a fly species of forensic importance. Forensic Science International, 154, 195199.

Swofford, D. \& Olsen, G. (1990) Phylogeny reconstruction. Molecular systematic (ed. by D. Hillis \& C. Moritz), pp. 401-511, Sinauer Associates, Sunderland, Massachusetts. 
Swofford, D.L. (2002) PAUP, phylogenetic analysis using parsimony (and other methods), version 4. Sinauer Associates, Sunderland, Massachusetts.

Tachi, T. \& Shima, H. (2010) Molecular phylogeny of the subfamily Exoristinae (Diptera, Tachinidae), with discussions on the evolutionary history of female oviposition strategy. Systematic Entomology, 35, 148-163.

Tamura, K., Peterson, D., Peterson, N., Stecher, G., Nei, M. \& Kumar, S. (In press) MEGA5: Molecular Evolutionary Genetics Analysis using Maximum Likelihood, Evolutionary Distance, and Maximum Parsimony Methods. Molecular Biology and Evolution.

Thompson, W.R. (1934) The tachinid parasite of woodlice. Parasitology, 26, 378-448.

Townsend, C.H.T. (1916) Diagnosis of new genera of muscoid flies founded on old species. Proceedings of the United States National Museum, 49, 617-633.

Townsend, C.H.T. (1934-1942) Manual of Myiology in twelve parts. Charles Townsend and Filhos, Itaquaquecetuba, Sao Paulo, Brazil.

Tsang, W.S., Pape, T. \& Toole, D.K. (2008). The first blow fly parasitoid takes a head start in its termite host (Diptera: Calliphoridae, Bengaliinae; Isoptera: Microtermitidae). Systematics and Biodiversity, 6, 25-30.

Tschorsnig, H.-P. (1985) Die Struktur des männlichen Postabdomens der Rhinophoridae (Diptera). Stuttgarter Beiträge zurNaturkunde, 375, 1-18.

Ullerich, F.-H. (1958) Monogene Fortpflanzung bei der Fliege Chrysomya albiceps. Zeitschrift für Naturforschung, 13, 473-474.

Ullerich, F.-H. (1963) Geschlechtschromosomen und Geschlechtsbestimmung bei einigen Calliphorinen (Calliphoridae: Diptera). Chromosoma, 14, 45-110. 
Ullerich, F.-H. (1976) Chromosomenverhaltnisse, konstitutives Heterochromatin und Geschlechtsbestimmung bei einigen Artender Gattung Chrysomya (Diptera: Calliphoridae). Chromosoma, 58, 113-136.

Ullerich, F.-H. \& Schottke, M. (2006) Karyotypes,Constitutive heterochromatin and genomic DNA values in the blow fly genera Chrysomya, Lucilia, and Protophormia (Diptera: Calliphoridae). Genome, 49, 584-597.

Ulleyett, G.C. (1950) Competition for food and Allied Phenomena in sheep blowfly populations. Philosophical Transactions of the Royal Society of London Series B - Biological Sciences, 234, 77-174.

Verves, Y.G. (1986) Family Sarcophagidae. Catalog of the Palaearctic Diptera, Calliphoridae-Sarcophagidae, pp. 58-193, Vol. 12 (ed. by A. Soos \& L. Papp).

Verves, Y.G. (2005) A catalogue of Oriental Calliphoridae (Diptera). An International Journal of Dipterological Research, 16, 233-310.

Wallman, J.F., Leys, R. \& Hogendoom, K. (2005) Molecular systematics of Australian carrion-breeding blow flies (Diptera: Calliphoridae) based on mitochondrial DNA. Invertebrate Systematics, 19, 1-15.

Wells, J.D. (1991) Chrysomya megacephala (Diptera: Calliphoridae) has reached the continental United States: Review of its biology, pest status, and spread around the World. Journal of Medical Entomology, 28, 471-473.

Wells, J.D. \& Greenberg, B. (1992a) Laboratory interaction between introduced Chrysomya rufifacies and native Cochliomyia macellaria (Diptera: Calliphoridae). Environmental Entomology, 21, 640-645.

Wells, J.D. \& Greenberg, B. (1992b) Interaction between Chrysomya rufifacies and Cochliomyia macellaria (Diptera: Calliphoridae): the possible consequences of an invasion. Bulletin of Entomological Research, 82, 133-137. 
Wells, J.D. \& Kurahashi, H. (1994) Chrysomya megacephala (Fabricius) (Diptera: Calliphoridae) development: Rate, variation and the implications for forensic entomology. Japanese Journal of Sanitary Zoology, 45, 303-309.

Wells, J.D., Singh, M. M., Suzuki, K., Miura, M. \& Kurahashi, H. (1994) Male eye dimorphism and synanthropy in Chrysomya pinguis (Walker) (Diptera: Calliphoridae). Japanese Journal of Sanitary Zoology, 45, 299-302.

Wells, J.D. \& Kurahashi, H. (1996) A new species of Chrysomya (Diptera: Calliphoridae) from Sulawesi, Indonesia, with a key to the Oriental, Australasian and Oceanian species. Medical Entomology \& Zoology, 47, 131-138.

Wells, J.D. \& Kurahashi, H. (1997) Chrysomya megacephala is more resistant to attack by Chrysomya rufifacies in a laboratory arena than is Cochliomyia macellaria. The Pan-Pacific Entomologist, 73, 16-20.

Wells, J.D. \& Sperling, F.A.H. (1999) Molecular Phylogeny of Chrysomya albiceps and C. rufifacies (Diptera: Calliphoridae). Journal of Medical Entomology, 36, 222226.

Wells, J.D. \& Sperling, F.A.H. (2001) DNA-based identification of forensically important Chrysomyinae (Diptera: Calliphoridae). Forensic Science International, 120, 110115.

Wells, J.D., Pape, T. \& Sperling, F.A.H. (2001) DNA-based identification and molecular systematics of forensically important Sarcophagidae. Journal of Forensic Sciences, 46, 1098-1102.

Wells, J.D., Goff, M.L., Tomberlin, J.K. \& Kurahashi, H. (2002) Molecular systematic of the endemic Hawaiian blowfly genus Dyscritomyia Grimshaw (Diptera: Calliphoridae). Medical Entomology and Zoology, 53, 231-238.

Wells, J.D. \& Williams, D.W. (2007) Validation of a DNA-based method for identifying Chrysomyinae (Diptera: Calliphoridae) used in death investigation. International Journal of Legal Medicine, 121, 1-8. 
Whitworth, T.L. (2003) A key to the puparia of 27 species of North American Protocalliphora Hough (Diptera: Calliphoridae) from bird nests and two new puparial descriptions. Proceedings of the Entomological Society of Washington, 105, 995-1033.

Whitworth, T.L. (2006). Keys to the genera and species of blow flies (Diptera: Calliphoridae) of America north of Mexico. Proceedings of the Entomological Society of Washington, 108, 689-725.

Whitworth, T.L., Dawson, R.D., Magalon, H. \& Baudry, E. (2007) DNA barcoding cannot reliably identify species of the blow fly genus Protocalliphora (Diptera: Calliphoridae). Proceedings of the Royal Society B, 274, 1731-1739.

Wiegmann, B.M., Trautwein, M.D., Winkler, I.S. et al. (2011) Episodic radiations in the fly tree of life. Proceedings of the National Academy of Sciences of the United States of America, 108, 5690-5695.

Wiens, J.J., Brandley, M.C. \& Reeder, T.W. (2006) Why does a trait evolve multiple times within a clade? Repeated evolution of snakelike body form in squamate reptiles. Evolution, 60, 123-141.

Wolfe, L.S. (1959) Observations on the histopathological changes caused by the larvae of Hypoderma bovis (de Villers.) (Diptera: Oestridae) in tissue of cattle. Canadian Journal of Animal Science, 39, 145-157.

Wood, D.M. (1987a) Oestridae. Manual of Nearctic Diptera, (ed. by J.F. McAlpine), Vol. 2, Monograph No. 28, pp. 1147-1158, Research Branch, Agriculture Canada.

Wood, D.M. (1987b) Rhinophoridae. Manual of Nearctic Diptera, (ed. by J.F. McAlpine), Vol. 2, Monograph No. 28, pp. 1187-1191, Research Branch, Agriculture Canada.

Wood, D.M. (1987c) Tachinidae. Manual of Nearctic Diptera, (ed. by J.F. McAlpine), Vol. 2, Monograph No. 28, pp. 1193-1269, Research Branch, Agriculture Canada. 
Zuccon, A. \& Zuccon, D. (2010) MrEnt v.2.2 Program distributed by the authors [WWW document] URL http://www.mrent.org [accessed in 2010 and 2011].

Zumpt, F. (1951) Myiasis in man and animals in Africa. South African Journal of Clinical Science, 2, 38-69.

Zumpt, F. (1957) Some remarks on the classification of the Oestridae s.lat. (Diptera). Journal of the Entomological Society of Southern Africa, 20, 154-161.

Zumpt, F. (1965) Myiasis in man and animals in the Old World. Butterworths, London.

Zwickl, D.J. (2006) Genetic algorithm approaches for the phylogenetic analysis of large biological sequence datasets under the maximum likelihood criterion. Ph.D. dissertation, The University of Texas, Austin, USA. 


\section{APPENDIX A: List of morphological characters that support monophyly of various oestroid groups.}

Appendix 1: Characters that support monophyly of the Axiniidae (Colless, 1994).

1. Characteristic antennal segment 3 (axe-head type or fissicorn type) in male.

2. Antennal segment 2 with long apical projections that articulate with segment 3 .

3. Small but distinct bristles on middle of fronto-orbital plate.

4. Fronto-orbital plates broad.

5. Subcosta of wing with no sub-basal kink.

6. Fork of Rs unswollen and without setulae.

7. Male surstylus with pointed inner and broad outer lobe.

Appendix 2: Characters that support monophyly of the Tachinidae (Wood, 1987c; Pape, 1992; Rognes, 1997).

1. Subscutellum well-developed.

2. Mandibles reduced in first instar larvae.

3. Labrum fused and contiguous with rest of cephalopharyngeal skeleton in first instar larvae

Appendix 3: Characters that support monophyly of the Rhinophoridae (Crosskey, 1977; Pape, 1986; Rognes, 1991; 1997).

1. Mandible toothed in the first instar larva.

2. Ventral plate of the distiphallus fused and well-developed.

3. All members parasitic on woodlice.

Appendix 4: Characters that support monophyly of the Sarcophagidae (Pape, 1992).

1. Margin of tergite 1 and 2 covered by abdominal sternite 2 .

2. No alpha setae.

3. $10^{\text {th }}$ sternite in male divided, small, and positioned at a right angle to median plane.

4. Posterior spiracles are located in the cavity and peritreme are incomplete in the second and third instar larvae. 
Appendix 5: Characters that support monophyly of the Oestridae (Pape, 2001).

1. Sticky eggs.

2. Several segments of first instar larva with circle of thorn-like band.

3. The puparium opens by splitting of a dorsal valve.

4. Adult mouthparts reduced and non-functional.

5. Adult body pilose and bristleless.

6. Setae absent on anatergite.

7. Subcosta strait and runs parallel to costa before merging into it.

8. Second abdominal sternite and tergal margin are well-separated by folded membrane.

Appendix 6: Characters that support monophyly of different subfamilies of the Calliphoridae.

Appendix 6.1: Ameniinae (Rognes, 1986; 1997).

1. Facial carina very strong

2. $2+1$ branching pattern of spermathecal ducts.

3. Subscutellum comparatively developed but weaker than Tachinidae.

4. Sternum (ST) 8 of ovipositor larger in width than in length.

Appendix 6.2: Auchmeromyiinae (Rognes, 1997).

1. Presence of small but unique setae in between first and second post-sutural supraalars.

2. Lateral scutellar marginals in large numbers.

Appendix 6.3: Bengaliinae (Senior-White et al., 1940; James, 1966, Kurahashi, 1987).

1. Humeral setae two.

2. Outer post humeral seta absent.

3. Metakatepisternum with setulae.

4. Posterior side of hind coxa with setae.

Appendix 6.4: Phumosiinae (Rognes, 1997).

1. Aedeagus without epiphallus.

2. Katatergite with long bristles.

Appendix 6.5: Mesembrinellinae (Guimaraes, 1977; Rognes, 1997). 
1. Single large reniform operculum on the metathoracic spiracle.

2. Comparatively strong subscutellum.

3. Female with crossed inter-frontals.

4. Translucent wings with strongly curved $M_{1}$.

Appendix 6.6: Helicoboscinae (Rognes, 1991; 1993; 1997).

1. Setae absent on post-alar wall.

2. $2+1+1$ or $1+1+1$ pattern of katepisternal setae.

3. Anterior projections of the tentoropharygeal sclerite are absent in first instar larvae.

4. Posterior spiracular plates completely sclerotised in third instar larva.

Appendix 6.7: Toxotarsinae (Dear, 1979; Rognes, 1997).

1. Setae present on ventral surface of stem vein (exceptions are Toxotarsus ambrosianus Lupes and T. nigrocyaneus (Walker))

2. Only two scutellar marginals present.

\section{Appendix 6.8: Calliphorinae (Rognes, 1991).}

1. Upper part of lower calypter and lower half of anterior part of anepimeron with bristles.

2. Setae absent on ventral surface of costa beyond the point where $R_{1}$ joins it.

3. Katepimeron not well-separated from meron.

4. ST8 incomplete and apically divided into two lobes.

Appendix 6.9: Luciliinae (Rognes, 1991; 1997).

1. No setae on parafacialia.

2. Bristles present in lowermost region of metakatepisternum.

3. Presence of metallic-green setose sclerites on the posterior part of suprasquamal ridge

\section{Appendix 6.10: Melanomyinae (Rognes, 1991).}

1. T8 and epiproct fused.

2. Cerci small and wide.

3. Microtrichiae absent on sclerites (except hypoproct) and pleural membrane of ovipositor.

4. ST8 either very reduced or absent. 
5. No setae and denticles on acrophallus.

Appendix 6.11: Polleniinae (Rognes, 1991; 1997).

1. Comparatively strong facial carina.

2. Acrophallus unarmed and lacks denticles.

Appendix 6.12: Rhiniinae (Rognes, 1991; 1997).

1. Protruded lower part of the face.

2. Shiny submarginal band on upper half of occiput.

3. Upper side of stem vein with row of setae.

4. Apical spines on the lobes of male sternite 5 .

5. Ventral plates fused and form a ring around distiphallus.

Appendix 6.13: Chrysomyinae (Rognes, 1991).

1. Separation of katepimeron and meron not clear.

2. Presence of a row of setae on the antero-ventral edge of the posterior spiracle.

3. Upper side of the stem vein with row of setae.

4. Peritreme incomplete in the third instar larvae. 


\section{APPENDIX B: Tables showing pairwise p-distance and pairwise transition-transversion ratio of different genes used in this study.}

TABLE A1: Pairwise p-distance of cytochrome oxidase subunit one $(C O I)$ gene used in Chrysomya phylogeny (Chapter 2).

\begin{tabular}{|c|c|c|c|c|c|c|c|c|c|c|c|c|c|c|c|c|}
\hline & 1 & 2 & 3 & 4 & 5 & 6 & 7 & 8 & 9 & 10 & 11 & 12 & 13 & 14 & 15 & 16 \\
\hline 2 & 0.079 & & & & & & & & & & & & & & & \\
\hline 3 & 0.085 & 0.109 & & & & & & & & & & & & & & \\
\hline 4 & 0.098 & 0.101 & 0.074 & & & & & & & & & & & & & \\
\hline 5 & 0.087 & 0.094 & 0.077 & 0.101 & & & & & & & & & & & & \\
\hline 6 & 0.096 & 0.107 & 0.087 & 0.098 & 0.077 & & & & & & & & & & & \\
\hline 7 & 0.102 & 0.108 & 0.094 & 0.104 & 0.089 & 0.033 & & & & & & & & & & \\
\hline 8 & 0.096 & 0.101 & 0.092 & 0.1 & 0.083 & 0.039 & 0.048 & & & & & & & & & \\
\hline 9 & 0.098 & 0.104 & 0.093 & 0.1 & 0.083 & 0.044 & 0.049 & 0.03 & & & & & & & & \\
\hline 10 & 0.105 & 0.111 & 0.104 & 0.11 & 0.093 & 0.068 & 0.07 & 0.064 & 0.054 & & & & & & & \\
\hline 11 & 0.094 & 0.109 & 0.086 & 0.102 & 0.081 & 0.071 & 0.078 & 0.066 & 0.067 & 0.088 & & & & & & \\
\hline 12 & 0.104 & 0.121 & 0.101 & 0.117 & 0.095 & 0.085 & 0.091 & 0.079 & 0.081 & 0.108 & 0.046 & & & & & \\
\hline 13 & 0.088 & 0.089 & 0.075 & 0.094 & 0.064 & 0.066 & 0.071 & 0.068 & 0.067 & 0.076 & 0.058 & 0.071 & & & & \\
\hline 14 & 0.092 & 0.096 & 0.084 & 0.099 & 0.078 & 0.07 & 0.078 & 0.07 & 0.074 & 0.091 & 0.068 & 0.077 & 0.055 & & & \\
\hline 15 & 0.091 & 0.09 & 0.078 & 0.098 & 0.076 & 0.068 & 0.077 & 0.068 & 0.07 & 0.085 & 0.074 & 0.092 & 0.063 & 0.065 & & \\
\hline 16 & 0.082 & 0.093 & 0.08 & 0.104 & 0.073 & 0.075 & 0.074 & 0.073 & 0.072 & 0.085 & 0.066 & 0.078 & 0.058 & 0.06 & 0.05 & \\
\hline 17 & 0.078 & 0.085 & 0.07 & 0.092 & 0.068 & 0.063 & 0.069 & 0.067 & 0.061 & 0.079 & 0.066 & 0.073 & 0.05 & 0.053 & 0.052 & 0.053 \\
\hline 18 & 0.09 & 0.109 & 0.079 & 0.098 & 0.076 & 0.072 & 0.08 & 0.072 & 0.074 & 0.093 & 0.069 & 0.081 & 0.061 & 0.057 & 0.051 & 0.057 \\
\hline 19 & 0.091 & 0.094 & 0.078 & 0.096 & 0.071 & 0.068 & 0.078 & 0.074 & 0.067 & 0.084 & 0.068 & 0.082 & 0.061 & 0.057 & 0.055 & 0.053 \\
\hline 20 & 0.083 & 0.102 & 0.077 & 0.095 & 0.075 & 0.074 & 0.08 & 0.073 & 0.07 & 0.087 & 0.069 & 0.075 & 0.052 & 0.058 & 0.056 & 0.054 \\
\hline 21 & 0.087 & 0.108 & 0.07 & 0.099 & 0.07 & 0.07 & 0.076 & 0.072 & 0.069 & 0.085 & 0.067 & 0.082 & 0.053 & 0.053 & 0.051 & 0.051 \\
\hline 22 & 0.087 & 0.1 & 0.074 & 0.094 & 0.075 & 0.061 & 0.07 & 0.063 & 0.066 & 0.079 & 0.064 & 0.071 & 0.055 & 0.047 & 0.053 & 0.051 \\
\hline 23 & 0.082 & 0.098 & 0.074 & 0.09 & 0.07 & 0.063 & 0.074 & 0.066 & 0.066 & 0.083 & 0.063 & 0.078 & 0.052 & 0.05 & 0.046 & 0.049 \\
\hline 24 & 0.087 & 0.106 & 0.079 & 0.094 & 0.076 & 0.066 & 0.077 & 0.07 & 0.069 & 0.087 & 0.066 & 0.079 & 0.056 & 0.053 & 0.054 & 0.057 \\
\hline
\end{tabular}




\begin{tabular}{|l|l|l|l|l|l|l|l|l|l|l|l|l|l|l|l|l|}
$\mathbf{2 5}$ & 0.082 & 0.097 & 0.074 & 0.091 & 0.072 & 0.063 & 0.074 & 0.066 & 0.066 & 0.082 & 0.064 & 0.077 & 0.051 & 0.05 & 0.045 & 0.048 \\
\hline $\mathbf{2 6}$ & 0.079 & 0.09 & 0.082 & 0.095 & 0.076 & 0.07 & 0.074 & 0.071 & 0.073 & 0.085 & 0.07 & 0.076 & 0.062 & 0.066 & 0.066 & 0.061 \\
\hline $\mathbf{2 7}$ & 0.074 & 0.082 & 0.078 & 0.091 & 0.072 & 0.065 & 0.075 & 0.066 & 0.067 & 0.077 & 0.067 & 0.069 & 0.056 & 0.062 & 0.059 & 0.057 \\
\hline
\end{tabular}

\begin{tabular}{|l|l|l|l|l|l|l|l|l|l|l|}
\hline & $\mathbf{1 7}$ & $\mathbf{1 8}$ & $\mathbf{1 9}$ & $\mathbf{2 0}$ & $\mathbf{2 1}$ & $\mathbf{2 2}$ & $\mathbf{2 3}$ & $\mathbf{2 4}$ & $\mathbf{2 5}$ & $\mathbf{2 6}$ \\
\hline $\mathbf{1 8}$ & 0.051 & & & & & & & & & \\
\hline $\mathbf{1 9}$ & 0.05 & 0.052 & & & & & & & & \\
\hline $\mathbf{2 0}$ & 0.044 & 0.03 & 0.052 & & & & & & & \\
\hline $\mathbf{2 1}$ & 0.04 & 0.024 & 0.044 & 0.026 & & & & & & \\
\hline $\mathbf{2 2}$ & 0.04 & 0.021 & 0.044 & 0.034 & 0.025 & & & & & \\
\hline $\mathbf{2 3}$ & 0.042 & 0.015 & 0.045 & 0.03 & 0.019 & 0.015 & & & & \\
\hline $\mathbf{2 4}$ & 0.046 & 0.022 & 0.049 & 0.036 & 0.026 & 0.02 & 0.007 & & & \\
\hline $\mathbf{2 5}$ & 0.042 & 0.014 & 0.045 & 0.029 & 0.021 & 0.015 & 0.001 & 0.009 & & \\
\hline $\mathbf{2 6}$ & 0.059 & 0.064 & 0.058 & 0.065 & 0.061 & 0.056 & 0.061 & 0.063 & 0.061 & \\
\hline $\mathbf{2 7}$ & 0.053 & 0.067 & 0.056 & 0.065 & 0.06 & 0.057 & 0.058 & 0.06 & 0.056 & 0.022 \\
\hline
\end{tabular}

\section{Taxon key for table A1:}

\begin{tabular}{|l|l|l|l|l|l|}
\hline $\mathbf{1}$ & Lucilia sericata & $\mathbf{1 0}$ & Chrysomya incisuralis & $\mathbf{1 9}$ & Chrysomya bezziana \\
\hline $\mathbf{2}$ & Calliphora vomitoria & $\mathbf{1 1}$ & Chrysomya varipes & $\mathbf{2 0}$ & Chrysomya thanomthini \\
\hline $\mathbf{3}$ & Cochliomyia macellaria & $\mathbf{1 2}$ & Chrysomya flavifrons & $\mathbf{2 1}$ & Chrysomya pinguis \\
\hline $\mathbf{4}$ & Cochliomyia hominivorax & $\mathbf{1 3}$ & Chrysomya norrisi & $\mathbf{2 2}$ & Chrysomya greenbergi \\
\hline $\mathbf{5}$ & Phormia regina & $\mathbf{1 4}$ & Chrysomya nigripes & $\mathbf{2 3}$ & Chrysomya cabrearai \\
\hline $\mathbf{6}$ & Chrysomya albiceps & $\mathbf{1 5}$ & Chrysomya putoria & $\mathbf{2 4}$ & Chrysomya megacephala \\
\hline $\mathbf{7}$ & Chrysomya rufifacies & $\mathbf{1 6}$ & Chrysomya marginalis & $\mathbf{2 5}$ & Chrysomya pacifica \\
\hline $\mathbf{8}$ & Chrysomya villeneuvi & $\mathbf{1 7}$ & Chrysomya chani & $\mathbf{2 6}$ & Chrysomya semimetallica \\
\hline $\mathbf{9}$ & Chrysomya yayukae & $\mathbf{1 8}$ & Chrysomya defixa & $\mathbf{2 7}$ & Chrysomya latifrons \\
\hline
\end{tabular}


TABLE A2: Pairwise transition-transversion ratio of cytochrome oxidase subunit one (CO I) gene used in Chrysomya phylogeny (Chapter 2).

\begin{tabular}{|c|c|c|c|c|c|c|c|c|c|c|c|c|c|c|c|c|c|c|}
\hline & 1 & 2 & 3 & 4 & 5 & 6 & 7 & 8 & 9 & 10 & 11 & 12 & 13 & 14 & 15 & 16 & 17 & 18 \\
\hline 2 & 1.16 & & & & & & & & & & & & & & & & & \\
\hline 3 & 0.83 & 0.9 & & & & & & & & & & & & & & & & \\
\hline 4 & 0.92 & 0.78 & 2.65 & & & & & & & & & & & & & & & \\
\hline 5 & 1.13 & 1 & 0.98 & 1.25 & & & & & & & & & & & & & & \\
\hline 6 & 1 & 0.71 & 1.2 & 1.21 & 1.25 & & & & & & & & & & & & & \\
\hline 7 & 1.03 & 0.85 & 1.27 & 1.24 & 1.45 & 4.56 & & & & & & & & & & & & \\
\hline 8 & 0.97 & 0.64 & 1.2 & 1.11 & 1.27 & 4.45 & 3.11 & & & & & & & & & & & \\
\hline 9 & 1.01 & 0.73 & 1.23 & 1.04 & 1.28 & 2.82 & 2.32 & 3.5 & & & & & & & & & & \\
\hline 10 & 1.05 & 0.93 & 1.31 & 1.16 & 1.56 & 2.06 & 1.84 & 2.39 & 1.63 & & & & & & & & & \\
\hline 11 & 1.03 & 0.92 & 1.06 & 1.14 & 1.6 & 1.53 & 1.73 & 1.55 & 1.54 & 1.73 & & & & & & & & \\
\hline 12 & 1.43 & 1.07 & 1.02 & 1.04 & 1.69 & 1.8 & 1.78 & 1.6 & 1.75 & 2.26 & 2.17 & & & & & & & \\
\hline 13 & 1.01 & 0.68 & 1.13 & 1.15 & 1.61 & 1.49 & 1.37 & 1.5 & 1.33 & 1.38 & 1.97 & 1.9 & & & & & & \\
\hline 14 & 0.88 & 0.96 & 1.02 & 1.14 & 1.31 & 1.18 & 1.22 & 1.16 & 1.04 & 1.27 & 1.36 & 0.85 & 1.36 & & & & & \\
\hline 15 & 0.88 & 0.92 & 1.04 & 1.1 & 1.64 & 1.83 & 1.91 & 1.93 & 1.47 & 1.79 & 1.79 & 1.67 & 1.82 & 1.31 & & & & \\
\hline 16 & 1.03 & 0.98 & 1.19 & 1.24 & 1.72 & 1.57 & 1.61 & 1.56 & 1.46 & 1.71 & 1.57 & 1.44 & 1.71 & 1.23 & 2.44 & & & \\
\hline 17 & 0.94 & 0.89 & 0.96 & 1.29 & 1.69 & 1.43 & 1.47 & 1.51 & 1.17 & 1.49 & 1.76 & 1.31 & 1.66 & 1 & 1.5 & 1.62 & & \\
\hline 18 & 1.25 & 1.29 & 1.73 & 1.53 & 2.62 & 2.79 & 2.59 & 2.24 & 2.11 & 2.31 & 2.28 & 2.14 & 3.18 & 1.72 & 2.76 & 3.37 & 3.53 & \\
\hline 19 & 1.26 & 1.08 & 1.53 & 1.45 & 2.3 & 2.06 & 2.05 & 2.05 & 1.63 & 1.78 & 1.81 & 1.68 & 2.48 & 1.84 & 2.58 & 2.45 & 2.85 & 10.14 \\
\hline 20 & 0.95 & 1.05 & 1.38 & 1.35 & 2.26 & 2.55 & 2.13 & 2.03 & 1.73 & 1.89 & 1.83 & 1.46 & 2.25 & 1.53 & 2.5 & 2.39 & 2.1 & 6.5 \\
\hline 21 & 1.08 & 1.25 & 1.4 & 1.53 & 2.27 & 2.57 & 2.16 & 2.36 & 2.03 & 2.07 & 1.94 & 1.91 & 2.9 & 1.65 & 2.56 & 2.7 & 2.44 & 11.33 \\
\hline 22 & 1.15 & 1.05 & 1.51 & 1.5 & 2.48 & 2.36 & 2.06 & 1.94 & 1.88 & 1.88 & 2 & 1.64 & 3 & 1.18 & 2.67 & 2.7 & 2.88 & 31 \\
\hline 23 & 1.02 & 1.05 & 1.43 & 1.34 & 2.31 & 2.28 & 2.11 & 1.94 & 1.74 & 1.93 & 1.79 & 1.74 & 2.9 & 1.24 & 2 & 2.38 & 2.71 & 10 \\
\hline 24 & 1.13 & 1.14 & 1.52 & 1.36 & 2.41 & 2.26 & 2.11 & 2 & 1.78 & 1.93 & 2 & 1.6 & 2.91 & 1.25 & 2.24 & 2.57 & 3.18 & 7.25 \\
\hline 25 & 1.07 & 1.04 & 1.48 & 1.37 & 2.44 & 2.34 & 2.17 & 2 & 1.8 & 1.93 & 1.88 & 1.74 & 2.95 & 1.26 & 1.95 & 2.33 & 2.82 & 9.5 \\
\hline 26 & 1.03 & 1.02 & 1.29 & 1.28 & 1.49 & 1.33 & 1.4 & 1.22 & 1.2 & 1.4 & 1.3 & 1.42 & 1.44 & 1.17 & 1.65 & 1.75 & 1.5 & 2.34 \\
\hline 27 & 0.95 & 0.88 & 1.15 & 1.16 & 1.35 & 1.26 & 1.55 & 1.15 & 1.11 & 1.28 & 1.27 & 1.28 & 1.21 & 1.02 & 1.47 & 1.68 & 1.26 & 2.57 \\
\hline
\end{tabular}




\begin{tabular}{|l|l|l|l|l|l|l|l|l|}
\hline & $\mathbf{1 9}$ & $\mathbf{2 0}$ & $\mathbf{2 1}$ & $\mathbf{2 2}$ & $\mathbf{2 3}$ & $\mathbf{2 4}$ & $\mathbf{2 5}$ & $\mathbf{2 6}$ \\
\hline $\mathbf{2 0}$ & 6 & & & & & & & \\
\hline $\mathbf{2 1}$ & 7.38 & 6.8 & & & & & & \\
\hline $\mathbf{2 2}$ & 7.5 & 9 & 18.5 & & & & & \\
\hline $\mathbf{2 3}$ & 6.56 & 6.33 & 8.67 & 21 & & & & \\
\hline $\mathbf{2 4}$ & 5.82 & 5.62 & 7 & 9.33 & 4.5 & & & \\
\hline $\mathbf{2 5}$ & 6.67 & 6.17 & 9.67 & 22 & -- & 6 & & \\
\hline $\mathbf{2 6}$ & 1.97 & 1.94 & 2.32 & 1.87 & 1.97 & 1.94 & 2 & \\
\hline $\mathbf{2 7}$ & 1.9 & 1.97 & 2.33 & 1.93 & 1.83 & 1.81 & 1.8 & 10 \\
\hline
\end{tabular}

Taxa key for table A2: Same as table A1. 
TABLE A3: Pairwise p-distance of carbamoylphosphate synthetase (CPS) gene used in Chrysomya phylogeny (Chapter 2).

\begin{tabular}{|c|c|c|c|c|c|c|c|c|c|c|c|c|c|c|c|c|}
\hline & 1 & 2 & 3 & 4 & 5 & 6 & 7 & 8 & 9 & 10 & 11 & 12 & 13 & 14 & 15 & 16 \\
\hline 2 & 0.112 & & & & & & & & & & & & & & & \\
\hline 3 & 0.139 & 0.145 & & & & & & & & & & & & & & \\
\hline 4 & 0.139 & 0.14 & 0.062 & & & & & & & & & & & & & \\
\hline 5 & 0.131 & 0.127 & 0.1 & 0.102 & & & & & & & & & & & & \\
\hline 6 & 0.134 & 0.159 & 0.126 & 0.13 & 0.124 & & & & & & & & & & & \\
\hline 7 & 0.133 & 0.16 & 0.126 & 0.134 & 0.128 & 0.008 & & & & & & & & & & \\
\hline 8 & 0.146 & 0.165 & 0.135 & 0.135 & 0.133 & 0.035 & 0.038 & & & & & & & & & \\
\hline 9 & 0.144 & 0.166 & 0.127 & 0.132 & 0.128 & 0.026 & 0.03 & 0.032 & & & & & & & & \\
\hline 10 & 0.127 & 0.158 & 0.122 & 0.121 & 0.119 & 0.039 & 0.042 & 0.054 & 0.052 & & & & & & & \\
\hline 11 & 0.146 & 0.157 & 0.113 & 0.128 & 0.138 & 0.074 & 0.077 & 0.085 & 0.079 & 0.07 & & & & & & \\
\hline 12 & 0.147 & 0.16 & 0.123 & 0.128 & 0.131 & 0.077 & 0.077 & 0.086 & 0.083 & 0.08 & 0.047 & & & & & \\
\hline 13 & 0.134 & 0.167 & 0.136 & 0.132 & 0.135 & 0.09 & 0.085 & 0.092 & 0.088 & 0.086 & 0.103 & 0.09 & & & & \\
\hline 14 & 0.123 & 0.158 & 0.13 & 0.139 & 0.125 & 0.062 & 0.064 & 0.074 & 0.075 & 0.065 & 0.084 & 0.082 & 0.096 & & & \\
\hline 15 & 0.146 & 0.149 & 0.139 & 0.126 & 0.124 & 0.084 & 0.083 & 0.084 & 0.089 & 0.087 & 0.109 & 0.095 & 0.105 & 0.077 & & \\
\hline 16 & 0.122 & 0.149 & 0.114 & 0.119 & 0.115 & 0.087 & 0.088 & 0.1 & 0.098 & 0.093 & 0.11 & 0.109 & 0.112 & 0.085 & 0.101 & \\
\hline 17 & 0.12 & 0.154 & 0.129 & 0.129 & 0.122 & 0.095 & 0.093 & 0.111 & 0.109 & 0.105 & 0.109 & 0.109 & 0.12 & 0.091 & 0.102 & 0.053 \\
\hline 18 & 0.127 & 0.156 & 0.124 & 0.128 & 0.125 & 0.102 & 0.102 & 0.118 & 0.11 & 0.108 & 0.117 & 0.111 & 0.119 & 0.099 & 0.108 & 0.06 \\
\hline 19 & 0.118 & 0.147 & 0.119 & 0.12 & 0.112 & 0.08 & 0.08 & 0.094 & 0.095 & 0.092 & 0.108 & 0.103 & 0.112 & 0.081 & 0.088 & 0.046 \\
\hline 20 & 0.124 & 0.152 & 0.122 & 0.124 & 0.119 & 0.085 & 0.086 & 0.105 & 0.099 & 0.093 & 0.109 & 0.108 & 0.113 & 0.089 & 0.092 & 0.054 \\
\hline 21 & 0.114 & 0.147 & 0.11 & 0.118 & 0.112 & 0.083 & 0.082 & 0.099 & 0.096 & 0.09 & 0.108 & 0.102 & 0.109 & 0.077 & 0.086 & 0.052 \\
\hline 22 & 0.122 & 0.152 & 0.117 & 0.123 & 0.111 & 0.091 & 0.091 & 0.11 & 0.105 & 0.096 & 0.112 & 0.106 & 0.121 & 0.087 & 0.096 & 0.053 \\
\hline 23 & 0.122 & 0.158 & 0.12 & 0.126 & 0.119 & 0.091 & 0.092 & 0.112 & 0.105 & 0.104 & 0.11 & 0.102 & 0.119 & 0.088 & 0.096 & 0.062 \\
\hline 24 & 0.128 & 0.16 & 0.129 & 0.129 & 0.124 & 0.092 & 0.091 & 0.108 & 0.102 & 0.101 & 0.115 & 0.105 & 0.114 & 0.093 & 0.099 & 0.06 \\
\hline 25 & 0.116 & 0.139 & 0.119 & 0.126 & 0.114 & 0.087 & 0.088 & 0.103 & 0.102 & 0.094 & 0.104 & 0.105 & 0.118 & 0.092 & 0.106 & 0.075 \\
\hline 26 & 0.147 & 0.148 & 0.136 & 0.133 & 0.116 & 0.107 & 0.114 & 0.113 & 0.112 & 0.102 & 0.114 & 0.117 & 0.129 & 0.114 & 0.119 & 0.105 \\
\hline
\end{tabular}




\begin{tabular}{|l|l|l|l|l|l|l|l|l|l|}
\hline & $\mathbf{1 7}$ & $\mathbf{1 8}$ & $\mathbf{1 9}$ & $\mathbf{2 0}$ & $\mathbf{2 1}$ & $\mathbf{2 2}$ & $\mathbf{2 3}$ & $\mathbf{2 4}$ & $\mathbf{2 5}$ \\
\hline $\mathbf{1 8}$ & 0.051 & & & & & & & & \\
\hline 19 & 0.032 & 0.041 & & & & & & & \\
\hline 20 & 0.044 & 0.041 & 0.031 & & & & & & \\
\hline $\mathbf{2 1}$ & 0.041 & 0.044 & 0.032 & 0.04 & & & & & \\
\hline $\mathbf{2 2}$ & 0.047 & 0.044 & 0.034 & 0.039 & 0.045 & & & & \\
\hline 23 & 0.047 & 0.042 & 0.039 & 0.036 & 0.046 & 0.03 & & & \\
\hline 24 & 0.041 & 0.034 & 0.038 & 0.04 & 0.042 & 0.04 & 0.031 & & \\
\hline 25 & 0.069 & 0.085 & 0.057 & 0.073 & 0.074 & 0.079 & 0.084 & 0.083 & \\
\hline 26 & 0.113 & 0.115 & 0.105 & 0.113 & 0.118 & 0.118 & 0.122 & 0.12 & 0.059 \\
\hline
\end{tabular}

Taxa key for table A3:

\begin{tabular}{|r|l|r|l|r|l|}
\hline $\mathbf{1}$ & Lucilia sericata & $\mathbf{1 0}$ & Chrysomya incisuralis & $\mathbf{1 9}$ & Chrysomya thanomthini \\
\hline $\mathbf{2}$ & Calliphora vomitoria & $\mathbf{1 1}$ & Chrysomya varipes & $\mathbf{2 0}$ & Chrysomya pinguis \\
\hline $\mathbf{3}$ & Cochliomyia macellaria & $\mathbf{1 2}$ & Chrysomya norrisi & $\mathbf{2 1}$ & Chrysomya greenbergi \\
\hline $\mathbf{4}$ & Cochliomyia hominivorax & $\mathbf{1 3}$ & Chrysomya nigripes & $\mathbf{2 2}$ & Chrysomya cabrearai \\
\hline $\mathbf{5}$ & Phormia regina & $\mathbf{1 4}$ & Chrysomya putoria & $\mathbf{2 3}$ & Chrysomya megacephala \\
\hline $\mathbf{6}$ & Chrysomya albiceps & $\mathbf{1 5}$ & Chrysomya marginalis & $\mathbf{2 4}$ & Chrysomya pacifica \\
\hline $\mathbf{7}$ & Chrysomya rufifacies & $\mathbf{1 6}$ & Chrysomya chani & $\mathbf{2 5}$ & Chrysomya semimetallica \\
\hline $\mathbf{8}$ & Chrysomya villeneuvi & $\mathbf{1 7}$ & Chrysomya defixa & $\mathbf{2 6}$ & Chrysomya latifrons \\
\hline $\mathbf{9}$ & Chrysomya yayukae & $\mathbf{1 8}$ & Chrysomya bezziana & & \\
\hline
\end{tabular}


TABLE A4: Pairwise transition- transversion ratio of carbamoy/phosphate synthetase (CPS) gene used in Chrysomya phylogeny (Chapter 2).

\begin{tabular}{|c|c|c|c|c|c|c|c|c|c|c|c|c|c|c|c|c|c|c|}
\hline & 1 & 2 & 3 & 4 & 5 & 6 & 7 & 8 & 9 & 10 & 11 & 12 & 13 & 14 & 15 & 16 & 17 & 18 \\
\hline 2 & 1.32 & & & & & & & & & & & & & & & & & \\
\hline 3 & 1.88 & 1.28 & & & & & & & & & & & & & & & & \\
\hline 4 & 1.81 & 1.16 & 1.79 & & & & & & & & & & & & & & & \\
\hline 5 & 2.47 & 1.77 & 1.18 & 0.98 & & & & & & & & & & & & & & \\
\hline 6 & 2.42 & 2.07 & 1.97 & 1.97 & 2.18 & & & & & & & & & & & & & \\
\hline 7 & 2.18 & 1.89 & 2.03 & 1.94 & 2.06 & 2 & & & & & & & & & & & & \\
\hline 9 & 2.13 & 1.82 & 1.7 & 1.73 & 1.66 & 1.2 & 1.18 & 0.8 & & & & & & & & & & \\
\hline 10 & 2.09 & 1.91 & 1.89 & 1.78 & 2.06 & 2.3 & 2.67 & 2.07 & 1.75 & & & & & & & & & \\
\hline 11 & 2.27 & 1.95 & 2 & 2.03 & 2 & 2.39 & 2.47 & 1.8 & 1.95 & 2.22 & & & & & & & & \\
\hline 12 & 2.22 & 2.1 & 1.94 & 1.97 & 1.72 & 2.1 & 2.21 & 1.92 & 1.79 & 2.25 & 2.08 & & & & & & & \\
\hline 13 & 1.78 & 1.84 & 1.42 & 1.11 & 1.67 & 1.71 & 1.68 & 1.69 & 1.68 & 2.04 & 1.83 & 1.81 & & & & & & \\
\hline 14 & 2.13 & 1.84 & 1.86 & 1.82 & 2.41 & 2.77 & 2.92 & 2.69 & 1.95 & 2.64 & 2.37 & 2.25 & 2.17 & & & & & \\
\hline 15 & 2.26 & 1.82 & 1.74 & 1.55 & 1.76 & 2.09 & 2.3 & 1.73 & 1.81 & 1.96 & 1.73 & 1.41 & 1.87 & 1.9 & & & & \\
\hline 17 & 2.4 & 1.67 & 2.14 & 2.06 & 1.6 & 1.96 & 1.85 & 1.76 & 1.66 & 2.3 & 2.1 & 2.03 & 1.62 & 1.88 & 2.11 & 1.37 & & \\
\hline 18 & 2.06 & 1.75 & 2.09 & 1.92 & 1.59 & 2.58 & 2.38 & 2.23 & 2.1 & 2.5 & 3 & 2.75 & 1.81 & 2.39 & 2.14 & 1.83 & 1.53 & \\
\hline 19 & 2.12 & 1.91 & 2.06 & 2 & 1.64 & 2.24 & 2.15 & 1.86 & 1.79 & 2.39 & 2.87 & 2.61 & 1.71 & 2.37 & 2.12 & 1.6 & 1.7 & 2.18 \\
\hline 20 & 2 & 1.69 & 1.89 & 1.84 & 1.46 & 2 & 1.96 & 1.87 & 1.8 & 2.04 & 2 & 1.9 & 1.82 & 1.92 & 2.39 & 1.3 & 1.47 & 1.5 \\
\hline 21 & 2.13 & 1.72 & 1.91 & 1.86 & 1.57 & 2.5 & 2.25 & 2.11 & 2.12 & 2.45 & 2.56 & 2.15 & 2.07 & 2.21 & 1.92 & 1.75 & 1.92 & 3.11 \\
\hline 22 & 2.09 & 1.78 & 1.8 & 1.78 & 1.45 & 2.45 & 2.38 & 2.17 & 1.93 & 2.33 & 2.29 & 2.27 & 1.81 & 2.4 & 2.48 & 2.14 & 1.6 & 2.08 \\
\hline 23 & 2.25 & 1.85 & 2.52 & 2.15 & 1.66 & 2.35 & 2.17 & 2.17 & 1.87 & 2.52 & 2.64 & 2.32 & 1.73 & 2.18 & 1.93 & 2.12 & 2.33 & 4.14 \\
\hline 24 & 2.21 & 1.67 & 2.14 & 2.06 & 1.62 & 2.12 & 2 & 2.07 & 1.64 & 2.19 & 2.28 & 2.04 & 1.62 & 2.22 & 1.8 & 2 & 1.92 & 2.22 \\
\hline 25 & 2.06 & 1.85 & 1.38 & 1.52 & 1.59 & 1.7 & 1.65 & 1.56 & 1.46 & 1.93 & 1.61 & 2.11 & 1.54 & 1.67 & 1.97 & 1.33 & 1.64 & 1.63 \\
\hline 26 & 1.78 & 1.62 & 1.32 & 1.51 & 1.54 & 1.68 & 1.81 & 1.74 & 1.5 & 1.9 & 1.61 & 1.97 & 1.62 & 1.9 & 1.59 & 1.97 & 1.91 & 1.69 \\
\hline
\end{tabular}




\begin{tabular}{|r|r|r|r|r|r|r|r|}
\hline & $\mathbf{1 9}$ & $\mathbf{2 0}$ & $\mathbf{2 1}$ & $\mathbf{2 2}$ & $\mathbf{2 3}$ & $\mathbf{2 4}$ & $\mathbf{2 5}$ \\
\hline $\mathbf{2 0}$ & 1 & & & & & & \\
\hline $\mathbf{2 1}$ & 2.38 & 1.62 & & & & & \\
\hline $\mathbf{2 2}$ & 2.11 & 1.36 & 1.92 & & & & \\
\hline $\mathbf{2 3}$ & 2.3 & 1.82 & 2.9 & 1.78 & & & \\
\hline $\mathbf{2 4}$ & 1.67 & 1.62 & 3.5 & 2 & 3.33 & & \\
\hline $\mathbf{2 5}$ & 1.4 & 1.44 & 1.58 & 1.64 & 1.73 & 1.5 & \\
\hline $\mathbf{2 6}$ & 1.7 & 2 & 1.94 & 2.09 & 1.97 & 1.76 & 2.33 \\
\hline
\end{tabular}

Taxa key for table A4: Same as table A3. 
TABLE A5: Pairwise p-distance of cytochrome oxidase subunit one ( $C O I$ ) gene used in Chrysomyinae phylogeny (Chapter 3).

\begin{tabular}{|r|r|r|r|r|r|r|r|r|r|r|r|r|r|r|r|}
\hline & $\mathbf{1}$ & $\mathbf{2}$ & $\mathbf{3}$ & $\mathbf{4}$ & $\mathbf{5}$ & $\mathbf{6}$ & $\mathbf{7}$ & $\mathbf{8}$ & $\mathbf{9}$ & $\mathbf{1 0}$ & $\mathbf{1 1}$ & $\mathbf{1 2}$ & $\mathbf{1 3}$ & $\mathbf{1 4}$ & $\mathbf{1 5}$ \\
\hline $\mathbf{2}$ & 0.076 & & & & & & & & & & & & & & \\
\hline $\mathbf{3}$ & 0.094 & 0.094 & & & & & & & & & & & & & \\
\hline $\mathbf{4}$ & 0.089 & 0.084 & 0.096 & & & & & & & & & & & & \\
\hline $\mathbf{5}$ & 0.088 & 0.088 & 0.106 & 0.107 & & & & & & & & & & & \\
\hline $\mathbf{6}$ & 0.088 & 0.1 & 0.107 & 0.109 & 0.065 & & & & & & & & & & \\
\hline $\mathbf{7}$ & 0.082 & 0.109 & 0.099 & 0.112 & 0.081 & 0.045 & & & & & & & & & \\
\hline $\mathbf{8}$ & 0.111 & 0.097 & 0.108 & 0.112 & 0.086 & 0.087 & 0.08 & & & & & & & & \\
\hline $\mathbf{9}$ & 0.111 & 0.105 & 0.111 & 0.112 & 0.098 & 0.102 & 0.097 & 0.086 & & & & & & & \\
\hline $\mathbf{1 0}$ & 0.113 & 0.106 & 0.112 & 0.114 & 0.099 & 0.104 & 0.1 & 0.086 & 0.006 & & & & & & \\
\hline $\mathbf{1 1}$ & 0.095 & 0.106 & 0.125 & 0.111 & 0.107 & 0.095 & 0.099 & 0.111 & 0.117 & 0.119 & & & & & \\
\hline $\mathbf{1 2}$ & 0.086 & 0.102 & 0.119 & 0.11 & 0.08 & 0.081 & 0.099 & 0.111 & 0.112 & 0.116 & 0.092 & & & & \\
\hline $\mathbf{1 3}$ & 0.098 & 0.098 & 0.118 & 0.11 & 0.104 & 0.098 & 0.101 & 0.113 & 0.116 & 0.118 & 0.093 & 0.076 & & & \\
\hline $\mathbf{1 4}$ & 0.104 & 0.105 & 0.105 & 0.106 & 0.091 & 0.079 & 0.068 & 0.086 & 0.096 & 0.099 & 0.114 & 0.099 & 0.106 & & \\
\hline $\mathbf{1 5}$ & 0.089 & 0.086 & 0.108 & 0.1 & 0.071 & 0.07 & 0.065 & 0.084 & 0.099 & 0.102 & 0.097 & 0.075 & 0.095 & 0.074 & \\
\hline $\mathbf{1 6}$ & 0.088 & 0.103 & 0.111 & 0.107 & 0.078 & 0.072 & 0.077 & 0.092 & 0.105 & 0.108 & 0.097 & 0.082 & 0.096 & 0.077 & 0.049 \\
\hline $\mathbf{1 7}$ & 0.091 & 0.09 & 0.106 & 0.098 & 0.072 & 0.069 & 0.056 & 0.085 & 0.096 & 0.099 & 0.096 & 0.079 & 0.097 & 0.077 & 0.049 \\
\hline $\mathbf{1 8}$ & 0.091 & 0.096 & 0.105 & 0.105 & 0.082 & 0.08 & 0.085 & 0.092 & 0.098 & 0.101 & 0.092 & 0.059 & 0.084 & 0.09 & 0.075 \\
\hline $\mathbf{1 9}$ & 0.089 & 0.098 & 0.106 & 0.105 & 0.082 & 0.08 & 0.088 & 0.096 & 0.098 & 0.101 & 0.088 & 0.057 & 0.082 & 0.095 & 0.074 \\
\hline $\mathbf{2 0}$ & 0.084 & 0.094 & 0.097 & 0.1 & 0.094 & 0.095 & 0.09 & 0.096 & 0.112 & 0.114 & 0.095 & 0.085 & 0.092 & 0.095 & 0.094 \\
\hline $\mathbf{2 1}$ & 0.078 & 0.089 & 0.101 & 0.097 & 0.079 & 0.071 & 0.083 & 0.089 & 0.096 & 0.098 & 0.086 & 0.052 & 0.079 & 0.093 & 0.068 \\
\hline
\end{tabular}




\begin{tabular}{|l|r|r|r|r|r|}
\hline & $\mathbf{1 6}$ & $\mathbf{1 7}$ & $\mathbf{1 8}$ & $\mathbf{1 9}$ & $\mathbf{2 0}$ \\
\hline $\mathbf{1 7}$ & 0.051 & & & & \\
\hline $\mathbf{1 8}$ & 0.069 & 0.067 & & & \\
\hline $\mathbf{1 9}$ & 0.073 & 0.064 & 0.006 & & \\
\hline $\mathbf{2 0}$ & 0.098 & 0.091 & 0.078 & 0.076 & \\
\hline $\mathbf{2 1}$ & 0.072 & 0.073 & 0.049 & 0.048 & 0.071 \\
\hline
\end{tabular}

Taxa key for table A5:

\begin{tabular}{|l|l|l|l|}
\hline $\mathbf{1}$ & Lucilia sericata & $\mathbf{1 2}$ & Cochliomyia macellaria \\
\hline 2 & Calliphora vomitoria & $\mathbf{1 3}$ & Cochliomyia hominivorax \\
\hline 3 & Verticia orientalis & $\mathbf{1 4}$ & Chrysomya rufifacies \\
\hline 4 & Sarconesia versicolor & 15 & Chrysomya putoria \\
\hline 5 & Phormia regina & 16 & Chrysomya megacephala \\
\hline 6 & Protophormia terraenovae & 17 & Chrysomya bezziana \\
\hline 7 & Protophormia atriceps & 18 & Compsomyiops callipes \\
\hline 8 & Trypocalliphora braueri & 19 & Compsomyiops fulvicrura \\
\hline $\mathbf{9}$ & Protocalliphora sialia & 20 & Hemilucilia segmentaria \\
\hline 10 & Protocalliphora occidentalis & 21 & Paralucilia paraensis \\
\hline 11 & Chloroprocta idioidea & & \\
\hline
\end{tabular}


TABLE A6: Pairwise transition- transversion ratio of cytochrome oxidase subunit one ( $C O$ I) gene used in Chrysomyinae phylogeny (Chapter 3).

\begin{tabular}{|l|l|l|l|l|l|l|l|l|l|l|l|l|l|l|l|l|l|l|l|l|}
\hline & $\mathbf{1}$ & $\mathbf{2}$ & $\mathbf{3}$ & $\mathbf{4}$ & $\mathbf{5}$ & $\mathbf{6}$ & $\mathbf{7}$ & $\mathbf{8}$ & $\mathbf{9}$ & $\mathbf{1 0}$ & $\mathbf{1 1}$ & $\mathbf{1 2}$ & $\mathbf{1 3}$ & $\mathbf{1 4}$ & $\mathbf{1 5}$ & $\mathbf{1 6}$ & $\mathbf{1 7}$ & $\mathbf{1 8}$ & $\mathbf{1 9}$ & $\mathbf{2 0}$ \\
\hline $\mathbf{2}$ & 1.28 & & & & & & & & & & & & & & & & & & & \\
\hline $\mathbf{3}$ & 1.18 & 0.8 & & & & & & & & & & & & & & & & & & \\
\hline $\mathbf{4}$ & 1.09 & 0.96 & 0.87 & & & & & & & & & & & & & & & & & \\
\hline $\mathbf{5}$ & 1.14 & 1.12 & 1.14 & 1.07 & & & & & & & & & & & & & & & & \\
\hline $\mathbf{6}$ & 1 & 1.25 & 1.22 & 1.06 & 1.58 & & & & & & & & & & & & & & & \\
\hline $\mathbf{7}$ & 1.45 & 1.15 & 1.5 & 0.95 & 1.79 & 2.33 & & & & & & & & & & & & & & \\
\hline $\mathbf{8}$ & 1.24 & 1.06 & 0.91 & 0.95 & 2.24 & 2.47 & 2.31 & & & & & & & & & & & & & \\
\hline $\mathbf{9}$ & 1.16 & 1.24 & 1.11 & 1.08 & 1.98 & 2.11 & 1.56 & 2.97 & & & & & & & & & & & & \\
\hline $\mathbf{1 0}$ & 1.11 & 1.16 & 1.06 & 1.04 & 1.82 & 2.06 & 1.56 & 2.81 & 2 & & & & & & & & & & & \\
\hline $\mathbf{1 1}$ & 0.81 & 0.88 & 0.88 & 0.79 & 1.08 & 1.01 & 0.81 & 1.16 & 1.13 & 1.11 & & & & & & & & & & \\
\hline $\mathbf{1 2}$ & 0.8 & 1.01 & 1.06 & 1.07 & 0.98 & 1.23 & 1.71 & 1.48 & 1.48 & 1.41 & 1.28 & & & & & & & & & \\
\hline $\mathbf{1 3}$ & 0.87 & 0.93 & 0.94 & 0.9 & 1.26 & 1.35 & 1.06 & 1.31 & 1.27 & 1.2 & 1.22 & 2.63 & & & & & & & & \\
\hline $\mathbf{1 4}$ & 1.04 & 1.03 & 1.05 & 0.84 & 1.5 & 1.59 & 1.5 & 1.56 & 1.71 & 1.61 & 0.9 & 1.29 & 1.24 & & & & & & & \\
\hline $\mathbf{1 5}$ & 0.92 & 1.1 & 1.04 & 0.91 & 1.76 & 1.44 & 1.69 & 2.24 & 1.96 & 1.84 & 0.96 & 1.04 & 1.11 & 1.86 & & & & & & \\
\hline $\mathbf{1 6}$ & 1.07 & 1.32 & 1.18 & 1.12 & 2.5 & 1.57 & 1.68 & 2.14 & 2.06 & 1.94 & 1.11 & 1.44 & 1.3 & 2.08 & 2.38 & & & & & \\
\hline $\mathbf{1 7}$ & 1.2 & 1.25 & 1.14 & 1.08 & 2.43 & 1.75 & 1.64 & 2.27 & 2.07 & 1.94 & 1.09 & 1.46 & 1.4 & 2.06 & 2.68 & 6.3 & & & & \\
\hline $\mathbf{1 8}$ & 0.83 & 0.86 & 0.91 & 0.96 & 1.46 & 1.4 & 1.43 & 1.64 & 1.75 & 1.65 & 1.13 & 2.04 & 1.88 & 1.22 & 1.38 & 1.48 & 1.53 & & & \\
\hline $\mathbf{1 9}$ & 0.78 & 0.8 & 0.88 & 0.94 & 1.31 & 1.27 & 1.43 & 1.51 & 1.6 & 1.55 & 1.04 & 1.77 & 1.62 & 1.2 & 1.26 & 1.45 & 1.34 & --- & & \\
\hline $\mathbf{2 0}$ & 1 & 0.79 & 0.72 & 0.68 & 1.02 & 1.11 & 1.08 & 1.03 & 1.01 & 0.96 & 1.18 & 1.54 & 1.44 & 0.96 & 1.2 & 1.29 & 1.31 & 1.51 & 1.47 & \\
\hline $\mathbf{2 1}$ & 0.8 & 1.02 & 0.97 & 0.85 & 1.47 & 1.22 & 1.52 & 1.47 & 1.41 & 1.34 & 1 & 1.52 & 1.58 & 1.15 & 1.18 & 1.46 & 1.51 & 1.56 & 1.35 & 1.58 \\
\hline
\end{tabular}

Taxa key for table A6: Same as table A5. 
TABLE A7: Pairwise p-distance of carbamoylphosphate synthetase (CPS) gene used in Chrysomyinae phylogeny (Chapter 3).

\begin{tabular}{|c|c|c|c|c|c|c|c|c|c|c|c|c|c|c|c|c|c|}
\hline & 1 & 2 & 3 & 4 & 5 & 6 & 7 & 8 & 9 & 10 & 11 & 12 & 13 & 14 & 15 & 16 & 17 \\
\hline 2 & 0.111 & & & & & & & & & & & & & & & & \\
\hline 3 & 0.152 & 0.155 & & & & & & & & & & & & & & & \\
\hline 4 & 0.141 & 0.104 & 0.163 & & & & & & & & & & & & & & \\
\hline 5 & 0.135 & 0.131 & 0.165 & 0.157 & & & & & & & & & & & & & \\
\hline 6 & 0.134 & 0.147 & 0.151 & 0.166 & 0.059 & & & & & & & & & & & & \\
\hline 7 & 0.131 & 0.134 & 0.148 & 0.147 & 0.079 & 0.078 & & & & & & & & & & & \\
\hline 8 & 0.134 & 0.131 & 0.145 & 0.151 & 0.076 & 0.071 & 0.028 & & & & & & & & & & \\
\hline 9 & 0.135 & 0.134 & 0.148 & 0.147 & 0.08 & 0.073 & 0.027 & 0.011 & & & & & & & & & \\
\hline 10 & 0.155 & 0.148 & 0.159 & 0.183 & 0.118 & 0.126 & 0.118 & 0.125 & 0.122 & & & & & & & & \\
\hline 11 & 0.139 & 0.144 & 0.14 & 0.148 & 0.1 & 0.095 & 0.117 & 0.114 & 0.113 & 0.115 & & & & & & & \\
\hline 12 & 0.139 & 0.139 & 0.148 & 0.153 & 0.105 & 0.095 & 0.112 & 0.106 & 0.108 & 0.124 & 0.062 & & & & & & \\
\hline 13 & 0.134 & 0.161 & 0.156 & 0.173 & 0.127 & 0.108 & 0.138 & 0.127 & 0.132 & 0.154 & 0.124 & 0.13 & & & & & \\
\hline 14 & 0.119 & 0.15 & 0.149 & 0.17 & 0.126 & 0.107 & 0.117 & 0.113 & 0.117 & 0.148 & 0.122 & 0.131 & 0.064 & & & & \\
\hline 15 & 0.122 & 0.156 & 0.154 & 0.167 & 0.118 & 0.094 & 0.132 & 0.124 & 0.129 & 0.155 & 0.12 & 0.126 & 0.093 & 0.088 & & & \\
\hline 16 & 0.127 & 0.157 & 0.157 & 0.171 & 0.124 & 0.104 & 0.132 & 0.126 & 0.132 & 0.164 & 0.124 & 0.128 & 0.104 & 0.097 & 0.042 & & \\
\hline 17 & 0.173 & 0.18 & 0.174 & 0.173 & 0.12 & 0.117 & 0.115 & 0.119 & 0.113 & 0.12 & 0.087 & 0.101 & 0.153 & 0.157 & 0.144 & 0.158 & \\
\hline 18 & 0.163 & 0.158 & 0.178 & 0.162 & 0.107 & 0.113 & 0.115 & 0.116 & 0.11 & 0.124 & 0.086 & 0.096 & 0.15 & 0.157 & 0.138 & 0.151 & 0.019 \\
\hline
\end{tabular}

\section{Taxa key for table A7:}

\begin{tabular}{|r|l|r|l|l|l|}
\hline $\mathbf{1}$ & Lucilia sericata & $\mathbf{7}$ & Trypocalliphora braueri & $\mathbf{1 3}$ & Chrysomya rufifacies \\
\hline $\mathbf{2}$ & Calliphora vomitoria & $\mathbf{8}$ & Protocalliphora sialia & $\mathbf{1 4}$ & Chrysomya putoria \\
\hline $\mathbf{3}$ & Verticia orientalis & $\mathbf{9}$ & Protocalliphora occidentalis & $\mathbf{1 5}$ & Chrysomya megacephala \\
\hline $\mathbf{4}$ & Sarconesia versicolor & $\mathbf{1 0}$ & Chloroprocta idioidea & $\mathbf{1 6}$ & Chrysomya bezziana \\
\hline $\mathbf{5}$ & Phormia regina & $\mathbf{1 1}$ & Cochliomyia macellaria & $\mathbf{1 7}$ & Compsomyiops callipes \\
\hline 6 & Protophormia terraenovae & $\mathbf{1 2}$ & Cochliomyia hominivorax & $\mathbf{1 8}$ & Compsomyiops fulvicrura \\
\hline
\end{tabular}


TABLE A8: Pairwise transition- transversion ratio of carbamoylphosphate synthetase (CPS) gene used in Chrysomyinae phylogeny (Chapter 3$)$.

\begin{tabular}{|c|c|c|c|c|c|c|c|c|c|c|c|c|c|c|c|c|c|}
\hline & 1 & 2 & 3 & 4 & 5 & 6 & 7 & 8 & 9 & 10 & 11 & 12 & 13 & 14 & 15 & 16 & 17 \\
\hline 2 & 1.29 & & & & & & & & & & & & & & & & \\
\hline 3 & 1.8 & 1.49 & & & & & & & & & & & & & & & \\
\hline 4 & 1.35 & 1.84 & 1.5 & & & & & & & & & & & & & & \\
\hline 5 & 2.59 & 1.85 & 1.59 & 1.65 & & & & & & & & & & & & & \\
\hline 6 & 2.24 & 1.47 & 1.79 & 1.9 & 1.06 & & & & & & & & & & & & \\
\hline 7 & 2.31 & 1.66 & 1.86 & 1.66 & 2.56 & 2.62 & & & & & & & & & & & \\
\hline 8 & 2.17 & 1.47 & 1.46 & 1.72 & 2.25 & 2.07 & 2.83 & & & & & & & & & & \\
\hline 9 & 2.11 & 1.48 & 1.47 & 1.57 & 1.96 & 1.93 & 2.14 & 2 & & & & & & & & & \\
\hline 10 & 1.78 & 1.18 & 1.17 & 1.26 & 1.42 & 1.62 & 1.56 & 1.56 & 1.65 & & & & & & & & \\
\hline 11 & 1.88 & 1.26 & 1.09 & 1.26 & 1.18 & 1.11 & 1.44 & 1.26 & 1.18 & 1.24 & & & & & & & \\
\hline 12 & 1.81 & 1.15 & 1.25 & 1.42 & 1.02 & 1.38 & 1.53 & 1.25 & 1.24 & 1.68 & 1.79 & & & & & & \\
\hline 13 & 2.26 & 1.98 & 1.71 & 1.73 & 2.09 & 1.95 & 2.61 & 2.09 & 2.11 & 1.85 & 2.09 & 1.97 & & & & & \\
\hline 14 & 2.16 & 1.82 & 1.93 & 1.78 & 2.59 & 2.56 & 3.32 & 2.44 & 2.46 & 1.95 & 1.97 & 1.92 & 2.79 & & & & \\
\hline 15 & 2.25 & 1.83 & 1.73 & 1.35 & 1.63 & 2 & 2.57 & 2.09 & 2.14 & 1.8 & 2.52 & 2.15 & 2.16 & 2.48 & & & \\
\hline 16 & 2.06 & 1.77 & 1.71 & 1.41 & 1.56 & 2 & 2.24 & 1.89 & 1.95 & 1.75 & 2.09 & 1.92 & 2.38 & 2.64 & 4.14 & & \\
\hline 17 & 1.67 & 1.04 & 1.06 & 1.37 & 0.94 & 1.2 & 1 & 1.13 & $\begin{array}{l}1.1 \\
\end{array}$ & 1.03 & 2.2 & $\begin{array}{l}1.8 \\
\end{array}$ & 1.66 & 1.81 & 1.67 & 1.75 & \\
\hline 18 & 1.47 & 0.84 & 0.96 & 1.27 & 0.83 & 1.03 & 0.84 & 1 & 0.97 & 1.06 & 1.93 & 1.45 & 1.75 & 1.61 & 1.37 & 1.44 & 2.33 \\
\hline
\end{tabular}

Taxa key for table A8: Same as table A7. 
TABLE A9: Pairwise p-distance of 28 S ribosomal RNA (28S rRNA) gene used in Oestridae phylogeny (Chapter 4).

\begin{tabular}{|c|c|c|c|c|c|c|c|c|c|c|c|c|c|c|c|}
\hline & 1 & 2 & 3 & 4 & 5 & 6 & 7 & 8 & 9 & 10 & 11 & 12 & 13 & 14 & 15 \\
\hline 1 & & & & & & & & & & & & & & & \\
\hline 2 & 0.076 & & & & & & & & & & & & & & \\
\hline 3 & 0.06 & 0.079 & & & & & & & & & & & & & \\
\hline 4 & 0.03 & 0.078 & 0.061 & & & & & & & & & & & & \\
\hline 5 & 0.068 & 0.117 & 0.092 & 0.071 & & & & & & & & & & & \\
\hline 6 & 0.027 & 0.076 & 0.053 & 0.014 & 0.065 & & & & & & & & & & \\
\hline 7 & 0.03 & 0.08 & 0.056 & 0.026 & 0.068 & 0.017 & & & & & & & & & \\
\hline 8 & 0.044 & 0.095 & 0.068 & 0.04 & 0.083 & 0.032 & 0.033 & & & & & & & & \\
\hline 9 & 0.095 & 0.179 & 0.125 & 0.098 & 0.113 & 0.091 & 0.095 & 0.113 & & & & & & & \\
\hline 10 & 0.109 & 0.181 & 0.134 & 0.109 & 0.122 & 0.099 & 0.104 & 0.128 & 0.029 & & & & & & \\
\hline 11 & 0.059 & 0.106 & 0.081 & 0.059 & 0.096 & 0.057 & 0.06 & 0.068 & 0.002 & 0.027 & & & & & \\
\hline 12 & 0.095 & 0.133 & 0.115 & 0.094 & 0.13 & 0.088 & 0.087 & 0.094 & 0.186 & 0.177 & 0.105 & & & & \\
\hline 13 & 0.069 & 0.111 & 0.077 & 0.065 & 0.098 & 0.059 & 0.063 & 0.072 & 0.096 & 0.095 & 0.066 & 0.089 & & & \\
\hline 14 & 0.096 & 0.138 & 0.111 & 0.095 & 0.124 & 0.093 & 0.094 & 0.102 & 0.195 & 0.201 & 0.116 & 0.134 & 0.118 & & \\
\hline 15 & 0.112 & 0.156 & 0.129 & 0.11 & 0.139 & 0.103 & 0.109 & 0.118 & 0.192 & 0.194 & 0.129 & 0.133 & 0.126 & 0.083 & \\
\hline 16 & 0.099 & 0.135 & 0.114 & 0.098 & 0.128 & 0.096 & 0.098 & 0.105 & 0.182 & 0.188 & 0.116 & 0.133 & 0.119 & 0.022 & 0.086 \\
\hline 17 & 0.099 & 0.132 & 0.124 & 0.103 & 0.131 & 0.102 & 0.102 & 0.105 & 0.186 & 0.185 & 0.116 & 0.121 & 0.116 & 0.069 & 0.082 \\
\hline 18 & 0.047 & 0.085 & 0.065 & 0.045 & 0.079 & 0.04 & 0.045 & 0.056 & 0.106 & 0.111 & 0.065 & 0.101 & 0.067 & 0.105 & 0.119 \\
\hline 19 & 0.036 & 0.076 & 0.056 & 0.037 & 0.072 & 0.033 & 0.036 & 0.05 & 0.102 & 0.116 & 0.06 & 0.099 & 0.069 & 0.101 & 0.119 \\
\hline 20 & 0.042 & 0.083 & 0.062 & 0.044 & 0.083 & 0.039 & 0.044 & 0.057 & 0.138 & 0.152 & 0.068 & 0.103 & 0.078 & 0.099 & 0.123 \\
\hline 21 & 0.065 & 0.108 & 0.081 & 0.069 & 0.092 & 0.065 & 0.069 & 0.089 & 0.12 & 0.129 & 0.085 & 0.123 & 0.089 & 0.134 & 0.139 \\
\hline 22 & 0.067 & 0.107 & 0.08 & 0.067 & 0.096 & 0.065 & 0.07 & 0.09 & 0.123 & 0.129 & 0.084 & 0.118 & 0.079 & 0.131 & 0.135 \\
\hline
\end{tabular}




\begin{tabular}{|l|l|l|l|l|l|l|}
\hline & 16 & 17 & 18 & 19 & 20 & 21 \\
\hline 17 & 0.069 & & & & & \\
\hline 18 & 0.108 & 0.112 & & & & \\
\hline 19 & 0.103 & 0.11 & 0.02 & & & \\
\hline 20 & 0.105 & 0.109 & 0.026 & 0.005 & & \\
\hline 21 & 0.138 & 0.138 & 0.076 & 0.07 & 0.081 & \\
\hline 22 & 0.136 & 0.131 & 0.072 & 0.071 & 0.081 & 0.016 \\
\hline
\end{tabular}

\section{Taxa key table A9:}

\begin{tabular}{|r|l|r|l|r|l|}
\hline $\mathbf{1}$ & Epalpus signifier & $\mathbf{9}$ & Cephenemyia stimulator & $\mathbf{1 7}$ & Przhevalskiana silenus \\
\hline $\mathbf{2}$ & Musca domestica & $\mathbf{1 0}$ & Cephenemyia ultrichii & $\mathbf{1 8}$ & Cuterebra baeri \\
\hline $\mathbf{3}$ & Glossina morsitans & $\mathbf{1 1}$ & Cephenemyia trompe & $\mathbf{1 9}$ & Cuterebra fontinella \\
\hline $\mathbf{4}$ & Sarcophaga crassipalpis & $\mathbf{1 2}$ & Oestrus ovis & $\mathbf{2 0}$ & Cuterebra spp. \\
\hline $\mathbf{5}$ & Mystacinobia zelandica & $\mathbf{1 3}$ & Rhinoestrus phacochoeri & $\mathbf{2 1}$ & Gasterophilus intestinalis \\
\hline $\mathbf{6}$ & Chrysomya rufifacies & $\mathbf{1 4}$ & Hypoderma lineatum & $\mathbf{2 2}$ & Gasterophilus pecorum \\
\hline $\mathbf{7}$ & Calliphora vomitoria & $\mathbf{1 5}$ & Hypoderma tarandi & & \\
\hline $\mathbf{8}$ & Rhinophora lepida & $\mathbf{1 6}$ & Hypoderma bovis & & \\
\hline
\end{tabular}


TABLE A10: Pairwise transition-transversion ratio of $28 S$ ribosomal RNA (28S $r R N A)$ gene used in Oestridae phylogeny (Chapter 4).

\begin{tabular}{|l|l|l|l|l|l|l|l|l|l|l|l|l|l|l|l|l|l|l|l|}
\hline & $\mathbf{1}$ & $\mathbf{2}$ & $\mathbf{3}$ & $\mathbf{4}$ & $\mathbf{5}$ & $\mathbf{6}$ & $\mathbf{7}$ & $\mathbf{8}$ & $\mathbf{9}$ & $\mathbf{1 0}$ & $\mathbf{1 1}$ & $\mathbf{1 2}$ & $\mathbf{1 3}$ & $\mathbf{1 4}$ & $\mathbf{1 5}$ & $\mathbf{1 6}$ & $\mathbf{1 7}$ & $\mathbf{1 8}$ & $\mathbf{1 9}$ \\
\hline $\mathbf{2}$ & 1.3 & & & & & & & & & & & & & & & & & \\
\hline $\mathbf{3}$ & 0.91 & 1.2 & & & & & & & & & & & & & & & & \\
\hline $\mathbf{4}$ & 0.91 & 1.08 & 0.62 & & & & & & & & & & & & & & & \\
\hline $\mathbf{5}$ & 0.88 & 0.93 & 0.88 & 0.75 & & & & & & & & & & & & & & \\
\hline $\mathbf{6}$ & 0.9 & 0.96 & 0.76 & 0.43 & 0.8 & & & & & & & & & & & & & & \\
\hline $\mathbf{7}$ & 1.1 & 1.07 & 0.86 & 1 & 0.88 & 1 & & & & & & & & & & & & & \\
\hline $\mathbf{8}$ & 0.63 & 1.06 & 0.88 & 0.56 & 0.71 & 0.69 & 0.77 & & & & & & & & & & & \\
\hline $\mathbf{9}$ & 1.06 & 1.03 & 0.69 & 1.27 & 1.22 & 1.13 & 0.89 & 0.74 & & & & & & & & & & \\
\hline $\mathbf{1 0}$ & 1.47 & 0.97 & 0.84 & 1.31 & 1.47 & 1.43 & 1.12 & 1 & 9 & & & & & & & & & & \\
\hline $\mathbf{1 1}$ & 1.56 & 1.18 & 0.87 & 1.56 & 0.97 & 1.35 & 1.21 & 0.96 & --- & 8 & & & & & & & & & \\
\hline $\mathbf{1 2}$ & 1.06 & 1.19 & 0.9 & 1.03 & 0.91 & 1.1 & 1.07 & 1.17 & 0.85 & 0.84 & 1.03 & & & & & & & & \\
\hline $\mathbf{1 3}$ & 1.09 & 1.08 & 0.74 & 0.96 & 0.84 & 1.05 & 1 & 1 & 0.67 & 0.7 & 0.92 & 0.82 & & & & & & & \\
\hline $\mathbf{1 4}$ & 0.78 & 0.82 & 0.9 & 0.7 & 0.67 & 0.63 & 0.66 & 0.7 & 0.79 & 0.88 & 1.08 & 1.17 & 1.03 & & & & & & \\
\hline $\mathbf{1 5}$ & 0.95 & 0.89 & 0.88 & 0.93 & 0.83 & 0.95 & 0.95 & 0.91 & 0.76 & 0.81 & 1.2 & 1.21 & 1.15 & 1.15 & & & & & \\
\hline $\mathbf{1 6}$ & 0.64 & 0.74 & 0.76 & 0.58 & 0.62 & 0.52 & 0.55 & 0.59 & 0.72 & 0.8 & 0.88 & 0.98 & 0.84 & 1.5 & 1.03 & & & & \\
\hline $\mathbf{1 7}$ & 1.03 & 1.19 & 1.1 & 1.06 & 0.86 & 0.97 & 0.97 & 0.82 & 0.91 & 0.94 & 1.31 & 1.24 & 1.19 & 1.88 & 1.23 & 1.72 & & & \\
\hline $\mathbf{1 8}$ & 1.75 & 1.27 & 0.96 & 1.21 & 0.96 & 1.15 & 1.38 & 0.95 & 1.18 & 1.11 & 1.5 & 1.33 & 1.47 & 1.06 & 1.07 & 0.88 & 1.29 & & \\
\hline $\mathbf{1 9}$ & 2.12 & 1.12 & 0.95 & 1 & 0.85 & 0.92 & 1.08 & 1.06 & 1.06 & 1.17 & 1.33 & 1.16 & 0.92 & 0.97 & 1.07 & 0.8 & 1.26 & 0.75 & \\
\hline $\mathbf{2 0}$ & 1.6 & 0.96 & 0.81 & 0.8 & 0.89 & 0.71 & 0.93 & 0.94 & 0.84 & 0.9 & 1.1 & 1 & 0.92 & 0.85 & 1 & 0.71 & 1.09 & 1 & 0.5 \\
\hline $\mathbf{2 1}$ & 1.14 & 1.34 & 1.43 & 1.18 & 1 & 1.37 & 1.29 & 1.07 & 0.76 & 0.92 & 1.03 & 1 & 1.14 & 0.93 & 1.11 & 0.85 & 1.13 & 1.3 & 1.33 \\
\hline $\mathbf{2 2}$ & 1.19 & 1.47 & 1.39 & 1.3 & 0.94 & 1.37 & 1.29 & 1.07 & 0.83 & 0.96 & 1.07 & 1.1 & 1.5 & 1.02 & 1.14 & 0.92 & 1.17 & 1.5 & 1.33 \\
\hline
\end{tabular}

\begin{tabular}{|l|l|l|}
\hline & $\mathbf{2 0}$ & $\mathbf{2 1}$ \\
\hline $\mathbf{2 1}$ & 1.38 & \\
\hline $\mathbf{2 2}$ & 1.38 & 0.57 \\
\hline
\end{tabular}

Taxa key for table A10: Same as table A9. 
TABLE A11: Pairwise p-distance of cytochrome oxidase subunit one $(C O I)$ gene used in Oestridae phylogeny (Chapter 4).

\begin{tabular}{|c|c|c|c|c|c|c|c|c|c|c|c|c|c|c|c|}
\hline & 1 & 2 & 3 & 4 & 5 & 6 & 7 & 8 & 9 & 10 & 11 & 12 & 13 & 14 & 15 \\
\hline 2 & 0.179 & & & & & & & & & & & & & & \\
\hline 3 & 0.158 & 0.138 & & & & & & & & & & & & & \\
\hline 4 & 0.173 & 0.12 & 0.135 & & & & & & & & & & & & \\
\hline 5 & 0.153 & 0.156 & 0.134 & 0.137 & & & & & & & & & & & \\
\hline 6 & 0.161 & 0.137 & 0.144 & 0.149 & 0.158 & & & & & & & & & & \\
\hline 7 & 0.19 & 0.135 & 0.124 & 0.123 & 0.118 & 0.126 & & & & & & & & & \\
\hline 8 & 0.184 & 0.108 & 0.119 & 0.129 & 0.13 & 0.111 & 0.109 & & & & & & & & \\
\hline 9 & 0.184 & 0.158 & 0.155 & 0.149 & 0.149 & 0.178 & 0.154 & 0.142 & & & & & & & \\
\hline 10 & 0.182 & 0.151 & 0.159 & 0.14 & 0.139 & 0.146 & 0.141 & 0.134 & 0.083 & & & & & & \\
\hline 11 & 0.193 & 0.164 & 0.17 & 0.163 & 0.165 & 0.166 & 0.151 & 0.151 & 0.084 & 0.093 & & & & & \\
\hline 12 & 0.212 & 0.193 & 0.178 & 0.173 & 0.19 & 0.174 & 0.169 & 0.169 & 0.141 & 0.113 & 0.147 & & & & \\
\hline 13 & 0.211 & 0.182 & 0.198 & 0.179 & 0.201 & 0.182 & 0.179 & 0.179 & 0.126 & 0.118 & 0.112 & 0.164 & & & \\
\hline 14 & 0.211 & 0.192 & 0.2 & 0.186 & 0.199 & 0.191 & 0.17 & 0.179 & 0.151 & 0.14 & 0.141 & 0.19 & 0.18 & & \\
\hline 15 & 0.2 & 0.186 & 0.208 & 0.2 & 0.211 & 0.201 & 0.172 & 0.202 & 0.214 & 0.198 & 0.205 & 0.222 & 0.203 & 0.205 & \\
\hline 16 & 0.201 & 0.185 & 0.177 & 0.162 & 0.171 & 0.191 & 0.16 & 0.173 & 0.192 & 0.172 & 0.193 & 0.199 & 0.195 & 0.201 & 0.167 \\
\hline 17 & 0.195 & 0.183 & 0.17 & 0.161 & 0.162 & 0.189 & 0.158 & 0.172 & 0.19 & 0.173 & 0.192 & 0.199 & 0.19 & 0.199 & 0.166 \\
\hline 18 & 0.209 & 0.177 & 0.178 & 0.168 & 0.165 & 0.187 & 0.176 & 0.183 & 0.18 & 0.185 & 0.186 & 0.215 & 0.198 & 0.203 & 0.169 \\
\hline 19 & 0.198 & 0.177 & 0.182 & 0.186 & 0.193 & 0.184 & 0.161 & 0.17 & 0.188 & 0.183 & 0.188 & 0.199 & 0.212 & 0.193 & 0.163 \\
\hline 20 & 0.215 & 0.222 & 0.194 & 0.181 & 0.182 & 0.201 & 0.188 & 0.198 & 0.222 & 0.203 & 0.214 & 0.193 & 0.215 & 0.228 & 0.177 \\
\hline 21 & 0.228 & 0.173 & 0.196 & 0.182 & 0.201 & 0.185 & 0.18 & 0.173 & 0.166 & 0.174 & 0.166 & 0.199 & 0.188 & 0.208 & 0.215 \\
\hline 22 & 0.232 & 0.177 & 0.2 & 0.186 & 0.204 & 0.186 & 0.18 & 0.176 & 0.17 & 0.176 & 0.164 & 0.202 & 0.188 & 0.208 & 0.217 \\
\hline 23 & 0.261 & 0.211 & 0.236 & 0.227 & 0.224 & 0.214 & 0.202 & 0.217 & 0.208 & 0.198 & 0.198 & 0.215 & 0.228 & 0.209 & 0.234 \\
\hline 24 & 0.275 & 0.228 & 0.259 & 0.257 & 0.259 & 0.245 & 0.234 & 0.251 & 0.23 & 0.233 & 0.222 & 0.251 & 0.24 & 0.228 & 0.241 \\
\hline 25 & 0.183 & 0.135 & 0.143 & 0.164 & 0.16 & 0.159 & 0.135 & 0.138 & 0.161 & 0.16 & 0.161 & 0.189 & 0.185 & 0.192 & 0.179 \\
\hline 26 & 0.166 & 0.141 & 0.146 & 0.152 & 0.136 & 0.154 & 0.125 & 0.14 & 0.154 & 0.158 & 0.157 & 0.18 & 0.173 & 0.19 & 0.172 \\
\hline 27 & 0.17 & 0.151 & 0.161 & 0.179 & 0.147 & 0.142 & 0.156 & 0.132 & 0.185 & 0.167 & 0.192 & 0.206 & 0.177 & 0.232 & 0.214 \\
\hline 28 & 0.173 & 0.153 & 0.144 & 0.17 & 0.154 & 0.153 & 0.163 & 0.132 & 0.184 & 0.171 & 0.185 & 0.193 & 0.18 & 0.227 & 0.201 \\
\hline
\end{tabular}




\begin{tabular}{|l|l|l|l|l|l|l|l|l|l|l|l|l|}
\hline & $\mathbf{1 6}$ & $\mathbf{1 7}$ & $\mathbf{1 8}$ & $\mathbf{1 9}$ & $\mathbf{2 0}$ & $\mathbf{2 1}$ & $\mathbf{2 2}$ & $\mathbf{2 3}$ & $\mathbf{2 4}$ & $\mathbf{2 5}$ & $\mathbf{2 6}$ & $\mathbf{2 7}$ \\
\hline $\mathbf{1 7}$ & 0.019 & & & & & & & & & & & \\
\hline $\mathbf{1 8}$ & 0.089 & 0.087 & & & & & & & & & & \\
\hline $\mathbf{1 9}$ & 0.142 & 0.148 & 0.161 & & & & & & & & & \\
\hline $\mathbf{2 0}$ & 0.17 & 0.17 & 0.18 & 0.151 & & & & & & & & \\
\hline $\mathbf{2 1}$ & 0.206 & 0.206 & 0.202 & 0.195 & 0.222 & & & & & & & \\
\hline $\mathbf{2 2}$ & 0.203 & 0.203 & 0.201 & 0.198 & 0.222 & 0.009 & & & & & & \\
\hline $\mathbf{2 3}$ & 0.237 & 0.234 & 0.224 & 0.225 & 0.254 & 0.094 & 0.1 & & & & & \\
\hline $\mathbf{2 4}$ & 0.253 & 0.251 & 0.235 & 0.24 & 0.27 & 0.14 & 0.144 & 0.09 & & & & \\
\hline $\mathbf{2 5}$ & 0.192 & 0.193 & 0.182 & 0.183 & 0.211 & 0.196 & 0.205 & 0.227 & 0.247 & & & \\
\hline $\mathbf{2 6}$ & 0.17 & 0.166 & 0.17 & 0.169 & 0.202 & 0.186 & 0.19 & 0.218 & 0.234 & 0.057 & & \\
\hline $\mathbf{2 7}$ & 0.191 & 0.186 & 0.19 & 0.193 & 0.202 & 0.206 & 0.211 & 0.237 & 0.268 & 0.147 & 0.12 & \\
\hline $\mathbf{2 8}$ & 0.186 & 0.178 & 0.181 & 0.164 & 0.183 & 0.197 & 0.204 & 0.236 & 0.273 & 0.144 & 0.131 & 0.014 \\
\hline
\end{tabular}

\section{Taxa key for table A11:}

\begin{tabular}{|l|l|l|l|l|l|}
\hline $\mathbf{1}$ & Glossina morsitans & $\mathbf{1 1}$ & Hypoderma diana & $\mathbf{2 0}$ & Rhinoestrus phacochoeri \\
\hline $\mathbf{2}$ & Musca domestica & $\mathbf{1 2}$ & Hypoderma tarandi & $\mathbf{2 1}$ & Gasterophilus intestinalis \\
\hline $\mathbf{3}$ & Mystacinobia zelandica & $\mathbf{1 3}$ & Hypoderma actaeon & $\mathbf{2 2}$ & Gasterophilus haemorrhoidalis \\
\hline $\mathbf{4}$ & Epalpus signifier & $\mathbf{1 4}$ & Przhevalskiana silenus & $\mathbf{2 3}$ & Gasterophilus nasalis \\
\hline $\mathbf{5}$ & Rhinophora lepida & $\mathbf{1 5}$ & Oestrus ovis & $\mathbf{2 4}$ & Gasterophilus pecorum \\
\hline $\mathbf{6}$ & Sarcophaga crassipalpis & $\mathbf{1 6}$ & Cephenemyia stimulator & $\mathbf{2 5}$ & Cuterebra baeri \\
\hline $\mathbf{7}$ & Calliphora vomitoria & $\mathbf{1 7}$ & Cephenemyia trompe & $\mathbf{2 6}$ & Cuterebra jellisoni \\
\hline $\mathbf{8}$ & Chrysomya rufifacies & $\mathbf{1 8}$ & Cephenemyia ulrichii & $\mathbf{2 7}$ & Cuterebra fontinella \\
\hline $\mathbf{9}$ & Hypoderma bovis & $\mathbf{1 9}$ & Rhinoestrus usbekistanicus & $\mathbf{2 8}$ & Cuterebra spp. \\
\hline $\mathbf{1 0}$ & Hypoderma lineatum & \multicolumn{5}{|l}{} \\
\hline
\end{tabular}


TABLE A12: Pairwise transition-transversion ratio of cytochrome oxidase subunit one ( $C O$ I) gene used in Oestridae phylogeny (Chapter 4).

\begin{tabular}{|c|c|c|c|c|c|c|c|c|c|c|c|c|c|c|c|c|c|}
\hline & 1 & 2 & 3 & 4 & 5 & 6 & 7 & 8 & 9 & 10 & 11 & 12 & 13 & 14 & 15 & 16 & 17 \\
\hline 2 & 0.55 & & & & & & & & & & & & & & & & \\
\hline 3 & 0.52 & 0.49 & & & & & & & & & & & & & & & \\
\hline 4 & 0.41 & 0.64 & 0.47 & & & & & & & & & & & & & & \\
\hline 5 & 0.58 & 0.86 & 0.76 & 0.45 & & & & & & & & & & & & & \\
\hline 6 & 0.9 & 1.08 & 0.69 & 0.65 & 1.06 & & & & & & & & & & & & \\
\hline 7 & 0.58 & 0.86 & 0.58 & 0.69 & 0.73 & 0.92 & & & & & & & & & & & \\
\hline 8 & 0.66 & 1.18 & 0.66 & 0.54 & 0.87 & 0.78 & 0.88 & & & & & & & & & & \\
\hline 9 & 0.45 & 0.7 & 0.73 & 0.7 & 0.48 & 1.04 & 0.71 & 0.81 & & & & & & & & & \\
\hline 10 & 0.46 & 0.7 & 0.72 & 0.67 & 0.49 & 0.91 & 0.7 & 0.67 & 1.71 & & & & & & & & \\
\hline 11 & 0.63 & 0.77 & 1.02 & 0.82 & 0.71 & 0.94 & 0.79 & 0.93 & 3.83 & 2.37 & & & & & & & \\
\hline 12 & 0.68 & 0.68 & 0.8 & 0.94 & 0.91 & 0.82 & 0.84 & 0.97 & 1.49 & 0.86 & 1.46 & & & & & & \\
\hline 13 & 0.73 & 0.95 & 1.09 & 0.92 & 0.87 & 0.96 & 0.98 & 1.28 & 2.62 & 2 & 3.28 & 1.4 & & & & & \\
\hline 14 & 0.73 & 1.03 & 1.17 & 1.14 & 1.2 & 1.04 & 0.86 & 0.95 & 1.31 & 1.29 & 1.62 & 1.26 & 1.88 & & & & \\
\hline 15 & 0.64 & 0.75 & 0.72 & 0.69 & 0.68 & 0.93 & 0.76 & 0.76 & 0.65 & 0.55 & 0.74 & 0.78 & 0.73 & 0.76 & & & \\
\hline 16 & 0.55 & 0.69 & 0.66 & 0.66 & 0.69 & 0.62 & 0.69 & 0.59 & 0.59 & 0.51 & 0.73 & 0.67 & 0.65 & 0.72 & 0.92 & & \\
\hline 17 & 0.48 & 0.7 & 0.62 & 0.61 & 0.64 & 0.63 & 0.7 & 0.59 & 0.6 & 0.55 & 0.69 & 0.65 & 0.64 & 0.73 & 0.87 & 12 & \\
\hline 18 & 0.61 & 0.77 & 0.79 & 0.85 & 0.82 & 0.74 & 0.92 & 0.77 & 0.57 & 0.72 & 0.8 & 0.85 & 0.81 & 0.89 & 1.23 & 2.81 & 2.53 \\
\hline 19 & 0.6 & 0.72 & 0.68 & 0.75 & 0.76 & 0.86 & 0.71 & 0.65 & 0.59 & 0.54 & 0.59 & 0.76 & 0.64 & 0.71 & 1.33 & 0.88 & 0.92 \\
\hline 20 & 0.68 & 0.68 & 0.63 & 0.7 & 0.57 & 0.84 & 0.72 & 0.72 & 0.76 & 0.56 & 0.81 & 0.62 & 0.74 & 1.12 & 1.26 & 0.77 & 0.75 \\
\hline 21 & 0.76 & 1.12 & 1.04 & 1 & 1.05 & 0.96 & 1.14 & 1.12 & 1.28 & 1.11 & 1.19 & 1.04 & 1.15 & 1.13 & 1.08 & 0.89 & 0.87 \\
\hline 22 & 0.78 & 1.18 & 1.07 & 1.04 & 1.07 & 0.98 & 1.14 & 1.16 & 1.34 & 1.12 & 1.17 & 1.07 & 1.15 & 1.13 & 1.1 & 0.87 & 0.84 \\
\hline 23 & 0.76 & 1.07 & 0.96 & 0.86 & 1.22 & 0.92 & 0.88 & 1.01 & 1.1 & 1.03 & 1 & 0.92 & 1.01 & 0.92 & 0.85 & 0.83 & 0.83 \\
\hline 24 & 0.87 & 0.94 & 0.91 & 0.92 & 1.3 & 0.93 & 0.94 & 0.99 & 1.11 & 1.11 & 1.1 & 1.06 & 1.04 & 0.96 & 0.93 & 1.02 & 0.99 \\
\hline 25 & 0.53 & 0.94 & 0.61 & 0.74 & 0.73 & 0.92 & 0.79 & 0.83 & 0.73 & 0.69 & 0.85 & 0.88 & 1.05 & 0.86 & 0.64 & 0.55 & 0.55 \\
\hline 26 & 0.5 & 0.9 & 0.69 & 0.55 & 0.54 & 0.85 & 0.76 & 0.81 & 0.63 & 0.51 & 0.77 & 0.94 & 0.83 & 0.93 & 0.74 & 0.62 & 0.56 \\
\hline 27 & 0.69 & 1.02 & 0.72 & 0.54 & 0.78 & 0.91 & 0.84 & 0.85 & 0.93 & 0.57 & 1.12 & 0.79 & 0.87 & 1.18 & 0.84 & 0.59 & 0.57 \\
\hline 28 & 0.71 & 1 & 0.67 & 0.51 & 0.96 & 0.83 & 0.89 & 0.83 & 1.05 & 0.69 & 1.11 & 0.76 & 0.85 & 1.57 & 0.95 & 0.71 & 0.68 \\
\hline
\end{tabular}




\begin{tabular}{|r|r|r|r|r|r|r|r|r|r|r|}
\hline & $\mathbf{1 8}$ & $\mathbf{1 9}$ & $\mathbf{2 0}$ & $\mathbf{2 1}$ & $\mathbf{2 2}$ & $\mathbf{2 3}$ & $\mathbf{2 4}$ & $\mathbf{2 5}$ & $\mathbf{2 6}$ & $\mathbf{2 7}$ \\
\hline $\mathbf{1 9}$ & 1.13 & & & & & & & & & \\
\hline $\mathbf{2 0}$ & 1.07 & 1.26 & & & & & & & & \\
\hline $\mathbf{2 1}$ & 0.96 & 1 & 0.89 & & & & & & & \\
\hline $\mathbf{2 2}$ & 0.94 & 1.03 & 0.89 & --- & & & & & & \\
\hline $\mathbf{2 3}$ & 0.86 & 0.87 & 0.8 & 0.81 & 0.92 & & & & & \\
\hline $\mathbf{2 4}$ & 0.93 & 1.06 & 1.11 & 0.88 & 0.94 & 1.14 & & & & \\
\hline $\mathbf{2 5}$ & 0.58 & 0.68 & 0.79 & 1.05 & 1.14 & 0.95 & 0.95 & & & \\
\hline $\mathbf{2 6}$ & 0.77 & 0.71 & 0.93 & 1.1 & 1.15 & 0.95 & 1.01 & 1.05 & & \\
\hline $\mathbf{2 7}$ & 0.73 & 0.73 & 0.71 & 0.87 & 0.92 & 0.81 & 1.03 & 1.3 & 1.09 & \\
\hline $\mathbf{2 8}$ & 0.79 & 0.89 & 0.77 & 0.8 & 0.87 & 0.72 & 0.98 & 1.03 & 0.96 & 5 \\
\hline
\end{tabular}

Taxa key for table A12: Same as table A11. 
TABLE A13: Pairwise p-distance of elongation factor one alpha (EF1a) gene used in Oestridae phylogeny (Chapter 4).

\begin{tabular}{|c|c|c|c|c|c|c|c|c|c|c|c|c|c|c|c|c|c|}
\hline & 1 & 2 & 3 & 4 & 5 & 6 & 7 & 8 & 9 & 10 & 11 & 12 & 13 & 14 & 15 & 16 & 17 \\
\hline 2 & 0.172 & & & & & & & & & & & & & & & & \\
\hline 3 & 0.2 & 0.106 & & & & & & & & & & & & & & & \\
\hline 4 & 0.173 & 0.063 & 0.097 & & & & & & & & & & & & & & \\
\hline 5 & 0.176 & 0.104 & 0.137 & 0.102 & & & & & & & & & & & & & \\
\hline 6 & 0.178 & 0.074 & 0.095 & 0.053 & 0.118 & & & & & & & & & & & & \\
\hline 7 & 0.169 & 0.07 & 0.093 & 0.036 & 0.089 & 0.06 & & & & & & & & & & & \\
\hline 8 & 0.185 & 0.143 & 0.149 & 0.133 & 0.158 & 0.142 & 0.129 & & & & & & & & & & \\
\hline 9 & 0.18 & 0.148 & 0.148 & 0.137 & 0.156 & 0.147 & 0.133 & 0.044 & & & & & & & & & \\
\hline 10 & 0.182 & 0.138 & 0.139 & 0.124 & 0.157 & 0.139 & 0.129 & 0.005 & 0.027 & & & & & & & & \\
\hline 11 & 0.187 & 0.178 & 0.184 & 0.186 & 0.196 & 0.193 & 0.178 & 0.213 & 0.22 & 0.211 & & & & & & & \\
\hline 12 & 0.28 & 0.27 & 0.26 & 0.263 & 0.26 & 0.274 & 0.258 & 0.284 & 0.284 & 0.287 & 0.281 & & & & & & \\
\hline 13 & 0.275 & 0.261 & 0.267 & 0.263 & 0.258 & 0.27 & 0.26 & 0.282 & 0.285 & 0.289 & 0.282 & 0.014 & & & & & \\
\hline 14 & 0.296 & 0.273 & 0.282 & 0.277 & 0.272 & 0.289 & 0.277 & 0.293 & 0.293 & 0.298 & 0.297 & 0.029 & 0.021 & & & & \\
\hline 15 & 0.289 & 0.278 & 0.276 & 0.282 & 0.278 & 0.281 & 0.279 & 0.3 & 0.298 & 0.293 & 0.291 & 0.025 & 0.01 & 0.022 & & & \\
\hline 16 & 0.182 & 0.168 & 0.179 & 0.151 & 0.165 & 0.178 & 0.149 & 0.16 & 0.164 & 0.15 & 0.218 & 0.253 & 0.263 & 0.282 & 0.285 & & \\
\hline 17 & 0.17 & 0.15 & 0.164 & 0.13 & 0.142 & 0.154 & 0.13 & 0.137 & 0.135 & 0.121 & 0.215 & 0.263 & 0.266 & 0.286 & 0.285 & 0.066 & \\
\hline 18 & 0.176 & 0.163 & 0.153 & 0.142 & 0.142 & 0.151 & 0.138 & 0.149 & 0.144 & 0.138 & 0.218 & 0.245 & 0.259 & 0.279 & 0.276 & 0.085 & 0.062 \\
\hline
\end{tabular}

\section{Taxa key for table A13:}

\begin{tabular}{|l|l|l|l|l|l|}
\hline $\mathbf{1}$ & Glossina morsitans & $\mathbf{7}$ & Chrysomya rufifacies & $\mathbf{1 3}$ & Hypoderma lineatum \\
\hline $\mathbf{2}$ & Musca domestica & $\mathbf{8}$ & Cuterebra fontinella & $\mathbf{1 4}$ & Hypoderma tarandi \\
\hline $\mathbf{3}$ & Epalpus signifier & $\mathbf{9}$ & Cuterebra baeri & $\mathbf{1 5}$ & Przhevalskiana silenus \\
\hline $\mathbf{4}$ & Sarcophaga crassipalpis & $\mathbf{1 0}$ & Cuterebra spp. & $\mathbf{1 6}$ & Oestrus ovis \\
\hline $\mathbf{5}$ & Rhinophora lepida & $\mathbf{1 1}$ & Gasterophilus pecorum & $\mathbf{1 7}$ & Rhinoestrus phacochoeri \\
\hline $\mathbf{6}$ & Calliphora vomitoria & $\mathbf{1 2}$ & Hypoderma bovis & $\mathbf{1 8}$ & Cephenemyia trompe \\
\hline
\end{tabular}


TABLE A14: Pairwise transition-transversion ratio of elongation factor one alpha (EF1a) gene used in Oestridae phylogeny (Chapter 4).

\begin{tabular}{|l|l|l|l|l|l|l|l|l|l|l|l|l|l|l|l|l|l|}
\hline & $\mathbf{1}$ & $\mathbf{2}$ & $\mathbf{3}$ & $\mathbf{4}$ & $\mathbf{5}$ & $\mathbf{6}$ & $\mathbf{7}$ & $\mathbf{8}$ & $\mathbf{9}$ & $\mathbf{1 0}$ & $\mathbf{1 1}$ & $\mathbf{1 2}$ & $\mathbf{1 3}$ & $\mathbf{1 4}$ & $\mathbf{1 5}$ & $\mathbf{1 6}$ & $\mathbf{1 7}$ \\
\hline $\mathbf{2}$ & 2 & & & & & & & & & & & & & & & & \\
\hline $\mathbf{3}$ & 1.75 & 1.71 & & & & & & & & & & & & & & \\
\hline $\mathbf{4}$ & 2.8 & 3.25 & 1.52 & & & & & & & & & & & & & \\
\hline $\mathbf{5}$ & 3.04 & 2.73 & 1.88 & 7 & & & & & & & & & & & & & \\
\hline $\mathbf{6}$ & 2.16 & 1.86 & 1.26 & 1.42 & 4 & & & & & & & & & & & & \\
\hline $\mathbf{7}$ & 2.72 & 2.17 & 1.43 & 4 & 6 & 1.06 & & & & & & & & & & & \\
\hline $\mathbf{8}$ & 1.91 & 2.67 & 2.04 & 3.56 & 2.78 & 2.25 & 2.94 & & & & & & & & & & \\
\hline $\mathbf{9}$ & 1.61 & 1.86 & 1.53 & 2.26 & 2.07 & 1.79 & 1.92 & 2.43 & & & & & & & & & \\
\hline $\mathbf{1 0}$ & 1.68 & 2.73 & 2.41 & 3.25 & 2.82 & 2.35 & 2.79 & --- & 1.75 & & & & & & & & \\
\hline $\mathbf{1 1}$ & 2.32 & 2 & 1.81 & 2.64 & 2.72 & 1.94 & 3.08 & 2.44 & 1.95 & 2.48 & & & & & & & \\
\hline $\mathbf{1 2}$ & 1.24 & 1.28 & 1.04 & 1.21 & 1.14 & 1.41 & 1.07 & 1.24 & 1.17 & 1.15 & 1.32 & & & & & & \\
\hline $\mathbf{1 3}$ & 1.16 & 1.26 & 1.23 & 1.28 & 1.1 & 1.39 & 1.18 & 1.22 & 1.17 & 1.16 & 1.41 & 4 & & & & & \\
\hline $\mathbf{1 4}$ & 1.08 & 1.13 & 1.07 & 1.09 & 0.95 & 1.22 & 1.02 & 1.14 & 1.14 & 1.12 & 1.21 & 2.33 & 0.8 & & & & \\
\hline $\mathbf{1 5}$ & 1.03 & 1.21 & 1.13 & 1.17 & 1.05 & 1.3 & 1.1 & 1.16 & 1.06 & 1.11 & 1.24 & 2 & 1.5 & 1.25 & & & \\
\hline $\mathbf{1 6}$ & 1.86 & 2.25 & 1.8 & 3.15 & 2.37 & 2.5 & 2.73 & 3 & 2.33 & 2.65 & 3.29 & 0.9 & 0.97 & 0.89 & 0.93 & & \\
\hline $\mathbf{1 7}$ & 2 & 1.89 & 1.81 & 2.63 & 2.12 & 2.28 & 2.63 & 2.43 & 2.38 & 2.12 & 3.22 & 0.94 & 0.97 & 0.9 & 0.92 & 3.38 & \\
\hline $\mathbf{1 8}$ & 2.23 & 2.26 & 1.8 & 3.11 & 2.55 & 2.61 & 2.62 & 3.32 & 2.59 & 3.07 & 3.14 & 0.96 & 1.06 & 0.97 & 0.99 & 4.22 & 3.71 \\
\hline
\end{tabular}

Taxa key for table A14: Same as table A13. 
TABLE A15: Pairwise p-distance of $28 S$ ribosomal RNA (28S rRNA) gene used in Calliphoridae phylogeny (Chapter 5).

\begin{tabular}{|c|c|c|c|c|c|c|c|c|c|c|c|c|c|c|c|c|c|}
\hline & 1 & 2 & 3 & 4 & 5 & 6 & 7 & 8 & 9 & 10 & 11 & 12 & 13 & 14 & 15 & 16 & 17 \\
\hline 2 & 0.07 & & & & & & & & & & & & & & & & \\
\hline 3 & 0.087 & 0.052 & & & & & & & & & & & & & & & \\
\hline 4 & 0.067 & 0.041 & 0.056 & & & & & & & & & & & & & & \\
\hline 5 & 0.093 & 0.056 & 0.042 & 0.05 & & & & & & & & & & & & & \\
\hline 6 & 0.068 & 0.044 & 0.04 & 0.041 & 0.048 & & & & & & & & & & & & \\
\hline 7 & 0.093 & 0.033 & 0.037 & 0.061 & 0.057 & 0.044 & & & & & & & & & & & \\
\hline 8 & 0.072 & 0.049 & 0.033 & 0.043 & 0.043 & 0.037 & 0.033 & & & & & & & & & & \\
\hline 9 & 0.085 & 0.051 & 0.041 & 0.064 & 0.05 & 0.04 & 0.031 & 0.03 & & & & & & & & & \\
\hline 10 & 0.067 & 0.045 & 0.051 & 0.038 & 0.05 & 0.032 & 0.05 & 0.035 & 0.043 & & & & & & & & \\
\hline 11 & 0.064 & 0.042 & 0.04 & 0.038 & 0.047 & 0.031 & 0.04 & 0.028 & 0.03 & 0.024 & & & & & & & \\
\hline 12 & 0.079 & 0.048 & 0.032 & 0.058 & 0.045 & 0.035 & 0.027 & 0.019 & 0.018 & 0.04 & 0.025 & & & & & & \\
\hline 13 & 0.134 & 0.09 & 0.066 & 0.109 & 0.08 & 0.072 & 0.066 & 0.063 & 0.059 & 0.076 & 0.071 & 0.052 & & & & & \\
\hline 14 & 0.07 & 0.047 & 0.041 & 0.043 & 0.052 & 0.035 & 0.044 & 0.033 & 0.037 & 0.031 & 0.022 & 0.027 & 0.072 & & & & \\
\hline 15 & 0.079 & 0.051 & 0.029 & 0.056 & 0.044 & 0.034 & 0.03 & 0.025 & 0.031 & 0.041 & 0.026 & & 0.065 & 0.019 & & & \\
\hline 16 & 0.091 & 0.056 & 0.043 & 0.069 & 0.055 & 0.044 & 0.037 & 0.036 & 0.031 & 0.05 & 0.036 & 0.019 & 0.065 & 0.028 & 0.018 & & \\
\hline 17 & 0.061 & 0.037 & 0.025 & 0.031 & 0.037 & 0.023 & 0.023 & 0.026 & 0.024 & 0.025 & 0.014 & 0.013 & 0.055 & 0.021 & 0.014 & 0.025 & \\
\hline 18 & 0.085 & 0.054 & 0.036 & 0.057 & 0.042 & 0.038 & 0.035 & 0.028 & 0.034 & 0.051 & 0.027 & 0.02 & 0.062 & 0.033 & 0.025 & 0.035 & 0.007 \\
\hline 19 & 0.068 & 0.046 & 0.033 & 0.041 & 0.049 & 0.031 & 0.039 & 0.037 & 0.037 & 0.034 & 0.023 & 0.026 & 0.069 & 0.028 & 0.025 & 0.037 & 0.016 \\
\hline 20 & 0.079 & 0.038 & 0.028 & 0.054 & 0.038 & 0.03 & 0.028 & 0.026 & 0.028 & 0.043 & 0.025 & 0.02 & 0.062 & 0.029 & 0.021 & 0.028 & 0.013 \\
\hline 21 & 0.066 & 0.04 & 0.034 & 0.033 & 0.04 & 0.025 & 0.039 & 0.031 & 0.034 & 0.029 & 0.022 & 0.03 & 0.063 & 0.025 & 0.026 & 0.037 & 0.014 \\
\hline 22 & 0.089 & 0.064 & 0.078 & 0.07 & 0.086 & 0.06 & 0.075 & 0.067 & 0.065 & 0.062 & 0.056 & 0.061 & 0.105 & 0.06 & 0.07 & 0.069 & 0.053 \\
\hline 23 & 0.092 & 0.073 & 0.085 & 0.071 & 0.096 & 0.064 & 0.094 & 0.069 & 0.074 & 0.069 & 0.06 & 0.068 & 0.106 & 0.062 & 0.073 & 0.076 & 0.052 \\
\hline 24 & 0.061 & 0.034 & 0.034 & 0.033 & 0.04 & 0.026 & 0.033 & 0.026 & 0.031 & 0.022 & 0.017 & 0.019 & 0.057 & 0.016 & 0.018 & 0.026 & 0.015 \\
\hline 25 & 0.062 & 0.037 & 0.034 & 0.034 & 0.043 & 0.027 & 0.033 & 0.027 & 0.031 & 0.022 & 0.016 & 0.019 & 0.06 & 0.015 & 0.018 & 0.027 & 0.014 \\
\hline 26 & 0.079 & 0.045 & 0.034 & 0.058 & 0.048 & 0.034 & 0.028 & 0.026 & 0.022 & 0.04 & 0.027 & 0.009 & 0.053 & 0.024 & 0.018 & 0.017 & 0.015 \\
\hline 27 & 0.055 & 0.033 & 0.036 & 0.036 & 0.046 & 0.028 & 0.03 & 0.029 & 0.021 & 0.025 & 0.02 & 0.012 & 0.055 & 0.019 & 0.02 & 0.02 & 0.017 \\
\hline 28 & 0.059 & 0.038 & 0.037 & 0.036 & 0.047 & 0.029 & 0.039 & 0.029 & 0.035 & 0.024 & 0.019 & 0.022 & 0.068 & 0.018 & 0.02 & 0.031 & 0.016 \\
\hline
\end{tabular}




\begin{tabular}{|c|c|c|c|c|c|c|c|c|c|c|c|c|c|c|c|c|c|}
\hline 29 & 0.172 & 0.153 & 0.109 & 0.157 & 0.109 & 0.141 & 0.135 & 0.131 & 0.111 & 0.144 & 0.135 & 0.098 & 0.076 & 0.132 & 0.096 & 0.103 & 0.126 \\
\hline 30 & 0.058 & .037 & 043 & 0.039 & .054 & 0.033 & 0.036 & 0.032 & 0.029 & .026 & 0.022 & 018 & 0.061 & 0.022 & 0.026 & 0.028 & 0.02 \\
\hline 31 & 0.044 & 026 & 031 & .032 & .046 & 0.023 & .022 & 0.027 & 0.023 & .023 & .014 & .011 & .045 & .013 & 0.014 & .009 & .012 \\
\hline 32 & 0.06 & 0.035 & 026 & .032 & .04 & 0.023 & .023 & 0.022 & 0.024 & 0.02 & 013 & 0.013 & 0.053 & .016 & 0.014 & 024 & .008 \\
\hline 33 & 0.059 & 0.035 & 0.027 & & 0.038 & 0.023 & 0.024 & 0.022 & 0.025 & 0.02 & & & 0.052 & 0.016 & 0.015 & 0.025 & 0.009 \\
\hline 34 & 0.059 & & & & 0.038 & 0.023 & 0.025 & 0.023 & 0.025 & & & & 0.054 & & 0.015 & & 0.008 \\
\hline 35 & 0.058 & 0.035 & 0.029 & 0.034 & 0.041 & 0.026 & 0.023 & 0.027 & 0.018 & 0.023 & 0.017 & 0.007 & 0.046 & 0.02 & 0.018 & 0.019 & 0.013 \\
\hline 36 & 0.06 & 0.035 & 0.027 & 0.031 & 0.04 & 0.025 & 0.024 & 0.023 & 0.025 & 0.021 & 0.014 & 0.019 & 0.055 & 0.019 & 0.017 & 0.027 & 0.011 \\
\hline 37 & 0.06 & 0.037 & 0.031 & 0.036 & 0.043 & 0.029 & 0.025 & 0.028 & 0.019 & 0.025 & 0.019 & 0.012 & 0.045 & 0.023 & 0.02 & 0.021 & 0.015 \\
\hline 38 & 0.089 & .05 & 0.035 & .067 & 0.048 & 0.035 & 0.027 & 0.023 & 0.022 & 0.044 & & 0.011 & 0.045 & 0.029 & 0.021 & & 0.013 \\
\hline 39 & 0.062 & 0.038 & 0.024 & 0.034 & 0.039 & 0.026 & 0.025 & 0.025 & 0.024 & 0.023 & & & 0.058 & 0018 & 0.015 & 025 & 0.01 \\
\hline 40 & 0.059 & 0.037 & 0.032 & 0.034 & 0.038 & 0.024 & 0.028 & 0.023 & 0.022 & 0.023 & 0.014 & 0.017 & 0.051 & 0.018 & 0.016 & 0.027 & 0.011 \\
\hline 41 & 0.084 & 0.05 & 0.036 & 0.06 & 0.045 & 0.037 & 0.028 & 0.026 & 0.022 & 0.047 & 0.028 & 0.013 & 0.05 & 0.032 & 0.022 & 0.023 & 0.015 \\
\hline 42 & 0.088 & 055 & 0.032 & 0.065 & 0.043 & 0.041 & 0.033 & 0.028 & 0.032 & 0.047 & 0.027 & 0.02 & 0.063 & 0.028 & 0.022 & .033 & 0.013 \\
\hline 43 & 0.063 & 0.033 & 0.032 & & 0.044 & & & & 0.02 & & & 0.011 & & 0.023 & & & 0.01 \\
\hline 44 & 0.067 & 0.046 & 0.043 & 0.041 & 0.054 & 0.032 & 0.046 & 0.032 & 0.043 & 0.026 & 0.025 & 0.028 & 0.07 & 0.028 & 0.029 & 0.04 & 0.022 \\
\hline 45 & 0.057 & 0.038 & 0.035 & 0.039 & 0.042 & 0.029 & 0.03 & 0.03 & 0.022 & 0.024 & 0.02 & 0.011 & 0.049 & 0.022 & 0.022 & 0.023 & 0.018 \\
\hline 46 & 0.057 & 0.037 & 0.032 & 0.039 & 0.04 & 0.029 & 0.027 & 0.029 & 0.02 & 0.024 & 0.02 & 0.009 & 0.044 & 0.021 & 0.019 & 0.021 & 0.017 \\
\hline 47 & 0.09 & 0.054 & 0.04 & 0.068 & 0.052 & 0.042 & 0.034 & 0.032 & 0.027 & 0.049 & 0.032 & 0.015 & 0.051 & 0.028 & 0.022 & 0.019 & 0.021 \\
\hline 48 & 0.073 & 0.052 & 0.063 & 0.047 & 0.065 & 0.039 & 0.067 & 0.044 & 0.06 & 0.041 & 0.035 & 0.048 & 0.105 & 0.037 & 0.047 & 0.058 & 0.029 \\
\hline 49 & 0.109 & 0.076 & 0.058 & 0.082 & 0.062 & 0.059 & 0.061 & 0.049 & 0.051 & 0.074 & 0.058 & 0.043 & 0.087 & 0.059 & 0.047 & 0.052 & 0.045 \\
\hline 50 & 0.06 & 0.037 & 0.034 & 0.031 & 0.038 & 0.026 & 0.034 & 0.025 & 0.032 & 0.022 & 0.018 & 0.022 & 0.056 & 0.019 & 0.022 & 0.031 & 0.014 \\
\hline 51 & 0.079 & 0.053 & 0.034 & 0.056 & 0.038 & 0.036 & 0.038 & 0.024 & 0.028 & 0.041 & 0.021 & 0.021 & 0.055 & 0.022 & 0.022 & 0.033 & 0.013 \\
\hline 52 & 0.082 & 0.049 & 0.028 & 0.058 & 0.041 & 0.031 & 0.03 & 0.021 & 0.028 & 0.039 & 0.022 & 0.013 & 0.055 & 0.019 & 0.011 & 0.023 & 0.009 \\
\hline
\end{tabular}




\begin{tabular}{|c|c|c|c|c|c|c|c|c|c|c|c|c|c|c|c|c|c|}
\hline & 18 & 19 & 20 & 21 & 22 & 23 & 24 & 25 & 26 & 27 & 28 & 29 & 30 & 31 & 32 & 33 & 34 \\
\hline 19 & 0.023 & & & & & & & & & & & & & & & & \\
\hline 20 & 0.019 & 0.021 & & & & & & & & & & & & & & & \\
\hline 21 & 0.03 & 0.024 & 0.02 & & & & & & & & & & & & & & \\
\hline 22 & 0.08 & 0.061 & 0.059 & 0.057 & & & & & & & & & & & & & \\
\hline 23 & 0.079 & 0.062 & 0.074 & 0.055 & 0.08 & & & & & & & & & & & & \\
\hline 24 & 0.021 & 0.023 & 0.022 & 0.02 & 0.054 & 0.058 & & & & & & & & & & & \\
\hline 25 & 0.022 & 0.022 & 0.022 & 0.02 & 0.054 & 0.058 & 0.002 & & & & & & & & & & \\
\hline 26 & 0.021 & 0.024 & 0.018 & 0.027 & 0.059 & 0.071 & 0.009 & 0.01 & & & & & & & & & \\
\hline 27 & 0.024 & 0.025 & 0.02 & 0.021 & 0.047 & 0.054 & 0.009 & 0.009 & 0.002 & & & & & & & & \\
\hline 28 & 0.026 & 0.023 & 0.024 & 0.022 & 0.055 & 0.061 & 0.008 & 0.01 & 0.017 & 0.012 & & & & & & & \\
\hline 29 & 0.046 & 0.131 & 0.101 & 0.136 & 0.172 & 0.165 & 0.123 & 0.123 & 0.092 & 0.127 & 0.121 & & & & & & \\
\hline 30 & 0.031 & 0.027 & 0.026 & 0.026 & 0.052 & 0.06 & 0.012 & 0.012 & 0.011 & 0.009 & 0.007 & 0.122 & & & & & \\
\hline 31 & 0.018 & 0.014 & 0.017 & 0.016 & 0.038 & 0.049 & 0.008 & 0.009 & 0.004 & 0.003 & 0.004 & 0.138 & 0.005 & & & & \\
\hline 32 & 0.015 & 0.019 & 0.015 & 0.016 & 0.052 & 0.056 & 0.009 & 0.008 & 0.013 & 0.011 & 0.01 & 0.124 & 0.014 & 0.01 & & & \\
\hline 33 & 0.017 & 0.019 & 0.017 & 0.016 & 0.053 & 0.057 & 0.008 & 0.008 & 0.014 & 0.011 & 0.01 & 0.125 & 0.014 & 0.01 & 0.001 & & \\
\hline 34 & 0.011 & 0.017 & 0.012 & 0.015 & 0.051 & 0.055 & 0.008 & 0.007 & 0.012 & 0.01 & 0.01 & 0.124 & 0.013 & 0.008 & 0.002 & 0.002 & \\
\hline 35 & 0.014 & 0.022 & 0.012 & 0.019 & 0.046 & 0.052 & 0.011 & 0.011 & 0.005 & 0.004 & 0.012 & 0.126 & 0.01 & 0.005 & 0.007 & 0.007 & 0.006 \\
\hline 36 & 0.013 & 0.021 & 0.019 & 0.016 & 0.055 & 0.058 & 0.012 & 0.011 & 0.018 & 0.013 & 0.013 & 0.129 & 0.016 & 0.01 & 0.005 & 0.005 & 0.005 \\
\hline 37 & 0.02 & 0.025 & 0.017 & 0.02 & 0.05 & 0.055 & 0.015 & 0.016 & 0.012 & 0.007 & 0.015 & 0.132 & 0.013 & 0.008 & 0.009 & 0.009 & 0.01 \\
\hline 38 & 0.019 & 0.027 & 0.018 & 0.025 & 0.072 & 0.084 & 0.021 & 0.023 & 0.011 & 0.012 & 0.024 & 0.088 & 0.02 & 0.011 & 0.012 & 0.011 & 0.014 \\
\hline 39 & 0.014 & 0.02 & 0.015 & 0.019 & 0.054 & 0.058 & 0.012 & 0.011 & 0.014 & 0.013 & 0.013 & 0.126 & 0.016 & 0.01 & 0.004 & 0.005 & 0.004 \\
\hline 40 & 0.017 & 0.022 & 0.017 & 0.016 & 0.053 & 0.059 & 0.013 & 0.012 & 0.019 & 0.014 & 0.014 & 0.129 & 0.018 & 0.01 & 0.008 & 0.008 & 0.008 \\
\hline 41 & 0.022 & 0.029 & 0.019 & 0.028 & 0.064 & 0.08 & 0.025 & 0.026 & 0.016 & 0.018 & 0.027 & 0.101 & 0.024 & 0.016 & 0.017 & 0.017 & 0.019 \\
\hline 42 & 0.022 & 0.026 & 0.024 & 0.033 & 0.071 & 0.08 & 0.021 & 0.021 & 0.021 & 0.021 & 0.023 & 0.085 & 0.028 & 0.019 & 0.014 & 0.015 & 0.013 \\
\hline 43 & 0.02 & 0.021 & 0.018 & 0.023 & 0.048 & 0.055 & 0.015 & 0.016 & 0.011 & 0.01 & 0.015 & 0.132 & 0.015 & 0.01 & 0.011 & 0.011 & 0.01 \\
\hline 44 & 0.033 & 0.029 & 0.033 & 0.027 & 0.061 & 0.064 & 0.02 & 0.019 & 0.028 & 0.022 & 0.02 & 0.131 & 0.023 & 0.015 & 0.016 & 0.016 & 0.015 \\
\hline 45 & 0.022 & 0.024 & 0.019 & 0.022 & 0.051 & 0.057 & 0.016 & 0.015 & 0.008 & 0.009 & 0.016 & 0.13 & 0.015 & 0.007 & 0.012 & 0.012 & 0.012 \\
\hline 46 & 0.019 & 0.024 & 0.016 & 0.021 & 0.051 & 0.055 & 0.015 & 0.014 & 0.006 & 0.008 & 0.015 & 0.128 & 0.014 & 0.005 & 0.011 & 0.011 & 0.01 \\
\hline 47 & 0.026 & 0.032 & 0.022 & 0.033 & 0.066 & 0.079 & 0.015 & 0.015 & 0.004 & 0.007 & 0.023 & 0.091 & 0.016 & 0.008 & 0.017 & 0.018 & 0.016 \\
\hline
\end{tabular}




\begin{tabular}{|c|c|c|c|c|c|c|c|c|c|c|c|c|c|c|c|c|c|}
\hline 48 & 0.064 & 0.04 & 0.05 & 0.035 & 0.068 & 0.067 & 0.031 & 0.031 & 0.05 & 0.034 & 0.031 & 0.151 & 0.035 & 0.029 & 0.029 & 0.03 & 0.029 \\
\hline 49 & 0.056 & 0.056 & 0.05 & 0.054 & 0.096 & 0.104 & 0.05 & 0.05 & 0.044 & 0.047 & 0.053 & 0.115 & 0.053 & 0.04 & 0.042 & 0.044 & 0.041 \\
\hline 50 & 0.022 & 0.023 & .024 & 0.019 & 0.055 & 0.059 & 0.012 & 0.011 & 0.021 & 0.015 & 0.014 & 0.132 & 0.018 & 0.013 & 0.011 & 0.011 & 0.01 \\
\hline 51 & 0.019 & 0.025 & 0.021 & 0.025 & 0.067 & 0.078 & 0.018 & 0.018 & 0.021 & 0.022 & 0.023 & 0.093 & 0.029 & 0.017 & 0.014 & 0.015 & 0.012 \\
\hline 52 & 0.015 & 0.019 & 0.017 & 0.022 & 0.068 & 0.074 & 0.008 & 0.008 & 0.008 & 0.01 & 0.01 & 0.071 & 0.017 & 0.007 & 0.006 & 0.007 & 0.005 \\
\hline
\end{tabular}

\begin{tabular}{|c|c|c|c|c|c|c|c|c|c|c|c|c|c|c|c|c|c|}
\hline & 35 & 36 & 37 & 38 & 39 & 40 & 41 & 42 & 43 & 44 & 45 & 46 & 47 & 48 & 49 & 50 & 51 \\
\hline 36 & 0.01 & & & & & & & & & & & & & & & & \\
\hline 37 & 0.005 & 0.007 & & & & & & & & & & & & & & & \\
\hline 38 & 0.006 & 0.01 & 0.002 & & & & & & & & & & & & & & \\
\hline 39 & 0.01 & 0.007 & 0.011 & 0.013 & & & & & & & & & & & & & \\
\hline 40 & 0.012 & 0.008 & 0.012 & 0.012 & 0.01 & & & & & & & & & & & & \\
\hline 41 & 0.011 & 0.018 & 0.012 & 0.009 & 0.019 & 0.01 & & & & & & & & & & & \\
\hline 42 & 0.018 & 0.019 & 0.022 & 0.022 & 0.01 & 0.021 & 0.027 & & & & & & & & & & \\
\hline 43 & 0.007 & 0.013 & 0.007 & 0.01 & 0.01 & 0.015 & 0.016 & 0.006 & & & & & & & & & \\
\hline 44 & 0.019 & 0.018 & 0.021 & 0.037 & 0.019 & 0.02 & 0.038 & 0.031 & 0.023 & & & & & & & & \\
\hline 45 & 0.007 & 0.013 & 0.008 & 0.011 & 0.015 & 0.015 & 0.017 & 0.017 & 0.009 & 0.015 & & & & & & & \\
\hline 46 & 0.005 & 0.012 & 0.007 & 0.008 & 0.013 & 0.014 & 0.014 & 0.014 & 0.008 & 0.015 & 0.002 & & & & & & \\
\hline 47 & 0.009 & 0.024 & 0.016 & 0.015 & 0.019 & 0.023 & 0.019 & 0.026 & 0.016 & 0.034 & 0.014 & 0.01 & & & & & \\
\hline 48 & 0.032 & 0.032 & 0.036 & 0.062 & 0.032 & 0.031 & 0.054 & 0.057 & 0.04 & 0.038 & 0.036 & 0.035 & 0.057 & & & & \\
\hline 49 & 0.04 & 0.048 & 0.045 & 0.045 & 0.044 & 0.047 & 0.048 & 0.054 & 0.049 & 0.061 & 0.047 & 0.043 & 0.046 & 0.046 & & & \\
\hline 50 & 0.014 & 0.011 & 0.015 & 0.021 & 0.014 & 0.01 & 0.024 & 0.026 & 0.02 & 0.02 & 0.015 & 0.016 & 0.029 & 0.032 & 0.05 & & \\
\hline 51 & 0.015 & 0.018 & 0.021 & 0.021 & 0.014 & 0.014 & 0.022 & 0.02 & 0.022 & 0.029 & 0.015 & 0.015 & 0.024 & 0.052 & 0.05 & 0.011 & \\
\hline 52 & 0.007 & 0.012 & 0.016 & 0.014 & 0.008 & 0.013 & 0.019 & 0.013 & 0.014 & 0.023 & 0.012 & 0.009 & 0.012 & 0.047 & 0.042 & 0.018 & 0.014 \\
\hline
\end{tabular}




\section{Taxa key for table A15:}

\begin{tabular}{|l|l|l|l|l|l|l|l|}
\hline $\mathbf{1}$ & Drosophila melanogaster & $\mathbf{1 4}$ & Rhinophora lepida & $\mathbf{2 7}$ & Onesia tibialis & $\mathbf{4 0}$ & Pollenia rudis \\
\hline $\mathbf{2}$ & Glossina morsitans & $\mathbf{1 5}$ & Stevenia hertingi & $\mathbf{2 8}$ & Lucilia sericata & $\mathbf{4 1}$ & Pollenia amentaria \\
\hline $\mathbf{3}$ & Fannia canicularis & $\mathbf{1 6}$ & Stevenia atramentaria & $\mathbf{2 9}$ & Hypopygiopsis infumata & $\mathbf{4 2}$ & Bengalia peuhi \\
\hline $\mathbf{4}$ & Musca domestica & $\mathbf{1 7}$ & Sarcophaga crassipalpis & $\mathbf{3 0}$ & Hemipyrellia fernandica & $\mathbf{4 3}$ & Bengalia depressa \\
\hline $\mathbf{5}$ & Hydrotaea cyrtoneurina & $\mathbf{1 8}$ & Notochaeta spp. & $\mathbf{3 1}$ & Dyscritomyia robusta & $\mathbf{4 4}$ & Verticia orientalis \\
\hline $\mathbf{6}$ & Mystacinobia zelandica & $\mathbf{1 9}$ & Metopia campestris & $\mathbf{3 2}$ & Phormia regina & $\mathbf{4 5}$ & Auchmeromyia luteola \\
\hline $\mathbf{7}$ & McAlpine's fly & $\mathbf{2 0}$ & Sarcophila meridionalis & $\mathbf{3 3}$ & Protophormia terraenovae & $\mathbf{4 6}$ & Cordylobia anthropophaga \\
\hline $\mathbf{8}$ & Epalpus signifier & $\mathbf{2 1}$ & Cuterebra fontinella & $\mathbf{3 4}$ & Chrysomya rufifacies & $\mathbf{4 7}$ & Melinda viridicyanea \\
\hline $\mathbf{9}$ & Gymnocheta viridis & $\mathbf{2 2}$ & Hypoderma lineatum & $\mathbf{3 5}$ & Chrysomya megacephala & $\mathbf{4 8}$ & Mesembrinella spp. \\
\hline $\mathbf{1 0}$ & Cyrtophleba nitida & $\mathbf{2 3}$ & Oestrus ovis & $\mathbf{3 6}$ & Cochliomyia macellaria & $\mathbf{4 9}$ & Eumesembrinella quadrilineata \\
\hline $\mathbf{1 1}$ & Nemorilla floralis & $\mathbf{2 4}$ & Cynomya cadaverina & $\mathbf{3 7}$ & Cochliomyia hominivorax & $\mathbf{5 0}$ & Isomyia gomezmenori \\
\hline $\mathbf{1 2}$ & Gymnosoma nitens & $\mathbf{2 5}$ & Calliphora vomitoria & $\mathbf{3 8}$ & Compsomyiops fulvicrura & $\mathbf{5 1}$ & Rhyncomya nigripes \\
\hline $\mathbf{1 3}$ & Phania funesta & $\mathbf{2 6}$ & Bellardia vulgaris & $\mathbf{3 9}$ & Protocalliphora sialia & $\mathbf{5 2}$ & Eurychaeta palpalis \\
\hline
\end{tabular}


TABLE A16: Pairwise transition-transversion ratio of $28 S$ ribosomal RNA (28S rRNA) gene used in Calliphoridae phylogeny (Chapter 5).

\begin{tabular}{|c|c|c|c|c|c|c|c|c|c|c|c|c|c|c|c|c|c|c|}
\hline & 1 & 2 & 3 & 4 & 5 & 6 & 7 & 8 & 9 & 10 & 11 & 12 & 13 & 14 & 15 & 16 & 17 & 18 \\
\hline 2 & 0.97 & & & & & & & & & & & & & & & & & \\
\hline 3 & 0.94 & 1.21 & & & & & & & & & & & & & & & & \\
\hline 4 & 1.38 & 1.65 & 1.87 & & & & & & & & & & & & & & & \\
\hline 5 & 1.31 & 1 & 1.67 & 1.29 & & & & & & & & & & & & & & \\
\hline 6 & 1.22 & 1.28 & 1.67 & 1.46 & 1.79 & & & & & & & & & & & & & \\
\hline 7 & 0.72 & 1.2 & 1.3 & 1.17 & 1 & 1.42 & & & & & & & & & & & & \\
\hline 8 & 1.33 & 1.28 & 1.36 & 1.77 & 1.06 & 1.77 & 0.57 & & & & & & & & & & & \\
\hline 9 & 1.09 & 1.2 & 1.46 & 1.7 & 1.67 & 1.33 & 0.75 & 1.17 & & & & & & & & & & \\
\hline 10 & 1.31 & 1.59 & 1.35 & 1.52 & 1.35 & 2.18 & 1.06 & 1.76 & 1.31 & & & & & & & & & \\
\hline 11 & 1.12 & 1.12 & 1.13 & 1.78 & 1.53 & 1.74 & 0.69 & 1.76 & 0.86 & 1.86 & & & & & & & & \\
\hline 12 & 1 & 0.95 & 1.5 & 1.53 & 1.25 & 2 & 0.64 & 1.29 & 0.78 & 1.62 & 1.33 & & & & & & & \\
\hline 13 & 1.03 & 1.3 & 1.75 & 1.65 & 1.67 & 2.27 & 1.38 & 1.82 & 2.33 & 1.38 & 1.92 & 3.5 & & & & & & \\
\hline 14 & 1.19 & 1.17 & 0.94 & 1.57 & 1.21 & 1.68 & 0.58 & 1.29 & 0.6 & 1.68 & 1.12 & 0.77 & 1.47 & & & & & \\
\hline 15 & 0.89 & 0.91 & 0.92 & 1.24 & 1.19 & 1.9 & 0.43 & 0.91 & 0.8 & 1.69 & 1.44 & 0.88 & 2.3 & 2.2 & & & & \\
\hline 16 & 0.85 & 0.96 & 1 & 1.15 & 1.1 & 1.47 & 0.6 & 0.88 & 0.86 & 1.28 & 1.14 & 0.78 & 2.3 & 1.88 & 2 & & & \\
\hline 17 & 1.08 & 0.94 & 1 & 1.36 & 1.14 & 1.71 & 0.45 & 1.75 & 0.62 & 1.8 & 1.67 & 1.75 & 2.11 & 1.19 & 1 & 0.91 & & \\
\hline 18 & 1.04 & 0.76 & 1.09 & 1.31 & 1.55 & 2.25 & 0.55 & 1.38 & 1.09 & 1.83 & 1.25 & 2.5 & 2.1 & 0.92 & 1.43 & 1.18 & 4 & \\
\hline 19 & 1.02 & 1.05 & 1 & 1.23 & 1.05 & 1.43 & 0.73 & 1.44 & 0.78 & 1.59 & 1.17 & 1.44 & 1.62 & 1.24 & 1.33 & 1.14 & 1.08 & 0.88 \\
\hline 20 & 0.89 & 0.94 & 0.83 & 1.14 & 0.88 & 1.6 & 0.58 & 1.09 & 0.85 & 1.18 & 1 & 1.12 & 1.82 & 0.92 & 1.25 & 1.09 & 0.5 & 0.62 \\
\hline 21 & 1.18 & 1.16 & 1.45 & 1.39 & 1.13 & 1.8 & 1 & 2.06 & 1.42 & 1.67 & 2.6 & 1.78 & 1.82 & 1.8 & 2.14 & 2 & 1.67 & 1.5 \\
\hline 22 & 1.19 & 1.23 & 0.97 & 1.67 & 1.2 & 1.45 & 0.71 & 1.62 & 1 & 1.49 & 1.56 & 1.08 & 1.23 & 1.72 & 1.07 & 1.04 & 1.42 & 1.04 \\
\hline 23 & 1.47 & 1.69 & 1.96 & 2.19 & 1.85 & 2.42 & 1.74 & 2.26 & 2.2 & 2.17 & 2.33 & 1.81 & 2.6 & 2.12 & 2 & 2.2 & 2.48 & 1.7 \\
\hline 24 & 1.2 & 1.28 & 1.25 & 1.62 & 1.06 & 1.87 & 0.57 & 1.32 & 0.59 & 1.64 & 1.07 & 1 & 1.42 & 1.08 & 1.5 & 1 & 1.27 & 1.14 \\
\hline 25 & 1.15 & 1.26 & 1.45 & 1.71 & 1.06 & 2 & 0.69 & 1.65 & 0.69 & 1.64 & 1.25 & 1.29 & 1.73 & 1.27 & 2 & 1.2 & 1.56 & 1.5 \\
\hline 26 & 0.97 & 1 & 1.25 & 1.53 & 1.11 & 1.9 & 0.58 & 1 & 0.46 & 1.27 & 1.09 & 1 & 2 & 0.91 & 1.5 & 1 & 1.17 & 1.33 \\
\hline 27 & 1.17 & 1.08 & 1.15 & 1.61 & 1.31 & 1.71 & 0.43 & 1.29 & 0.38 & 1.93 & 1.06 & 0.67 & 1.45 & 1.21 & 1.12 & 0.78 & 1 & 1 \\
\hline 28 & 1.02 & 1.25 & 1.23 & 1.5 & 1.24 & 2 & 0.73 & 1.4 & 0.67 & 1.67 & 1.07 & 1 & 1.62 & 1.14 & 1.43 & 1.17 & 1.25 & 1.25 \\
\hline 29 & 0.99 & 1.05 & 1.15 & 1.12 & 1.02 & 1.18 & 0.89 & 1.06 & 0.9 & 1.08 & 1.06 & 1.02 & 1.64 & 1.01 & 1.1 & 1.02 & 1.07 & 0.88 \\
\hline 30 & 1.07 & 1.35 & 1.54 & 1.78 & 1.39 & 2 & 0.71 & 1.48 & 0.79 & 1.62 & 1.31 & 1.5 & 1.73 & 1.4 & 1.75 & 1.56 & 1.54 & 1.62 \\
\hline 31 & 1.12 & 0.88 & 1.11 & 0.95 & 1.23 & 2.25 & 0.43 & 1.21 & 0.67 & 2 & 0.78 & 0.4 & 1.5 & 2 & 2 & 2 & 0.75 & 0.5 \\
\hline 32 & 1.04 & 1.11 & 1.33 & 1.41 & 1.06 & 1.79 & 0.45 & 1.57 & 0.4 & 1.62 & 1 & 0.83 & 2.38 & 1.17 & 1 & 0.82 & 0.75 & 1.2 \\
\hline 33 & 1.06 & 1.15 & 1.2 & 1.35 & 1.13 & 1.92 & 0.42 & 1.4 & 0.38 & 1.75 & 0.92 & 0.71 & 2 & 1.08 & 0.86 & 0.75 & 0.67 & 1 \\
\hline
\end{tabular}




\begin{tabular}{|c|c|c|c|c|c|c|c|c|c|c|c|c|c|c|c|c|c|c|}
\hline 34 & 1.04 & 1.15 & 1.25 & 1.43 & 1.07 & 1.92 & 0.7 & 1.6 & 0.57 & 1.75 & 1.1 & 1.4 & 2.38 & 1.36 & 1.6 & 1.1 & 0.86 & 1 \\
\hline 35 & 1.04 & 1.23 & 1.3 & 1.55 & 1.12 & 1.75 & 0.6 & 1.5 & 0.45 & 1.6 & 1.23 & 2 & 2.43 & 1.36 & 1.5 & 1.29 & 1.1 & 1.5 \\
\hline 36 & 1.08 & 1.15 & 1.75 & 1.43 & 1.2 & 1.73 & 0.42 & 1.53 & 0.83 & 1.92 & 1.4 & 1.29 & 1.8 & 1.38 & 1.14 & 0.92 & 1 & 0.67 \\
\hline 37 & 1.04 & 1.18 & 1.27 & 1.5 & 1 & 1.4 & 0.38 & 1.3 & 0.55 & 1.41 & 1.07 & 0.83 & 1.4 & 1.11 & 0.8 & 0.64 & 0.79 & 0.88 \\
\hline 38 & 1.06 & 1 & 1.27 & 1.56 & 1.06 & 1.78 & 0.45 & 1 & 0.6 & 1.58 & 1.38 & 1.67 & 1.88 & 0.75 & 1.14 & 0.88 & $\begin{array}{l}0.8 \\
\end{array}$ & 1.4 \\
\hline 39 & 1.08 & 1.21 & 1.38 & 1.48 & 1.13 & 1.87 & 0.7 & 1.47 & 0.5 & 1.79 & 1.08 & 1.4 & 2.62 & 1.31 & 1.6 & 1.1 & 0.89 & 1.5 \\
\hline 40 & 1.13 & 1.1 & 1.17 & 1.67 & 1.29 & 1.35 & 0.54 & 1.53 & 0.82 & 2.17 & 1.88 & 1.5 & 2 & 1.31 & 1.33 & 1.09 & 1.11 & 1.6 \\
\hline 41 & 0.92 & 0.95 & 1.33 & 1.53 & 1.25 & 1.5 & 0.64 & 0.91 & 0.64 & 1.53 & 1.44 & 1.75 & 2.25 & 1 & 1.25 & 1.11 & 1 & 1.5 \\
\hline 42 & 1 & 1.05 & 1.4 & 1.58 & 1.12 & 2.2 & 1 & 1 & 0.67 & 1.77 & 0.91 & 1 & 2.2 & 0.69 & 1.12 & 1 & 1.5 & 2 \\
\hline 43 & 1.03 & 0.95 & 1.27 & 1.36 & 1.33 & 1.82 & 0.6 & 0.85 & 0.55 & 1.62 & 0.77 & 0.5 & 1.89 & 0.69 & 0.8 & 0.73 & 0.71 & 1.33 \\
\hline 44 & 0.88 & 1 & 1.2 & 1.16 & 1.05 & 1.45 & 0.76 & 1.08 & 0.85 & 1.1 & 1 & 1.09 & 1.43 & 1.09 & 1.18 & 1.06 & 1 & 1.44 \\
\hline 45 & 1.04 & 1.17 & 1.7 & 1.46 & 1.43 & 1.82 & 0.82 & 1.5 & 0.9 & 2 & 1.54 & 2 & 2 & 1.12 & 1.57 & 1.38 & 1.31 & 2 \\
\hline 46 & 1.11 & 1.1 & 1.5 & 1.46 & 1.29 & 1.76 & 0.64 & 1.4 & 0.7 & 1.6 & 1.2 & 1.33 & 1.75 & 1.06 & 1.29 & 1.12 & 1.15 & 1.6 \\
\hline 47 & 0.91 & 0.9 & 1.14 & 1.33 & 1.11 & 1.58 & 0.62 & 0.85 & 0.54 & 1.12 & 1.18 & 0.83 & 2.25 & 0.91 & 1.67 & 1 & 1 & 1 \\
\hline 48 & 1.22 & 1.15 & 1.23 & 1.44 & 1 & 1.32 & 1.1 & 1.85 & 1.22 & 1.56 & 2.11 & 1.5 & 2 & 1.58 & 1.5 & 1.29 & 1.45 & 1.53 \\
\hline 49 & 0.93 & 0.97 & 1.39 & 1.03 & 0.92 & 1.44 & 1 & 1.4 & 1 & 1.2 & 1.26 & 1.29 & 1.75 & 1.32 & 1.5 & 1.29 & 1.12 & 1.12 \\
\hline 50 & 1.17 & 1.26 & 1.45 & 1.68 & 1.07 & 1.93 & 0.92 & 2.15 & 1.25 & 2.6 & 2.75 & 2.6 & 1.8 & 1.46 & 1.71 & 1.17 & 2.43 & 2.75 \\
\hline 51 & 1 & 0.91 & 0.93 & 1.59 & 1.14 & 1.5 & 0.6 & 1.22 & 0.77 & 1.54 & 1.43 & 1.12 & 1.55 & 0.64 & 1.25 & 1.08 & 0.83 & 0.86 \\
\hline 52 & 0.94 & 0.95 & 1.33 & 1.44 & 1.13 & 2.43 & 0.64 & 1 & 0.57 & 1.5 & 1.12 & 1 & 2.11 & 0.88 & 2 & 1.25 & 1.33 & 1.5 \\
\hline
\end{tabular}

\begin{tabular}{|l|l|l|l|l|l|l|l|l|l|l|l|l|l|l|l|l|l|l|}
\hline & $\mathbf{1 9}$ & $\mathbf{2 0}$ & $\mathbf{2 1}$ & $\mathbf{2 2}$ & $\mathbf{2 3}$ & $\mathbf{2 4}$ & $\mathbf{2 5}$ & $\mathbf{2 6}$ & $\mathbf{2 7}$ & $\mathbf{2 8}$ & $\mathbf{2 9}$ & $\mathbf{3 0}$ & $\mathbf{3 1}$ & $\mathbf{3 2}$ & $\mathbf{3 3}$ & $\mathbf{3 4}$ & $\mathbf{3 5}$ & $\mathbf{3 6}$ \\
\hline $\mathbf{2 0}$ & 1 & & & & & & & & & & & & & & & & & \\
\hline $\mathbf{2 1}$ & 1.22 & 1.43 & & & & & & & & & & & & & & & & \\
\hline $\mathbf{2 2}$ & 1.35 & 0.88 & 1.66 & & & & & & & & & & & & & & & \\
\hline $\mathbf{2 3}$ & 2.03 & 2.05 & 3.14 & 1.93 & & & & & & & & & & & & & & \\
\hline $\mathbf{2 4}$ & 1.11 & 0.9 & 1.43 & 1.38 & 2.2 & & & & & & & & & & & & & \\
\hline $\mathbf{2 5}$ & 1.25 & 1.11 & 1.75 & 1.38 & 2.2 & 1 & & & & & & & & & & & & \\
\hline $\mathbf{2 6}$ & 1.22 & 0.88 & 1.56 & 0.85 & 1.9 & 1 & 1.67 & & & & & & & & & & & \\
\hline $\mathbf{2 7}$ & 0.95 & 0.7 & 1.19 & 1.33 & 2.14 & 1.33 & 1.14 & 0 & & & & & & & & & & \\
\hline $\mathbf{2 8}$ & 1.05 & 0.91 & 1.4 & 1.39 & 2.26 & 1.8 & 1.29 & 1 & 1.38 & & & & & & & & & \\
\hline $\mathbf{2 9}$ & 1 & 1 & 1.1 & 1.01 & 1.21 & 1.08 & 1.11 & 1.08 & 1.04 & 0.96 & & & & & & & & \\
\hline $\mathbf{3 0}$ & 1.25 & 1.2 & 1.62 & 1.66 & 2.38 & 2.8 & 2.33 & 3.5 & 2 & 1.75 & 0.97 & & & & & & & \\
\hline $\mathbf{3 1}$ & 0.45 & 0.57 & 1.38 & 1.75 & 2.5 & 0.5 & 0.67 & 0 & 0 & 0.25 & 0.95 & 0.5 & & & & & & \\
\hline $\mathbf{3 2}$ & 1.07 & 0.75 & 1.36 & 1.39 & 2.24 & 1.14 & 1.6 & 0.83 & 0.8 & 1.12 & 1.09 & 1.56 & 0.57 & & & & & \\
\hline
\end{tabular}




\begin{tabular}{|c|c|c|c|c|c|c|c|c|c|c|c|c|c|c|c|c|c|c|}
\hline 33 & 1 & 0.67 & 1.17 & 1.35 & 2.17 & 1.33 & 1.33 & 0.71 & 0.8 & 1.29 & 1.08 & 1.56 & 0.57 & 0 & & & & \\
\hline 34 & 1 & 0.57 & 1.5 & 1.4 & 2.25 & 1.33 & 2 & 1 & 0.89 & 1.29 & 1.06 & 1.75 & 0.5 & 2 & 1 & & & \\
\hline 35 & 1.12 & 0.83 & 1.38 & 1.53 & 2.48 & 1.57 & 1.57 & 1 & 0.75 & 1.5 & 1.06 & 2.2 & 0.5 & 0.83 & 0.71 & 1 & & \\
\hline 36 & 1.19 & 0.89 & 1.6 & 1.57 & 2.43 & 1.5 & 2.17 & 1.29 & 1.33 & 1.44 & 1.09 & 2 & 0.83 & 1.67 & 1 & 3.5 & 1.43 & \\
\hline 37 & 1 & 0.6 & 1.2 & 1.56 & 2.41 & 1.27 & 1.36 & 0.83 & 1 & 1.5 & 1.04 & 2 & 0.8 & 0.88 & 0.67 & 1.29 & 1 & 1.2 \\
\hline 38 & 1.25 & 0.86 & 1.83 & 0.96 & 2.05 & 1.14 & 1.67 & 1.67 & 1 & 1.12 & 1.1 & 1.8 & 1 & 1 & 0.6 & 2 & 3 & 1.33 \\
\hline 39 & 1.12 & 0.86 & 1.58 & 1.41 & 2.2 & 1.5 & 2 & 1.4 & 1 & 1.44 & 1.11 & 1.7 & 0.83 & 1.33 & 1 & 2 & 1.29 & 2 \\
\hline 40 & 1 & 1 & 1.7 & 1.49 & 2.3 & 1.1 & 1.5 & 1.12 & 0.92 & 1.09 & 1.06 & 1.42 & 1 & 0.86 & 0.62 & 1.33 & 1.22 & 1.17 \\
\hline 41 & 1.09 & 1 & 1.44 & 1.08 & 2.14 & 1 & 1.33 & 1.17 & 0.75 & 1 & 1.05 & 1.38 & 1 & 0.75 & 0.56 & 1.14 & 1.25 & 0.67 \\
\hline 42 & 1.22 & 0.9 & 1.78 & 1.04 & 1.74 & 1 & 1.29 & 1 & 0.6 & 1 & 1 & 1.1 & 0.38 & 0.83 & 0.71 & 1 & 1.33 & 1.14 \\
\hline 43 & 0.79 & 0.6 & 1.25 & 1.24 & 1.87 & 0.8 & 0.9 & 0.5 & 0.5 & 1 & 1.03 & 1 & 0.25 & 0.44 & 0.44 & 0.5 & 0.6 & 0.88 \\
\hline 44 & 1.09 & 1.15 & 1.14 & 1.2 & 1.74 & 0.94 & 1.07 & 1.09 & 0.8 & 1.06 & 1 & 1.11 & 1.43 & 0.86 & 0.8 & 0.92 & 0.94 & 1 \\
\hline 45 & 1.22 & 1.29 & 1.47 & 1.44 & 2.21 & 1.36 & 1.5 & 1.33 & 0.88 & 1.6 & 1.07 & 1.5 & 0.6 & 1.22 & 1.22 & 1.38 & 1.2 & 1.62 \\
\hline 46 & 1 & 1 & 1.33 & 1.44 & 2.14 & 1.18 & 1.3 & 0.67 & 0.62 & 1.4 & 1.09 & 1.3 & 0.5 & 1 & 1 & 1.12 & 0.8 & 1.38 \\
\hline 47 & 1.09 & 1 & 1.67 & 0.81 & 1.81 & 0.83 & 1.2 & 0.5 & 0.25 & 0.89 & 1.06 & 2 & 0.25 & 0.86 & 0.75 & 1 & 0.75 & 1.25 \\
\hline 48 & 1.31 & 1.15 & 1.52 & 1.49 & 1.87 & 1.48 & 1.68 & 1.33 & 1.43 & 1.36 & 1.1 & 1.59 & 1.36 & 1.45 & 1.38 & 1.53 & 1.41 & 1.57 \\
\hline 49 & 1.16 & 1.31 & 1.67 & 1 & 2.12 & 1.31 & 1.47 & 1.36 & 1.27 & 1.29 & 1.18 & 1.6 & 1.75 & 1.13 & 1.06 & 1.21 & 1.14 & 1.25 \\
\hline 50 & 1.44 & 1.33 & 2.2 & 1.6 & 2.3 & 1.5 & 2.17 & 1.57 & 1.4 & 1.67 & 1.13 & 2 & 1.14 & 2.6 & 2 & 3.25 & 2.29 & 3.5 \\
\hline 51 & 0.82 & 0.7 & 1.86 & 1 & 1.78 & 0.5 & 0.67 & 0.7 & 0.64 & 0.73 & 1 & 1 & 0.57 & 0.5 & 0.44 & 0.43 & 0.62 & 1.14 \\
\hline 52 & 1.33 & 0.86 & 1.83 & 0.89 & 1.95 & 1 & 2 & 1 & 0.6 & 1 & 1 & 1.6 & 0.33 & 0.67 & 0.5 & 1 & 1 & 1.5 \\
\hline
\end{tabular}

\begin{tabular}{|l|l|l|l|l|l|l|l|l|l|l|l|l|l|l|l|}
\hline & $\mathbf{3 7}$ & $\mathbf{3 8}$ & $\mathbf{3 9}$ & $\mathbf{4 0}$ & $\mathbf{4 1}$ & $\mathbf{4 2}$ & $\mathbf{4 3}$ & $\mathbf{4 4}$ & $\mathbf{4 5}$ & $\mathbf{4 6}$ & $\mathbf{4 7}$ & $\mathbf{4 8}$ & $\mathbf{4 9}$ & $\mathbf{5 0}$ & $\mathbf{5 1}$ \\
\hline $\mathbf{3 8}$ & 0 & & & & & & & & & & & & & & \\
\hline $\mathbf{3 9}$ & 1.11 & 2 & & & & & & & & & & & & & \\
\hline $\mathbf{4 0}$ & 0.82 & 0.8 & 1.12 & & & & & & & & & & & & \\
\hline $\mathbf{4 1}$ & 0.25 & 0.4 & 1.14 & 0.33 & & & & & & & & & & & \\
\hline $\mathbf{4 2}$ & 0.8 & 1.29 & 0.6 & 1.12 & 1.1 & & & & & & & & & & \\
\hline $\mathbf{4 3}$ & 0.5 & 0.75 & 0.5 & 0.8 & 0.62 & 1.5 & & & & & & & & & \\
\hline $\mathbf{4 4}$ & 0.94 & 1.5 & 1.07 & 1.2 & 1.31 & 1.09 & 0.93 & & & & & & & & \\
\hline $\mathbf{4 5}$ & 1.17 & 6 & 1.4 & 1.78 & 1.6 & 0.86 & 0.83 & 1.08 & & & & & & & \\
\hline $\mathbf{4 6}$ & 0.83 & 4 & 1.2 & 1.56 & 1.2 & 0.57 & 0.5 & 1.08 & 1 & & & & & & \\
\hline $\mathbf{4 7}$ & 0.86 & 1.2 & 1.33 & 1.25 & 1.33 & 0.9 & 0.5 & 0.92 & 1 & 0.6 & & & & & \\
\hline $\mathbf{4 8}$ & 1.31 & 1.32 & 1.57 & 1.74 & 1.44 & 1.2 & 1.14 & 1.13 & 1.46 & 1.38 & 1.33 & & & & \\
\hline $\mathbf{4 9}$ & 1.06 & 1.2 & 1.36 & 1.25 & 1.25 & 1.22 & 1.12 & 1.14 & 1.43 & 1.29 & 1.36 & 1.36 & & & \\
\hline
\end{tabular}




\begin{tabular}{|l|l|l|l|l|l|l|l|l|l|l|l|l|l|l|l|}
$\mathbf{5 0}$ & 1.78 & 2.5 & 2.83 & 3.25 & 1.71 & 1.86 & 1.67 & 1.2 & 1.78 & 1.89 & 1.33 & 1.79 & 1.18 & & \\
\hline $\mathbf{5 1}$ & 0.8 & 1.14 & 0.71 & 2 & 1.25 & 0.6 & 0.64 & 0.77 & 0.5 & 0.62 & 0.8 & 1.33 & 1.06 & 2 & \\
\hline $\mathbf{5 2}$ & 0.86 & 1.5 & 2 & 1.2 & 1.14 & 1 & 0.57 & 1.12 & 1.25 & 0.75 & 0.8 & 1.4 & 1.38 & 2.5 & 0.57 \\
\hline
\end{tabular}

Taxa key for table A16: Same as table A15. 
TABLE A17: Pairwise p-distance of cytochrome oxidase subunit one ( $C O$ I) gene used in Calliphoridae phylogeny (Chapter 5).

\begin{tabular}{|c|c|c|c|c|c|c|c|c|c|c|c|c|c|c|c|c|c|}
\hline & 1 & 2 & 3 & 4 & 5 & 6 & 7 & 8 & 9 & 10 & 11 & 12 & 13 & 14 & 15 & 16 & 17 \\
\hline 2 & 0.126 & & & & & & & & & & & & & & & & \\
\hline 3 & 0.112 & 0.146 & & & & & & & & & & & & & & & \\
\hline 4 & 0.116 & 0.141 & 0.113 & & & & & & & & & & & & & & \\
\hline 5 & 0.115 & 0.126 & 0.108 & 0.118 & & & & & & & & & & & & & \\
\hline 6 & 0.133 & 0.148 & 0.148 & 0.132 & 0.142 & & & & & & & & & & & & \\
\hline 7 & 0.171 & 0.175 & 0.161 & 0.154 & 0.161 & 0.139 & & & & & & & & & & & \\
\hline 8 & 0.12 & 0.147 & 0.115 & 0.128 & 0.129 & 0.129 & 0.154 & & & & & & & & & & \\
\hline 9 & 0.124 & 0.142 & 0.13 & 0.129 & 0.117 & 0.14 & 0.144 & 0.113 & & & & & & & & & \\
\hline 10 & 0.118 & 0.137 & 0.128 & 0.133 & 0.129 & 0.133 & 0.163 & 0.12 & 0.111 & & & & & & & & \\
\hline 11 & 0.127 & 0.127 & 0.132 & 0.139 & 0.121 & 0.132 & 0.162 & 0.121 & 0.104 & 0.119 & & & & & & & \\
\hline 12 & 0.131 & 0.151 & 0.118 & 0.14 & 0.116 & 0.153 & 0.136 & 0.126 & 0.118 & 0.12 & 0.129 & & & & & & \\
\hline 13 & 0.145 & 0.14 & 0.13 & 0.154 & 0.131 & 0.144 & 0.166 & 0.127 & 0.122 & 0.129 & 0.126 & 0.132 & & & & & \\
\hline 14 & 0.126 & 0.138 & 0.124 & 0.142 & 0.122 & 0.134 & 0.17 & 0.13 & 0.13 & 0.125 & 0.115 & 0.124 & 0.127 & & & & \\
\hline 15 & 0.132 & 0.142 & 0.126 & 0.141 & 0.119 & 0.132 & 0.174 & 0.13 & 0.111 & 0.125 & 0.107 & 0.11 & 0.127 & 0.114 & & & \\
\hline 16 & 0.129 & 0.147 & 0.125 & 0.146 & 0.123 & 0.14 & 0.146 & 0.13 & 0.126 & 0.113 & 0.13 & 0.105 & 0.116 & 0.132 & 0.117 & & \\
\hline 17 & 0.154 & 0.155 & 0.144 & 0.134 & 0.142 & 0.148 & 0.164 & 0.134 & 0.138 & 0.15 & 0.151 & 0.152 & 0.155 & 0.148 & 0.139 & 0.144 & \\
\hline 18 & 0.114 & 0.144 & 0.14 & 0.139 & 0.126 & 0.136 & 0.16 & 0.137 & 0.122 & 0.139 & 0.119 & 0.134 & 0.14 & 0.142 & 0.124 & 0.119 & 0.13 \\
\hline 19 & 0.127 & 0.131 & 0.143 & 0.134 & 0.114 & 0.131 & 0.144 & 0.125 & 0.114 & 0.122 & 0.106 & 0.139 & 0.129 & 0.123 & 0.122 & 0.12 & 0.144 \\
\hline 20 & 0.149 & 0.145 & 0.154 & 0.143 & 0.139 & 0.14 & 0.16 & 0.147 & 0.13 & 0.15 & 0.129 & 0.148 & 0.15 & 0.142 & 0.133 & 0.146 & 0.141 \\
\hline 21 & 0.147 & 0.157 & 0.151 & 0.151 & 0.137 & 0.153 & 0.177 & 0.153 & 0.144 & 0.144 & 0.143 & 0.156 & 0.161 & 0.104 & 0.142 & 0.149 & 0.147 \\
\hline 22 & 0.128 & 0.143 & 0.124 & 0.125 & 0.128 & 0.143 & 0.169 & 0.137 & 0.126 & 0.134 & 0.129 & 0.137 & 0.149 & 0.127 & 0.132 & 0.126 & 0.148 \\
\hline 23 & 0.132 & 0.148 & 0.144 & 0.14 & 0.143 & 0.149 & 0.172 & 0.126 & 0.131 & 0.134 & 0.135 & 0.147 & 0.134 & 0.136 & 0.14 & 0.14 & 0.142 \\
\hline 24 & 0.2 & 0.183 & 0.206 & 0.192 & 0.179 & 0.205 & 0.197 & 0.198 & 0.191 & 0.164 & 0.173 & 0.169 & 0.189 & 0.206 & 0.186 & 0.196 & 0.2 \\
\hline 25 & 0.13 & 0.154 & 0.146 & 0.131 & 0.126 & 0.139 & 0.166 & 0.125 & 0.133 & 0.136 & 0.128 & 0.142 & 0.145 & 0.126 & 0.122 & 0.124 & 0.13 \\
\hline 26 & 0.114 & 0.138 & 0.135 & 0.119 & 0.114 & 0.13 & 0.156 & 0.114 & 0.108 & 0.127 & 0.107 & 0.13 & 0.125 & 0.114 & 0.108 & 0.107 & 0.117 \\
\hline 27 & 0.117 & 0.149 & 0.426 & 0.136 & 0.118 & 0.144 & 0.426 & \begin{tabular}{|l|}
0.132 \\
\end{tabular} & 0.104 & 0.135 & 0.12 & 0.149 & 0.141 & 0.123 & 0.089 & 0.426 & 0.135 \\
\hline
\end{tabular}




\begin{tabular}{|c|c|c|c|c|c|c|c|c|c|c|c|c|c|c|c|c|c|}
\hline 28 & 0.118 & 0.136 & 0.124 & 0.141 & 0.122 & 0.124 & 0.149 & 0.12 & 0.118 & 0.11 & 0.11 & 0.105 & 0.12 & 0.101 & 0.111 & 0.1 & 0.133 \\
\hline 29 & 0.118 & 0.135 & 0.132 & 0.114 & 0.116 & 0.126 & 0.145 & 0.112 & 0.104 & 0.128 & 0.118 & 0.138 & 0.128 & 0.108 & 0.111 & 0.119 & 0.116 \\
\hline 30 & 0.123 & 0.141 & 0.117 & 0.121 & 0.112 & 0.144 & 0.156 & 0.116 & 0.116 & 0.133 & 0.118 & 0.13 & 0.137 & 0.109 & 0.113 & 0.108 & 0.13 \\
\hline 31 & 0.106 & 0.129 & 0.098 & 0.101 & 0.102 & 0.129 & 0.138 & 0.114 & 0.097 & 0.118 & 0.111 & 0.132 & 0.122 & 0.106 & 0.097 & 0.099 & 0.121 \\
\hline 32 & 0.134 & 0.146 & 0.145 & 0.134 & 0.125 & 0.134 & 0.154 & 0.122 & 0.129 & 0.142 & 0.133 & 0.141 & 0.143 & 0.137 & 0.126 & 0.114 & 0.124 \\
\hline 33 & 0.116 & 0.143 & 0.131 & 0.108 & 0.123 & 0.134 & 0.154 & 0.128 & 0.126 & 0.133 & 0.125 & 0.136 & 0.146 & 0.115 & 0.122 & 0.133 & 0.134 \\
\hline 34 & 0.123 & 0.154 & 0.136 & 0.114 & 0.126 & 0.134 & 0.142 & 0.123 & 0.128 & 0.136 & 0.131 & 0.138 & 0.154 & 0.122 & 0.118 & 0.123 & 0.126 \\
\hline 35 & 0.112 & 0.141 & 0.118 & 0.11 & 0.114 & 0.128 & 0.144 & 0.12 & 0.118 & 0.129 & 0.126 & 0.122 & 0.14 & 0.124 & 0.115 & 0.116 & 0.12 \\
\hline 36 & 0.124 & 0.153 & 0.138 & 0.109 & 0.128 & 0.137 & 0.168 & 0.123 & 0.127 & 0.134 & 0.131 & 0.132 & 0.151 & 0.124 & 0.123 & 0.144 & .128 \\
\hline 37 & 0.128 & 0.148 & 0.141 & 0.105 & 0.134 & 0.14 & 0.16 & 0.128 & 0.122 & 0.136 & 0.126 & 0.149 & 0.159 & 0.123 & 0.132 & 0.145 & 0.138 \\
\hline 38 & 0.128 & 0.14 & 0.126 & 0.129 & 0.128 & 0.137 & 0.146 & 0.124 & 0.133 & 0.141 & 0.121 & 0.142 & 0.15 & 0.114 & 0.127 & 0.138 & 0.13 \\
\hline 39 & 0.12 & 0.142 & 0.12 & 0.105 & 0.117 & 0.14 & 0.155 & 0.118 & 0.113 & 0.126 & 0.118 & 0.128 & 0.139 & 0.108 & 0.117 & 0.129 & 0.129 \\
\hline 40 & 0.125 & 0.15 & 0.109 & & & & & 0.123 & & & & 0.127 & & 2 & 13 & & 14 \\
\hline 41 & 0.128 & 0.136 & 0.145 & 0.131 & 0.13 & 0.134 & 0.161 & 0.125 & 0.133 & 0.14 & 0.128 & 0.141 & 0.149 & 0.124 & 0.125 & 0.143 & 0.137 \\
\hline 42 & 0.134 & 0.139 & 0.138 & 0.127 & 0.123 & 0.145 & 0.171 & 0.124 & 0.12 & 0.133 & 0.13 & 0.137 & 0.142 & 0.126 & 0.12 & 0.123 & 0.146 \\
\hline 43 & 0.112 & 0.139 & 0.124 & 0.118 & 0.112 & 0.136 & 0.161 & 0.114 & 0.109 & 0.126 & 0.114 & 0.133 & 0.133 & 0.117 & 0.108 & 0.114 & 0.12 \\
\hline 44 & 0.123 & 0.137 & 0.143 & 0.125 & 0.12 & 0.128 & 0.147 & 0.123 & 0.116 & & 0.116 & 0.124 & 0.144 & 0.12 & 0.116 & 0.125 & 0.13 \\
\hline 45 & 0.109 & 0.137 & 0.122 & 0.128 & 0.108 & 0.135 & 0.166 & 0.108 & 0.098 & 0.117 & 0.111 & 0.123 & 0.135 & 0.105 & 0.1 & 0.116 & 0.134 \\
\hline 46 & 0.109 & 0.143 & 0.426 & 0.109 & 0.12 & 0.134 & 0.426 & 0.123 & 0.106 & 0.123 & 0.122 & 0.152 & 0.14 & 0.115 & 0.09 & 0.426 & 0.128 \\
\hline 47 & 0.109 & 0.13 & 0.117 & 0.122 & 0.104 & 0.13 & 0.15 & 0.107 & 0.101 & 0.117 & .114 & 0.121 & 0.126 & 0.112 & 0.105 & 121 & 0.128 \\
\hline 48 & 0.122 & 0.146 & 0.12 & 0.138 & 0.112 & 0.118 & 0.157 & 0.109 & 0.116 & 0.113 & 0.109 & 0.093 & 0.118 & 0.091 & 0.112 & 0.092 & 0.131 \\
\hline 49 & 0.134 & 0.147 & 0.156 & 0.156 & 0.129 & 0.148 & 0.166 & 0.139 & 0.133 & 0.141 & 0.133 & 0.142 & 0.152 & 0.139 & 0.134 & 0.139 & 0.151 \\
\hline 50 & 0.116 & 0.131 & 0.123 & 0.13 & 0.108 & 0.132 & 0.174 & 0.124 & 0.118 & 0.126 & 0.12 & 0.13 & 0.133 & 0.114 & 0.12 & 0.128 & 0.142 \\
\hline 51 & 0.117 & 0.136 & 0.124 & 0.12 & 0.112 & 0.141 & 0.16 & 0.12 & 0.108 & 0.124 & 0.119 & 0.121 & 0.134 & 0.113 & 0.077 & 0.108 & 0.129 \\
\hline 52 & 0.107 & 0.122 & 0.113 & 0.113 & 0.104 & 0.128 & 0.15 & 0.11 & 0.114 & 0.114 & 0.116 & 0.122 & 0.128 & 0.11 & 0.094 & 0.099 & 0.122 \\
\hline 53 & 0.119 & 0.134 & 0.113 & 0.116 & 0.11 & 0.126 & 0.166 & 0.102 & 0.11 & 0.112 & 0.111 & 0.113 & 0.132 & 0.109 & 0.107 & 0.103 & 0.133 \\
\hline 54 & 0.122 & 0.146 & 0.119 & 0.115 & 0.119 & 0.133 & 0.131 & 0.112 & 0.108 & 0.122 & 0.123 & 0.127 & 0.13 & 0.115 & 0.112 & 0.111 & 0.139 \\
\hline 55 & 0.121 & 0.13 & 0.114 & 0.12 & 0.109 & 0.136 & 0.128 & 0.113 & 0.103 & 0.119 & 0.11 & 0.118 & 0.125 & 0.113 & 0.1 & 0.103 & 0.136 \\
\hline 56 & 0.137 & 0.152 & 0.137 & 0.141 & 0.12 & 0.143 & 0.146 & 0.137 & 0.125 & 0.135 & 0.127 & 0.127 & 0.128 & 0.113 & 0.123 & 0.118 & 0.143 \\
\hline
\end{tabular}




\begin{tabular}{|c|c|c|c|c|c|c|c|c|c|c|c|c|c|c|c|c|c|}
\hline & 18 & 19 & 20 & 21 & 22 & 23 & 24 & 25 & 26 & 27 & 28 & 29 & 30 & 31 & 32 & 33 & 34 \\
\hline 19 & 0.113 & & & & & & & & & & & & & & & & \\
\hline 20 & 0.137 & 0.122 & & & & & & & & & & & & & & & \\
\hline 21 & 0.14 & 0.138 & 0.145 & & & & & & & & & & & & & & \\
\hline 22 & 0.14 & 0.117 & 0.132 & 0.112 & & & & & & & & & & & & & \\
\hline 23 & 0.124 & 0.135 & 0.149 & 0.156 & 0.159 & & & & & & & & & & & & \\
\hline 24 & 0.16 & 0.19 & 0.189 & 0.213 & 0.19 & 0.209 & & & & & & & & & & & \\
\hline 25 & 0.134 & 0.124 & 0.133 & 0.152 & 0.141 & 0.14 & 0.2 & & & & & & & & & & \\
\hline 26 & 0.118 & 0.118 & 0.133 & 0.146 & 0.123 & 0.128 & 0.178 & 0.059 & & & & & & & & & \\
\hline 27 & 0.426 & 0.118 & 0.129 & 0.139 & 0.123 & 0.147 & 0.426 & 0.109 & 0.083 & & & & & & & & \\
\hline 28 & 0.103 & 0.099 & 0.117 & 0.134 & 0.124 & 0.13 & 0.198 & 0.09 & 0.082 & 0.426 & & & & & & & \\
\hline 29 & 0.121 & 0.113 & 0.122 & 0.133 & 0.126 & 0.123 & 0.195 & 0.091 & 0.076 & 0.086 & 0.103 & & & & & & \\
\hline 30 & 0.111 & 0.125 & 0.133 & 0.134 & 0.129 & 0.132 & 0.189 & 0.098 & 0.084 & 0.103 & 0.103 & 0.071 & & & & & \\
\hline 31 & 0.112 & 0.109 & 0.12 & 0.135 & 0.107 & 0.122 & 0.155 & 0.083 & 0.072 & 0.094 & 0.093 & 0.062 & 0.046 & & & & \\
\hline 32 & 0.115 & 0.129 & 0.121 & 0.158 & 0.152 & 0.15 & 0.192 & 0.099 & 0.089 & 0.112 & 0.107 & 0.083 & 0.103 & 0.089 & & & \\
\hline 33 & 0.122 & 0.128 & 0.137 & 0.139 & 0.128 & 0.134 & 0.202 & 0.101 & 0.088 & 0.098 & 0.115 & 0.088 & 0.103 & 0.085 & 0.113 & & \\
\hline 34 & 0.113 & 0.127 & 0.143 & 0.141 & 0.131 & 0.141 & 0.197 & 0.108 & 0.1 & 0.109 & 0.113 & 0.088 & 0.098 & 0.092 & 0.115 & 0.065 & \\
\hline 35 & 0.125 & 0.123 & 0.127 & 0.134 & 0.117 & 0.134 & 0.212 & 0.117 & 0.105 & 0.125 & 0.111 & 0.104 & 0.107 & 0.101 & 0.124 & 0.091 & 0.079 \\
\hline 36 & 0.135 & 0.134 & 0.143 & 0.146 & 0.132 & 0.143 & 0.211 & 0.11 & 0.103 & 0.116 & 0.118 & 0.088 & 0.099 & 0.093 & 0.118 & 0.078 & 0.072 \\
\hline 37 & 0.133 & 0.13 & 0.132 & 0.145 & 0.136 & 0.149 & 0.188 & 0.115 & 0.102 & 0.109 & 0.122 & 0.086 & 0.093 & 0.082 & 0.123 & 0.08 & 0.081 \\
\hline 38 & 0.119 & 0.13 & 0.131 & 0.153 & 0.137 & 0.144 & 0.197 & 0.113 & 0.098 & 0.111 & 0.115 & 0.098 & 0.103 & 0.098 & 0.12 & 0.104 & 0.098 \\
\hline 39 & 0.132 & 0.124 & 0.136 & 0.132 & 0.126 & 0.137 & 0.198 & 0.104 & 0.098 & 0.11 & 0.118 & 0.089 & 0.089 & 0.085 & 0.115 & 0.082 & 0.08 \\
\hline 40 & 0.137 & 0.133 & 0.135 & 0.148 & 0.135 & 0.143 & 0.198 & 0.111 & 0.105 & 0.109 & 0.111 & 0.111 & 0.107 & 0.1 & 0.121 & 0.098 & 0.102 \\
\hline 41 & 0.151 & 0.119 & 0.139 & 0.151 & 0.138 & 0.143 & 0.204 & 0.121 & 0.11 & 0.117 & 0.123 & 0.116 & 0.125 & 0.115 & 0.133 & 0.116 & 0.111 \\
\hline 42 & 0.14 & 0.122 & 0.134 & 0.152 & 0.135 & 0.148 & 0.199 & 0.126 & 0.114 & 0.125 & 0.117 & 0.118 & 0.124 & 0.118 & 0.12 & 0.129 & 0.121 \\
\hline 43 & 0.115 & 0.118 & 0.127 & 0.139 & 0.125 & 0.128 & 0.2 & 0.101 & 0.09 & 0.109 & 0.095 & 0.086 & 0.099 & 0.09 & 0.107 & 0.097 & 0.093 \\
\hline 44 & 0.125 & 0.111 & 0.115 & 0.135 & 0.124 & 0.129 & 0.179 & 0.103 & 0.095 & 0.104 & 0.099 & 0.088 & 0.102 & 0.085 & 0.115 & 0.1 & 0.093 \\
\hline 45 & 0.122 & 0.11 & 0.124 & 0.14 & 0.119 & 0.119 & 0.168 & 0.107 & 0.094 & 0.098 & 0.096 & 0.094 & 0.103 & 0.094 & 0.124 & 0.106 & 0.107 \\
\hline 46 & 0.426 & 0.114 & 0.111 & 0.125 & 0.122 & 0.134 & 0.426 & 0.103 & 0.094 & 0.109 & 0 & 0.069 & 0.102 & 0.077 & 0.109 & 0.11 & 0.093 \\
\hline 47 & 0.117 & 0.106 & 0.126 & 0.135 & 0.12 & 0.131 & 0.179 & 0.104 & 0.088 & 0.1 & 0.099 & 0.087 & 0.098 & 0.092 & 0.11 & 0.104 & 0.102 \\
\hline
\end{tabular}




\begin{tabular}{|c|c|c|c|c|c|c|c|c|c|c|c|c|c|c|c|c|c|}
\hline 48 & 0.124 & 0.108 & 0.132 & 0.15 & 0.111 & 0.131 & 0.178 & 0.083 & 0.066 & 0.426 & 0.081 & 0.101 & 0.096 & 0.092 & 0.103 & 0.104 & 0.106 \\
\hline 49 & 0.138 & 0.132 & 0.157 & 0.162 & 0.143 & 0.149 & 0.201 & 0.132 & 0.122 & 0.112 & 0.127 & 0.123 & 0.132 & 0.116 & 0.134 & 0.136 & 0.137 \\
\hline 50 & 0.117 & 0.117 & 0.14 & 0.143 & 0.128 & 0.132 & 0.192 & 0.126 & 0.113 & 0.116 & 0.119 & 0.119 & 0.118 & 0.11 & 0.131 & 0.118 & 0.116 \\
\hline 51 & 0.113 & 0.12 & 0.131 & 0.142 & 0.13 & 0.13 & 0.181 & 0.1 & 0.084 & 0.09 & 0.098 & 0.089 & 0.092 & 0.085 & 0.116 & 0.107 & 0.109 \\
\hline 52 & 0.098 & 0.107 & 0.134 & 0.132 & 0.119 & 0.126 & 0.188 & 0.091 & 0.079 & 0.091 & 0.084 & 0.078 & 0.088 & 0.075 & 0.111 & 0.095 & 0.099 \\
\hline 53 & 0.125 & 0.114 & 0.138 & 0.132 & 0.124 & 0.128 & 0.187 & 0.123 & 0.102 & 0.116 & 0.108 & 0.102 & 0.106 & 0.097 & 0.122 & & 114 \\
\hline 54 & 0.132 & 0.124 & 0.119 & 0.139 & 0.126 & 0.123 & 0.192 & 0.12 & 0.109 & 0.123 & 0.109 & 0.104 & 0.107 & 0.101 & 0.129 & 0.115 & 0.115 \\
\hline 55 & 0.109 & 0.112 & 0.131 & 0.13 & 0.113 & 0.125 & 0.163 & 0.122 & 0.101 & 0.125 & 0.1 & 0.107 & 0.113 & 0.094 & 0.123 & 0.109 & 0.115 \\
\hline 56 & 0.129 & 0.118 & 0.128 & 0.141 & 0.126 & 0.149 & 0.191 & 0.124 & 0.118 & 0.115 & 0.1 & 0.111 & 0.116 & 0.105 & 0.133 & 0.126 & 0.129 \\
\hline
\end{tabular}

\begin{tabular}{|c|c|c|c|c|c|c|c|c|c|c|c|c|c|c|c|c|c|}
\hline & 35 & 36 & 37 & 38 & 39 & 40 & 41 & 42 & 43 & 44 & 45 & 46 & 47 & 48 & 49 & 50 & 51 \\
\hline 36 & 0.077 & & & & & & & & & & & & & & & & \\
\hline 37 & 0.099 & 0.082 & & & & & & & & & & & & & & & \\
\hline 38 & 0.106 & 0.096 & 0.076 & & & & & & & & & & & & & & \\
\hline 39 & 0.095 & 0.073 & 0.057 & 0.082 & & & & & & & & & & & & & \\
\hline 40 & 0.096 & 0.105 & 0.112 & 0.116 & 0.098 & & & & & & & & & & & & \\
\hline 41 & 0.122 & 0.132 & 0.128 & 0.123 & 0.119 & 0.125 & & & & & & & & & & & \\
\hline 42 & 0.129 & 0.133 & 0.125 & 0.131 & 0.115 & 0.129 & 0.088 & & & & & & & & & & \\
\hline 43 & 0.103 & 0.101 & 0.106 & 0.107 & 0.09 & 0.109 & 0.126 & 0.12 & & & & & & & & & \\
\hline 44 & 0.095 & 0.097 & 0.102 & 0.103 & 0.099 & 0.112 & 0.122 & 0.118 & 0.077 & & & & & & & & \\
\hline 45 & 0.105 & 0.111 & 0.119 & 0.118 & 0.106 & 0.111 & 0.112 & 0.107 & 0.091 & 0.091 & & & & & & & \\
\hline 46 & 0.104 & 0.097 & 0.108 & 0.11 & 0.096 & 0.114 & 0.105 & 0.102 & 0.076 & 0.099 & 0.085 & & & & & & \\
\hline 47 & 0.104 & 0.111 & 0.117 & 0.115 & 0.107 & 0.122 & 0.112 & 0.115 & 0.084 & 0.097 & 0.086 & 0.077 & & & & & \\
\hline 48 & 0.111 & 0.116 & 0.123 & 0.105 & 0.102 & 0.105 & 0.114 & 0.114 & 0.097 & 0.093 & 0.095 & 0.426 & 0.085 & & & & \\
\hline 49 & 0.139 & 0.142 & 0.14 & 0.136 & 0.141 & 0.144 & 0.126 & 0.132 & 0.141 & 0.137 & 0.13 & 0.126 & 0.13 & 0.129 & & & \\
\hline 50 & 0.113 & 0.132 & 0.125 & 0.126 & 0.113 & 0.127 & 0.12 & 0.114 & 0.116 & 0.117 & 0.107 & 0.123 & 0.11 & 0.107 & 0.112 & & \\
\hline 51 & 0.106 & 0.107 & 0.11 & 0.11 & 0.105 & 0.112 & 0.112 & 0.105 & 0.1 & 0.111 & 0.096 & 0.09 & 0.093 & 0.097 & 0.122 & 0.116 & \\
\hline 52 & 0.096 & 0.1 & 0.101 & 0.098 & 0.091 & 0.106 & 0.115 & 0.112 & 0.09 & 0.102 & 0.092 & 0.077 & 0.084 & 0.091 & 0.109 & 0.104 & 0.076 \\
\hline 53 & 0.11 & 0.113 & 0.118 & 0.114 & 0.103 & 0.108 & 0.123 & 0.121 & 0.112 & 0.103 & 0.094 & 0.105 & 0.103 & 0.088 & 0.134 & 0.115 & 0.11 \\
\hline
\end{tabular}




\begin{tabular}{|c|c|c|c|c|c|c|c|c|c|c|c|c|c|c|c|c|c|}
\hline 54 & 0.111 & 0.12 & 0.114 & 0.115 & 0.099 & 0.111 & 0.127 & 0.116 & 0.104 & 0.114 & 0.102 & 0.095 & 0.114 & 0.112 & 0.145 & 0.12 & 0.109 \\
\hline 55 & 0.103 & 0.116 & 0.122 & 0.122 & 0.102 & 0.106 & 0.128 & 0.123 & 0.101 & 0.095 & 0.094 & 0.107 & 0.101 & 0.089 & 0.142 & 0.119 & 0.107 \\
\hline 56 & 0.123 & 0.131 & 0.131 & 0.126 & 0.123 & 0.13 & 0.129 & 0.121 & 0.117 & 0.121 & 0.109 & 0.103 & 0.12 & 0.113 & 0.114 & 0.124 & 0.112 \\
\hline
\end{tabular}

\begin{tabular}{|l|l|l|l|l|}
\hline & $\mathbf{5 2}$ & $\mathbf{5 3}$ & $\mathbf{5 4}$ & $\mathbf{5 5}$ \\
\hline $\mathbf{5 3}$ & 0.092 & & & \\
\hline $\mathbf{5 4}$ & 0.103 & 0.096 & & \\
\hline $\mathbf{5 5}$ & 0.099 & 0.081 & 0.087 & \\
\hline $\mathbf{5 6}$ & 0.112 & 0.123 & 0.113 & 0.117 \\
\hline
\end{tabular}

\section{Taxa key for table A17:}

\begin{tabular}{|r|l|r|l|l|l|l|l|}
\hline $\mathbf{1}$ & Drosophila melanogaster & $\mathbf{1 5}$ & Stevenia hertingi & $\mathbf{2 9}$ & Lucilia sericata & $\mathbf{4 3}$ & Bengalia peuhi \\
\hline $\mathbf{2}$ & Glossina morsitans & $\mathbf{1 6}$ & Stevenia atramentaria & $\mathbf{3 0}$ & Hypopygiopsis infumata & $\mathbf{4 4}$ & Bengalia depressa \\
\hline $\mathbf{3}$ & Fannia canicularis & $\mathbf{1 7}$ & Sarcophaga crassipalpis & $\mathbf{3 1}$ & Hemipyrellia fernandica & $\mathbf{4 5}$ & Verticia orientalis \\
\hline $\mathbf{4}$ & Musca domestica & $\mathbf{1 8}$ & Notochaeta spp. & $\mathbf{3 2}$ & Dyscritomyia robusta & $\mathbf{4 6}$ & Auchmeromyia luteola \\
\hline $\mathbf{5}$ & Hydrotaea cyrtoneurina & $\mathbf{1 9}$ & Metopia campestris & $\mathbf{3 3}$ & Phormia regina & $\mathbf{4 7}$ & Cordylobia anthropophaga \\
\hline $\mathbf{6}$ & Mystacinobia zelandica & $\mathbf{2 0}$ & Sarcophila meridionalis & $\mathbf{3 4}$ & Protophormia terraenovae & $\mathbf{4 8}$ & Melinda viridicyanea \\
\hline $\mathbf{7}$ & McAlpine's fly & $\mathbf{2 1}$ & Cuterebra fontinella & $\mathbf{3 5}$ & Chrysomya rufifacies & $\mathbf{4 9}$ & Mesembrinella spp. \\
\hline $\mathbf{8}$ & Epalpus signifier & $\mathbf{2 2}$ & Cuterebra baeri & $\mathbf{3 6}$ & Chrysomya megacephala & $\mathbf{5 0}$ & Eumesembrinella quadrilineata \\
\hline $\mathbf{9}$ & Gymnocheta viridis & $\mathbf{2 3}$ & Hypoderma lineatum & $\mathbf{3 7}$ & Cochliomyia macellaria & $\mathbf{5 1}$ & Sarconesia versicolor \\
\hline $\mathbf{1 0}$ & Cyrtophleba nitida & $\mathbf{2 4}$ & Oestrus ovis & $\mathbf{3 8}$ & Cochliomyia hominivorax & $\mathbf{5 2}$ & Sarconesia chlorogaster \\
\hline $\mathbf{1 1}$ & Nemorilla floralis & $\mathbf{2 5}$ & Cynomya cadaverina & $\mathbf{3 9}$ & Compsomyiops fulvicrura & $\mathbf{5 3}$ & Isomyia gomezmenori \\
\hline $\mathbf{1 2}$ & Gymnosoma nitens & $\mathbf{2 6}$ & Calliphora vomitoria & $\mathbf{4 0}$ & Protocalliphora sialia & $\mathbf{5 4}$ & Rhyncomya nigripes \\
\hline $\mathbf{1 3}$ & Phania funesta & $\mathbf{2 7}$ & Bellardia vulgaris & $\mathbf{4 1}$ & Pollenia rudis & $\mathbf{5 5}$ & Metallea erinacea \\
\hline $\mathbf{1 4}$ & Rhinophora lepida & $\mathbf{2 8}$ & Onesia tibialis & $\mathbf{4 2}$ & Pollenia amentaria & $\mathbf{5 6}$ & Eurychaeta palpalis \\
\hline
\end{tabular}


TABLE A18: Pairwise transition-transversion ratio of cytochrome oxidase subunit one $(C O I)$ gene used in Calliphoridae phylogeny (Chapter 5).

\begin{tabular}{|c|c|c|c|c|c|c|c|c|c|c|c|c|c|c|c|c|c|c|}
\hline & 1 & 2 & 3 & 4 & 5 & 6 & 7 & 8 & 9 & 10 & 11 & 12 & 13 & 14 & 15 & 16 & 17 & 18 \\
\hline 2 & 0.58 & & & & & & & & & & & & & & & & & \\
\hline 3 & 0.67 & 0.55 & & & & & & & & & & & & & & & & \\
\hline 4 & 0.74 & 0.75 & 0.9 & & & & & & & & & & & & & & & \\
\hline 5 & 0.56 & 0.59 & 0.69 & 0.8 & & & & & & & & & & & & & & \\
\hline 6 & 0.58 & 0.69 & 0.64 & 0.74 & 0.67 & & & & & & & & & & & & & \\
\hline 7 & 0.89 & 0.7 & 0.98 & 1 & 0.87 & 1.03 & & & & & & & & & & & & \\
\hline 8 & 0.52 & 0.55 & 0.55 & 0.71 & 0.54 & 0.59 & 0.6 & & & & & & & & & & & \\
\hline 9 & 0.41 & 0.44 & 0.43 & 0.61 & 0.5 & 0.6 & 0.92 & 0.61 & & & & & & & & & & \\
\hline 10 & 0.52 & 0.6 & 0.48 & 0.7 & 0.51 & 0.73 & 0.91 & 0.57 & 0.47 & & & & & & & & & \\
\hline 11 & 0.48 & 0.54 & 0.62 & 0.74 & 0.58 & 0.61 & 0.89 & 0.66 & 0.47 & 0.54 & & & & & & & & \\
\hline 12 & 0.54 & 0.49 & 0.32 & 0.65 & 0.63 & 0.61 & 0.83 & 0.61 & 0.58 & 0.64 & 0.71 & & & & & & & \\
\hline 13 & 0.57 & 0.57 & 0.37 & 0.7 & 0.58 & 0.7 & 0.62 & 0.66 & 0.51 & 0.52 & 0.51 & 0.61 & & & & & & \\
\hline 14 & 0.7 & 0.84 & 0.66 & 1.01 & 0.67 & 0.96 & 1.17 & 0.78 & 0.59 & 0.79 & 0.71 & 0.68 & 0.72 & & & & & \\
\hline 15 & 0.46 & 0.54 & 0.59 & 0.6 & 0.46 & 0.61 & 0.78 & 0.55 & 0.38 & 0.5 & 0.53 & 0.66 & 0.59 & 0.71 & & & & \\
\hline 16 & 0.6 & 0.44 & 0.49 & 0.63 & 0.45 & 0.78 & 0.79 & 0.53 & 0.32 & 0.53 & 0.51 & 0.41 & 0.58 & 0.8 & 0.57 & & & \\
\hline 17 & 0.74 & 0.99 & 0.85 & 0.99 & 0.78 & 0.8 & 0.79 & 0.88 & 0.88 & 0.96 & 0.86 & 0.74 & 0.85 & 1.02 & 0.66 & 0.94 & & \\
\hline 18 & 0.49 & 0.61 & 0.61 & 0.94 & 0.56 & 0.64 & 0.78 & 0.56 & 0.66 & 0.64 & 0.74 & 0.41 & 0.64 & 0.63 & 0.5 & 0.71 & 0.94 & \\
\hline 19 & 0.6 & 0.6 & 0.65 & 0.75 & 0.46 & 0.66 & 1.03 & 0.58 & 0.42 & 0.54 & 0.48 & 0.65 & 0.64 & 0.86 & 0.53 & 0.6 & 0.9 & 0.81 \\
\hline 20 & 0.67 & 0.81 & 0.83 & 0.8 & 0.73 & 0.82 & 1.13 & 0.87 & 0.78 & 0.77 & 0.99 & 0.83 & 0.79 & 0.97 & 0.73 & 0.72 & 1.17 & 1.3 \\
\hline 21 & 0.8 & 0.81 & 0.89 & 0.98 & 0.73 & 0.96 & 0.92 & 0.8 & 0.67 & 1.04 & 0.9 & 0.86 & 0.75 & 0.88 & 0.78 & 0.82 & 0.95 & 0.71 \\
\hline 22 & 0.64 & 0.58 & 0.74 & 0.77 & 0.67 & 0.6 & 0.96 & 0.63 & 0.54 & 0.58 & 0.56 & 0.66 & 0.56 & 0.81 & 0.57 & 0.51 & 0.83 & 0.73 \\
\hline 23 & 0.54 & 0.65 & 0.72 & 0.78 & 0.55 & 0.75 & 1 & 0.77 & 0.59 & 0.6 & 0.67 & 0.61 & 0.73 & 0.8 & 0.53 & 0.8 & 0.92 & 0.68 \\
\hline 24 & 0.81 & 0.68 & 0.7 & 0.79 & 0.79 & 0.72 & 0.77 & 0.69 & 0.82 & 0.8 & 0.8 & 0.9 & 0.55 & 0.68 & 0.65 & 0.66 & 0.93 & 1.07 \\
\hline 25 & 0.88 & 0.99 & 0.94 & 0.98 & 0.83 & 0.92 & 0.69 & 1 & 0.83 & 0.97 & 0.99 & 0.94 & 0.95 & 1.31 & 0.9 & 0.98 & 1.02 & 0.86 \\
\hline 26 & 0.69 & 0.8 & 0.76 & 0.82 & 0.7 & 0.77 & 0.69 & 0.81 & 0.72 & 0.83 & 0.77 & 0.8 & 0.79 & 1.04 & 0.71 & 0.7 & 1.02 & 0.76 \\
\hline 27 & 0.69 & 0.93 & --- & 0.75 & 0.81 & 0.91 & --- & 0.88 & 0.9 & 0.95 & 0.89 & 1.07 & 0.95 & 1.1 & 0.88 & --- & 0.97 & --- \\
\hline 28 & 0.58 & 0.52 & 0.57 & 0.75 & 0.51 & 0.65 & 0.93 & 0.49 & 0.47 & 0.68 & 0.62 & 0.41 & 0.55 & 0.66 & 0.65 & 0.56 & 0.83 & 0.93 \\
\hline 29 & 0.7 & 0.86 & 0.94 & 0.73 & 0.89 & 0.83 & 0.97 & 0.85 & 0.81 & 0.77 & 0.75 & 0.79 & 0.85 & 1.02 & 0.79 & 0.87 & 1.06 & 1.03 \\
\hline 30 & 0.81 & 0.98 & 0.71 & 0.87 & 0.81 & 0.94 & 1.19 & 0.93 & 0.92 & 0.92 & 0.88 & 0.8 & 0.94 & 1.13 & 0.78 & 0.69 & 1.16 & 1 \\
\hline 31 & 0.67 & 0.9 & 0.65 & 0.81 & 0.81 & 0.87 & 1.37 & 0.87 & 0.84 & 0.79 & 0.74 & 0.93 & 0.84 & 1.27 & 0.69 & 0.79 & 1.01 & 1.09 \\
\hline 32 & 0.73 & 0.91 & 0.85 & 1.09 & 0.77 & 0.88 & 1 & 0.95 & 0.76 & 0.84 & 0.84 & 0.82 & 0.78 & 1.03 & 0.6 & 0.82 & 1.25 & 1.07 \\
\hline
\end{tabular}




\begin{tabular}{|c|c|c|c|c|c|c|c|c|c|c|c|c|c|c|c|c|c|c|}
\hline 3 & 0.91 & 0.84 & 1 & 0.91 & 0.89 & 0.93 & 0.9 & 0.96 & 0.78 & 0.94 & 1.03 & 0.84 & 0.91 & 1.33 & 0.9 & 0.82 & 1.01 & 0.72 \\
\hline 34 & 1.02 & 0.89 & 1.04 & 0.98 & 1.04 & 0.88 & 1 & 0.8 & 0.9 & 0.9 & 1 & 0.88 & 0.93 & 1.24 & 0.84 & 0.95 & 1.06 & 0.78 \\
\hline 35 & 0.85 & 0.76 & 0.87 & 1 & 0.8 & 0.76 & 0.83 & 0.69 & 0.68 & 0.79 & 0.77 & 0.8 & 0.76 & 1.04 & 0.74 & 0.64 & 0.91 & 1.03 \\
\hline 36 & 1.14 & 1.03 & 1.13 & 1.03 & 1.01 & 0.96 & 1.07 & 0.97 & 0.95 & 0.98 & 1.09 & 1.03 & 0.92 & 1.27 & 1.04 & 0.91 & 1.08 & 1.19 \\
\hline 37 & 0.94 & 0.94 & 1.02 & 0.91 & 0.93 & 1.01 & 1.07 & 1.04 & 0.99 & 0.96 & 1.21 & 0.93 & 0.89 & 1.19 & 0.8 & 0.82 & 1.25 & 1.09 \\
\hline 38 & 0.85 & 0.84 & 0.93 & 0.95 & 0.91 & 0.78 & 1.11 & 0.98 & 0.8 & 0.89 & 1.22 & 0.93 & 0.84 & 0.94 & 0.76 & 0.76 & 1.12 & 1 \\
\hline 39 & 0.8 & 0.79 & 0.89 & 0.86 & 0.7 & 0.82 & 0.98 & 0.79 & 0.76 & 0.78 & 1 & 0.67 & 0.73 & 1.15 & 0.69 & 0.82 & 1.19 & 0.97 \\
\hline 40 & 0.95 & 0.82 & 0.75 & 1.14 & 0.83 & 0.8 & 0.92 & 0.99 & 0.75 & 0.94 & 0.95 & 0.9 & 0.84 & 1.08 & 0.87 & 0.57 & 1.03 & 0.92 \\
\hline 41 & 0.7 & 0.75 & 0.63 & 0.88 & 0.72 & 0.71 & 1.05 & 0.7 & 0.78 & 0.83 & 0.86 & 0.81 & 0.85 & 1.05 & 0.76 & 0.94 & 0.94 & 0.6 \\
\hline 42 & 0.55 & 0.62 & 0.56 & 0.62 & 0.59 & 0.64 & 0.89 & 0.58 & 0.54 & 0.53 & 0.55 & 0.64 & 0.68 & 0.76 & 0.64 & 0.76 & 0.91 & 0.69 \\
\hline 43 & 0.68 & 0.8 & 0.81 & 0.84 & 0.85 & 0.76 & 0.95 & 0.68 & 0.89 & 0.71 & 0.82 & 0.8 & 0.82 & 1.12 & 0.8 & 0.78 & 1.01 & 0.93 \\
\hline 44 & 0.8 & 0.78 & 0.68 & 0.87 & 0.8 & 0.78 & 0.97 & 0.8 & 0.8 & 0.66 & 0.9 & 0.9 & 0.71 & 1.1 & 0.81 & 0.73 & 1.03 & 0.91 \\
\hline 45 & 0.56 & 0.62 & 0.67 & 0.79 & 0.64 & 0.63 & 1.05 & 0.6 & 0.45 & 0.5 & 0.5 & 0.62 & 0.55 & 0.91 & 0.6 & 0.61 & 0.94 & 0.63 \\
\hline 46 & 0.81 & 0.94 & --- & 0.81 & 0.97 & 0.81 & --- & 1 & 1.06 & 0.87 & 0.85 & 1.24 & 1.18 & 1.33 & 0.88 & --- & 0.91 & --- \\
\hline 47 & 0.6 & 0.58 & 0.62 & 0.86 & 0.62 & 0.71 & 0.86 & 0.67 & 0.62 & 0.57 & 0.64 & 0.64 & 0.72 & 0.89 & 0.51 & 0.6 & 0.81 & 0.54 \\
\hline 48 & 0.59 & 0.49 & 0.5 & 0.73 & 0.39 & 0.73 & 0.88 & 0.64 & 0.32 & 0.44 & 0.6 & 0.41 & 0.33 & 0.53 & 0.52 & 0.59 & 0.88 & 0.66 \\
\hline 49 & 0.56 & 0.83 & 0.68 & 0.75 & 0.71 & 0.82 & 0.85 & 0.64 & 0.68 & 0.71 & 0.82 & 0.8 & 0.81 & 0.87 & 0.7 & 0.61 & 0.92 & 0.71 \\
\hline 50 & 0.49 & 0.61 & 0.57 & 0.7 & 0.56 & 0.62 & 0.84 & 0.42 & 0.43 & 0.46 & 0.5 & 0.5 & 0.55 & 0.65 & 0.51 & 0.54 & 0.85 & 0.58 \\
\hline 51 & 0.71 & 0.68 & 0.81 & 0.79 & 0.55 & 0.75 & 0.89 & 0.65 & 0.56 & 0.72 & 0.63 & 0.71 & 0.71 & 0.77 & 0.58 & 0.69 & 0.81 & 0.68 \\
\hline 52 & 0.57 & 0.76 & 0.54 & 0.59 & 0.58 & 0.73 & 0.7 & 0.69 & 0.59 & 0.7 & 0.72 & 0.66 & 0.75 & 0.89 & 0.68 & 0.79 & 0.95 & 0.72 \\
\hline 53 & 0.51 & 0.59 & 0.43 & 0.71 & 0.48 & 0.71 & 0.72 & 0.71 & 0.48 & 0.53 & 0.51 & 0.55 & 0.56 & 0.65 & 0.55 & 0.38 & 0.84 & 0.6 \\
\hline 54 & 0.59 & 0.68 & 0.71 & 0.94 & 0.7 & 0.68 & 1 & 0.78 & 0.67 & 0.73 & 0.69 & 0.73 & 0.83 & 0.71 & 0.72 & 0.7 & 0.97 & 0.91 \\
\hline 55 & 0.56 & 0.56 & 0.65 & 1.03 & 0.65 & 0.75 & 0.86 & 0.68 & 0.5 & 0.6 & 0.69 & 0.71 & 0.64 & 0.92 & 0.5 & 0.66 & 0.88 & 0.81 \\
\hline 56 & 0.66 & 0.84 & 0.85 & 0.8 & 0.75 & 0.73 & 1 & 0.67 & 0.65 & 0.83 & 0.8 & 0.85 & 0.88 & 0.85 & 0.77 & 0.77 & 0.93 & 1.17 \\
\hline
\end{tabular}

\begin{tabular}{|l|r|r|r|r|r|r|r|r|r|r|r|r|r|r|r|r|r|r|}
\hline & $\mathbf{1 9}$ & $\mathbf{2 0}$ & $\mathbf{2 1}$ & $\mathbf{2 2}$ & $\mathbf{2 3}$ & $\mathbf{2 4}$ & $\mathbf{2 5}$ & $\mathbf{2 6}$ & $\mathbf{2 7}$ & $\mathbf{2 8}$ & $\mathbf{2 9}$ & $\mathbf{3 0}$ & $\mathbf{3 1}$ & $\mathbf{3 2}$ & $\mathbf{3 3}$ & $\mathbf{3 4}$ & $\mathbf{3 5}$ & $\mathbf{3 6}$ \\
\hline $\mathbf{2 0}$ & 0.82 & & & & & & & & & & & & & & & & & \\
\hline $\mathbf{2 1}$ & 0.78 & 1.06 & & & & & & & & & & & & & & & & \\
\hline $\mathbf{2 2}$ & 0.58 & 0.82 & 1.23 & & & & & & & & & & & & & & & \\
\hline $\mathbf{2 3}$ & 0.72 & 0.71 & 0.81 & 0.64 & & & & & & & & & & & & & & \\
\hline $\mathbf{2 4}$ & 0.68 & 0.86 & 0.84 & 0.64 & 0.56 & & & & & & & & & & & & & \\
\hline $\mathbf{2 5}$ & 1.05 & 1.09 & 0.95 & 0.88 & 0.93 & 0.87 & & & & & & & & & & & & \\
\hline $\mathbf{2 6}$ & 0.86 & 1.17 & 0.94 & 0.72 & 0.78 & 0.79 & 2.61 & & & & & & & & & & & \\
\hline $\mathbf{2 7}$ & 0.86 & 1.03 & 1.14 & 0.94 & 0.8 & --- & 1.3 & 1.14 & & & & & & & & & & \\
\hline
\end{tabular}




\begin{tabular}{|c|c|c|c|c|c|c|c|c|c|c|c|c|c|c|c|c|c|c|}
\hline 28 & 0.92 & 1.22 & 0.76 & 0.61 & 0.63 & 0.68 & 0.91 & 0.79 & --- & & & & & & & & & \\
\hline 29 & 0.84 & 1.09 & 0.89 & 0.78 & 0.9 & 0.92 & 1.36 & 1.28 & 1.33 & 1.03 & & & & & & & & \\
\hline 30 & 0.89 & 1.22 & 0.93 & 0.79 & 0.97 & 0.88 & 1.43 & 1.29 & 1.57 & 0.88 & 1.91 & & & & & & & \\
\hline 31 & 0.74 & 1.05 & 1.11 & 0.68 & 0.87 & 1 & 1.29 & 1.07 & 1.25 & 0.79 & 1.54 & 5.62 & & & & & & \\
\hline 32 & 0.83 & 1.08 & 0.94 & 0.75 & 0.79 & 0.91 & 1.23 & 1.26 & 1.11 & 0.86 & 1.65 & 1.81 & 1.61 & & & & & \\
\hline 33 & 0.9 & 1.13 & 1.17 & 0.88 & 0.92 & 0.95 & 1.5 & 1.12 & 1.07 & 0.87 & 1.14 & 1.39 & 1 & 1.18 & & & & \\
\hline 34 & 0.84 & 1.12 & 1.16 & 0.95 & 0.84 & 0.84 & 1.28 & 1.25 & 1.58 & 0.91 & 1 & 1.33 & 1.21 & 1.11 & 1.58 & & & \\
\hline 35 & 0.71 & 0.98 & 0.97 & 0.83 & 0.75 & 0.76 & 1.21 & 1.03 & 1.09 & 0.88 & 1.04 & 1.08 & 0.93 & 0.97 & 1.5 & 1.59 & & \\
\hline 36 & 0.9 & 1.19 & 1.22 & 1.15 & 0.97 & 0.88 & 1.47 & 1.32 & 1.54 & 1.21 & 1.07 & 1.22 & 1.1 & 1.23 & 2.5 & 1.57 & 2.08 & \\
\hline 37 & 0.93 & 1.33 & 1.08 & 0.99 & 0.88 & 0.98 & 1.36 & 1.01 & 1.21 & 1.07 & 0.8 & 1.22 & 1.11 & 1.38 & 0.98 & 1.23 & 1.29 & 1.44 \\
\hline 38 & 0.82 & 1.06 & 1.08 & 0.86 & 0.94 & 0.9 & 1.19 & 0.93 & 1.25 & 0.91 & 0.87 & 1.47 & 1.35 & 1.04 & 1.26 & 1.35 & 1.24 & 1.3 \\
\hline 39 & 0.66 & 1.09 & 0.95 & 0.81 & 0.86 & 0.8 & 0.99 & 0.8 & 1.18 & 0.69 & 0.78 & 0.95 & 0.87 & 1.11 & 1.31 & 1.27 & 1.2 & 1.45 \\
\hline 40 & 0.87 & 0.98 & 0.94 & 0.76 & 0.99 & 0.77 & 1.52 & 1.24 & 1.21 & 0.65 & 1.16 & 1.28 & 1.09 & 1.09 & 1.98 & 2.11 & 1.71 & 2.06 \\
\hline 41 & 0.71 & 1.06 & 0.92 & 0.75 & 0.78 & 0.75 & 1.2 & 1 & 1.09 & 0.76 & 0.9 & 1.17 & 0.82 & 0.97 & 1.06 & 1.39 & 1.01 & 1.18 \\
\hline 42 & 0.5 & 0.95 & 0.71 & 0.51 & 0.66 & 0.67 & 0.83 & 0.74 & 0.82 & 0.74 & 0.94 & 0.89 & 0.72 & 1.08 & 0.79 & 0.91 & 0.71 & 0.9 \\
\hline 43 & 0.89 & 1.28 & 0.99 & 0.87 & 0.78 & 0.87 & 1.48 & 1.25 & 1.58 & 0.76 & 1.24 & 1.23 & 1.17 & 1.24 & 1.34 & 1.25 & 1.1 & 1.5 \\
\hline 44 & 0.72 & 1.21 & 1.13 & 0.85 & 0.72 & 0.65 & 1.33 & 1.16 & 1.36 & 0.8 & 1.03 & 1.16 & 0.96 & 1.21 & 1.38 & 1.2 & 0.88 & 1.3 \\
\hline 45 & 0.61 & 0.97 & 0.91 & 0.6 & 0.63 & 0.66 & 1.23 & 0.8 & 0.9 & 0.69 & 1.18 & 0.97 & 0.74 & 1.03 & 1.14 & 1.22 & 1.05 & 1.18 \\
\hline 46 & 0.86 & 0.97 & 0.87 & 0.7 & 0.96 & --- & 1.32 & 1.36 & 2.1 & --- & 1.29 & 1.77 & 1.16 & 1.13 & 1.2 & 1.32 & 1.28 & 1.06 \\
\hline 47 & 0.58 & 0.88 & 0.85 & 0.52 & 0.71 & 0.71 & 1.43 & 1.18 & 1.19 & 0.69 & 1.32 & 1.04 & 0.89 & 0.98 & 1.16 & 1.12 & 0.95 & 1.32 \\
\hline 48 & 0.54 & 0.9 & 0.79 & 0.44 & 0.55 & 0.75 & 1.76 & 1.19 & --- & 0.58 & 1.09 & 0.97 & 0.6 & 1.18 & 0.82 & 0.8 & 0.73 & 1.05 \\
\hline 49 & 0.75 & 0.89 & 0.75 & 0.71 & 0.86 & 0.75 & 0.96 & 0.9 & 1.21 & 0.48 & 0.96 & 1 & 0.91 & 0.84 & 0.86 & 1.2 & 0.93 & 1.1 \\
\hline 50 & 0.46 & 0.78 & 0.72 & 0.59 & 0.65 & 0.71 & 0.89 & 0.61 & 1.06 & 0.32 & 0.8 & 0.69 & 0.73 & 0.67 & 0.76 & 0.86 & 0.63 & 0.81 \\
\hline 51 & 0.74 & 1.01 & 0.76 & 0.69 & 0.64 & 0.91 & 1.2 & 0.96 & 0.96 & 0.82 & 1.09 & 1.18 & 0.96 & 1.08 & 1.07 & 1.06 & 0.84 & 1.12 \\
\hline 52 & 0.77 & 0.9 & 0.84 & 0.54 & 0.73 & 0.88 & 1.33 & 0.91 & 2.06 & 0.47 & 1.1 & 1.35 & 1.23 & 1 & 0.94 & 1.1 & 0.91 & 1.22 \\
\hline 53 & 0.5 & 0.8 & 0.93 & 0.62 & 0.7 & 0.8 & 1 & 0.79 & 1.44 & 0.43 & 0.8 & 0.85 & 0.9 & 0.99 & 1.05 & 0.99 & 0.8 & 1.13 \\
\hline 54 & 0.73 & 0.88 & 0.89 & 0.61 & 0.81 & 0.71 & 1.16 & 1.13 & 1.26 & 0.79 & 0.99 & 1.04 & 1.06 & 1.12 & 0.96 & 1.01 & 0.91 & 1.15 \\
\hline 55 & 0.6 & 0.94 & 0.91 & 0.74 & 0.64 & 0.7 & 1.36 & 1.08 & 0.97 & 0.73 & 1.3 & 1.14 & 1.11 & 1.05 & 1.29 & 1.34 & 1.16 & 1.48 \\
\hline 56 & 0.75 & 0.92 & 0.74 & 0.68 & 0.81 & 0.95 & 1.08 & 0.96 & 1.2 & 0.84 & 1.01 & 1 & 0.91 & 0.99 & 1.02 & 1.13 & 0.89 & 1.09 \\
\hline
\end{tabular}




\begin{tabular}{|l|l|l|l|l|l|l|l|l|l|l|l|l|l|l|l|l|l|l|l|}
\hline & $\mathbf{3 7}$ & $\mathbf{3 8}$ & $\mathbf{3 9}$ & $\mathbf{4 0}$ & $\mathbf{4 1}$ & $\mathbf{4 2}$ & $\mathbf{4 3}$ & $\mathbf{4 4}$ & $\mathbf{4 5}$ & $\mathbf{4 6}$ & $\mathbf{4 7}$ & $\mathbf{4 8}$ & $\mathbf{4 9}$ & $\mathbf{5 0}$ & $\mathbf{5 1}$ & $\mathbf{5 2}$ & $\mathbf{5 3}$ & $\mathbf{5 4}$ & $\mathbf{5 5}$ \\
\hline $\mathbf{3 8}$ & 2.63 & & & & & & & & & & & & & & & & & & \\
\hline $\mathbf{3 9}$ & 1.77 & 1.62 & & & & & & & & & & & & & & & & & \\
\hline $\mathbf{4 0}$ & 1.48 & 1.27 & 1.6 & & & & & & & & & & & & & & & & \\
\hline $\mathbf{4 1}$ & 1.26 & 1.24 & 1.24 & 1.14 & & & & & & & & & & & & & & & \\
\hline $\mathbf{4 2}$ & 0.91 & 0.85 & 0.79 & 0.81 & 1.13 & & & & & & & & & & & & & & \\
\hline $\mathbf{4 3}$ & 1.09 & 1.08 & 1.15 & 1.33 & 1.05 & 0.77 & & & & & & & & & & & & & \\
\hline $\mathbf{4 4}$ & 1.15 & 1.04 & 1.1 & 1.21 & 1.26 & 0.87 & 2.16 & & & & & & & & & & & & \\
\hline $\mathbf{4 5}$ & 1.06 & 0.94 & 0.88 & 1.11 & 0.96 & 0.62 & 1.27 & 1.22 & & & & & & & & & & & \\
\hline $\mathbf{4 6}$ & 1.38 & 0.97 & 1.2 & 1.16 & 1.11 & 0.69 & 1.44 & 1.09 & 1.36 & & & & & & & & & & \\
\hline $\mathbf{4 7}$ & 0.98 & 0.81 & 0.85 & 1.06 & 0.92 & 0.66 & 1.08 & 1.19 & 0.88 & 2 & & & & & & & & & \\
\hline $\mathbf{4 8}$ & 1 & 0.76 & 0.67 & 0.68 & 0.78 & 0.54 & 0.79 & 0.81 & 0.52 & --- & 0.87 & & & & & & & & \\
\hline $\mathbf{4 9}$ & 1.07 & 0.97 & 0.88 & 0.87 & 0.89 & 0.78 & 0.99 & 0.93 & 0.82 & 1.34 & 0.8 & 0.57 & & & & & & & \\
\hline $\mathbf{5 0}$ & 0.88 & 0.8 & 0.73 & 0.79 & 0.81 & 0.65 & 0.74 & 0.69 & 0.55 & 1 & 0.57 & 0.38 & 0.82 & & & & & & \\
\hline $\mathbf{5 1}$ & 1.07 & 0.9 & 0.94 & 1.08 & 0.9 & 0.66 & 0.73 & 0.9 & 0.87 & 1.04 & 0.81 & 0.79 & 0.87 & 0.66 & & & & & \\
\hline $\mathbf{5 2}$ & 1.13 & 0.93 & 0.93 & 1.01 & 0.89 & 0.61 & 1.02 & 1.03 & 0.83 & 1.61 & 0.76 & 0.68 & 0.88 & 0.56 & 1.13 & & & & \\
\hline $\mathbf{5 3}$ & 0.97 & 0.95 & 0.79 & 0.87 & 0.74 & 0.5 & 0.96 & 0.93 & 0.67 & 1.21 & 0.68 & 0.41 & 0.76 & 0.57 & 0.68 & 0.66 & & & \\
\hline $\mathbf{5 4}$ & 1.05 & 0.95 & 0.85 & 1.04 & 0.85 & 0.74 & 1.08 & 0.99 & 0.71 & 1.23 & 0.83 & 0.68 & 0.9 & 0.67 & 0.87 & 0.92 & 0.87 & & \\
\hline $\mathbf{5 5}$ & 1.21 & 1.08 & 1.17 & 1.07 & 0.86 & 0.67 & 1.13 & 1.3 & 0.76 & 1.37 & 0.78 & 0.8 & 0.93 & 0.58 & 0.77 & 1.03 & 1 & 1.07 & \\
\hline $\mathbf{5 6}$ & 1.06 & 1.12 & 0.89 & 1.02 & 1.13 & 0.85 & 0.89 & 0.86 & 0.67 & 0.68 & 0.89 & 0.65 & 0.97 & 0.83 & 0.87 & 0.91 & 0.67 & 0.9 & 1.04 \\
\hline
\end{tabular}

Taxa key for table A18: Same as table A17. 
TABLE A19: Pairwise p-distance of carbamoy/phosphate synthetase (CPS) gene used in Calliphoridae phylogeny (Chapter 5).

\begin{tabular}{|c|c|c|c|c|c|c|c|c|c|c|c|c|c|c|c|c|}
\hline & 1 & 2 & 3 & 4 & 5 & 6 & 7 & 8 & 9 & 10 & 11 & 12 & 13 & 14 & 15 & 16 \\
\hline 2 & 0.326 & & & & & & & & & & & & & & & \\
\hline 3 & 0.373 & 0.256 & & & & & & & & & & & & & & \\
\hline 4 & 0.279 & 0.273 & 0.257 & & & & & & & & & & & & & \\
\hline 5 & 0.335 & 0.26 & 0.274 & 0.209 & & & & & & & & & & & & \\
\hline 6 & 0.312 & 0.26 & 0.257 & 0.234 & 0.236 & & & & & & & & & & & \\
\hline 7 & 0.343 & 0.25 & 0.266 & 0.211 & 0.227 & 0.141 & & & & & & & & & & \\
\hline 8 & 0.319 & 0.269 & 0.266 & 0.216 & 0.251 & 0.17 & 0.18 & & & & & & & & & \\
\hline 9 & 0.312 & 0.246 & 0.245 & 0.224 & 0.236 & 0.166 & 0.169 & 0.184 & & & & & & & & \\
\hline 10 & 0.35 & 0.243 & 0.296 & 0.249 & 0.243 & 0.169 & 0.149 & 0.185 & 0.188 & & & & & & & \\
\hline 11 & 0.368 & 0.254 & 0.283 & 0.271 & 0.257 & 0.148 & 0.141 & 0.174 & 0.198 & 0.162 & & & & & & \\
\hline 12 & 0.243 & 0.133 & 0.131 & 0.177 & 0.133 & 0.207 & 0.147 & 0.152 & 0.14 & 0.137 & 0.753 & & & & & \\
\hline 13 & 0.345 & 0.244 & 0.264 & 0.244 & 0.257 & 0.186 & 0.195 & 0.2 & 0.203 & 0.185 & 0.179 & 0.069 & & & & \\
\hline 14 & 0.318 & 0.233 & 0.243 & 0.208 & 0.254 & 0.179 & 0.197 & 0.18 & 0.175 & 0.204 & 0.216 & 0.131 & 0.196 & & & \\
\hline 15 & 0.343 & 0.237 & 0.256 & 0.219 & 0.233 & 0.18 & 0.185 & 0.21 & 0.185 & 0.2 & 0.207 & 0.125 & 0.18 & 0.08 & & \\
\hline 16 & 0.325 & 0.243 & 0.26 & 0.207 & 0.26 & 0.192 & 0.19 & 0.188 & 0.177 & 0.191 & 0.226 & 0.15 & 0.177 & 0.133 & 0.125 & \\
\hline 17 & 0.262 & 0.172 & 0.161 & 0.183 & 0.146 & 0.168 & 0.162 & 0.166 & 0.19 & 0.176 & 0.753 & 0.174 & 0.197 & 0.181 & 0.151 & 0.144 \\
\hline 18 & 0.317 & 0.239 & 0.236 & 0.237 & 0.263 & 0.187 & 0.212 & 0.197 & 0.197 & 0.194 & 0.196 & 0.209 & 0.207 & 0.185 & 0.186 & 0.19 \\
\hline 19 & 0.311 & 0.249 & 0.275 & 0.245 & 0.243 & 0.202 & 0.232 & 0.224 & 0.199 & 0.218 & 0.232 & 0.159 & 0.203 & 0.216 & 0.202 & 0.2 \\
\hline 20 & 0.307 & 0.241 & 0.256 & 0.227 & 0.234 & 0.168 & 0.168 & 0.169 & 0.176 & 0.169 & 0.146 & 0.093 & 0.143 & 0.158 & 0.169 & 0.16 \\
\hline 21 & 0.299 & 0.245 & 0.249 & 0.214 & 0.241 & 0.167 & 0.179 & 0.176 & 0.185 & 0.178 & 0.157 & 0.101 & 0.157 & 0.158 & 0.168 & 0.169 \\
\hline 22 & 0.309 & 0.245 & 0.249 & 0.219 & 0.229 & 0.152 & 0.147 & 0.185 & 0.195 & 0.16 & 0.14 & 0.111 & 0.16 & 0.163 & 0.157 & 0.183 \\
\hline 23 & 0.314 & 0.238 & 0.262 & 0.214 & 0.234 & 0.162 & 0.182 & 0.185 & 0.184 & 0.182 & 0.187 & 0.132 & 0.178 & 0.151 & 0.132 & 0.161 \\
\hline 24 & 0.326 & 0.24 & 0.255 & 0.208 & 0.228 & 0.167 & 0.172 & 0.18 & 0.181 & 0.175 & 0.164 & 0.12 & 0.154 & 0.146 & 0.152 & 0.149 \\
\hline 25 & 0.292 & 0.227 & 0.247 & 0.227 & 0.21 & 0.176 & 0.151 & 0.173 & 0.166 & 0.17 & 0.154 & 0.135 & 0.169 & 0.167 & 0.148 & 0.161 \\
\hline 26 & 0.337 & 0.213 & 0.236 & 0.237 & 0.236 & 0.173 & 0.157 & 0.185 & 0.184 & 0.179 & 0.148 & 0.132 & 0.17 & 0.167 & 0.142 & 0.174 \\
\hline 27 & 0.331 & 0.231 & 0.242 & 0.232 & 0.218 & 0.19 & 0.164 & 0.207 & 0.174 & 0.183 & 0.182 & 0.141 & 0.177 & 0.165 & 0.164 & 0.171 \\
\hline
\end{tabular}




\begin{tabular}{|c|c|c|c|c|c|c|c|c|c|c|c|c|c|c|c|c|}
\hline 28 & 0.328 & 0.244 & 0.235 & 0.227 & 0.242 & 0.179 & 0.187 & 0.198 & 0.187 & 0.206 & 0.191 & 0.151 & 0.189 & 0.154 & 0.155 & 0.155 \\
\hline 29 & 0.294 & 0.227 & 0.24 & 0.215 & 0.229 & 0.195 & 0.185 & 0.192 & 0.178 & 0.188 & 0.187 & 0.141 & 0.176 & 0.158 & 0.153 & 0.171 \\
\hline 30 & 0.304 & 0.22 & 0.238 & 0.221 & 0.244 & 0.19 & 0.179 & 0.187 & 0.178 & 0.178 & 0.179 & 0.145 & 0.18 & 0.153 & 0.165 & 0.163 \\
\hline 31 & 0.356 & 0.258 & 0.245 & 0.247 & 0.227 & 0.186 & 0.175 & 0.197 & 0.203 & 0.178 & 0.182 & 0.094 & 0.172 & 0.192 & 0.178 & 0.206 \\
\hline 32 & 0.294 & 0.24 & 0.261 & 0.223 & 0.232 & 0.173 & 0.166 & 0.175 & 0.164 & 0.16 & 0.15 & 0.138 & 0.171 & 0.162 & 0.159 & 0.16 \\
\hline 33 & 0.301 & 0.231 & 0.261 & 0.224 & 0.24 & 0.16 & 0.176 & 0.17 & 0.169 & 0.184 & 0.177 & 0.154 & 0.188 & 0.154 & 0.162 & 0.179 \\
\hline 34 & 0.327 & 0.25 & 0.241 & 0.223 & 0.267 & 0.178 & 0.209 & 0.217 & 0.181 & 0.181 & 0.189 & 0.166 & 0.162 & 0.174 & 0.171 & 0.159 \\
\hline 35 & 0.319 & 0.237 & 0.277 & 0.223 & 0.244 & 0.187 & 0.195 & 0.196 & 0.176 & 0.176 & 0.196 & 0.158 & 0.181 & 0.179 & 0.168 & 0.162 \\
\hline 36 & 0.344 & 0.232 & 0.254 & 0.237 & 0.233 & 0.165 & 0.167 & 0.185 & 0.201 & 0.169 & 0.148 & 0.101 & 0.137 & 0.166 & 0.166 & 0.176 \\
\hline 37 & 0.326 & 0.232 & 0.263 & 0.217 & 0.222 & 0.184 & 0.17 & 0.195 & 0.177 & 0.168 & 0.202 & 0.162 & 0.192 & 0.171 & 0.159 & 0.16 \\
\hline 38 & 0.344 & 0.263 & 0.246 & 0.239 & 0.241 & 0.163 & 0.175 & 0.204 & 0.191 & 0.171 & 0.165 & 0.127 & 0.183 & 0.19 & 0.19 & 0.197 \\
\hline 39 & 0.326 & 0.251 & 0.26 & 0.224 & 0.228 & 0.149 & 0.178 & 0.201 & 0.195 & 0.172 & 0.164 & 0.113 & 0.172 & 0.176 & 0.17 & 0.196 \\
\hline 40 & 0.333 & 0.254 & 0.261 & 0.238 & 0.257 & 0.194 & 0.202 & 0.197 & 0.202 & 0.199 & 0.217 & 0.15 & 0.216 & 0.179 & 0.181 & 0.183 \\
\hline 41 & 0.364 & 0.251 & 0.264 & 0.251 & 0.239 & 0.202 & 0.2 & 0.216 & 0.222 & 0.216 & 0.21 & 0.098 & 0.212 & 0.18 & 0.182 & 0.188 \\
\hline 42 & 0.366 & 0.249 & 0.249 & 0.239 & 0.249 & 0.18 & 0.199 & 0.198 & 0.198 & 0.202 & 0.198 & 0.122 & 0.21 & 0.166 & 0.168 & 0.165 \\
\hline 43 & 0.376 & 0.249 & 0.263 & 0.25 & 0.241 & 0.151 & 0.169 & 0.171 & 0.179 & 0.15 & 0.153 & 0 & 0.188 & 0.192 & 0.191 & 0.202 \\
\hline
\end{tabular}

\begin{tabular}{|l|r|r|r|r|r|r|r|r|r|r|r|r|r|r|r|r|}
\hline & $\mathbf{1 7}$ & $\mathbf{1 8}$ & $\mathbf{1 9}$ & $\mathbf{2 0}$ & $\mathbf{2 1}$ & $\mathbf{2 2}$ & $\mathbf{2 3}$ & $\mathbf{2 4}$ & $\mathbf{2 5}$ & $\mathbf{2 6}$ & $\mathbf{2 7}$ & $\mathbf{2 8}$ & $\mathbf{2 9}$ & $\mathbf{3 0}$ & $\mathbf{3 1}$ & $\mathbf{3 2}$ \\
\hline $\mathbf{1 8}$ & 0 & & & & & & & & & & & & & & & \\
\hline $\mathbf{1 9}$ & 0.171 & 0.194 & & & & & & & & & & & & & & \\
\hline $\mathbf{2 0}$ & 0.153 & 0.198 & 0.196 & & & & & & & & & & & & & \\
\hline $\mathbf{2 1}$ & 0.158 & 0.186 & 0.201 & 0.036 & & & & & & & & & & & & \\
\hline $\mathbf{2 2}$ & 0.122 & 0.171 & 0.205 & 0.075 & 0.077 & & & & & & & & & & & \\
\hline $\mathbf{2 3}$ & 0.137 & 0.193 & 0.187 & 0.124 & 0.112 & 0.127 & & & & & & & & & & \\
\hline $\mathbf{2 4}$ & 0.143 & 0.188 & 0.188 & 0.112 & 0.119 & 0.098 & 0.081 & & & & & & & & & \\
\hline $\mathbf{2 5}$ & 0.141 & 0.178 & 0.193 & 0.126 & 0.127 & 0.119 & 0.131 & 0.127 & & & & & & & & \\
\hline $\mathbf{2 6}$ & 0.149 & 0.163 & 0.188 & 0.146 & 0.149 & 0.146 & 0.134 & 0.128 & 0.06 & & & & & & & \\
\hline $\mathbf{2 7}$ & 0.157 & 0.173 & 0.188 & 0.156 & 0.16 & 0.132 & 0.133 & 0.131 & 0.128 & 0.109 & & & & & & \\
\hline $\mathbf{2 8}$ & 0.144 & 0.179 & 0.182 & 0.15 & 0.158 & 0.148 & 0.122 & 0.128 & 0.119 & 0.094 & 0.092 & & & & & \\
\hline
\end{tabular}




\begin{tabular}{|c|c|c|c|c|c|c|c|c|c|c|c|c|c|c|c|c|}
\hline 29 & 0.152 & 0.18 & 0.193 & 0.148 & 0.145 & 0.141 & 0.139 & 0.139 & 0.1 & 0.095 & 0.126 & 0.12 & & & & \\
\hline 30 & 0.14 & 0.178 & 0.185 & 0.146 & 0.14 & 0.145 & 0.139 & 0.137 & 0.102 & 0.095 & 0.134 & 0.126 & 0.062 & & & \\
\hline 31 & 0.105 & 0.188 & 0.201 & 0.158 & 0.16 & 0.144 & 0.163 & 0.156 & 0.109 & 0.113 & 0.151 & 0.138 & 0.086 & 0.096 & & \\
\hline 32 & 0.143 & 0.174 & 0.178 & 0.129 & 0.132 & 0.12 & 0.134 & 0.133 & 0.073 & 0.071 & 0.128 & 0.124 & 0.114 & 0.106 & 0.116 & \\
\hline 33 & 0.163 & 0.181 & 0.183 & 0.141 & 0.146 & 0.142 & 0.145 & 0.137 & 0.145 & 0.14 & 0.182 & 0.158 & 0.152 & 0.144 & 0.163 & 0.141 \\
\hline 34 & 0.181 & 0.192 & 0.204 & 0.154 & 0.158 & 0.172 & 0.145 & 0.13 & 0.158 & 0.156 & 0.16 & 0.157 & 0.149 & 0.165 & 0.161 & 0.144 \\
\hline 35 & 0.143 & 0.197 & 0.201 & 0.155 & 0.156 & 0.159 & 0.152 & 0.155 & 0.162 & 0.151 & 0.157 & 0.154 & 0.14 & 0.148 & 0.178 & 0.145 \\
\hline 36 & 0.144 & 0.186 & 0.205 & 0.014 & 0.037 & 0.079 & 0.127 & 0.113 & 0.134 & 0.145 & 0.156 & 0.163 & 0.153 & 0.149 & 0.155 & 0.127 \\
\hline 37 & 0.134 & 0.172 & 0.183 & 0.161 & 0.171 & 0.159 & 0.165 & 0.16 & 0.156 & 0.154 & 0.158 & 0.156 & 0.161 & 0.165 & 0.184 & 0.159 \\
\hline 38 & 0.119 & 0.167 & 0.207 & 0.105 & 0.106 & 0.109 & 0.141 & 0.127 & 0.155 & 0.166 & 0.175 & 0.167 & 0.148 & 0.153 & 0.162 & 0.151 \\
\hline 39 & 0.085 & 0.168 & 0.203 & 0.09 & 0.095 & 0.083 & 0.112 & 0.102 & 0.15 & 0.165 & 0.168 & 0.165 & 0.156 & 0.145 & 0.149 & 0.142 \\
\hline 40 & 0.152 & 0.186 & 0.224 & 0.179 & 0.182 & 0.18 & 0.158 & 0.153 & 0.156 & 0.144 & 0.177 & 0.159 & 0.16 & 0.158 & 0.179 & 0.149 \\
\hline 41 & 0.164 & 0.186 & 0.242 & 0.172 & 0.168 & 0.153 & 0.175 & 0.164 & 0.162 & 0.155 & 0.181 & 0.171 & 0.181 & 0.177 & 0.197 & 0.165 \\
\hline 42 & 0.139 & 0.182 & 0.226 & 0.179 & 0.176 & 0.146 & 0.146 & 0.152 & 0.154 & 0.137 & 0.16 & 0.149 & 0.165 & 0.155 & 0.166 & 0.138 \\
\hline 43 & 0.274 & 0.186 & 0.203 & 0.14 & 0.157 & 0.138 & 0.156 & 0.141 & 0.147 & 0.151 & 0.166 & 0.164 & 0.151 & 0.145 & 0.154 & 0.151 \\
\hline
\end{tabular}

\begin{tabular}{|l|r|r|r|r|r|r|r|r|r|r|}
\hline & $\mathbf{3 3}$ & $\mathbf{3 4}$ & $\mathbf{3 5}$ & $\mathbf{3 6}$ & $\mathbf{3 7}$ & $\mathbf{3 8}$ & $\mathbf{3 9}$ & $\mathbf{4 0}$ & $\mathbf{4 1}$ & $\mathbf{4 2}$ \\
\hline $\mathbf{3 4}$ & 0.171 & & & & & & & & & \\
\hline $\mathbf{3 5}$ & 0.166 & 0.134 & & & & & & & & \\
\hline $\mathbf{3 6}$ & 0.145 & 0.146 & 0.151 & & & & & & & \\
\hline $\mathbf{3 7}$ & 0.175 & 0.191 & 0.17 & 0.168 & & & & & & \\
\hline $\mathbf{3 8}$ & 0.162 & 0.158 & 0.163 & 0.101 & 0.186 & & & & & \\
\hline $\mathbf{3 9}$ & 0.165 & 0.165 & 0.159 & 0.088 & 0.184 & 0.08 & & & & \\
\hline $\mathbf{4 0}$ & 0.192 & 0.148 & 0.167 & 0.178 & 0.182 & 0.182 & 0.174 & & & \\
\hline $\mathbf{4 1}$ & 0.192 & 0.172 & 0.185 & 0.169 & 0.212 & 0.195 & 0.193 & 0.13 & & \\
\hline $\mathbf{4 2}$ & 0.166 & 0.15 & 0.165 & 0.177 & 0.191 & 0.183 & 0.177 & 0.104 & 0.106 & \\
\hline $\mathbf{4 3}$ & 0.158 & 0.159 & 0.163 & 0.143 & 0.191 & 0.156 & 0.147 & 0.184 & 0.189 & 0.179 \\
\hline
\end{tabular}


Taxa key for table A19:

\begin{tabular}{|l|l|l|l|l|l|l|l|}
\hline $\mathbf{1}$ & Drosophila melanogaster & $\mathbf{1 2}$ & Rhinophora lepida & $\mathbf{2 3}$ & Lucilia sericata & $\mathbf{3 4}$ & Bengalia peuhi \\
\hline $\mathbf{2}$ & Glossina morsitans & $\mathbf{1 3}$ & Stevenia hertingi & $\mathbf{2 4}$ & Hypopygiopsis infumata & $\mathbf{3 5}$ & Verticia orientalis \\
\hline $\mathbf{3}$ & Fannia canicularis & $\mathbf{1 4}$ & Sarcophaga crassipalpis & $\mathbf{2 5}$ & Phormia regina & $\mathbf{3 6}$ & Melinda viridicyanea \\
\hline $\mathbf{4}$ & Musca domestica & $\mathbf{1 5}$ & Notochaeta spp. & $\mathbf{2 6}$ & Protophormia terraenovae & $\mathbf{3 7}$ & Mesembrinella spp. \\
\hline $\mathbf{5}$ & Hydrotaea cyrtoneurina & $\mathbf{1 6}$ & Metopia campestris & $\mathbf{2 7}$ & Chrysomya rufifacies & $\mathbf{3 8}$ & Sarconesia versicolor \\
\hline $\mathbf{6}$ & Epalpus signifier & $\mathbf{1 7}$ & Cuterebra fontinella & $\mathbf{2 8}$ & Chrysomya megacephala & $\mathbf{3 9}$ & Sarconesia chlorogaster \\
\hline $\mathbf{7}$ & Gymnocheta viridis & $\mathbf{1 8}$ & Cuterebra baeri & $\mathbf{2 9}$ & Cochliomyia macellaria & $\mathbf{4 0}$ & Isomyia gomezmenori \\
\hline $\mathbf{8}$ & Cyrtophleba nitida & $\mathbf{1 9}$ & Hypoderma lineatum & $\mathbf{3 0}$ & Cochliomyia hominivorax & $\mathbf{4 1}$ & Rhyncomya nigripes \\
\hline $\mathbf{9}$ & Nemorilla floralis & $\mathbf{2 0}$ & Cynomya cadaverina & $\mathbf{3 1}$ & Compsomyiops fulvicrura & $\mathbf{4 2}$ & Metallea erinacea \\
\hline $\mathbf{1 0}$ & Gymnosoma nitens & $\mathbf{2 1}$ & Calliphora vomitoria & $\mathbf{3 2}$ & Protocalliphora sialia & $\mathbf{4 3}$ & Eurychaeta palpalis \\
\hline $\mathbf{1 1}$ & Phania funesta & $\mathbf{2 2}$ & Bellardia vulgaris & $\mathbf{3 3}$ & Pollenia rudis & & \\
\hline
\end{tabular}


TABLE A20: Pairwise transition-transversion ratio of carbamoy/phosphate synthetase (CPS) gene used in Calliphoridae phylogeny (Chapter 5).

\begin{tabular}{|c|c|c|c|c|c|c|c|c|c|c|c|c|c|c|c|c|c|c|}
\hline & 1 & 2 & 3 & 4 & 5 & 6 & 7 & 8 & 9 & 10 & 11 & 12 & 13 & 14 & 15 & 16 & 17 & 18 \\
\hline 2 & 0.99 & & & & & & & & & & & & & & & & & \\
\hline 3 & 0.8 & 1.17 & & & & & & & & & & & & & & & & \\
\hline 4 & 1.09 & 1.2 & 0.93 & & & & & & & & & & & & & & & \\
\hline 5 & 1.04 & 1.24 & 1.06 & 1.62 & & & & & & & & & & & & & & \\
\hline 6 & 1.07 & 0.88 & 0.9 & 1.27 & 1.35 & & & & & & & & & & & & & \\
\hline 7 & 1 & 0.88 & 0.96 & 1.18 & 1.13 & 1.52 & & & & & & & & & & & & \\
\hline 8 & 1.04 & 1.05 & 0.84 & 1.09 & 1.7 & 1.66 & 2 & & & & & & & & & & & \\
\hline 9 & 0.96 & 1.11 & 0.92 & 1.29 & 1.38 & 2.14 & 1.72 & 2.53 & & & & & & & & & & \\
\hline 10 & 0.99 & 0.72 & 0.93 & 1.28 & 1.29 & 1.37 & 1.7 & 1.57 & 1.68 & & & & & & & & & \\
\hline 11 & 1.04 & 0.86 & 0.82 & 1.43 & 1.37 & 1.68 & 1.55 & 2 & 2 & 1.37 & & & & & & & & \\
\hline 12 & 1.82 & 0.5 & 3.33 & 1.29 & 2.67 & 2.58 & 0.75 & 1.28 & 2.54 & 4 & --- & & & & & & & \\
\hline 13 & 1.09 & 0.92 & 0.8 & 1.4 & 1.32 & 1.59 & 1.66 & 1.29 & 1.89 & 1.43 & 1.29 & 1.33 & & & & & & \\
\hline 14 & 1.21 & 1.47 & 0.88 & 1.41 & 1.46 & 1.53 & 1.91 & 1.53 & 2.64 & 1.41 & 2.27 & 2.14 & 1.59 & & & & & \\
\hline 15 & 1.11 & 1.24 & 0.97 & 1.63 & 1.23 & 1.32 & 1.5 & 1.68 & 2.43 & 1.55 & 2 & 3.67 & 1.74 & 3.2 & & & & \\
\hline 16 & 1.11 & 1.33 & 1.1 & 1.25 & 1.43 & 1.76 & 1.72 & 1.65 & 2.33 & 1.51 & 1.7 & 2.33 & 1.53 & 2.42 & 2.82 & & & \\
\hline 17 & 1.47 & 2.2 & 0.89 & 1.43 & 2.25 & 1.7 & 1.67 & 0.92 & 2.05 & 1.8 & --- & 1.89 & 1.22 & 2.93 & 2 & 2 & & \\
\hline 18 & 1.03 & 1.1 & 0.84 & 1.07 & 1.09 & 0.94 & 1.11 & 0.97 & 1.7 & 1.09 & 1.11 & 1 & 1.3 & 1.43 & 1.52 & 1.59 & --- & \\
\hline 19 & 0.93 & 1.15 & 0.92 & 1.39 & 1.24 & 1.65 & 1.14 & 1.42 & 1.52 & 1.04 & 1.19 & 1.94 & 1.26 & 1.59 & 1.44 & 1.83 & 1.95 & 1.73 \\
\hline 20 & 1.06 & 0.96 & 0.8 & 1.11 & 1.19 & 1.35 & 1.15 & 1.28 & 2.11 & 1.32 & 0.96 & 4.17 & 1.09 & 1.4 & 1.43 & 1.82 & 1.63 & 1.64 \\
\hline 21 & 1.03 & 0.86 & 0.89 & 1.34 & 1.24 & 1.49 & 1.19 & 1.02 & 2.06 & 1.1 & 1 & 3.86 & 1.22 & 1.73 & 1.49 & 2 & 1.89 & 1.38 \\
\hline 22 & 1.19 & 1.06 & 0.78 & 1.35 & 1.38 & 1.38 & 0.96 & 1.35 & 2.2 & 1.48 & 1.19 & 2 & 1.74 & 1.41 & 1.32 & 1.73 & 1.33 & 1.55 \\
\hline 23 & 1.26 & 1.19 & 1 & 1.58 & 1.31 & 1.88 & 1.35 & 1.51 & 3.14 & 1.2 & 1.74 & 3.4 & 1.68 & 2.2 & 2.24 & 2.34 & 1.65 & 1.37 \\
\hline 24 & 1.22 & 0.97 & 0.98 & 1.22 & 1.3 & 2.46 & 1.87 & 1.88 & 3.17 & 1.43 & 1.83 & 2.33 & 1.55 & 1.88 & 2.16 & 2.02 & 1.76 & 1.3 \\
\hline 25 & 1.07 & 1.04 & 0.76 & 1.41 & 1.12 & 1.78 & 1.44 & 1.59 & 2.19 & 1.22 & 2.21 & 2.21 & 1.53 & 2.09 & 2.21 & 1.8 & 1.56 & 0.97 \\
\hline 26 & 1.09 & 1.11 & 0.83 & 1.47 & 1.18 & 1.76 & 1.34 & 1.55 & 1.97 & 1.32 & 2.28 & 2.12 & 1.51 & 2.26 & 2.57 & 2.28 & 1.42 & 1 \\
\hline 27 & 1.31 & 1.16 & 0.81 & 1.58 & 1.29 & 1.9 & 1.66 & 1.8 & 2.07 & 1.34 & 1.77 & 2.13 & 2.03 & 2.12 & 2.31 & 2.21 & 1.55 & 1.17 \\
\hline 28 & 1.21 & 1.47 & 0.8 & 1.35 & 1.14 & 1.92 & 1.67 & 1.8 & 2.77 & 1.44 & 2 & 3.55 & 1.43 & 2.85 & 2.68 & 2.77 & 1.94 & 1.17 \\
\hline 29 & 1 & 0.95 & 0.75 & 1.28 & 1.05 & 1.63 & 1.21 & 1.44 & 1.72 & 0.9 & 1.35 & 1.76 & 1.31 & 1.98 & 1.96 & 2.02 & 1.63 & 1 \\
\hline 30 & 1.02 & 0.98 & 0.88 & 1.23 & 1.08 & 1.6 & 1.09 & 1.26 & 1.77 & 0.91 & 1.33 & 1.82 & 1.42 & 2.02 & 1.87 & 1.82 & 1.65 & 1.41 \\
\hline 31 & 0.94 & 1.05 & 0.91 & 1.12 & 0.95 & 1.46 & 0.9 & 1.27 & 1.26 & 0.81 & 1.18 & 2 & 1.12 & 1.68 & 1.56 & 1.79 & 0.57 & 1.09 \\
\hline 32 & 1.05 & 1.24 & 1 & 1.35 & 1.11 & 1.72 & 1.53 & 1.47 & 2.17 & 1.17 & 2.33 & 2.83 & 1.44 & 2.14 & 2.46 & 1.89 & 1.94 & 1.13 \\
\hline
\end{tabular}




\begin{tabular}{|c|c|c|c|c|c|c|c|c|c|c|c|c|c|c|c|c|c|c|}
\hline 33 & 1.23 & 1.08 & 1.05 & 1.22 & 1.28 & 1.6 & 1.39 & 1.54 & 2.24 & 1.97 & 1.8 & 2.19 & 1.82 & 1.77 & 2 & 1.96 & 1.79 & 1.91 \\
\hline 34 & 1.13 & 1.05 & 0.98 & 1.16 & 1.29 & 1.33 & 1.55 & 1.62 & 1.67 & 1 & 1.55 & 1.25 & 1.15 & 1.5 & 2.33 & 1.8 & 1.2 & 1.09 \\
\hline 35 & 1.26 & 1.2 & 1 & 1.37 & 1.18 & 1.56 & 1.59 & 1.5 & 1.96 & 1.15 & 1.52 & 3 & 1.41 & 1.71 & 2.26 & 1.71 & 2.29 & 1.52 \\
\hline 36 & 1.05 & 0.95 & 0.79 & 1.24 & 1.23 & 1 & 1.1 & 1.23 & 1.97 & 1.28 & 1 & 2.67 & 1.09 & 1.35 & 1.53 & 1.63 & 0.6 & 1.65 \\
\hline 37 & 1.11 & 0.98 & 0.76 & 1.24 & 1.22 & 1.56 & 1.32 & 1.81 & 2.18 & 1.41 & 1.76 & 2.86 & 1.36 & 1.89 & 1.44 & 1.82 & 1.93 & 1.1 \\
\hline 38 & 0.86 & 0.97 & 0.85 & 1.24 & 1 & 1.24 & 1.33 & 1.3 & 1.83 & 1.47 & 1.13 & 2.25 & 2.06 & 1.48 & 1.85 & 1.91 & 0.5 & 1.33 \\
\hline 39 & 0.89 & 1 & 0.97 & 1.3 & 1.25 & 1.33 & 1.56 & 1.42 & 2.12 & 1.62 & 1.32 & 2.67 & 1.47 & 1.6 & 1.97 & 1.97 & 0.8 & 1.42 \\
\hline 40 & 1.2 & 1.16 & 0.93 & 1.21 & 1.24 & 1.14 & 1.33 & 1.33 & 1.62 & 1.26 & 1.69 & 2.62 & 1.38 & 1.82 & 2.06 & 1.8 & 1.58 & 1.23 \\
\hline 41 & 1.1 & 1.18 & 1.03 & 1.22 & 1.33 & 1.02 & 1 & 1.51 & 1.56 & 1.4 & 1.68 & 1.5 & 1.3 & 1.26 & 1.46 & 1.47 & 1 & 0.92 \\
\hline 42 & 1.3 & 1.3 & 0.89 & 1.23 & 1.48 & 0.98 & 0.94 & 1.31 & 1.54 & 1.18 & 1.44 & 5.5 & 1.18 & 1.51 & 1.84 & 1.35 & 1 & 0.81 \\
\hline 43 & 0.92 & 0.88 & 0.81 & 1.33 & 1.1 & 1.21 & 1.32 & 1.77 & 2.36 & 1.03 & 1.9 & --- & 1.39 & 1.67 & 1.89 & 1.71 & --- & 1.07 \\
\hline
\end{tabular}

\begin{tabular}{|l|l|l|l|l|l|l|l|l|l|l|l|l|l|l|l|l|l|l|}
\hline & $\mathbf{1 9}$ & $\mathbf{2 0}$ & $\mathbf{2 1}$ & $\mathbf{2 2}$ & $\mathbf{2 3}$ & $\mathbf{2 4}$ & $\mathbf{2 5}$ & $\mathbf{2 6}$ & $\mathbf{2 7}$ & $\mathbf{2 8}$ & $\mathbf{2 9}$ & $\mathbf{3 0}$ & $\mathbf{3 1}$ & $\mathbf{3 2}$ & $\mathbf{3 3}$ & $\mathbf{3 4}$ & $\mathbf{3 5}$ & $\mathbf{3 6}$ \\
\hline $\mathbf{2 0}$ & 1.6 & & & & & & & & & & & & & & & & & \\
\hline $\mathbf{2 1}$ & 1.51 & 1.42 & & & & & & & & & & & & & & & & \\
\hline $\mathbf{2 2}$ & 1.79 & 1.27 & 1.5 & & & & & & & & & & & & & & & \\
\hline $\mathbf{2 3}$ & 1.69 & 1.39 & 1.32 & 1.16 & & & & & & & & & & & & & & \\
\hline $\mathbf{2 4}$ & 1.76 & 1.41 & 1.52 & 1.46 & 2.29 & & & & & & & & & & & & & \\
\hline $\mathbf{2 5}$ & 1.52 & 1.78 & 1.77 & 2 & 2.47 & 2.09 & & & & & & & & & & & & \\
\hline $\mathbf{2 6}$ & 1.53 & 1.77 & 1.5 & 1.53 & 2.24 & 2.21 & 1.12 & & & & & & & & & & & \\
\hline $\mathbf{2 7}$ & 1.71 & 1.75 & 1.89 & 1.69 & 2.18 & 1.74 & 2.06 & 2 & & & & & & & & & & \\
\hline $\mathbf{2 8}$ & 1.72 & 1.77 & 1.85 & 1.29 & 2.25 & 1.95 & 1.66 & 2 & 2.17 & & & & & & & & & \\
\hline $\mathbf{2 9}$ & 1.65 & 1.13 & 1.28 & 1.09 & 1.88 & 1.68 & 1.18 & 1.11 & 2.03 & 2.52 & & & & & & & & \\
\hline $\mathbf{3 0}$ & 1.66 & 1.19 & 1.16 & 1.14 & 1.81 & 1.7 & 0.98 & 1.38 & 1.94 & 2.15 & 1.79 & & & & & & & \\
\hline $\mathbf{3 1}$ & 1.08 & 0.76 & 0.86 & 1.04 & 1.47 & 1.42 & 0.87 & 1.03 & 1.79 & 1.37 & 1.93 & 1.45 & & & & & & \\
\hline $\mathbf{3 2}$ & 1.32 & 1.49 & 1.49 & 1.6 & 2.17 & 1.76 & 2.1 & 2.07 & 2.06 & 2.09 & 1.26 & 1.25 & 1 & & & & & \\
\hline $\mathbf{3 3}$ & 1.44 & 1.41 & 1.24 & 1.71 & 2.05 & 2.29 & 1.54 & 2 & 2.11 & 2.02 & 1.51 & 1.63 & 1.33 & 1.59 & & & & \\
\hline $\mathbf{3 4}$ & 1 & 1.57 & 1.75 & 1.33 & 1.63 & 1.37 & 2 & 1.84 & 1.75 & 1.57 & 1.68 & 1.48 & 1.33 & 1.94 & 1.81 & & & \\
\hline $\mathbf{3 5}$ & 1.48 & 1.51 & 1.51 & 1.6 & 1.8 & 1.59 & 1.56 & 1.79 & 1.76 & 1.73 & 1.09 & 1.25 & 0.96 & 1.46 & 1.59 & 1.61 & & \\
\hline $\mathbf{3 6}$ & 1.23 & 6 & 1.11 & 1.6 & 1.06 & 0.97 & 1.65 & 1.62 & 1.56 & 1.36 & 0.93 & 1.03 & 0.72 & 1.36 & 1.27 & 1.5 & 1.26 & \\
\hline $\mathbf{3 7}$ & 1.9 & 1.84 & 1.78 & 1.89 & 2.12 & 2.43 & 2.44 & 2.03 & 2.21 & 1.82 & 1.67 & 1.79 & 1.16 & 1.86 & 1.94 & 1.44 & 1.7 & 1.38 \\
\hline $\mathbf{3 8}$ & 1.4 & 2.12 & 1.89 & 2.08 & 1.35 & 1.54 & 1.61 & 1.9 & 1.76 & 1.35 & 1.26 & 1.42 & 1.27 & 1.72 & 1.71 & 2.11 & 1.5 & 1.89 \\
\hline $\mathbf{3 9}$ & 1.39 & 1.65 & 1.45 & 2.11 & 1.42 & 1.79 & 2.25 & 2.44 & 1.9 & 1.66 & 1.42 & 1.34 & 1.03 & 1.85 & 2.04 & 1.64 & 1.65 & 1.37 \\
\hline $\mathbf{4 0}$ & 1.26 & 1.74 & 1.67 & 1.68 & 1.94 & 1.61 & 1.91 & 1.84 & 1.6 & 1.65 & 1.65 & 1.62 & 1.51 & 1.71 & 2.16 & 1.89 & 1.64 & 1.82 \\
\hline
\end{tabular}




\begin{tabular}{|c|c|c|c|c|c|c|c|c|c|c|c|c|c|c|c|c|c|c|}
\hline 41 & 1.17 & 1.47 & 1.35 & 0.92 & 1.37 & 1.17 & 1.14 & 1.39 & 1.32 & 1.25 & 1.1 & 1.21 & 1.09 & 1.14 & 1.46 & 1.86 & 1.54 & 1.55 \\
\hline 42 & 1.16 & 1.27 & 1.16 & 0.88 & 1.33 & 1.05 & 1.19 & 1.43 & 1.3 & 1.26 & 1.29 & 1.22 & 1.05 & 1.03 & 1.23 & 1.26 & 1.44 & 1.33 \\
\hline & 1.18 & 1.24 & 1.17 & 1.24 & 1.71 & 2.11 & 1.7 & 1.78 & 2 & 1.96 & 1.03 & 1.22 & 0.94 & 2.37 & 1.71 & 1.71 & 1.3 & 1.46 \\
\hline
\end{tabular}

\begin{tabular}{|l|l|l|l|l|l|l|}
\hline & $\mathbf{3 7}$ & $\mathbf{3 8}$ & $\mathbf{3 9}$ & $\mathbf{4 0}$ & $\mathbf{4 1}$ & $\mathbf{4 2}$ \\
\hline $\mathbf{3 8}$ & 1.49 & & & & & \\
\hline $\mathbf{3 9}$ & 1.64 & 2.15 & & & & \\
\hline $\mathbf{4 0}$ & 1.73 & 1.5 & 1.57 & & & \\
\hline $\mathbf{4 1}$ & 1.46 & 1.38 & 1.36 & 2.1 & & \\
\hline $\mathbf{4 2}$ & 1.49 & 1.16 & 1.33 & 1.75 & 2.12 & \\
\hline $\mathbf{4 3}$ & 1.5 & 1.36 & 1.58 & 1.48 & 1.47 & 1.14 \\
\hline
\end{tabular}

Taxa key for table A20: Same as table A19. 
TABLE A21: Pairwise p-distance of elongation factor one alpha (EF1 $\alpha)$ gene used in Calliphoridae phylogeny (Chapter 5).

\begin{tabular}{|c|c|c|c|c|c|c|c|c|c|c|c|c|c|c|c|}
\hline & 1 & 2 & 3 & 4 & 5 & 6 & 7 & 8 & 9 & 10 & 11 & 12 & 13 & 14 & 15 \\
\hline 2 & 0.223 & & & & & & & & & & & & & & \\
\hline 3 & 0.151 & 0.172 & & & & & & & & & & & & & \\
\hline 4 & 0.141 & 0.175 & 0.082 & & & & & & & & & & & & \\
\hline 5 & 0.161 & 0.19 & 0.094 & 0.093 & & & & & & & & & & & \\
\hline 6 & 0.154 & 0.195 & 0.105 & 0.122 & 0.103 & & & & & & & & & & \\
\hline 7 & 0.177 & 0.185 & 0.102 & 0.118 & 0.099 & 0.089 & & & & & & & & & \\
\hline 8 & 0.174 & 0.184 & 0.106 & 0.126 & 0.105 & 0.097 & 0.089 & & & & & & & & \\
\hline 9 & 0.157 & 0.176 & 0.085 & 0.09 & 0.074 & 0.086 & 0.075 & 0.083 & & & & & & & \\
\hline 10 & 0.179 & 0.183 & 0.109 & 0.127 & 0.121 & 0.124 & 0.108 & 0.116 & 0.107 & & & & & & \\
\hline 11 & 0.185 & 0.191 & 0.149 & 0.156 & 0.138 & 0.123 & 0.121 & 0.126 & 0.113 & 0.127 & & & & & \\
\hline 12 & 0.183 & 0.176 & 0.104 & 0.111 & 0.111 & 0.132 & 0.119 & 0.115 & 0.103 & 0.118 & 0.135 & & & & \\
\hline 13 & 0.161 & 0.178 & 0.1 & 0.111 & 0.105 & 0.128 & 0.112 & 0.109 & 0.101 & 0.119 & 0.137 & 0.093 & & & \\
\hline 14 & 0.172 & 0.185 & 0.098 & 0.108 & 0.099 & 0.116 & 0.106 & 0.1 & 0.081 & 0.113 & 0.114 & 0.077 & 0.049 & & \\
\hline 15 & 0.153 & 0.17 & 0.058 & 0.084 & 0.055 & 0.088 & 0.077 & 0.08 & 0.064 & 0.096 & 0.119 & 0.093 & 0.085 & 0.084 & \\
\hline 16 & 0.143 & 0.185 & 0.07 & 0.094 & 0.069 & 0.097 & 0.078 & 0.085 & 0.066 & 0.099 & 0.106 & 0.091 & 0.094 & 0.081 & 0.041 \\
\hline 17 & 0.153 & 0.167 & 0.078 & 0.096 & 0.068 & 0.089 & 0.087 & 0.083 & 0.074 & 0.104 & 0.113 & 0.096 & 0.099 & 0.093 & 0.043 \\
\hline 18 & 0.145 & 0.173 & 0.065 & 0.086 & 0.056 & 0.085 & 0.074 & 0.077 & 0.06 & 0.095 & 0.108 & 0.104 & 0.092 & 0.082 & 0.032 \\
\hline 19 & 0.195 & 0.187 & 0.145 & 0.151 & 0.147 & 0.135 & 0.152 & 0.134 & 0.122 & 0.143 & 0.16 & 0.151 & 0.157 & 0.144 & 0.123 \\
\hline 20 & 0.206 & 0.18 & 0.145 & 0.154 & 0.146 & 0.143 & 0.149 & 0.148 & 0.136 & 0.136 & 0.158 & 0.154 & 0.172 & 0.159 & 0.133 \\
\hline 21 & 0.271 & 0.288 & 0.259 & 0.249 & 0.25 & 0.264 & 0.28 & 0.274 & 0.264 & 0.263 & 0.272 & 0.269 & 0.284 & 0.269 & 0.265 \\
\hline 22 & 0.276 & 0.292 & 0.267 & 0.255 & 0.264 & 0.267 & 0.287 & 0.284 & 0.278 & 0.274 & 0.285 & 0.282 & 0.294 & 0.28 & 0.277 \\
\hline 23 & 0.144 & 0.174 & 0.069 & 0.079 & 0.063 & 0.082 & 0.079 & 0.086 & 0.067 & 0.093 & 0.118 & 0.102 & 0.09 & 0.09 & 0.049 \\
\hline 24 & 0.147 & 0.177 & 0.075 & 0.089 & 0.068 & 0.096 & 0.085 & 0.098 & 0.074 & 0.104 & 0.125 & 0.111 & 0.098 & 0.1 & 0.053 \\
\hline 25 & 0.159 & 0.191 & 0.093 & 0.093 & 0.068 & 0.106 & 0.088 & 0.091 & 0.068 & 0.091 & 0.124 & 0.11 & 0.105 & 0.101 & 0.059 \\
\hline 26 & 0.148 & 0.187 & 0.08 & 0.085 & 0.066 & 0.086 & 0.083 & 0.083 & 0.066 & 0.093 & 0.119 & 0.105 & 0.103 & 0.101 & 0.054 \\
\hline 27 & 0.139 & 0.179 & 0.073 & 0.092 & 0.064 & 0.093 & 0.077 & 0.085 & 0.065 & 0.096 & 0.117 & 0.101 & 0.091 & 0.094 & 0.048 \\
\hline 28 & 0.138 & 0.181 & 0.07 & 0.096 & 0.066 & 0.086 & 0.078 & 0.087 & 0.066 & 0.097 & 0.116 & 0.105 & 0.098 & 0.101 & 0.045 \\
\hline
\end{tabular}




\begin{tabular}{|c|c|c|c|c|c|c|c|c|c|c|c|c|c|c|c|}
\hline 29 & 137 & & 65 & 092 & & & & & & & & & & & \\
\hline 30 & 139 & 173 & 73 & 088 & 057 & 09 & 078 & 084 & .067 & 096 & .119 & & .096 & & .05 \\
\hline 31 & & & & & & & & & & & & & & & \\
\hline 32 & & & & & & & & & & & & & & & \\
\hline 33 & & & & & & & ר? & & & & & & & & \\
\hline 4 & & & & & & & 083 & & & & & & & & \\
\hline 35 & 15 & & 065 & 094 & 055 & 086 & 0.079 & 0.07 & 0.056 & 099 & & 89 & .082 & 0.077 & .03 \\
\hline 0 & & & 085 & & & .097 & .084 & 0.084 & .001 & 115 & & & .096 & .09 & . \\
\hline & & & & & & & & & & & & & & & \\
\hline 38 & 15 & & 073 & 094 & 058 & 087 & 1.075 & .073 & 0.062 & 092 & & & .079 & 0 & 04 \\
\hline 39 & 19 & & 81 & & 092 & & .092 & .092 & 0.073 & & & & 108 & .099 & .06 \\
\hline & & & 084 & & 087 & 105 & .096 & 0.098 & 0.079 & & & & .104 & 泣. & .061 \\
\hline & & & & & & & & & & & & & & & \\
\hline 42 & 157 & 176 & 076 & 109 & 073 & 0.091 & 0.082 & 0.083 & 0064 & .107 & 0.126 & 106 & .099 & 0.09 & .05 \\
\hline 43 & & & 82 & & & 108 & 08 & .091 & 066 & & & & .085 & 08 & 05 \\
\hline & & & & & & & & & & & & & & & 4 \\
\hline & & & & & & & & & & & & & & & \\
\hline 46 & & & & & & & 0.125 & & & & & & .121 & & .08 \\
\hline 47 & 156 & 186 & 097 & 115 & 087 & 0.098 & 106 & 0.098 & 0 & 123 & 0.125 & & .114 & 0.098 & 0.067 \\
\hline 48 & & & & & & & c & 89 & & & & & & & 6 \\
\hline 40 & $0.14 c$ & & & & & & 0.00 & & & & & & & .104 & .00 \\
\hline 50 & & & & & & & & & & & & & & & 004 \\
\hline 51 & & & & & & & & & & & & & & & \\
\hline 52 & 0.158 & & 086 & 107 & 0.078 & 0.093 & 0.08 & 0.082 & 0.063 & & & & .095 & 0.083 & 0.055 \\
\hline 53 & 153 & .186 & .081 & 106 & 0.082 & 0.115 & 0.096 & 0.098 & 0.092 & 0.104 & 0.141 & .111 & .098 & .104 & 0.074 \\
\hline
\end{tabular}

\begin{tabular}{|l|l|l|l|l|l|l|l|l|l|l|l|l|l|l|l|}
\hline & 16 & 17 & 18 & 19 & 20 & 21 & 22 & 23 & 24 & 25 & 26 & 27 & 28 & 29 & 30 \\
\hline 17 & 0.053 & & & & & & & & & & & & & & \\
\hline 18 & 0.035 & 0.045 & & & & & & & & & & & & & \\
\hline
\end{tabular}




\begin{tabular}{|c|c|c|c|c|c|c|c|c|c|c|c|c|c|c|c|}
\hline 19 & 0.129 & 0.124 & 0.137 & & & & & & & & & & & & \\
\hline 20 & 0.133 & 0.138 & 0.143 & 0.041 & & & & & & & & & & & \\
\hline 21 & 0.261 & 0.276 & 0.272 & 0.286 & 0.288 & & & & & & & & & & \\
\hline 22 & 0.274 & 0.287 & 0.283 & 0.295 & 0.294 & 0.007 & & & & & & & & & \\
\hline 23 & 0.041 & 0.061 & 0.05 & 0.134 & 0.14 & 0.27 & 0.274 & & & & & & & & \\
\hline 24 & 0.046 & 0.07 & 0.056 & 0.143 & 0.149 & 0.276 & 0.28 & 0.009 & & & & & & & \\
\hline 25 & 0.054 & 0.069 & 0.061 & 0.142 & 0.142 & 0.277 & 0.286 & 0.044 & 0.049 & & & & & & \\
\hline 26 & 0.048 & 0.062 & 0.059 & 0.132 & 0.149 & 0.27 & 0.277 & 0.027 & 0.04 & 0.023 & & & & & \\
\hline 27 & 0.043 & 0.059 & 0.046 & 0.127 & 0.139 & 0.273 & 0.282 & 0.039 & 0.036 & 0.04 & 0.038 & & & & \\
\hline 28 & 0.044 & 0.056 & 0.046 & 0.129 & 0.142 & 0.269 & 0.277 & 0.037 & 0.04 & 0.047 & 0.043 & 0.018 & & & \\
\hline 29 & 0.047 & 0.055 & 0.049 & 0.124 & 0.135 & 0.267 & 0.275 & 0.033 & 0.035 & 0.05 & 0.04 & 0.017 & 0.011 & & \\
\hline 30 & 0.051 & 0.06 & 0.051 & 0.129 & 0.137 & 0.274 & 0.279 & 0.041 & 0.034 & 0.045 & 0.043 & 0.019 & 0.02 & 0.016 & \\
\hline 31 & 0.043 & 0.048 & 0.037 & 0.123 & 0.137 & 0.266 & 0.281 & 0.049 & 0.061 & 0.056 & 0.049 & 0.035 & 0.039 & 036 & 0.043 \\
\hline 32 & 0.037 & 0.045 & 0.026 & 0.122 & 0.132 & 0.268 & 0.284 & 0.043 & 0.053 & 0.056 & 0.047 & 0.038 & 0.033 & 0.034 & 0.041 \\
\hline 33 & 0.041 & 0.048 & 0.035 & 0.117 & 0.13 & 0.261 & 0.274 & 0.055 & 0.062 & 0.064 & 0.058 & 0.044 & 0.049 & 0.045 & 0.052 \\
\hline 34 & 0.041 & 0.047 & 0.029 & 0.123 & 0.126 & 0.261 & 0.276 & 0.053 & 0.059 & 0.06 & 0.057 & 0.048 & 0.05 & 0.05 & 0.057 \\
\hline 35 & 0.037 & 0.04 & 0.032 & 0.121 & 0.131 & 0.272 & 0.288 & 0.049 & 0.055 & 0.06 & 0.053 & 0.042 & 0.041 & 0.04 & 0.045 \\
\hline 36 & 0.056 & 0.06 & 0.042 & 0.121 & 0.13 & 0.268 & 0.283 & 0.068 & 0.068 & 0.078 & 0.075 & 0.055 & 0.056 & 0.057 & 0.063 \\
\hline 37 & 0.043 & 0.046 & 0.03 & 0.132 & 0.133 & 0.261 & 0.272 & 0.052 & 0.06 & 0.066 & 0.065 & 0.047 & 0.049 & 0.049 & 0.052 \\
\hline 38 & 0.041 & 0.052 & 0.032 & 0.125 & 0.135 & 0.266 & 0.282 & 0.053 & 0.058 & 0.062 & 0.056 & 0.048 & 0.048 & 0.046 & 0.053 \\
\hline 39 & 0.071 & 0.069 & 0.065 & 0.136 & 0.144 & 0.263 & 0.272 & 0.073 & 0.081 & 0.078 & 0.075 & 0.067 & 0.068 & 0.065 & 0.071 \\
\hline 40 & 0.071 & 0.073 & 0.06 & 0.14 & 0.133 & 0.273 & 0.286 & 0.077 & 0.081 & 0.082 & 0.089 & 0.074 & 0.07 & 0.072 & 0.075 \\
\hline 41 & 0.047 & 0.047 & 0.043 & 0.143 & 0.133 & 0.27 & 0.283 & 0.054 & 0.059 & 0.06 & 0.06 & 0.051 & 0.046 & 0.051 & 0.05 \\
\hline 42 & 0.053 & 0.062 & 0.045 & 0.134 & 0.138 & 0.271 & 0.284 & 0.065 & 0.072 & 0.071 & 0.064 & 0.053 & 0.047 & 0.048 & 0.055 \\
\hline 43 & 0.05 & 0.058 & 0.038 & 0.135 & 0.136 & 0.27 & 0.285 & 0.059 & 0.052 & 0.051 & 0.055 & 0.046 & 0.045 & 0.042 & 0.044 \\
\hline 44 & 0.605 & 0.052 & 0.605 & 0.106 & 0.605 & 0.605 & 0.605 & 0.053 & 0.605 & 0.605 & 0.05 & 0.058 & 0.043 & 0.037 & 0.057 \\
\hline 45 & 0.069 & 0.081 & 0.063 & 0.144 & 0.14 & 0.268 & 0.278 & 0.053 & 0.062 & 0.06 & 0.059 & 0.05 & 0.055 & 0.055 & 0.055 \\
\hline 46 & 0.106 & 0.096 & 0.107 & 0.136 & 0.166 & 0.288 & 0.302 & 0.097 & 0.111 & 0.114 & 0.1 & 0.095 & 0.095 & 0.094 & 0.099 \\
\hline 47 & 0.071 & 0.077 & 0.068 & 0.132 & 0.137 & 0.253 & 0.263 & 0.073 & 0.082 & 0.094 & 0.089 & 0.079 & 0.076 & 0.072 & 0.071 \\
\hline 48 & 0.059 & 0.068 & 0.062 & 0.144 & 0.145 & 0.279 & 0.291 & 0.073 & 0.076 & 0.08 & 0.083 & 0.067 & 0.069 & 0.065 & 0.068 \\
\hline
\end{tabular}




\begin{tabular}{|l|l|l|l|l|l|l|l|l|l|l|l|l|l|l|l|}
$\mathbf{4 9}$ & 0.07 & 0.085 & 0.071 & 0.164 & 0.158 & 0.276 & 0.278 & 0.047 & 0.045 & 0.056 & 0.05 & 0.035 & 0.041 & 0.039 & 0.033 \\
\hline $\mathbf{5 0}$ & 0.045 & 0.068 & 0.047 & 0.117 & 0.136 & 0.268 & 0.282 & 0.063 & 0.074 & 0.071 & 0.066 & 0.061 & 0.061 & 0.06 & 0.069 \\
\hline $\mathbf{5 1}$ & 0.066 & 0.091 & 0.074 & 0.163 & 0.165 & 0.277 & 0.279 & 0.045 & 0.048 & 0.054 & 0.046 & 0.042 & 0.046 & 0.044 & 0.037 \\
\hline $\mathbf{5 2}$ & 0.051 & 0.07 & 0.059 & 0.131 & 0.134 & 0.276 & 0.284 & 0.064 & 0.072 & 0.073 & 0.069 & 0.058 & 0.064 & 0.065 & 0.068 \\
\hline $\mathbf{5 3}$ & 0.071 & 0.077 & 0.069 & 0.155 & 0.143 & 0.27 & 0.279 & 0.07 & 0.076 & 0.078 & 0.076 & 0.07 & 0.071 & 0.069 & 0.071 \\
\hline
\end{tabular}

\begin{tabular}{|l|l|l|l|l|l|l|l|l|l|l|l|l|l|l|l|}
\hline & $\mathbf{3 1}$ & $\mathbf{3 2}$ & $\mathbf{3 3}$ & $\mathbf{3 4}$ & $\mathbf{3 5}$ & $\mathbf{3 6}$ & $\mathbf{3 7}$ & $\mathbf{3 8}$ & $\mathbf{3 9}$ & $\mathbf{4 0}$ & $\mathbf{4 1}$ & $\mathbf{4 2}$ & $\mathbf{4 3}$ & $\mathbf{4 4}$ & $\mathbf{4 5}$ \\
\hline $\mathbf{3 2}$ & 0.015 & & & & & & & & & & & & & \\
\hline $\mathbf{3 3}$ & 0.036 & 0.038 & & & & & & & & & & & & \\
\hline $\mathbf{3 4}$ & 0.04 & 0.037 & 0.019 & & & & & & & & & & & \\
\hline $\mathbf{3 5}$ & 0.022 & 0.022 & 0.032 & 0.036 & & & & & & & & & & & \\
\hline $\mathbf{3 6}$ & 0.036 & 0.032 & 0.04 & 0.042 & 0.019 & & & & & & & & & & \\
\hline $\mathbf{3 7}$ & 0.03 & 0.025 & 0.032 & 0.035 & 0.011 & 0.019 & & & & & & & & & \\
\hline $\mathbf{3 8}$ & 0.033 & 0.027 & 0.044 & 0.041 & 0.035 & 0.044 & 0.037 & & & & & & & & \\
\hline $\mathbf{3 9}$ & 0.055 & 0.056 & 0.062 & 0.066 & 0.06 & 0.07 & 0.061 & 0.061 & & & & & & & \\
\hline $\mathbf{4 0}$ & 0.059 & 0.057 & 0.065 & 0.06 & 0.059 & 0.06 & 0.055 & 0.064 & 0.035 & & & & & & \\
\hline $\mathbf{4 1}$ & 0.041 & 0.038 & 0.055 & 0.049 & 0.031 & 0.044 & 0.034 & 0.052 & 0.073 & 0.066 & & & & & \\
\hline $\mathbf{4 2}$ & 0.049 & 0.047 & 0.059 & 0.058 & 0.049 & 0.058 & 0.047 & 0.056 & 0.072 & 0.073 & 0.052 & & & & \\
\hline $\mathbf{4 3}$ & 0.043 & 0.036 & 0.061 & 0.069 & 0.039 & 0.044 & 0.031 & 0.048 & 0.082 & 0.092 & 0.057 & 0.045 & & & \\
\hline $\mathbf{4 4}$ & 0.047 & 0.04 & 0.047 & 0.048 & 0.043 & 0.605 & 0.605 & 0.051 & 0.049 & 0 & 0.046 & 0.049 & 0.032 & & \\
\hline $\mathbf{4 5}$ & 0.067 & 0.056 & 0.067 & 0.065 & 0.057 & 0.073 & 0.067 & 0.063 & 0.085 & 0.072 & 0.059 & 0.073 & 0.058 & 0.605 & \\
\hline $\mathbf{4 6}$ & 0.091 & 0.093 & 0.096 & 0.098 & 0.084 & 0.095 & 0.089 & 0.096 & 0.116 & 0.13 & 0.118 & 0.096 & 0.103 & 0.059 & 0.125 \\
\hline $\mathbf{4 7}$ & 0.072 & 0.063 & 0.075 & 0.072 & 0.068 & 0.082 & 0.064 & 0.072 & 0.08 & 0.081 & 0.079 & 0.08 & 0.076 & 0.605 & 0.09 \\
\hline $\mathbf{4 8}$ & 0.061 & 0.057 & 0.07 & 0.068 & 0.061 & 0.069 & 0.061 & 0.058 & 0.068 & 0.069 & 0.061 & 0.067 & 0.061 & 0.605 & 0.077 \\
\hline $\mathbf{4 9}$ & 0.069 & 0.061 & 0.073 & 0.075 & 0.071 & 0.084 & 0.068 & 0.066 & 0.095 & 0.089 & 0.067 & 0.082 & 0.056 & 0.605 & 0.069 \\
\hline $\mathbf{5 0}$ & 0.056 & 0.054 & 0.06 & 0.061 & 0.052 & 0.065 & 0.057 & 0.061 & 0.075 & 0.077 & 0.063 & 0.062 & 0.078 & 0.039 & 0.076 \\
\hline $\mathbf{5 1}$ & 0.071 & 0.067 & 0.081 & 0.082 & 0.076 & 0.09 & 0.081 & 0.075 & 0.095 & 0.095 & 0.071 & 0.086 & 0.061 & 0.605 & 0.069 \\
\hline $\mathbf{5 2}$ & 0.057 & 0.054 & 0.059 & 0.063 & 0.052 & 0.072 & 0.052 & 0.063 & 0.07 & 0.075 & 0.064 & 0.063 & 0.07 & 0.605 & 0.068 \\
\hline $\mathbf{5 3}$ & 0.075 & 0.068 & 0.087 & 0.081 & 0.073 & 0.085 & 0.071 & 0.072 & 0.087 & 0.092 & 0.074 & 0.088 & 0.082 & 0 & 0.081 \\
\hline
\end{tabular}




\begin{tabular}{|l|l|l|l|l|l|l|l|}
\hline & $\mathbf{4 6}$ & $\mathbf{4 7}$ & $\mathbf{4 8}$ & $\mathbf{4 9}$ & $\mathbf{5 0}$ & $\mathbf{5 1}$ & $\mathbf{5 2}$ \\
\hline $\mathbf{4 7}$ & 0.103 & & & & & & \\
\hline $\mathbf{4 8}$ & 0.124 & 0.096 & & & & & \\
\hline $\mathbf{4 9}$ & 0.113 & 0.089 & 0.086 & & & & \\
\hline $\mathbf{5 0}$ & 0.098 & 0.081 & 0.066 & 0.09 & & & \\
\hline $\mathbf{5 1}$ & 0.124 & 0.098 & 0.089 & 0.023 & 0.088 & & \\
\hline $\mathbf{5 2}$ & 0.104 & 0.084 & 0.062 & 0.08 & 0.048 & 0.085 & \\
\hline $\mathbf{5 3}$ & 0.143 & 0.096 & 0.079 & 0.088 & 0.086 & 0.091 & 0.085 \\
\hline
\end{tabular}

\section{Taxa key for table A21:}

\begin{tabular}{|c|c|c|c|c|c|c|c|}
\hline 1 & Drosophila melanogaster & 15 & Sarcophaga crassipalpis & 29 & Hemipyrellia fernandica & 43 & Auchmeromyia luteola \\
\hline 2 & Glossina morsitans & 16 & Notochaeta spp. & 30 & Dyscritomyia robusta & 44 & Cordylobia anthropophagi \\
\hline 3 & Musca domestica & 17 & Metopia campestris & 31 & Phormia regina & 45 & Melinda viridicyanea \\
\hline 4 & Hydrotaea cyrtoneurina & 18 & Sarcophila meridionalis & 32 & Protophormia terraenovae & 46 & Mesembrinella spp. \\
\hline 5 & McAlpine's fly & 19 & Cuterebra fontinella & 33 & Chrysomya rufifacies & 47 & Eumesembrinella quadrilineata \\
\hline 6 & Epalpus signifier & 20 & Cuterebra baeri & 34 & Chrysomya megacephala & 48 & Sarconesia versicolor \\
\hline 7 & Gymnocheta viridis & 21 & Hypoderma lineatum & 35 & Cochliomyia macellaria & 49 & Sarconesia chlorogaster \\
\hline 8 & Cyrtophleba nitida & 22 & Oestrus ovis & 36 & Cochliomyia hominivorax & 50 & Isomyia gomezmenori \\
\hline 9 & Nemorilla floralis & 23 & Cynomya cadaverina & 37 & Compsomyiops fulvicrura & 51 & Rhyncomya nigripes \\
\hline 10 & Gymnosoma nitens & 24 & Calliphora vomitoria & 38 & Protocalliphora sialia & 52 & Metallea erinacea \\
\hline 11 & Phania funesta & 25 & Bellardia vulgaris & 39 & Pollenia rudis & 53 & Eurychaeta palpalis \\
\hline 12 & Rhinophora lepida & 26 & Onesia tibialis & 40 & Pollenia amentaria & & \\
\hline 13 & Stevenia hertingi & 27 & Lucilia sericata & 41 & Bengalia depressa & & \\
\hline 14 & Stevenia atramentaria & 28 & Hypopygiopsis infumata & 42 & Verticia orientalis & & \\
\hline
\end{tabular}


TABLE A22: Pairwise transition-transversion ratio of elongation factor one alpha (EF1a) gene used in Calliphoridae phylogeny (Chapter 5).

\begin{tabular}{|c|c|c|c|c|c|c|c|c|c|c|c|c|c|c|c|c|c|c|c|}
\hline & 1 & 2 & 3 & 4 & 5 & 6 & 7 & 8 & 9 & 10 & 11 & 12 & 13 & 14 & 15 & 16 & 17 & 18 & 19 \\
\hline 2 & 1.92 & & & & & & & & & & & & & & & & & & \\
\hline 3 & 1.78 & 2.03 & & & & & & & & & & & & & & & & & \\
\hline 4 & 1.79 & 1.97 & 1.88 & & & & & & & & & & & & & & & & \\
\hline 5 & 1.8 & 2.56 & 2.8 & 3 & & & & & & & & & & & & & & & \\
\hline 6 & 2.18 & 1.67 & 1.87 & 2.24 & 1.44 & & & & & & & & & & & & & & \\
\hline 7 & 1.86 & 1.73 & 2.1 & 2.88 & 2.28 & 1.73 & & & & & & & & & & & & & \\
\hline 8 & 2.43 & 2.05 & 2.95 & 2.18 & 3.13 & 2 & 1.58 & & & & & & & & & & & & \\
\hline 9 & 2.08 & 1.97 & 2.68 & 1.68 & 1.44 & 1.52 & 1.94 & 2.22 & & & & & & & & & & & \\
\hline 10 & 2.28 & 2.14 & 2.18 & 2.55 & 2.27 & 2.4 & 2 & 2.04 & 2.85 & & & & & & & & & & \\
\hline 11 & 1.95 & 1.97 & 1.9 & 1.73 & 2.13 & 1.55 & 1.81 & 1.48 & 1.88 & 2.5 & & & & & & & & & \\
\hline 12 & 2.15 & 2.86 & 2.26 & 2.65 & 4.17 & 1.62 & 2.12 & 2.33 & 2.79 & 2.67 & 1.73 & & & & & & & & \\
\hline 13 & 1.71 & 1.82 & 1.61 & 1.82 & 2.93 & 1.38 & 1.55 & 2.12 & 1.8 & 2.39 & 2.07 & 3 & & & & & & & \\
\hline 14 & 1.75 & 1.9 & 1.52 & 1.36 & 2.06 & 1.35 & 1.5 & 1.56 & 2.11 & 2.17 & 2.4 & 2.53 & 2.09 & & & & & & \\
\hline 15 & 2.65 & 2.58 & 3 & 2.13 & 3.12 & 1.81 & 1.75 & 2.67 & 2.16 & 2.29 & 2.36 & 4.91 & 2.47 & 2.28 & & & & & \\
\hline 16 & 1.74 & 3.17 & 2.73 & 2.12 & 2.9 & 1.43 & 1.65 & 2.27 & 2.45 & 2.8 & 2.35 & 5.5 & 3.15 & 2.83 & 11 & & & & \\
\hline 17 & 2.39 & 2.41 & 2.76 & 2.18 & 3.56 & 1.84 & 1.82 & 2.32 & 2.41 & 2.57 & 2.18 & 5.8 & 2.45 & 2.42 & 5.62 & 4.17 & & & \\
\hline 18 & 1.93 & 3.17 & 2.5 & 1.87 & 2.5 & 1.47 & 1.93 & 2.82 & 2.3 & 2.79 & 1.86 & 4.27 & 2.4 & 2.21 & 3.5 & 3.5 & 2.12 & & \\
\hline 19 & 2.32 & 1.86 & 2.31 & 2.23 & 2.22 & 1.91 & 1.84 & 2.07 & 1.85 & 1.94 & 1.94 & 2.47 & 2.72 & 2.3 & 2.38 & 2.7 & 2.42 & 2.75 & \\
\hline 20 & 1.78 & 1.6 & 1.54 & 1.77 & 1.77 & 1.64 & 1.41 & 2.09 & 1.69 & 1.5 & 1.59 & 1.97 & 2.08 & 1.74 & 2 & 1.85 & 2.23 & 1.93 & 2.5 \\
\hline 21 & 1.37 & 1.11 & 1.26 & 1.25 & 1.21 & 1.25 & 1.44 & 1.08 & 1.21 & 1.2 & 1.13 & 1.11 & 1.11 & 1.11 & 1.27 & 1.28 & 1.45 & 1.41 & 1.15 \\
\hline 22 & 1.42 & 1.02 & 1.23 & 1.25 & 1.16 & 1.23 & 1.41 & 1.11 & 1.27 & 1.25 & 1.1 & 1.19 & 1.16 & 1.15 & 1.29 & 1.26 & 1.41 & 1.38 & 1.16 \\
\hline 23 & 2.4 & 1.92 & 1.85 & 4.62 & 2.17 & 1.42 & 1.28 & 1.76 & 1.93 & 1.83 & 1.39 & 3 & 1.74 & 1.42 & 1.9 & 1.18 & 2.43 & 1 & 1.93 \\
\hline 24 & 2.12 & 1.9 & 1.59 & 5.12 & 2.45 & 1.14 & 1.33 & 1.36 & 1.5 & 2.09 & 1.45 & 3.22 & 1.91 & 1.58 & 1.33 & 1.36 & 1.94 & 1.21 & 2.23 \\
\hline 25 & 1.84 & 2 & 1.38 & 3 & 1.79 & 1.3 & 1.38 & 1.81 & 1.37 & 2.28 & 1.39 & 2.63 & 2.05 & 1.46 & 1.05 & 1.38 & 1.42 & 1.43 & 2.29 \\
\hline 26 & 2.45 & 2.1 & 1.87 & 3.36 & 2.33 & 1.76 & 1.57 & 2.22 & 1.93 & 2.05 & 1.47 & 3.29 & 2 & 1.59 & 2.19 & 1.33 & 2.67 & 1.75 & 1.81 \\
\hline 27 & 2.19 & 2.16 & 2.21 & 2.47 & 3.88 & 1.82 & 1.5 & 2.93 & 1.96 & 1.8 & 1.7 & 3.73 & 2.37 & 2 & 3.92 & 3.33 & 3.56 & 2.71 & 2.08 \\
\hline 28 & 2.11 & 2.11 & 1.9 & 2.38 & 3.44 & 1.52 & 1.43 & 2.86 & 1.89 & 1.69 & 1.57 & 3.62 & 2.45 & 2.04 & 3.31 & 2.71 & 3.12 & 2.25 & 2.08 \\
\hline 29 & 2.33 & 2.05 & 2 & 2.47 & 4 & 1.67 & 1.5 & 2.69 & 2.17 & 1.72 & 1.7 & 3.87 & 2.47 & 1.95 & 4.78 & 3.67 & 3.71 & 3 & 2.02 \\
\hline 30 & 2.07 & 1.97 & 1.77 & 2.57 & 2.89 & 1.65 & 1.43 & 2.59 & 1.83 & 1.92 & 1.47 & 4 & 2.4 & 1.96 & 2.88 & 2.33 & 3.11 & 1.9 & 1.91 \\
\hline 31 & 2.39 & 2.45 & 2.57 & 1.72 & 2.6 & 1.79 & 1.76 & 2.76 & 1.84 & 2.72 & 2.08 & 3.85 & 2.8 & 2.06 & 3.9 & 4 & 3.92 & 3.2 & 2.26 \\
\hline 32 & 2.31 & 2.5 & 2.77 & 2 & 2.67 & 1.61 & 1.7 & 2.58 & 2 & 2.88 & 2.13 & 4 & 3 & 2.24 & 4.22 & 4.5 & 3.42 & 2.75 & 2.02 \\
\hline
\end{tabular}




\begin{tabular}{|c|c|c|c|c|c|c|c|c|c|c|c|c|c|c|c|c|c|c|c|}
\hline 33 & 2.27 & 2.45 & 2.59 & 1.55 & 2.42 & 1.86 & 1.9 & 2.52 & 2.04 & 2.57 & 2.14 & 4.7 & 3 & 2.67 & 3.8 & 2.43 & 5 & 2.17 & 2.22 \\
\hline 34 & 2.27 & 2.39 & 2.47 & 1.65 & 2.5 & 1.69 & 1.95 & 2.56 & 2.29 & 2.48 & 2.14 & 4.9 & 3.07 & 2.86 & 4.2 & 2.43 & 4.8 & 1.67 & 2.45 \\
\hline 35 & 2.6 & 2.63 & 3.5 & 2.53 & 2.67 & 1.8 & 1.8 & 2.36 & 2.19 & 2.79 & 2.09 & 5.3 & 3.07 & 2.18 & 7 & 10 & 5 & 3.5 & 2.4 \\
\hline 36 & 2.15 & 2.58 & 2.64 & 2.22 & 2.27 & 1.48 & 2.11 & 2.05 & 1.76 & 3 & 2.57 & 4.31 & 2.88 & 2.1 & 4 & 5.4 & 5.14 & 3.6 & 2.65 \\
\hline 37 & 2.07 & 2.69 & 2.58 & 2.25 & 2.44 & 1.29 & 1.94 & 1.94 & 1.71 & 2.59 & 2.14 & 5.22 & 2.4 & 1.82 & 16 & 7.33 & 8.67 & 2.4 & 3.32 \\
\hline 38 & 2.32 & 2.44 & 2.75 & 1.79 & 2.18 & 1.86 & 1.52 & 2.6 & 1.81 & 2.53 & 2.43 & 3.29 & 2.93 & 2.53 & 3.36 & 5 & 3.06 & 3.5 & 2.3 \\
\hline 39 & 2 & 1.86 & 2.53 & 1.83 & 1.39 & 1.95 & 1.6 & 3.52 & 2.3 & 2.17 & 1.74 & 2.22 & 1.7 & 1.68 & 2.24 & 1.28 & 2.4 & 1.12 & 1.88 \\
\hline 40 & 1.81 & 2.08 & 2.5 & 1.7 & 2 & 1.64 & 1.68 & 1.84 & 2.05 & 2.12 & 2.09 & 2.48 & 1.56 & 1.74 & 1.5 & 1.93 & 2.38 & 1.54 & 1.89 \\
\hline 41 & 2.38 & 2.53 & 2.38 & 2.14 & 3.33 & 1.57 & 1.89 & 2.36 & 1.89 & 2.6 & 1.96 & 4.8 & 2.33 & 1.79 & 5.17 & 4.4 & 4.25 & 3.8 & 2.85 \\
\hline 42 & 2.33 & 2.55 & 2 & 1.9 & 1.75 & 1.77 & 1.64 & 2.37 & 1.85 & 2.67 & 2.12 & 2.74 & 2.14 & 1.86 & 2.39 & 2.88 & 2.41 & 4 & 2.13 \\
\hline 43 & 1.97 & 2.61 & 2.19 & 2.42 & 1.45 & 1.39 & 1.53 & 1.95 & 1.41 & 1.47 & 1.56 & 4.12 & 2.7 & 1.64 & 3.71 & 3.4 & 2.27 & 3.67 & 2.07 \\
\hline 44 & 3.57 & --- & --- & --- & --- & 2.62 & --- & 5.2 & 4.75 & --- & --- & --- & --- & --- & --- & --- & 21 & --- & 1.82 \\
\hline 45 & 1.86 & 2.45 & 1.68 & 2.29 & 2.83 & 1.5 & 1.43 & 1.52 & 1.37 & 2.14 & 1.19 & 3.54 & 2 & 1.5 & 2.15 & 2.33 & 2.4 & 2.5 & 2.3 \\
\hline 46 & 1.97 & 2.09 & 1.95 & 2 & 1.42 & 1.4 & 1.89 & 2 & 1.78 & 2.2 & 1.54 & 3.75 & 2.13 & 1.78 & 2.5 & 2.73 & 2.87 & 1.62 & 1.83 \\
\hline 47 & 2.53 & 2.14 & 1.86 & 2.37 & 1.94 & 1.56 & 2.33 & 2.1 & 2 & 2.86 & 2.45 & 3.18 & 2.22 & 1.95 & 3.6 & 4.12 & 3.42 & 2.17 & 2.48 \\
\hline 48 & 2.11 & 2.21 & 2.4 & 1.9 & 3.5 & 1.83 & 1.62 & 2.65 & 2.44 & 3.11 & 2.35 & 3.53 & 2.45 & 2.26 & 5 & 4.67 & 3.36 & 5.8 & 2.33 \\
\hline 49 & 1.7 & 2.03 & 1.84 & 2.67 & 2.46 & 1.43 & 1.7 & 1.84 & 1.7 & 2.32 & 1.57 & 2.6 & 1.83 & 1.48 & 2.07 & 1.86 & 2.41 & 1.79 & 1.95 \\
\hline 50 & 2.61 & 2.05 & 2 & 1.59 & 2.67 & 1.89 & 1.86 & 2.15 & 1.58 & 2.9 & 2.68 & 2.75 & 2.05 & 2 & 3.19 & 2.71 & 3.2 & 2.25 & 2.22 \\
\hline 51 & 1.75 & 2.03 & 2.11 & 2.54 & 2.75 & 1.45 & 1.74 & 1.8 & 1.7 & 2.17 & 1.56 & 3.75 & 2.32 & 1.87 & 2.25 & 1.92 & 2.44 & 2.15 & 2.17 \\
\hline 52 & 2.12 & 2.26 & 1.68 & 1.81 & 2.58 & 1.57 & 1.48 & 1.84 & 1.47 & 2.57 & 1.8 & 2.72 & 2.1 & 1.84 & 3.11 & 2.62 & 2.92 & 2.67 & 2.91 \\
\hline 53 & 2.34 & 2.75 & 2 & 3.21 & 3.45 & 1.82 & 2 & 2.94 & 3.27 & 2.45 & 1.83 & 5.18 & 2.59 & 2.05 & 5.38 & 3.56 & 3.82 & 3.22 & 2.93 \\
\hline
\end{tabular}




\begin{tabular}{|c|c|c|c|c|c|c|c|c|c|c|c|c|c|c|c|c|c|c|c|}
\hline & 20 & 21 & 22 & 23 & 24 & 25 & 26 & 27 & 28 & 29 & 30 & 31 & 32 & 33 & 34 & 35 & 36 & 37 & 38 \\
\hline 21 & 1.13 & & & & & & & & & & & & & & & & & & \\
\hline 22 & 1.08 & ---- & & & & & & & & & & & & & & & & & \\
\hline 23 & 1.65 & 1.37 & 1.43 & & & & & & & & & & & & & & & & \\
\hline 24 & 1.8 & 1.37 & 1.44 & --- & & & & & & & & & & & & & & & \\
\hline 25 & 1.88 & 1.24 & 1.28 & 1.5 & 1.82 & & & & & & & & & & & & & & \\
\hline 26 & 1.64 & 1.33 & 1.35 & 1.67 & 2 & 0.88 & & & & & & & & & & & & & \\
\hline 27 & 1.77 & 1.4 & 1.4 & 1.71 & 1.27 & 1.08 & 2.62 & & & & & & & & & & & & \\
\hline 28 & 1.75 & 1.32 & 1.33 & 1.44 & 1.25 & 1.29 & 2.79 & 21 & & & & & & & & & & & \\
\hline 29 & 1.71 & 1.35 & 1.35 & 1.6 & 1.18 & 1.62 & 3.36 & 9 & 3.33 & & & & & & & & & & \\
\hline 30 & 1.67 & 1.4 & 1.41 & 2 & 1.3 & 1.58 & 3.08 & 5 & 4 & 2.8 & & & & & & & & & \\
\hline 31 & 1.88 & 1.22 & 1.25 & 1.64 & 1.28 & 0.95 & 1.9 & 2.14 & 2.2 & 2.58 & 1.94 & & & & & & & & \\
\hline 32 & 1.91 & 1.28 & 1.32 & 1.27 & 1.12 & 1.11 & 1.62 & 2.14 & 1.6 & 2.33 & 1.82 & 7.5 & & & & & & & \\
\hline 33 & 1.84 & 1.18 & 1.2 & 1.83 & 1.1 & 1.1 & 2.43 & 2.93 & 3.07 & 3.5 & 2.56 & 4.62 & 4.5 & & & & & & \\
\hline 34 & 1.87 & 1.21 & 1.24 & 1.74 & 1 & 1 & 2.38 & 3.29 & 3.13 & 3.92 & 2.94 & 5.25 & 4.38 & --- & & & & & \\
\hline 35 & 2.07 & 1.31 & 1.35 & 2.22 & 1.47 & 1.22 & 2.37 & 3.17 & 2.77 & 3.8 & 2.6 & 5.75 & 5.5 & 5.5 & 6.17 & & & & \\
\hline 36 & 2.07 & 1.27 & 1.31 & 1.67 & 1.61 & 1.63 & 1.94 & 2.25 & 2.08 & 2.42 & 2 & 3.33 & 3.6 & 3 & 3.29 & 3.67 & & & \\
\hline 37 & 2.32 & 1.34 & 1.34 & 1.36 & 1.64 & 1.41 & 1.93 & 2.75 & 2.44 & 2.88 & 2 & 3.75 & 4.33 & 4 & 4.5 & 6 & 5 & & \\
\hline 38 & 1.79 & 1.19 & 1.24 & 1.42 & 1.05 & 1.05 & 1.76 & 2.33 & 2.16 & 2.44 & 1.95 & 4.12 & 3 & 3.5 & 3.25 & 4.25 & 3.43 & 3.6 & \\
\hline 39 & 1.54 & 1.08 & 1.14 & 2.04 & 1.57 & 1.32 & 2.68 & 2.04 & 2 & 2.08 & 2.22 & 1.96 & 1.83 & 2.3 & 2.52 & 2.09 & 1.67 & 1.24 & 2.26 \\
\hline 40 & 1.54 & 1.14 & 1.16 & 1.38 & 1.41 & 1.21 & 1.75 & 1.62 & 1.36 & 1.57 & 1.55 & 1.44 & 1.53 & 1.82 & 1.65 & 1.59 & 1.86 & 1.62 & 1.82 \\
\hline 41 & 2.21 & 1.27 & 1.28 & 1.88 & 1.86 & 1.6 & 2.18 & 2.83 & 2.23 & 3.18 & 2.54 & 2.36 & 2.5 & 3.45 & 3 & 3 & 3.43 & 4.25 & 2.62 \\
\hline 42 & 2 & 1.41 & 1.34 & 1.5 & 1.35 & 1.24 & 2 & 2.2 & 1.71 & 2.11 & 1.75 & 1.95 & 1.65 & 2.55 & 2.5 & 2.22 & 2.25 & 1.9 & 2.09 \\
\hline 43 & 1.54 & 1.37 & 1.36 & 1.64 & 1.75 & 1.09 & 1.83 & 8.67 & 6 & 5.75 & 3.67 & 2 & 1.88 & 2.8 & 3.3 & 2.43 & 2.17 & 2.25 & 1.73 \\
\hline 44 & --- & --- & --- & 6 & --- & --- & 5.67 & 10 & 7 & --- & 10 & 18 & 6.5 & --- & --- & --- & --- & --- & 4.25 \\
\hline 45 & 1.72 & 1.25 & 1.25 & 1.62 & 1.92 & 2.36 & 2.7 & 3 & 2.89 & 3.38 & 4 & 2 & 1.77 & 1.62 & 1.56 & 1.77 & 2.21 & 1.93 & 1.67 \\
\hline 46 & 1.54 & 1.19 & 1.31 & 1.95 & 1.62 & 1.5 & 2.16 & 2.56 & 2.35 & 2.44 & 2.47 & 2.44 & 2.47 & 2.87 & 2.93 & 2.85 & 2.36 & 2.09 & 2.22 \\
\hline 47 & 1.9 & 1.17 & 1.22 & 1.94 & 2.12 & 1.9 & 2.53 & 2.86 & 2.47 & 2.57 & 2.27 & 2.5 & 2.38 & 2.92 & 2.77 & 3.27 & 4.3 & 4 & 2.27 \\
\hline 48 & 1.85 & 1.38 & 1.38 & 1.74 & 1.78 & 1.74 & 2.47 & 3.8 & 3.45 & 3.7 & 2.77 & 3.3 & 3.56 & 3.45 & 3.36 & 3.78 & 4.11 & 4.43 & 3.56 \\
\hline 49 & 1.6 & 1.38 & 1.38 & 1.67 & 1.64 & 1.57 & 3.25 & 1.18 & 1.55 & 1.45 & 1.3 & 1.61 & 1.47 & 1.63 & 1.68 & 1.82 & 1.89 & 1.8 & 1.37 \\
\hline 50 & 1.76 & 1.14 & 1.18 & 1.39 & 1.27 & 1.42 & 1.83 & 2.45 & 2.3 & 2.55 & 2.27 & 2.45 & 2.15 & 2.75 & 2.75 & 2.44 & 2.46 & 2.5 & 2.12 \\
\hline 51 & 1.77 & 1.34 & 1.34 & 2.44 & 2.88 & 2.18 & 3.57 & 1.9 & 1.91 & 2 & 1.89 & 1.67 & 1.71 & 1.89 & 1.95 & 2.06 & 2.11 & 2.12 & 1.68 \\
\hline 52 & 2.14 & 1.28 & 1.25 & 1.26 & 1.47 & 1.3 & 1.88 & 2.55 & 2.58 & 3 & 2.29 & 2.45 & 2.7 & 2.25 & 2.82 & 2.5 & 2.62 & 2.56 & 2.5 \\
\hline 53 & 2.21 & 1.37 & 1.36 & 2.77 & 2.92 & 1.88 & 3.08 & 3.9 & 3.55 & 3.9 & 4.56 & 3.73 & 3.8 & 3.62 & 3.31 & 5.38 & 4.3 & 4.5 & 3.17 \\
\hline
\end{tabular}




\begin{tabular}{|l|l|l|l|l|l|l|l|l|l|l|l|l|l|l|}
\hline & $\mathbf{3 9}$ & $\mathbf{4 0}$ & $\mathbf{4 1}$ & $\mathbf{4 2}$ & $\mathbf{4 3}$ & $\mathbf{4 4}$ & $\mathbf{4 5}$ & $\mathbf{4 6}$ & $\mathbf{4 7}$ & $\mathbf{4 8}$ & $\mathbf{4 9}$ & $\mathbf{5 0}$ & $\mathbf{5 1}$ & $\mathbf{5 2}$ \\
\hline $\mathbf{4 0}$ & 1.17 & & & & & & & & & & & & & \\
\hline $\mathbf{4 1}$ & 1.78 & 1.82 & & & & & & & & & & & & \\
\hline $\mathbf{4 2}$ & 2.03 & 1.57 & 1.65 & & & & & & & & & & & \\
\hline $\mathbf{4 3}$ & 1.43 & 1.71 & 2.89 & 1.8 & & & & & & & & & & \\
\hline $\mathbf{4 4}$ & 9 & --- & 5 & 4 & 3 & & & & & & & & & \\
\hline $\mathbf{4 5}$ & 1.3 & 1.14 & 2.08 & 1.88 & 1.89 & --- & & & & & & & & \\
\hline $\mathbf{4 6}$ & 1.92 & 1.62 & 2.33 & 1.76 & 1.93 & 3.5 & 1.88 & & & & & & & \\
\hline $\mathbf{4 7}$ & 1.79 & 1.52 & 2.79 & 2 & 2.78 & --- & 2.5 & 3.56 & & & & & & \\
\hline $\mathbf{4 8}$ & 1.53 & 2.2 & 3.3 & 3.27 & 3.83 & --- & 2.43 & 3 & 3.2 & & & & & \\
\hline $\mathbf{4 9}$ & 2.25 & 1.77 & 2.29 & 1.67 & 1.89 & --- & 1.87 & 1.76 & 2.11 & 2.28 & & & & \\
\hline $\mathbf{5 0}$ & 1.97 & 1.43 & 2.11 & 2.75 & 2.2 & 3.25 & 1.76 & 2.47 & 2.38 & 2.83 & 1.77 & & & \\
\hline $\mathbf{5 1}$ & 2.25 & 1.95 & 2.5 & 1.68 & 2.22 & --- & 2.91 & 2.06 & 2.25 & 2.39 & 2.2 & 1.86 & & \\
\hline $\mathbf{5 2}$ & 0.84 & 1.33 & 2.5 & 2.23 & 2.75 & --- & 1.41 & 1.6 & 2.38 & 2.33 & 1.83 & 1.67 & 1.84 & \\
\hline $\mathbf{5 3}$ & 1.73 & 2.15 & 6.29 & 2.81 & 3.1 & --- & 3.17 & 3.07 & 3.07 & 3 & 3.46 & 2.47 & 3.29 & 3 \\
\hline
\end{tabular}

Taxa key for table A22: Same as table A21.

John $\mathrm{H}$. 